\title{
Defined by a Label: \\ How Collective Action Brought about Change during the Second Half of the Twentieth Century for People with Cerebral Palsy
}

Teresa Hillier

Student number:

Submitted to Swansea University in fulfilment of the requirements for the

Degree Doctor of Philosophy

Swansea University

2019 


\begin{abstract}
Inequality of access to the education system in Britain, in the second half of the twentieth century, effectively discriminated against many children with cerebral palsy. Individuals with the condition, were judged by their physical impairment and their cognitive abilities were ignored. This thesis considers the key factors which brought about a change in attitudes and the provision of services for individuals with cerebral palsy. Concerned parents took action by forming parentled associations, advocating on behalf of their children and establishing parentled schools. Their proactive approach challenged medical authority and perceptions of cerebral palsy. Transnational networks provided a significant contribution to a greater understanding of the symptoms of cerebral palsy and effective treatment. National campaigns, to raise awareness and funds, utilised the media of the day, often employing emotive images to reinforce their message. The imagery portrayed presented a dichotomy for associations as it often hid the real progress that was being made. Social reform had a significant impact on individual and family lives, influencing change through the development of the voluntary sector. This sector has transformed from providing relief through, 'charitable good works', to delivering a professional multi-agency approach which now plays a significant role within society. An extensive analysis of the records of two parent-led associations, in Swansea and in the Midlands, reveals how successful these associations were at providing support and services. The influence and achievements of the national body for people with cerebral palsy are also considered. Despite achievements made, the actions taken by parentled associations had an unforeseen effect on the future employment prospects for people with cerebral palsy as they contributed to the development of an institutional culture. Oral history records used in this thesis reveal the real-life experiences of people with cerebral palsy and how they were generally perceived in post-war Britain.
\end{abstract}




\section{DECLARATION}

This work has not previously been accepted in substance for any degree and is not being concurrently submitted in candidature for any degree.

Signed (candidate)

Date

\section{STATEMENT 1}

This thesis is the result of my own investigations, except where otherwise stated.

Other sources are acknowledged by footnotes giving explicit references. A bibliography is appended.

Signed (candidate)

Date

\section{STATEMENT 2}

I hereby give consent for my thesis, if accepted, to be available for photocopying and for inter-library loan, and for the title and summary to be made available to outside organisations.

Signed (candidate)

Date

I hereby give consent for my thesis, if accepted, to be available for photocopying and for inter-library loans after expiry of a bar on access approved by the Swansea University.

Signed (candidate)

Date 
Table of Contents

Abstract ...

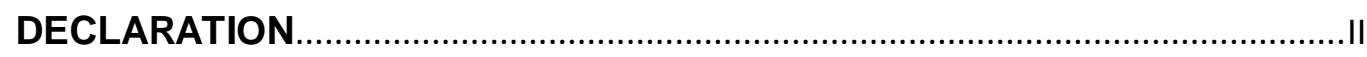

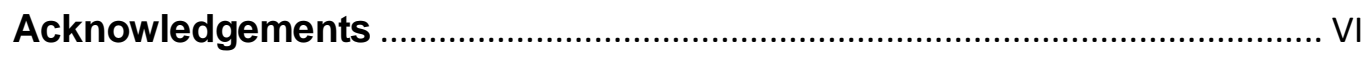

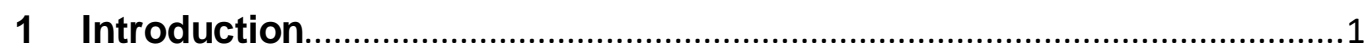

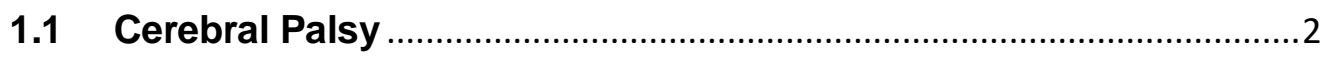

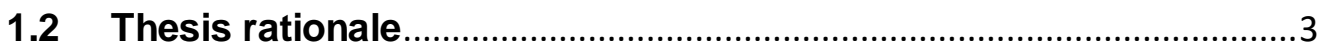

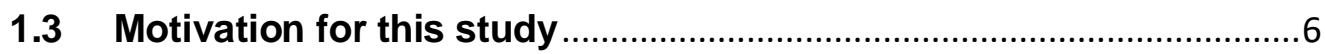

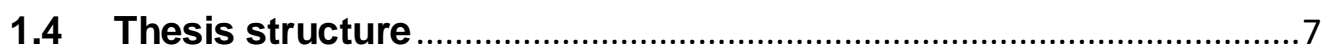

2 Literature Review and Methodology .....................................................10

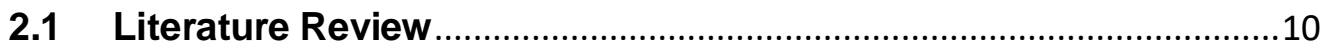

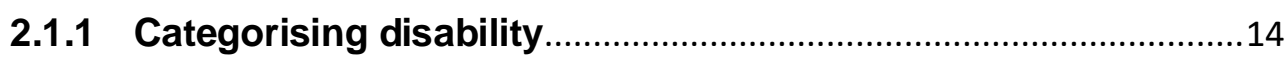

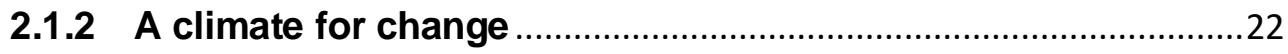

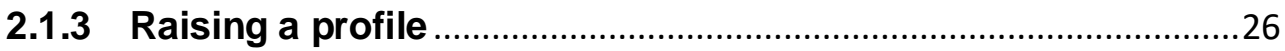

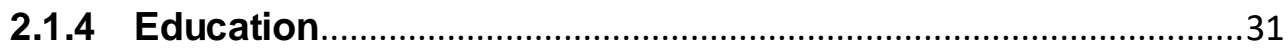

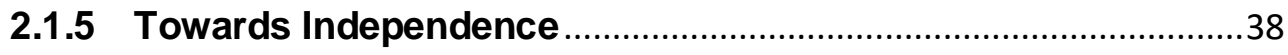

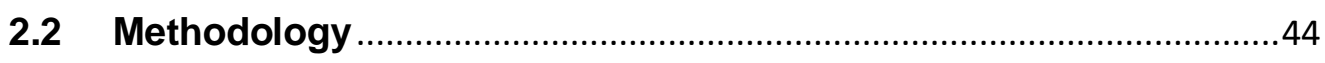

2.2.1 Challenges presented by the source materials.........................45

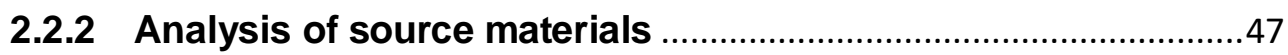

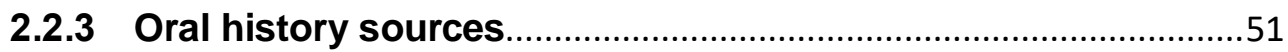

2.2.4 Challenges of obtaining oral history testimonies.....................53

2.2.5 Analysis of oral history sources ….........................................57

3 The exclusion of 'spastic' children: collective action by parents challenges the implementation of legislative change ..............................61

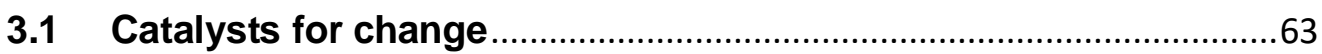

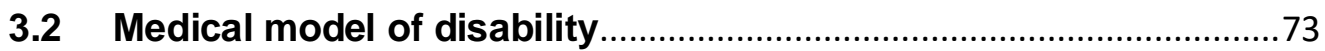

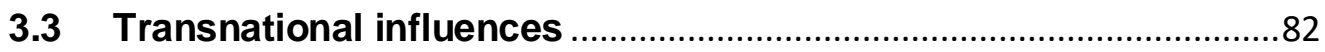

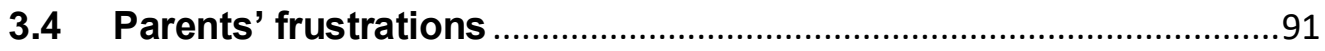




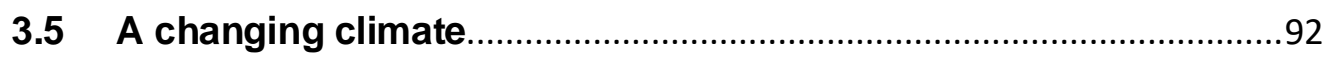

3.6 Development of local parent-led associations ...............................94

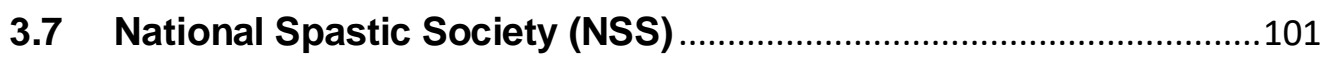

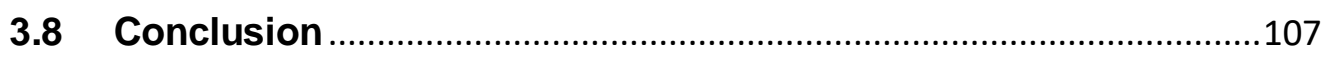

4 Providing education for children with cerebral palsy: the impact of transnational influences furthers the understanding of individual

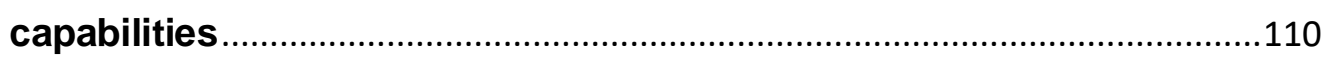

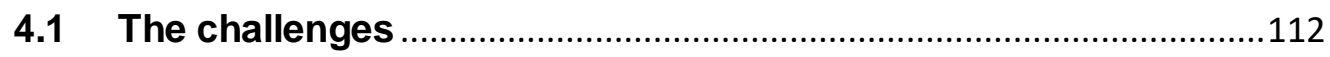

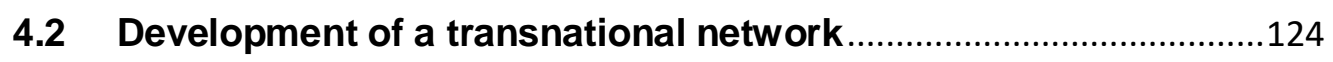

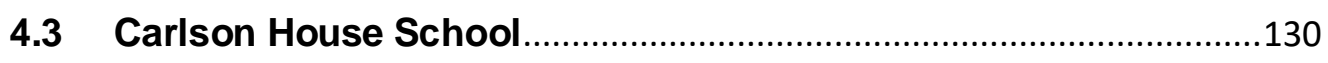

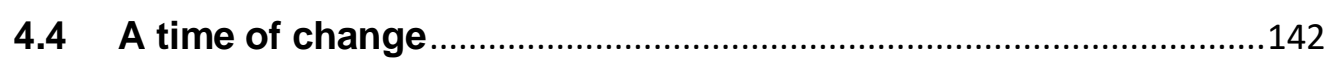

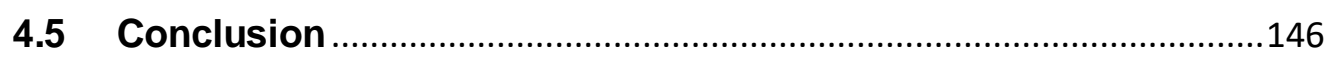

5 Sheltered employment: the development of Work Centres and the limited opportunities for school leavers with cerebral palsy ..............................149

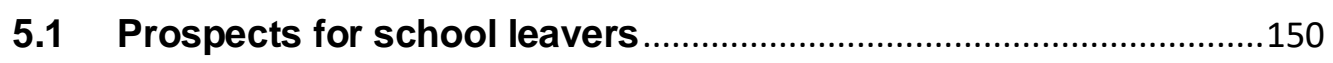

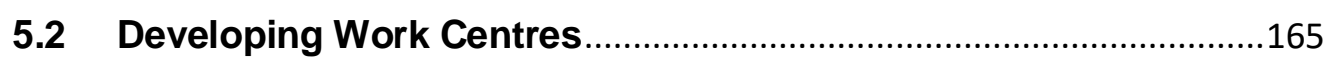

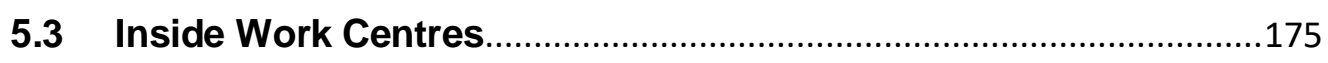

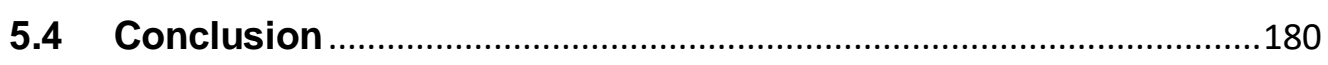

6 Challenging perceptions: the legacy of the 'spastic' label ..................182

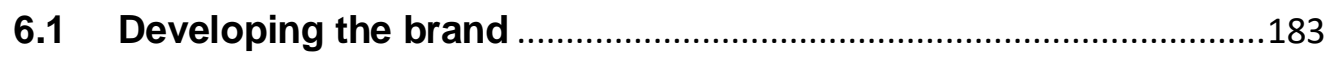

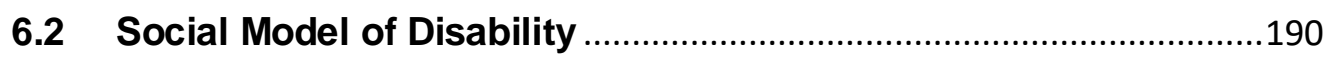

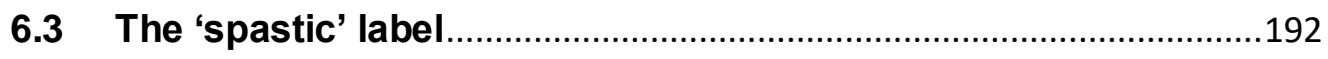

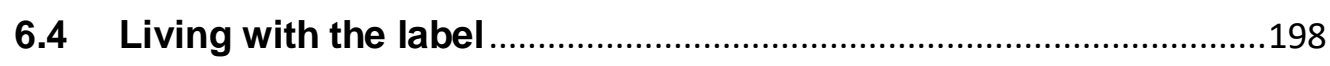

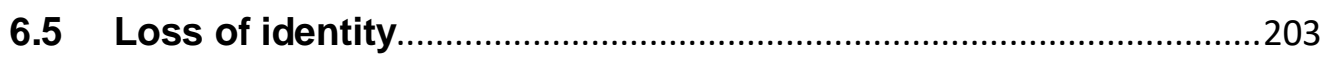

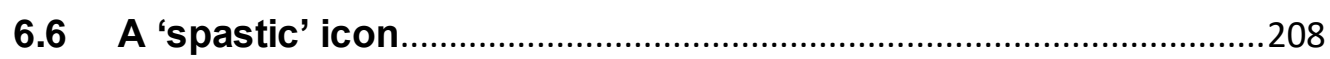

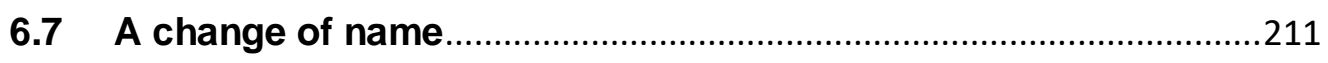

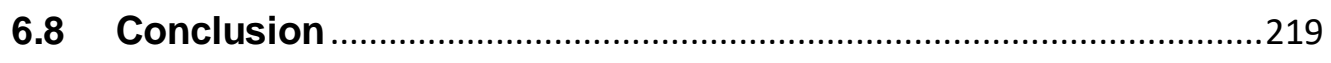

7 Forces for change: the impact of the Warnock Report and the future of

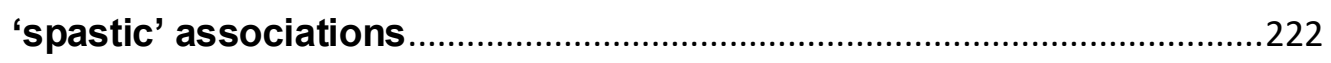




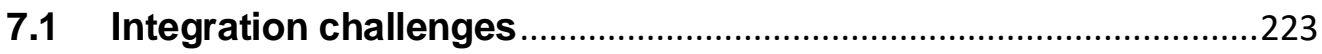

7.21970 s - maintaining communities in a time of change ................231

7.3 The Warnock Report - a new beginning? .......................................234

7.4 The Warnock Report - a loss of expertise? ...................................241

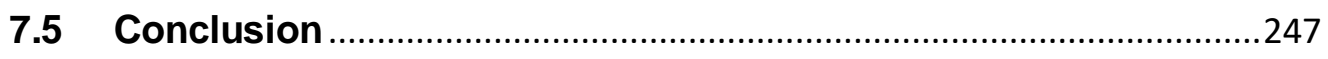

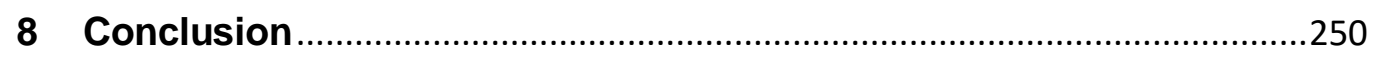

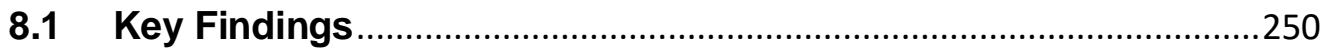

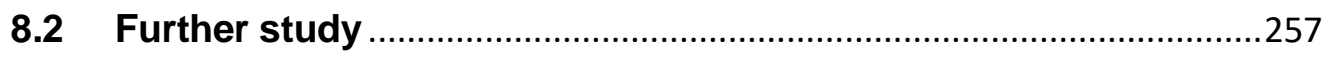

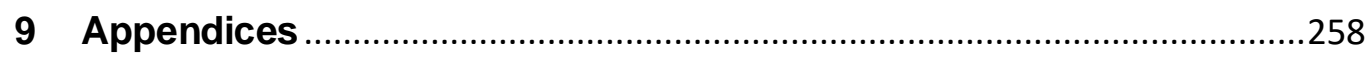

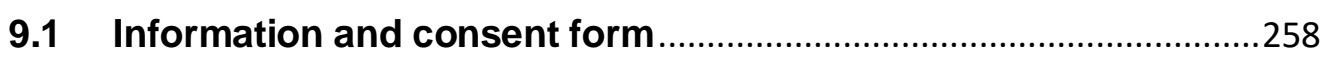

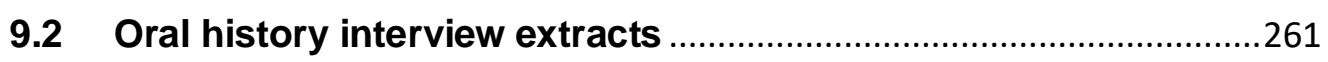

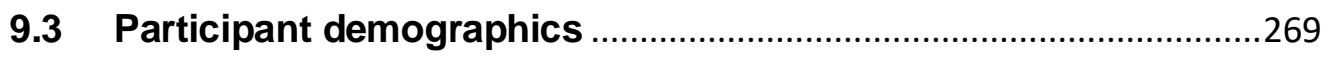

9.4 Renovation of Carlson House school (1940s) ..............................270

9.5 Innovative equipment at Carlson House school (early 1950s) .....272

9.6 Extract from the National Spastics Society Annual report (1954)274

9.7 Cover of the National Spastics Society Annual report (1964) ......275

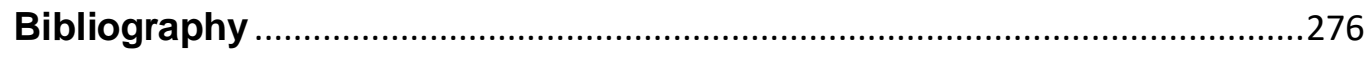




\section{Acknowledgements}

This thesis would not have been possible without the excellent support of my supervisors, David Turner and Rebecca Clifford. I thank them for their advice, comments and constant encouragement.

A special mention to everyone at Cerebral Palsy Midlands for their generous welcome. I especially thank Sarah and Allyson for their enthusiasm, interest and unwavering attention in providing me with such a wealth of sources. Thanks to Alex White of Scope for his responses to my queries and useful primary sources. I also appreciate the help of the staff at West Glamorgan Archive Services and the Wellcome Library.

Thank you to everyone who participated in oral history interviews and I would like to remember Ron D. and Peter B. who passed away within a few months of sharing their memories. To everyone involved with the Speaking for Ourselves collection, I would like to express my gratitude, especially to those individuals whose stories I have included in this thesis. I have learnt so much from you.

Thanks to my family and friends for their encouragement and most importantly, to Martin Hillier for his attention to detail in proofreading and his unconditional love and support. 


\section{Introduction}

At a time of great social change in mid-twentieth century Britain, a series of parliamentary reforms included the 1944 Education Act which aimed to remove inequalities in the system of education. This Act was one of a number of policies which emerged from the 1942 Report on Social Insurance and Allied Services (Beveridge Report). It mapped out a new era for education, with one of the aims being to provide more equality of opportunity to all children, including disabled children. However, for many children born with cerebral palsy, implementation of this Act led to them being excluded from education. They were marginalised relative to other disabled children and were classed as ineducable by the nature of their disability. Professor Stanley Segal ${ }^{1}$, a prominent educationalist and campaigner, said that following the 1944 Education Act, children with cerebral palsy, 'were not only classed as ineducable, but in the majority of cases were regarded as being mentally deficient'. ${ }^{2}$ The categorisation of children in this way led to a wave of parent activism which resulted in a network of parent-led associations being established during the 1940s and 1950s. A number of these associations set up parent-led day schools and residential schools specifically for the education and treatment of children with cerebral palsy. During the 1960s and 1970s associations evolved to provide sheltered employment for young adults with the condition in association work centres. From small beginnings these associations developed as effective campaigners, at local, national and international levels. Transnational networks were important in facilitating the exchange of emerging therapy practices. Raising awareness, initially at a local level, increased with the formation of the National Spastics Society and the term 'spastic' became the generic term by which people with cerebral palsy were labelled. Language used in relation to disability has changed over time and words, once generally accepted, are now viewed as offensive and terms of

\footnotetext{
${ }^{1}$ Stanley S Segal, was a respected educator and disability campaigner worked with children with learning and physical disabilities. He published widely and his book No Child is Ineducable (1967) was highly regarded within the field of education for children with 'special needs'.

Peter Mittler, 'Obituary: Stanley Segal', Independent, 9 July 1994.

<https://www.independent.co.uk/news/people/obituary-stanley-segal-1412745.html> [accessed 26 March, 2016].

${ }^{2}$ Stanley S Segal, No Child is Ineducable (Oxford: Pergamon Press Ltd., 1974), p.245.
} 
abuse. The term 'spastic' is one such word, and it remained in use until the 1990s. It is used in this thesis in an historical context.

This thesis addresses the following research questions:

- What were the core aims and objectives of parent-led associations and to what extent did they bring about the intended change in the lives of people with cerebral palsy?

- How did transnational networks develop and to what extent did they influence attitudes and promote a change in the treatment of cerebral palsy in Britain?

- How did the use of language and imagery by parent-led associations influence how individuals with cerebral palsy were perceived?

\subsection{Cerebral Palsy}

Cerebral palsy is a non-progressive, complex condition, commonly caused by an injury to the brain around the time of birth. It results in varying impairments that can affect movement, posture and co-ordination, speech and language. Symptoms are unique to each individual, with some being more profoundly affected. There are three different categories of cerebral palsy, and individuals may have just one type or a combination of the three:

- Spastic cerebral palsy affects muscle stiffness or weakness and is the most common type of cerebral palsy

- Athetoid cerebral palsy affects muscle tone, causing involuntary spasms

- Ataxic cerebral palsy affects balance and co-ordination and can affect posture, motor learning and communication. ${ }^{3}$

Cerebral palsy is not a learning disability, but some individuals with the condition might have learning difficulties which has led to cerebral palsy often being linked with learning disability. Prior to the twentieth century limited research had been undertaken into the condition, so its absence from the historical record did not provide cause for any significant challenge to this perception. It is important to

3 The definition of cerebral palsy is taken from the website of cerebralpalsy.org.uk which is a national information and network resource based in the UK. Website address is:

https://www.cerebralpalsy.org.uk/cerebral-palsy.html 
address this false assumption by presenting the history of cerebral palsy as separate and distinct from the history of learning disability.

\subsection{Thesis rationale}

This thesis examines the extent to which the network of parent-led 'spastic' associations helped to change attitudes and transform the lives of those living with cerebral palsy. The time frame chosen for the thesis covers a period of over forty years, from the 1940s to the late 1980s. It examines the wider implications of two significant pieces of education legislation, the Education Acts of 1944 and 1981 and the subsequent implementation of the legislation. The historical record does not reflect the impact that parent-led 'spastic' associations had, and the consequences of actions, initiated by parents, in post-war Britain, has been largely overlooked by historians. A recent publication by Jameel Hampton, Disability and the Welfare State in Britain (2016), ${ }^{4}$ refers to the Spastics Society in the discussion on voluntary organisations but it is a passing reference which does not convey its importance. The system which discriminated against a sector of society was challenged and existing authority was defied by setting up a bespoke provision of service and support. Associations developed to be part of a professional, multi-agency industry. This thesis aims to ensure that it will no longer be possible to present a comprehensive analysis in the historiography of the family, education, the post-war welfare state and transnationalism without consideration of the impact of parent-led 'spastic' associations.

Two parent-led associations receive detailed consideration in this thesis. Midland Spastic Association (MSA, established in 1947) was based in Harborne, a suburb of the city of Birmingham and was the first association to establish a parent-led day school in 1948. Swansea and District Spastic Association (SDSA, established in 1952) founded the first parent-led school in Wales for children with cerebral palsy which opened in 1953. The national organisations discussed are the British Council for the Welfare of Spastics (BCWS, established in 1946) and the National Spastics Society (NSS, established in 1952).

4 Jameel Hampton, Disability and the welfare state in Britain (Bristol: Policy Press, 2016). 
In researching the history of educating children with cerebral palsy, this thesis uses a chronological approach, which shows how services evolved and enables subsequent developments to be put into context. Whilst the national organisations worked with local parent-led associations to co-ordinate research and publicity, they could not have the same impact and meet the individual needs of the diverse local areas. The tailored approaches of local groups meant that they were able to focus on particular needs relevant to their geographical area. However, this thesis shows the importance of both national and local organisations in the history of educating children with cerebral palsy.

The thesis considers two theoretical models of disability, the medical model and the social model. Traditionally, medical diagnoses of disability were not questioned by families and historically many disabled children were classified using terms such as 'cripple' or 'idiot'. Those deemed to be 'ineducable', following post-war reform remained under the control of the health authority and, as such, were invisible within the education system. The tragic appeal of 'poster children' and the use of emotive imagery in marketing campaigns shaped the public perception of 'spastics' as being needy. This conflicted with the argument that with just the right support and education, 'spastic' children could be successful. The changing climate of the 1970s and the emergence of the social model of disability was a pivotal moment in time. However, challenging attitudinal barriers towards individuals with cerebral palsy proved difficult as the financial gain, associated with traditional charity advertising, overshadowed individual successes and also individual needs. It was not until the mid-1980s, when the campaign to lose the word 'spastic' became more political, that an increased awareness of the social model began to impact on individual expectations and also on the wider aims and objectives of associations.

The significance of transnational networks, examined in this thesis, supports the argument that they were key to the advancement of services for people with cerebral palsy in Britain. Transnational networks could not change legislation in individual countries but it was the sharing of new ideas and practices that made the difference. Discussion focused on broader issues and not simply 
on the injustices of exclusion from education. This led to an exchange of ideas which included the possibilities of what could be achieved through implementing a multi-disciplinary approach towards the treatment of cerebral palsy. Physical therapy combined with education, as part of everyday school life, was advocated and an effective network enabled the dissemination of information. Services provided within the network of parent-led 'spastic' associations were not mirrored in state run services and this thesis demonstrates how associations had the freedom to embrace new approaches, which allowed for a quicker pace of change.

A case study considers the significance of Carlson House School, established by the MSA in 1948. The focus of education in post-war Britain was centred around employment, and this thesis argues that children with cerebral palsy were not always seen as being worthy of the investment, as their education did not necessarily lead to employment. The purpose of education is brought into question as value judgements were being made of children with cerebral palsy, regarding their academic ability and suitability for education. In Association schools, diverse groups such as parents and professionals, often with competing views, worked together to meet the needs of the child. This thesis examines the issues raised at the time and argues that despite major reform to the education system, it reproduced and reinforced social inequalities.

The 1978 Report of the Committee of Enquiry into the Education of Handicapped Children and Young People (Warnock report) and the subsequent 1981 Education Act changed the dynamics of parent-led 'spastic' associations. Children with cerebral palsy could no longer be denied an education and so the need to campaign on this platform was, to a certain extent, removed. In order to remain in operation, associations had to negotiate service level agreements and contracts with local authorities and in doing so lost a certain level of autonomy. These changes required different skills and a more professional approach and this thesis examines the resilience of parent-led associations as they evolved to meet new demands. 
As the first wave of children supported by parent-led 'spastic' associations reached adulthood in the 1960s and 1970s, it became apparent that employment opportunities were limited. The 1944 Disabled Persons (Employment) Act maintained that disabled people had a right to work, and this policy ostensibly created a system whereby disabled people could find jobs. Disablement Resettlement Officers and quota systems failed in their effectiveness to secure employment for disabled people. 'Segregated' factories or workshops, run by the local authority or voluntary organisations, provided some sheltered employment opportunities. These opportunities were based around light industrial work or 'traditional' roles that had been viewed as therapy-based and craft-based tasks. Whilst post-war reforms had created an impetus for change in the employment of disabled people, state control and intervention were still key. The fact that many individuals with cerebral palsy struggled to find employers willing to give them a job as they became school leavers is examined in this thesis. The development of national and local parent-led 'spastic' Work Centres meant that parents continued to be involved in their adult child's life. This thesis examines the impact that Work Centres had as employers of adults with cerebral palsy.

\subsection{Motivation for this study}

My interest in the history of parent-led 'spastic' associations developed during the period of nearly six years, from 1999, when I was employed at SDSA. During that time, I became more aware of the Association's history and its importance in the context of disability history and the wider history of Swansea. Such was the legacy of the organisation at the time of my employment it was still supported by a network of families and friends. It was a unique environment in which to work as a distinctive community had been created of which staff members quickly became a part.

My work at SDSA was as the Administrator of the association but I also developed an advocacy role, working with the service user committee, facilitating discussions about centre activities and any issues or concerns to be raised with the Management Committee. Through my employment I had an insight into the challenges that both families and individuals faced and also the conflicts and 
frustrations that sometimes arose. My direct work experience provided a strong motivation to explore the history of parent-led 'spastic' associations in more detail. Returning to education as a mature student enabled me to pursue this interest from an academic perspective.

The sudden closure of the Association in 2011 also prompted me to explore options to tell its story to a wide audience, recognising its importance as part of the history of Swansea. Together with colleagues at Swansea University, a successful application was made to the Heritage Lottery to fund a community project to examine and celebrate the legacy of the Association. I managed this project on a part-time basis, over two years, whilst undertaking my PhD study.

\subsection{Thesis structure}

Chapter Two examines existing literature relating to disability history during the second half of the twentieth century. It aims to contextualise the discourse within the framework of this thesis as literature relating directly to the subject matter of this thesis is not prominent in the historiography of disability history. The literature review takes a thematic approach and includes discussion on social policy and the welfare state; disability theory; the use of language and the visual representation of disability; education and employment; and oral history theory and practice.

Chapter three considers how parent-led 'spastic' associations became established in post-war Britain, discussing the campaign for educational rights for children with cerebral palsy. The chapter examines the various factors behind the campaign for change, considers the importance of the BCWS in raising issues for parliamentary debate and in promoting the development of a transnational network. Transnational networks grew through the work of pioneering doctors and, the chapter argues, that the development of these networks led to a better understanding of cerebral palsy. An overview given in the chapter considers how research was disseminated and this sharing of knowledge enabled a more informed debate on the symptoms and treatment of cerebral palsy. The influence of the medical model of disability, which underpinned the development of service 
provision, is discussed. The chapter uses examples from local parent-led groups, MSA and SDSA and the national charity NSS to illustrate the ways in which they brought about change. The impact of the NSS on local groups and its wider influence is considered, as it forced a change in dynamics with its rapid growth and energetic approach to campaigning.

The fourth chapter considers the challenges of providing an education to those who had been deemed to be 'ineducable'. Despite major efforts, progress made to include children with cerebral palsy in state education was either disjointed or non-existent. The focus of educational reform had been on creating a better educated workforce with more opportunities for employment. The chapter discusses how the concept of a meaningful education without the goal of employment was viewed. The chapter argues that parent-led 'spastic' associations had more freedom to offer an alternative curriculum, which included a multi-disciplinary approach where education and therapy treatment formed part of the school day. The impact of economic constraints and a lack of suitably qualified teachers, in both voluntary and state-run services, is considered. Carlson House School, established by MSA in 1948, is used as a case study, and its influence in setting a standard to which other schools aspired is examined. The chapter questions whether parent-led 'spastic' schools, despite their successes, fitted with the core aims and objectives of parent-led 'spastic' associations as children with cerebral palsy remained segregated.

At their inception, the main purpose of parent-led 'spastic' associations had been to campaign for educational rights and for individuals to achieve a level of independence. Chapter five examines the impact of continued parental intervention into adult lives through the creation of sheltered employment work centres. It questions whether a level of independence was achieved or hindered by parent's actions. The type of work undertaken in sheltered work centres has been criticised and the chapter considers the value that was placed on activities and whether they influenced a negative view.

Throughout the history of parent-led 'spastic' associations, language and imagery played a significant role in raising awareness and in fundraising. Chapter 
six considers the success of the 'spastic' brand but also examines the dichotomy in the use of the 'spastic' label. The chapter argues that the term 'spastic' became part of popular culture and considers how far this shaped a negative attitude towards people with cerebral palsy. The emergence of the social model of disability in the 1970s could not address the issue of a collective experience of disability. The chapter considers why it took until the mid-1980s for individuals with cerebral palsy to become empowered to speak for themselves and lobby for change. The campaign to lose the term 'spastic' was not straightforward and the complexities of this are discussed, as this change, was both welcomed and opposed by different groups and individuals.

It was the enactment of the 1978 Report of the Committee of Enquiry into the Education of Handicapped Children and Young People (Warnock report) which began a new era in the relationship between state and voluntary sector. The creation of a new category, 'special educational needs' ostensibly meant that no child would be discriminated against because of their disability. Despite this change, parent-led 'spastic' associations remained a constant presence but have adapted in the services they provide. Chapter seven considers the changing relationship between professionals, government bodies and parent-led 'spastic' associations as they evolved into more professional, charitable bodies. The chapter considers whether the pioneering work of post-war parents has been diminished as a new generation of parents of children with cerebral palsy did not have to face the same issues for educational rights. However, the chapter argues that options for school leavers with cerebral palsy had not improved significantly and this is a problem which has spanned the generations. Access to 'spastic' day centres or sheltered employment has remained the main option for many. 


\section{Literature Review and Methodology}

\subsection{Literature Review}

Researching literature for this thesis has revealed that there is limited academic discourse within the historiography of disability history relating directly to the lives of people with cerebral palsy and particularly children's lives. In their book Disabled Children: Contested Caring, 1850 - 1979 (2012), Anne Borsay and Pamela Dale maintain that the 'distinctive voice of the disabled child has been silenced by both the historical marginalisation of disabled people and the focus of the disability rights movement on adult priorities'. ${ }^{5}$ This point is pertinent to this thesis, as children with cerebral palsy were marginalised by the nature of their impairment and their voices remained largely unheard. Through the authority of their parents and other adults, decisions were made about their lives and, for many, this continued as they reached adulthood. The growing disability movement in the 1970s, and the advent of the social model of disability, did not adequately consider the needs of children with cerebral palsy. In relation to disabled children, Borsay and Dale argue that the 'only really distinctive historiography concentrates on the development of special schools'. Therefore, 'it is the evaluation of this limited provision that has tended to marginalise the historical experiences of disabled children'. ${ }^{6}$ This thesis demonstrates that children with cerebral palsy often sat outside this provision.

A selection of articles discussed in a paper, 'Imperfect Children in Historical Perspective' (2013), Steven King and Steven J. Taylor examine how 'thinking in relation to childhood has evolved ... [particularly] in the emergence of notions of perfect and imperfect children's bodies and minds over the last 250 years'. They conclude that the 'medicalisation of childhood, like modernity, [was] a thread that [ran] through all of the contributions' they reviewed. They state that 'while

\footnotetext{
${ }^{5}$ Anne Borsay and Pamela Dale, 'Introduction: Disabled Children - Contested Caring', in Disabled Children, ed. by Anne Borsay and Pamela Dale (London: Pickering \& Chatto Ltd., 2012), pp.1-13 (p.2).

${ }^{6}$ Borsay and Dale, p.3.
} 
historians have focused on medicalisation in a broad sense throughout the eighteenth and nineteenth centuries, very little work has focused on children'. ${ }^{7}$

The disenfranchisement of children with cerebral palsy is emphasised by the fact that many had not been viewed as capable beings. Judged within the confines of the medical model of disability, individuals were seen as dependent, to be cared for rather than engaged with. Borsay and Dale argue that 'interest in the care/control paradox unites many strands of the historiography but reveals more about the intentions of service-providers than client responses'. 8 This paradox is considered through the examination of the level of power that overarching bureaucracy had in shaping individual lives. Whilst support services can control as well as empower aspects of daily life, many with cerebral palsy found it difficult to achieve a level of independence, particularly as adults. Borsay and Dale contend, 'within the social model' there is a tendency to 'inadvertently foster the historical neglect of groups reliant on support services managed by third parties' and so there is a 'struggle to escape the care/control paradox'. ${ }^{9}$

Allison C. Carey, Pamela Block and Richard K. Scotch argue 'the role of parents of children with disabilities in disability activism has provoked contention among scholars'. Opposing views include seeing 'parents as vibrant, path blazing advocates who fight selflessly for the rights and needs of their children' in contrast to 'parents and their organisations as likely barriers to the empowerment of people with disabilities'. ${ }^{10}$ This thesis argues that the provision of parent-led services, from childhood into adulthood sustained a culture of dependency which minimised opportunities for personal growth and independence. Parents, at the inception of local associations, may not have seen themselves as being politically active, but rather as concerned parents who were seeking to provide an education for their children. Primary sources and oral histories presented in this thesis support this contention.

\footnotetext{
7 Steven King and Steven J. Taylor, "Imperfect Children" in Historical Perspective', Social History of Medicine, 30.4 (2017), 718-726 (pp.723-724) < https://doi.org/10.1093/shm/hkx095>.

${ }^{8}$ Borsay and Dale, p.3.

${ }^{9}$ lbid.

${ }^{10}$ Allison C. Carey, Pamela Block and Richard K. Scotch, 'Sometimes Allies: Parent-Led Disability Organisations and Social Movements', Disability Studies Quarterly, 39.1 (2019), <http://dx.doi.org/10.18061/dsq.v39i1.6281>.
} 
Legislative change impacted significantly on the lives of disabled people through the policies that emerged from the vision in the Beveridge Report. In her chapter in Disability Studies Today (2002), Anne Borsay argues that 'history is the missing piece of the jigsaw in disability studies'. She maintains that the 'field has expanded from its origins in social theory, and social policy to include politics, culture, leisure and the media' but 'historical perspectives across the entire range of disabled people's experiences are virtually non-existent'. ${ }^{11}$ Whilst Borsay's comments can be said to be true at the time of her writing in 2002, disability studies has grown as a stand-alone discipline. In Disability and the welfare state in Britain (2016), Hampton discusses how disability has 'developed rapidly since 2000 as a major area of enquiry for 20th-century British historians'. He declares Borsay's Disability and Social Policy in Britain since $1750(2005)^{12}$ as being the 'only comprehensive study to date' of social policies that affected disability and makes reference to her contention that disabled people 'unable to work received little meaningful financial relief throughout the welfare state'. He discusses the claim that previous disability studies have tended to 'focus on institutionalism and exclusion, and do not usually offer empirical analyses within the relevant historical contexts'. Hampton maintains that his book is 'part of the beginning of a major engagement with disability in the 20th century' and that 'disabled people and 20th-century welfare is consequently a burgeoning field of historical enquiry'. ${ }^{13}$ This thesis provides a significant contribution to the historiography, within this period, by examining the history of parent-led 'spastic' associations and the impact on the lives of individuals with cerebral palsy.

Comparisons can be drawn with the history of learning disability. Founder members of the Social History of Learning Disability (SHLD), Jan Walmsley and Dorothy Atkinson, have written extensively on the history of learning disability. In a review of pertinent literature in their chapter in Oral History, Health and Welfare (2000), Walmsley and Atkinson maintain that the history of learning disability "has only recently come into vogue as a topic worthy of study in its own right'. Their

\footnotetext{
${ }^{11}$ Anne Borsay, 'History, Power and Identity', in Disability Studies Today, ed. by Colin Barnes, Mike Oliver and Len Barton (Cambridge. Polity Press, 2002), pp.98-119 (p. 98).

12 Anne Borsay, Disability and Social Policy in Britain since 1750 (Basingstoke: Palgrave Macmillan, 2005), p.59.

${ }^{13}$ Hampton, p.5.
} 
discussion has similarities to Borsay's argument as they contend that the history of learning disability has been 'treated as a subsidiary topic in other histories' and the subject areas they cite include the 'history of psychiatry, the history of social hygiene and eugenics' and the 'history of special education'. ${ }^{14}$ Medical interventions and practices taken by professionals, in relation to cerebral palsy, are more prominent in the historical record. The wider, social impact of the condition on children in the mid-twentieth century is not represented. This thesis addresses this disparity, recognising the role that parent-led 'spastic' associations played in co-ordinating new developments in research, on a local, national and international stage.

The examination of parent-led 'spastic' associations, in this thesis, reflects how the construction of a 'generic spastic' took away individuality and shaped the identity of many individuals with cerebral palsy. The construction of 'disabled identities' is discussed by Michael Oliver and Colin Barnes in Disabled People and Social Policy (1998). They argue that we learn 'social norms, cultural expectations and shared standards of behaviour of society through the process of socialisation', maintaining that 'primary socialisation relates to the experience of childhood'. Oliver and Barnes cite the work of Canadian social psychologist, Erving Goffman (1968) $)^{15}$ and his analysis of 'changes in self-perception of socially stigmatised individuals' and the 'acquisition of the devalued identity'. Goffman discusses how 'the majority of disabled children grow up in households and communities where there are no other disabled people' so they have no 'strong supportive role models with which to identify'. He also refers to those individuals who have 'been shielded by institutions such as the family or special schools'. ${ }^{16}$ Goffman's analysis holds true for many children born with cerebral palsy as this thesis demonstrates. Isolation within families and communities protected many

\footnotetext{
14 Jan Walmsley and Dorothy Atkinson, 'Oral history and the history of learning disability', in Oral History, Health and Welfare, ed. by Joanna Bornat, Robert Perks, and Paul Thompson (London: Routledge, 2000), pp.181-204 (p.181) ProQuest Ebook Central <https://ebookcentral.proquest.com/lib/swansea-ebooks/detail.action?doclD=240373> [accessed 26 February 2017].

${ }^{15}$ Erving Goffman, Stigma: Notes on the Management of Spoiled Identity (Penguin: Hammondsworth, 1968) cited in Michael Oliver and Colin Barnes, Disabled People and Social Policy (Harlow: Addison Wesley Longman Limited, 1998), p.66.

${ }^{16}$ Michael Oliver and Colin Barnes, Disabled People and Social Policy (Harlow: Addison Wesley Longman Limited, 1998), p.66.
} 
from wider society, which stifled independence and social development, as individuals were effectively hidden from daily life. Several studies ${ }^{17}$ have contended that 'disabled young people are apparently unaware of the consequences of living with perceived impairment' until the time when they 'begin to look for work or try to participate in mainstream leisure activities'. Consequences listed include, 'self-depreciation and low self-esteem' prominent in teenage years and early twenties'. ${ }^{18}$ Outcomes such as this are revealed through the study of parent-led 'spastic' associations and the problems encountered by many individuals in trying to find employment. Societal expectations did not comprehend full citizenship for those who did not conform to the expected 'norm'.

Colin Goble in his chapter, in Disabling Barriers - Enabling Environments (2014), argues that in 'western society, the mind/brain is seen as the seat of individuality and the autonomous self'. Therefore, to 'experience impairment of the mind/brain' is akin to losing 'a critical part of, the self, and the autonomy and independence that go with it'. He considers how such individuals are challenged in their rights to control aspects of their lives such as money, freedom of movement or sexuality', which is still relevant today. ${ }^{19}$ The perception that one has no control over one's brain impacts on the opportunity to make independent decisions and choices.

\subsubsection{Categorising disability}

Categorising a disability such as cerebral palsy, under a generic label was imprecise but it can be argued that, in practical terms, it was easier to administer services according to need. In Companion to Medicine in the Twentieth Century

\footnotetext{
${ }^{17}$ E. M. Anderson, L. Clarke \& B. Swain, Disability in Adolescence (London: Meuthen, 1982); A.P. Thomas, M.C.O. Bax, D.P.L. Smyth, The Health and Social Needs of Young Adults with Physical Disabilities (Oxford: Blackwell Scientific Publications, 1989); C. Barnes, The Cabbage Syndrome: The Social Construction of Dependency (London: Falmer Press, 1990); M. Hirst \& S. Baldwin, Unequal Opportunities: Growing up Disabled (York: York University, Social Policy Research Unit, 1995).

18 Oliver and Barnes, p.66.

${ }^{19}$ Colin Goble, 'Dependence, Independence and Normality', in Disabling Barriers - Enabling Environments, ed. by John Swain, Sally French, Colin Barnes and Carol Thomas (London: SAGE Publications Ltd., 2014), pp.31-36 (p.35).
} 
(2003), Roger Cooter discusses how people with impairments 'may have always been with us, but the "disabled" have not'. He considers how the 'cultural practice of translating physical abnormality into social inferiority extends deep into the past' but argues that the 'disabled', viewed as a 'separate administrative category of the welfare state', is 'almost wholly a creation of the twentieth century'. ${ }^{20}$ Categorisation did not allow for individual needs and conversely, it was also easier to castigate individuals by their label and not offer appropriate support. Similarly, Mark Priestley in Disabling Barriers - Enabling Environments (2014), argues that 'institutional responses to disability have relied on definitions that tend to group disabled people together according to impairment label or the convenience of service bureaucracies'. ${ }^{21}$ The use of the term 'spastic' quickly became a definition utilised within popular culture but was also used to group individuals for administration of services.

In Understanding Disability Policies (1999), Robert Drake provides a useful summary of the key issues which formed the backdrop against which the welfare state evolved. He argues that the development of disability policies in Britain, from Victorian times through to the twentieth century, have reflected 'four successive kinds of objective and medicine has provided the main context for the first three'. He contends that the goals of policy have been:

to effect the containment or segregation of disabled people; to provide redress for social exclusion, and especially to compensate disabled people for injuries received in war or at work; to provide welfare through social services, ostensibly as an attempt to reintegrate disabled people into society and also as an attempt to 'normalise' or control them; to secure rights and citizenship, and, where necessary, reconfigure the social and built environment. ${ }^{22}$

\footnotetext{
${ }^{20}$ Roger Cooter, 'The Disabled Body', in Companion to Medicine in the Twentieth Century, ed. by Roger Cooter and John Pickstone (London: Routledge, 2003), pp.367-383 (p.369).

${ }^{21}$ Mark Priestley, 'Generating Debates: Why We Need a Life-Course Approach to Disability Issues', in Disabling Barriers - Enabling Environments, ed. by John Swain, Sally French, Colin Barnes and Carol Thomas (London: SAGE Publications Ltd., 2014), pp.99-106 (p.102).

22 Robert F. Drake, Understanding Disability Policies (Basingstoke: Macmillan Press Ltd., 1999), p.45.
} 
Despite the positive intentions of post-war reform, a legacy of issues remained which impacted on the lives of many with cerebral palsy. Segregation by the state was unacceptable to the parents of children with the condition, however, this thesis argues that an outcome of parental action contributed to segregation through the establishment of 'spastic' associations, their schools and sheltered Work Centres. Subsequently, integration and citizenship within society proved elusive to many. The influence of the medical model of disability is evident through the limitations placed on individuals which were given credence through professional opinion.

The medical model of disability focused on the person's impairment as the cause of their disability which denied them citizenship and full participation in society. The medicalisation of disability was evident through its attempts to restore 'deviant' bodies to 'normality' and in post-war Britain, there was more of a focus on injured service men and women. Those individuals whose disability did not arise as a result of war injury or industrial injury, were dealt with as a separate group. In Disability and Social Policy in Britain since 1750 (2005), Anne Borsay argues 'the suggestion that without rehabilitation severely disabled people were neither useful nor respected citizens was indicative of an aggressive pursuit of normality'. ${ }^{23}$ Derogatory attitudes, shaped by a changing society, impeded progress for many with cerebral palsy and the condition became a 'social problem'. Educationalists and medical practitioners had to observe the formalities of the new welfare state but categorisation of individuals, according to aptitude and level of impairment, centred around the medical condition as a locus of difficulty. Colin Barnes and Geof Mercer in Disability (2003), discuss how disabled people 'for most of the twentieth century in "Western" societies' have been 'equated with "flawed" minds and bodies'. They argue that this view:

spans people who are 'crippled', 'confined' to wheelchairs, 'victims' of conditions such as cerebral palsy, or 'suffering' from deafness, blindness, 'mental illness' or 'mental handicap'. The individual's impairment or 'abnormality' necessitate[d] dependence on family, friends and welfare services,

${ }^{23}$ Borsay, Disability and Social Policy in Britain since 1750, p.59. 
with many segregated in specialised institutions. In short, disability amount[ed] to a 'personal tragedy' and a social problem or 'burden' for the rest of society. ${ }^{24}$

Borsay considers the 'Beveridge settlement' and argues convincingly that for Beveridge, it 'began from the needs of society rather than from the needs of the individual' and the 'rights of disabled people were a low priority' in the 'agenda for rebuilding Britain'. She considers the meaning of disability, 'defined as the "inability of a person of working age, through illness or accident, to pursue a gainful occupation" and how this was one of Beveridge's "primary causes of need"' and the 'ways in which benefits mapped out perpetuated the relationship between poverty and impairment' ${ }^{25}$ Borsay's views support the fact that people with cerebral palsy experienced difficulty in trying to achieve gainful employment as society did not perceive them as being able to contribute so their needs were not met under the 'Beveridge settlement'.

The implications of social reform are considered by Ken Blakemore and Louise Warwick-Booth in Social Policy: An Introduction (2013), where they maintain that the Beveridge report 'chimed in with wartime hopes and goals' and the creation of a better society was central to these aims. Tackling the 'five giants' of want, disease, ignorance, squalor and idleness not only highlighted the ambition to look after an individual from 'cradle to grave' but also proposed a 'practical means for attaining that vision'. ${ }^{26}$ However, as disability became a matter for the state, disabled individuals were perceived as being passive recipients. The social impact that cerebral palsy had, not just on the individual but also on their family and wider society, is not adequately addressed in literature. Individuals with the condition were said to be suffering from the tragedy of their impairment and terms used were contentious and demeaning. Being considered unable to contribute to a better society provoked a deleterious attitude towards those viewed as 'different' and this strengthened the causal link between illness and disability.

${ }^{24}$ Colin Barnes and Geof Mercer, Disability (Cambridge: Polity Press, 2003), p.1.

${ }_{25}$ Borsay, Disability and Social Policy in Britain since 1750, p.161.

${ }^{26}$ Ken Blakemore and Louise Warwick-Booth, Social Policy an introduction, $4^{\text {th }}$ edn (Maidenhead: Open University Press, 2013), p.59. 
The increasing role that medicine played in the lives of children with cerebral palsy is central to this thesis. In their chapter in Companion to Medicine in the Twentieth Century (2003), Russell Viner and Janet Golden discuss how 'child health became invested with a high social value in many twentieth-century nation-states'. They cite 'new technologies' of that time, which included taking height and weight measurements to chart childhood progress and thus 'normal growth was no longer defined by the simple comparison of a child with its peers' but was 'determined by statistical patterns'. Viner and Golden comment how these measurements were followed by 'other efforts to quantify development' such as 'intellectual coordinates', 'emotional growth' and 'physical coordination'. There was a 'redefinition of normality in statistical and clinical terms, and a shifting locus of judgment from family and peers to clinicians'. ${ }^{27}$ Similarly, Mark S.R. Jenner and Bertrand $\mathrm{O}$. Taithe, in their chapter in Companion to Medicine in the Twentieth Century (2003), discuss the 'historiographical body' and maintain that 'the history of medicine has almost always been concerned with the interpretation of sick bodies'. ${ }^{28}$ They refer to French philosopher, George Canguilhem who said, 'it has been predicated upon the shifting definitions of normativity and normality, the history of the normal and the pathological'. ${ }^{29}$ In Enforcing Normality: disability, deafness, and the body (1995), Lennard Davis declares that 'we live in a world of norms' and in order to 'understand the disabled body, one must return to the concept of the norm, the normal body'. He considers the 'construction of normalcy' as opposed to the 'construction of disability', arguing that 'normalcy is constructed to create the "problem" of the disabled person'. He contends that the 'idea of a norm is less a condition of human nature than it is a feature of a certain kind of society'. ${ }^{30}$ In defining 'normality' a debate was initiated

\footnotetext{
${ }^{27}$ Russell Viner and Janet Golden, 'Children's Experiences of Illness', in Companion to Medicine in the Twentieth Century, ed. by Roger Cooter and John Pickstone (London: Routledge, 2003), pp.575-587.

${ }_{28}$ Mark S.R. Jenner and Bertrand O. Taithe, 'The Historiographical Body', in Companion to Medicine in the Twentieth Century, ed. by Roger Cooter and John Pickstone (London: Routledge, 2003), pp.187-200 (p.188).

${ }^{29}$ George Canguilhem, The Normal and the Pathological, tr. Carolyn R. Fawcett. (New York: Zone Books, 1989), cited in Mark S.R. Jenner and Bertrand O. Taithe, 'The Historiographical Body', in Companion to Medicine in the Twentieth Century, ed. by Roger Cooter and John Pickstone (London: Routledge, 2003).

30 Lennard J Davis. Enforcing Normalcy: Disability, Deafness, and the Body (London: Verso, 1995), pp.23-49 (p.23) ACLS Humanities E-Book < https://hdl.handle.net/2027/heb.02823> [accessed 18 September 2019].
} 
by the failure of children with cerebral palsy to meet normative patterns, incorporating medical, political, ethical and economic issues.

Normative expectations are discussed by Anne Borsay in her chapter in Disabled Children: Contested Caring, 1850-1979 (2012). In her study of a range of advice literature, pertinent to the experiences of disabled children and their families, Borsay refers to the 'authoritarian literature of the pre-war period' which 'as part of Britain's eugenic mission' had drawn on a 'combination of hereditary principles and healthy living to advance strategies for the prevention and treatment of disability'. She argues that in the post-war period 'intuition' came to displace 'authoritarianism' but there was 'no weakening of the pre-war emphasis on medical supervision' for families with disabled children and the 'marginalising effect' was presented through literature. Borsay refers to two books, ${ }^{31}$ Hugh Jolly's Book of Child Care (1975) and Baby and Child (Penelope Leach, (1977). In her reflections on Jolly's book, Borsay comments that the 'chapters discussing disabled children' were in the part of the book which dealt with 'sick children, 'thus eliding long-term impairment with temporary illness'. In contrast, Leach's book, saw 'disability retreated to an encyclopaedia at the back' where 'little additional information was provided' apart from a 'short section on "handicapped children" outlining the interconnection between mental and physical impairments'. Increased classification of disability was also evident in popular magazines, and Borsay describes a 1959 edition of Good Housekeeping's Mothercraft in which there was a chapter on 'The Child with a Handicap'. This included 'eight categories of physically or mentally disabled children', one of which was 'spastic'. Borsay argues that this presentation of disability in terms of diagnostic categories, while simultaneously equating it with sickness, construed disabled children as permanent objects of professional intervention and inhibited family attempts to shape alternative definitions of their lives'. ${ }^{32}$

\footnotetext{
${ }^{31}$ Hugh Jolly, Book of Child Care: The Complete Guide for Today's Parents (London: George Allen and Unwin, 1975); Penelope Leach, Baby and Child: From Birth to Age Five (Harmondsworth: Penguin Books, 1977).

${ }^{32}$ Anne Borsay, 'From Representation to Experience: Disability in the British Advice Literature for Parents, 1890-1980', in Disabled Children: Contested Caring, 1850-1979, ed. by Anne Borsay and Pamela Dale (London: Pickering \& Chatto Ltd., 2012), pp.87-101 (p.91-92).
} 
This type of literature perpetuated the negative aspects of the medical model of disability and so popular media, in this respect, did not alleviate fears but was more alarmist. For families who did not have a disabled child or experience of disability, such information was misleading regarding the reality of individual situations. In Exploring Disability (2010), Barnes and Mercer quote Michael Oliver ${ }^{33}$ who contended that the 'central thrust of the individual model' was to 'cast disability as a personal tragedy where the person with an impairment has a health or social problem that must be prevented, treated or cured': in 'health terms' disability was a 'pathology' and in 'welfare terms' was a 'social problem'. Having a disability meant that there was 'something wrong with you' ${ }^{34}$ However, positive 'medical intervention', in the form of therapy treatment, was a turning point for many with cerebral palsy, as speech and ease of movement were improved. Whilst literature may consider medical outcomes of this type of intervention, it does not adequately reflect the positive social benefits that were achieved by advances in the understanding of cerebral palsy.

Michael Oliver argues that in the post-war period, "the "medical hegemony" in special education, legitimated the withdrawal of children from classes to receive "medical and paramedical interventions" which encouraged them to acquiesce in a passive sick role'. ${ }^{35}$ His view is based on an idealised concept and does not reflect the reality of the situation for many children. This thesis demonstrates the progress that was made through the development of a better understanding of cerebral palsy, and research outcomes. It acknowledges that, particularly in the early days, there would have been a level of experimentation to find the best course of treatment for individual children. Without medical intervention, many children with cerebral palsy would have languished at home or in hospitals, and would not have experienced an improved level of treatment.

\footnotetext{
${ }^{33}$ Michael Oliver, 'A sociology of disability or a disablist sociology'? in Disability \& Society: Emerging Issues and Insights, ed. by Len Barton (London: Longman 1996b), p.30, cited in Colin Barnes and Geof Mercer, Exploring Disability (Cambridge: Polity Press, 2010), p.24.

${ }^{34}$ Colin Barnes and Geof Mercer, Exploring Disability (Cambridge: Polity Press, 2010), p.24.

${ }^{35}$ Michael Oliver, 'Disability and Dependency: A Creation of Industrial Societies'? in Disabling Barriers - Enabling Environments, ed. by John Swain, Vic Finkelstein, Sally French, and Michael Oliver (London: SAGE Publications Ltd., 1993), cited in Anne Borsay, Disability and Social Policy in Britain since 1750 (Basingstoke: Palgrave Macmillan, 2005), p.97.
} 
The medical profession, during the twentieth century, encompassed other disciplines, such as psychology or therapy provision as branches of medicine. This expansion of roles made a marked impact on the delivery of services in varying degrees. Barnes and Mercer in Disability (2003) discuss how occupational therapists and physiotherapists who were 'allied to medicine' as well as the 'educational and social welfare fields' meant a 'widening professional involvement' in the lives of disabled children and adults. This included influence over 'educational provision, entry to paid employment, eligibility for welfare payments and the provision of technical aids and equipment. ${ }^{36}$

Matthew Thomson considers the discipline of psychology in his chapter in Companion to Medicine in the Twentieth Century (2003). He argues that during the 'first half of the century' the growth in the field:

would rest on its claim to be able to measure the mental abilities of individuals, and consequently its use to classify these individuals, to define new boundaries of normality within populations, and to regulate individual adjustment to social norms. ${ }^{37}$

Increased use of the IQ test was controversial for children with cerebral palsy as those who failed, or who were not given adequate opportunity to compete tasks, were singled out. However, as Thomson contends, the development of the mental test together with the willingness of the state to 'intervene to maintain the health, efficiency, and order of their subject populations' was, 'crucial to the emergence of psychology as an applied discipline'. He uses the example of emerging 'state education systems' as being the best to illustrate this conjuncture and says that testing made 'visible the backward and disruptive child' and so 'proved the perfect opportunity for the emergence and expansion of a machinery for psychological testing'. ${ }^{38}$ However, this thesis demonstrates that psychological testing in this way did not take sufficient account of individual factors that could

\footnotetext{
${ }^{36}$ Barnes \& Mercer, Disability, p.28.

${ }^{37}$ Mathew Thomson, 'The Psychological Body', in Companion to Medicine in the Twentieth Century, ed. by Roger Cooter and John Pickstone (London: Routledge, 2003), pp.291-306 (p.295).

38 Thomson, 'The Psychological Body', p.296.
} 
influence outcome. In his chapter on disability and the body, in Disability Studies Today (2002), Bill Hughes argues that the long 'partnership between modernity and medicalization produced a hegemonic conception of disability as an outcome of biophysical or mental impairment'. He said, those with 'broken bodies' or 'faulty minds' were destined to be 'swept up and disposed of' as is the 'fate of breakage'. ${ }^{39}$ Disability literature does not make the distinction that children with cerebral palsy needed an investment of time and trained staff in order to be considered fairly within the boundaries of psychological testing.

\subsubsection{A climate for change}

The commitment of parents and their campaign for educational reform generated strong bonds between families. Subsequently, resilient communities emerged as Vic Finkelstein remarks, in his chapter in Handicap in a Social World (1983). He discusses how, 'non-religious charitable organisations' came to play an 'increasingly significant role in the care of disabled people and disabled children' in the mid-twentieth century. He considers how they began to 'organise on a massive scale to agitate for state intervention and better forms of treatment'. He cites the Spastic Society as an example and says how they were 'particularly concerned about the education of their children and set about creating such a service' ${ }^{40}$ Despite significant developments within the voluntary sector, the role that associations played and the legacy of these communities are not prominent in literature. It was not just the Spastics Society but others, such as the National Association of Parents of Backward Children which emerged as parent-led organisations which sought to directly help individuals and their families.

In order to consider parent-led associations in an historical context it is essential to examine why the climate of post-war Britain was so conducive to their development. In her chapter in The Social Construction of Community Care (1998), Anthea Symonds discusses the 'creation of the welfare state after 1945'

${ }^{39}$ Bill Hughes, 'Disability and the Body', in Disability Studies Today, ed. by Colin Barnes, Mike Oliver and Len Barton (Cambridge. Polity Press, 2002), pp.58-76 (p. 58).

${ }^{40}$ Vic Finkelstein, 'Disability and the Helper/Helped Relationship. An Historical View,' in Handicap in a Social World. ed. by Ann Brechin, Penny Liddiard and John Swain (Sevenoaks. Hodder and Stoughton Educational, 1983), pp.58-63 (p.62). 
where she says it was 'assumed by some both in and outside the voluntary sector itself that the new dominance of state provision would leave it without a purposive role'. However, Symonds argues that the voluntary sector 'continued to play an important part in the field of social care even during the period of greatest state welfarism and public-sector provision'. She argues that it was 'during this period of the dominance of state provision that the voluntary sector took on a more open politicising role'. Groups formed to 'campaign on issues' where it was felt that the 'state was performing inadequately' and Symonds refers to 'Cinderella services' which had 'not been invited to the ball' such as 'services for the elderly, mentally and physically handicapped and the mentally ill', as those which were being neglected. Organisations including 'MIND, Mencap and Age Concern', were established around the time of the NHS. ${ }^{41}$ Symonds' contention that groups formed to highlight inadequate services is also discussed by John Swain, Sally French and Colin Cameron in Controversial Issues in a Disabling Society (2005). They argue that in the 'major time of change' following the Second World War and the welfare state, where the 'state assume[d] major responsibility for the welfare of its citizens', the impact of this 'transformed' the charity sector and 'a new series of organisations were established to fill the gaps and meet the perceived inadequacies of state welfare provision'. ${ }^{42}$ The actions taken by 'spastic' associations, discussed in this thesis, illustrate how they highlighted the failings of the welfare state and essentially challenged these to meet a gap in the provision of services.

Julie Anderson considers this changing climate in War, disability and rehabilitation in Britain (2011), and comments how some groups became engaged in 'issues as opposed to providing basic services, which were, in the main, [now] provided by the State'. She gives an example of the Red Cross which provided '"comforts" for disabled people from cigarettes to invalid chairs' and argues that 'part of the reason for expansion' of voluntary associations was that the 'State provided a system of basic care, so organisations were able to broaden

${ }^{41}$ Anthea Symonds, 'The social reconstruction of care: from the state to the community', in The Social Construction of Community Care, ed.by Anthea Symonds and Anne Kelly (Basingstoke: Macmillan Press Ltd., 1998), pp.33-50 (p.37).

42 John Swain, Sally French and Colin Cameron, Controversial Issues in a Disabling Society (Maidenhead: Open University Press, 2005), p.89. 
their range of activities'.43 Therefore this environment proved conducive to change as illustrated by the growth in the number of voluntary organisations reported by the '1952 Nathan Committee on Charity' which detailed that there were ' 110,000 charitable trusts in Great Britain in 1950'. ${ }^{44}$ Anderson illustrates this expansion by stating that the many interests of blind people were represented by approximately 100 different organisations' and 'new bodies, representing a myriad of groups and interests were also established'. In addition to the BCWS (1946), Anderson lists the British Epilepsy Association (1951), NSS (1952), Multiple Sclerosis Society (1953) and the Muscular Dystrophy Group (1954) as examples of charities which became established around the same time. ${ }^{45}$ It can be seen how different organisations engaged with a changing environment to develop services which continued to evolve. As Barnes and Mercer comment in Independent Futures Creating user-led disability services in a disabling society (2006), 'through the post-1945 decades', charitable activity 'increasingly overlapped with local authority social services departments' provision - from residential homes and sheltered workshops to day centres' ${ }^{46}$

Community Care in Perspective (2006), edited by John Welshman and Jan Walmsley has a primary focus on the history of learning disability yet the text is relevant. Welshman discusses 'control, eugenics and mental deficiency' and reflects on the role of voluntary organisations, considering how 'post-war saw the development of stakeholder membership groups which campaigned for fundamental changes'. He argues that the importance of this development 'would be hard to overstate'. In relation to the National Society for Parents of Backward Children, he says that the "why then" question is important, but its answer unclear' and refers to Sheena Rolph, who 'cites the coming of the welfare state as one of the key influences, because it raised expectations'. There was a:

\footnotetext{
43 Julie Anderson, War, disability and rehabilitation in Britain (Manchester: Manchester University Press, 2011), p186.

44 Statistics quoted from: F.K. Prochaska, 'Philanthropy' in The Cambridge Social History of Britain, 1750-1950, Vol II, ed.by F.M.L. Thomson (Cambridge, 1990), 358.

45 Julie Anderson, p.185.

${ }^{46}$ Colin Barnes and Geoffrey Mercer, Independent Futures: Creating user-led disability services in a disabling society (Bristol: Policy Press, 2006) p.16. ProQuest Ebook Central $<$ https://ebookcentral.proquest.com/lib/swansea-ebooks/detail.action?doclD=419302> [accessed 27 May 2019].
} 
realisation that children excluded from school were also excluded from free meals, free milk and supplements, and were not eligible for family allowances, caused much resentment among parents. ${ }^{47}$

Welshman discusses how 'this phenomenon' was not restricted to 'countries with welfare states' and points out that 'in the UK it was only after the Second World War that parents' groups gained national policy-influencing momentum' ${ }^{48}$

Hampton refers to those individuals who were part of the 'separate group' as the 'general classes' of disability and he includes cerebral palsy in his list of the 'most common particular pathologies'. ${ }^{49}$ In the case of people with cerebral palsy, this further singled them out as being different and not worthy of the investment promised within the new welfare state. Hampton presents a strong argument that there are 'historical and conceptual precedents for identifying' individuals from the 'general classes' as a 'distinct category of disabled people, and as a distinct category for the purposes of the welfare state'. He contends that such individuals were 'defined less by their inclusion in the welfare settlement of the 1940s than by their exclusion from it'. He refers to the separate provisions that were in place for 'adult blind and deaf people, disabled children and disabled people with mental health. ${ }^{50}$ However, cerebral palsy did not easily fit into an existing category and whilst it can be said to be part of the 'general classes of disability' as argued by Hampton, for the purpose of social welfare, cerebral palsy meant social exclusion and no welfare. Hampton argues that it was the intention of Beveridge that those groups who required Personal Social Services (PSS) should 'remain largely the responsibility of non-statutory agencies working in co-

47 Sheena Rolph, Reclaiming the Past: The Role of Local Mencap Societies in the Development of Community Care in East Anglia, 1946-1980 (Open University: Milton Keynes, 2002), cited in John Welshman, 'Ideology, Ideas and Care in the Community, 1948-71', in Community Care in Perspective: Care, Control and Citizenship, ed. by John Welshman and Jan Walmsley (London: Palgrave Macmillan, 2006), pp.17-37 (p.21).

48 John Welshman, 'Ideology, Ideas and Care in the Community, 1948-71', in Community Care in Perspective: Care, Control and Citizenship, ed. by John Welshman and Jan Walmsley (London: Palgrave Macmillan, 2006), pp.17-37 (p.21).

49 Jameel Hampton, Disability and the welfare state in Britain (Bristol: Policy Press, 2016), p.2.

50 Ibid., p.3. 
operation with the state'. ${ }^{51}$ In considering Hampton's views, one should not assume that all disabled individuals were provided for under the new welfare state. He argues that the 'existence of a general class of disabled people developed in the 1950s' and by the 'mid 1960s', were 'established in both the public and policy minds as a self-aware group'. ${ }^{52}$

\subsubsection{Raising a profile}

In his book The Creatures Time Forgot (1992), David Hevey is critical in his analysis of the use of disabled imagery and maintains that charities are "by far the largest producers and distributors of oppressive impairment/negative disability imagery'. He discusses their reluctance to 'accept a recontexting of the debate on disability imagery away from the impairment-fixation of the problem-inthe-body imagery'. This, he says is 'hardly surprising' as 'although they are called "disability" charities, they are in fact impairment charities'. ${ }^{53}$ Colin Barnes and Geof Mercer in Exploring Disability (2010), refer to Hevey's analysis that images of impairment should be 'stark', and centred on the 'physical flaw' with the purpose to evoke fear and sympathy in the viewer'. ${ }^{54}$ In her chapter in Disability on Equal Terms (2008), Margaret Taylor contends that through being disability specific, a particular 'impairment' became the charity's brand and she argues that 'oppressive images left an enduring legacy whereby negative and limiting perceptions became synonymous with impairment and disability'. Taylor makes the point that the "impairment became the "unique selling proposition" for the charity product'. To put it another way, 'the disabled person had become a commodity owned by the charity'. ${ }^{55}$ As can be seen in this thesis, the public façade of the National Spastics Society was entirely built around cerebral palsy as a 'tragic' impairment and the physical embodiment of the condition was on display in advertising literature in order to garner support. It was not just this type of imagery that was used, as discussed by Sheena Rolph in Community Care in

51 Ibid.

52 lbid.

53 David Hevey, The Creatures Time Forgot (London: Routledge, 1992), p.12.

54 Barnes \& Mercer, Exploring Disability p.198.

55 Margaret Taylor, 'Disabled in Images and Languages', in Disability on Equal Terms, ed.by John Swain and Sally French (London: SAGE Publications Ltd., 2008), pp.31-41 (p.33). 
Perspective (2006). She reflects on the actions of parents of children with learning disabilities in England, who used images of disabled children in 'ordinary situations, such as at parties, on outings or at work'. Rolph comments how different this was from the images of these children being depicted in 'institutions or as medical cases' and argues that this approach asserted the 'ordinariness of [the] children, set against society's prejudices'. ${ }^{56}$ Similarly, Paul K. Longmore in his book, Telethons: Spectacle, Disability and the Business of Charity (2016) argues, telethons presented disabled people as 'ordinary human beings who were struggling with affliction'. This was simply another way to elicit support and this approach suggested that the individual portrayed could be 'just like your neighbours' or 'just like you and your family' or, indeed 'could be you and your family'. ${ }^{57}$

Charity advertising has generated much discussion and criticism. The Spastics Society grew, partly, through the significant efforts that were put into raising monetary donations, though advertising. The fairly aggressive approach, adopted towards fundraising and campaigning, meant that they raised awkward questions and politicised their cause. The emotive use of imagery is discussed by Longmore as he considers the 'making of poster children'. He refers to Tiny Tim from Dickens's A Christmas Carol a 'little "crippled" boy whose sweetness and courage and pathetic plight melted the heart of miserly Ebenezer Scrooge'. Through marketing, Longmore comments how the 'Tiny Tim Image' became a 'constant and powerful cultural symbol' in America, particularly in telethons. He uses this example to illustrate how 'within both the charity tradition and the operation of the medical model, the fictional poster boy helped to shape the identities of millions of people with disabilities'. Longmore refers to telethons as a re-enacted 'version of $A$ Christmas Carol' and argues 'through much of Western history, disabled and sick children were central to the practice of charity' and he cites examples, from the seventeenth century onwards where 'images of children'

${ }^{56}$ Sheena Rolph, 'The role and perspectives of families', in Community Care in Perspective, ed. by John Welshman and Jan Walmsley (Basingstoke: Palgrave Macmillan, 2006), pp.173-186 (p.176).

${ }^{57}$ Paul K. Longmore, Telethons: Spectacle, disability and the business of charity (Oxford: Oxford University Press, 2016), p.88. 
were used as a 'charity fundraising tool' ${ }^{58}$ It was not just the images which incited people to contribute, they were the hook to draw people in. To use Longmore's analogy of $A$ Christmas Carol, as viewers 'peered through their TV screen [they] learned that they could join the family by opening their hearts to the afflicted Tims' and so 'buy a place at the telethon hearth'. 59

Through researching the methods and strategies adopted by parent-led 'spastic' associations it can be said that they were inspired by international influences. Strategies included the practice of selling penny 'seals' and the 1953 Annual report of the NSS describes how nearly three million penny Coronation seals were being sold with the inscription 'Please help Spastics'. ${ }^{60}$ The services of celebrities were employed to publicise their cause and the Stars Organisations for Spastics (SOS) was launched in 1955, 'a group of prominent Theatre, T.V., Screen and Radio stars' formed a fund-raising committee. Through this group, 'spastics were given over 1,740 separate mentions in the Press,' newsreels, television and radio. It was said that the monetary cost in advertising would have been the equivalent to $£ 72,000$ if the NSS had to pay for this. ${ }^{61}$ The financial success of charities was beholden to the benevolence of people who were not disabled, so continually reviewing the use of imagery for the maximum impact, monetary or otherwise, was essential.

Charities adapted in line with the developing media of the day and used popular icons and cultural images to support their cause. Arguably, mass media made more people 'disability aware' through infiltration into the public domain and so into people's homes. However, as discussed, it reinforced the 'tragedy' of disability. In initiatives, such as SOS, children with cerebral palsy were rarely seen amidst the 'glitz and glamour' of the stars and celebrities and when they were seen they were very much the 'Tiny Tim' characters. Longmore discusses how these types of strategies have persisted and argues that 'disability charities

\footnotetext{
${ }^{58}$ Ibid., p.154.

59 Ibid., p.155.

60 National Spastics Society Annual report (1953), p.3.

${ }^{61}$ National Spastics Society Annual report (1956), p.4.
} 
drew on the cult of sentimentalism's traditional tropes as they focused public attention on the icon of the innocent helpless child'. ${ }^{62}$

A level of financial security meant that the Spastics Society was able to play a significant role as a 'disability specific' organisation, in the wider voluntary sector. This has been viewed as being 'potentially divisive' by Laura Middleton in Disabled Children: Challenging Social Exclusion (1999). She argues that 'disability specific' charities have 'maintain[ed] a system' whereby the 'child's medical condition [was] pre-eminent in determining health, educational and social needs'. She considers the 'rights not charity' argument 'widely promoted by the disability movement' and contends that in order to achieve this, disabled people would need to reject their status as recipients of charity. There would also be a responsibility for charity donors to stop supporting families through separate organisations. However, she argues, this would lead to an acceptance that 'disabled children have a right to their place in the queue for health care, to their seat in the classroom and to protection from abusers.' Subsequently, major charities would need to refocus their direction to 'work towards the inclusion of disabled children in mainstream society' and 'to their own redundancy in the present form.' An 'organisation run for and by disabled people', interested in the promotion of disabled people as equal citizens 'is not compatible with the provision of segregated education and social services.' 63 This thesis argues that being 'disability specific' enabled progression, particularly in the early years, and this would have been almost impossible without the involvement of non-disabled people at many different levels.

Swain, French and Cameron, reflect how the 'sea-changes in charities and the voluntary sector' have to be considered in the 'broader context of changes in the economy, changing government policy and broad cultural changes'. They maintain that 'it is important to consider how the past is relevant today' as 'legacies from Victorian philanthropy have endured and can be found, albeit

\footnotetext{
62 Longmore, p.156.

${ }^{63}$ Laura Middleton, Disabled Children: Challenging Social Exclusion (Oxford: Blackwell Science Ltd., 1999), p.58-60.
} 
transformed by social and historical context, in current debates'.64 It is fairly inconceivable to consider that charities, such as those now known as Scope or Mencap, would cease in their present form and literature does not reveal the extent of the contribution that these organisations made. For example, without the efforts of the NSS, funding for research may have been at a much lower level and so could have had a detrimental effect on recipients of treatment. This can be illustrated through a Medical Research Scheme was launched in the early 1950s, reported on in the 1954 Annual Report of the NSS. It stated that the association 'had not lost sight of the desperate need for medical research into cerebral palsy' and that a Director of Medical Research would be appointed to:

survey existing facilities and methods of treatment, both at home and abroad, co-ordinate existing work on cerebral palsy and seek to institute fresh lines of approach to the problems of prevention and treatment. It is by establishing fundamental medical research, added to practical help in solving present problems, that the Society will continue to justify its existence. ${ }^{65}$

By 1955 the NSS had set aside $£ 25,000$ 'in a Trust Fund to meet the initial costs of [the] research' under the direction of paediatrician and geneticist, Dr. Paul Polani 66 of Guys Hospital, London. It did not just focus on medical aspects of the condition but included educational research together with interventions for an improved quality of life. The role of charity, within organisations such as the NSS, was continually evolving and during the 1980s, people with cerebral palsy were on the Executive Board of the organisation, yet segregated education and lack of employment opportunities still continue, but the blame cannot all be laid at the door of the voluntary sector.

Political change during the 1980s meant that charities had to adapt in order to survive and, as Drake comments, the Conservative government's 'assiduous courting of the voluntary sector' meant that charities were encouraged to take up

\footnotetext{
${ }^{64}$ Swain, French \& Cameron, p.88.

${ }^{65}$ National Spastics Society Annual report (1954), p.7.

${ }^{66}$ Dr. Paul Polani was the paediatric research director for the NSS for a period of time from 1954.
} 
'service contracts' and hold partnership agreements with 'state agencies'. ${ }^{67}$ Increased competition for services and funds led many charities into contracts with local authorities as 'resources and security', tempted groups. Drake argues that in addition to 'identifying themselves as a permanent and indispensable part of the welfare scene' the voluntary sector had moved on to 'claiming the right to help determine the future of welfare provision by participating in its planning'. ${ }^{68}$ Drake's argument highlights the start of a weakness in the network of parent-led 'spastic' associations. Maintaining close relationships with the national organisation may not have been as important as cultivating the new relationship with the local authority.

\subsubsection{Education}

Eugenic ideals of the late nineteenth century, concerning health and wellbeing, had far reaching consequences as they legitimised a level of social control over those seen to be 'mentally challenged'. Borsay states that the phrase 'eugenics', coined by Francis Galton ${ }^{69}$ in 1883, 'named the application of biological principles to upgrade the physical and mental strength of the nation'. ${ }^{70}$ The influence of eugenic ideals can be seen in the implementation of educational policy reform which segregated children who had a range of different impairments. Borsay provides evidence in Disability and Social Policy in Britain since 1750 (2005), which details the rise in the number of children who were not taken by 'mainstream' schools and who were set apart from their peers in special schools. ${ }^{71}$ Drake considers education policy and segregation, and argues that 'education policies have served to segregate disabled children from their nondisabled counterparts'. In considering the legislation of the twentieth century, and the Education Acts of 1914 and 1918, he says that segregated children were

\footnotetext{
${ }^{67}$ Drake, p.73.

68 Drake, p.74.

${ }^{69}$ Details can be found at F. Galton, Inquiries into Human Faculty and its Development (London: J.M.Dent \& Co., 1883). <http://www.gutenberg.org/ebooks/11562\#download>.

${ }^{70}$ Borsay, Disability and Social Policy in Britain since 1750, p.102.

71 In Borsay's Disability and Social Policy in Britain since 1750, chapter 5 details that the first special school opened in 1892 and by 1904 this number had increased to 116, and in 1916 it was 179. During the 1920s, Britain had in excess of 500 institutions for children with sensory or physical impairments. This pattern continued in post-war Britain where in the decade following 1945 the number attending special schools in England climbed from 38,499 to 58,034 and by 1972 was $106,367$.
} 
deemed to be 'mentally defective and epileptic' or 'physically defective'. Therefore, 'the separation of disabled and non-disabled children became a familiar feature on the educational landscape' and in considering the 1944 Education Act, Drake comments how the Act 'conferred powers' for 'classifying children suffering from a disability of mind as children unsuitable for education at school'. ${ }^{72}$ The denial of educational opportunities for 'spastic' children did not suddenly become an issue in post-war Britain as opinion was heavily skewed by ideologies of the past which included institutionalisation in long stay hospitals.

The 1944 Education Act is a key piece of legislation and as with Drake, Welshman refers to the recurring themes of 'segregation, exclusion and control' and considers the 'ideological significance' of dates, such as $1944 .^{73}$ He cites Rolph who said that the 1944 Education Act 'enshrined' within it 'many of the worst aspects of the [eugenic] ideology' which included 'segregation, ascertainment and the concept of ineducability". ${ }^{74}$ The implementation of the 1944 Education Act resulted in a legacy which did not reflect the true capabilities of individuals with cerebral palsy. The Education Acts of 1981 and 1993 replaced the term 'mentally handicapped' with 'learning difficulty' and some disabled children attended mainstream schools. However, some children with cerebral palsy may have communication difficulties and so need extra support, to function and compete alongside their non-disabled peers, but limited resources meant that they often had a different and separate experience of school. In Education in a Post Welfare Society (2005), Sally Tomlinson acknowledges that there is a large literature available which has documented 'educational policy, practice, ideology, development and change over the period 1945-80'.75 However, she

\footnotetext{
72 Drake, p.48.

73 Welshman, p.17.

${ }^{74}$ Welshman references the work of Sheena Rolph in relation to her studies on local Mencap societies (2005) and reference can be found at <http://www.open.ac.uk/health-and-socialcare/research/shld/research-group/biography-sheena-rolph>

75 Tomlinson cites: O. Banks, Parity and Prestige in English Secondary Education (London: Routledge, 1955); C. Benn, \& C. Chitty, Thirty Years On: Is Comprehensive Education Alive and Well or Struggling to Survive? (London: David Fulton, 1996); C. Benn \& B. Simon, Half Way There (London: McGraw-Hill, 1970); W. Carr, A. Hartnett, Education and the Struggle for Democracy (Buckingham: Open University Press, 1996); J. Floud, A.H Halsey \& F. M. Martin, Social Class and Educational Opportunity (London: Routledge, 1956); P. Gordon, R. Aldrich, \& D. Dean, Education and Policy in England in the 20th Century (London: Woburn Press, 1991); A.H Halsey. Educational Priority, vol. 1. (London: HMSO, 1972); J. Karabel \& A. H. Halsey, Power and Ideology
} 
maintains that despite 'educational successes' and 'advances', a major theme in the literature was that 'any expectations that more access to education would lead to a more equal society rapidly gave way to disillusionment'. She argues that education has persisted as a means in which 'inequalities were created, legitimized and justified' and whilst a meritocracy supported the 'principle of selection', it had in fact 'sanctioned the differential treatment of the supposedly able, less able and disabled'. ${ }^{76}$ Elements of Tomlinson's argument holds true for this thesis but it is not simply criticism against education policy that needs to be considered as the continued involvement of parents in managing 'spastic' schools meant that they also contributed to the isolation of their children. Changing definitions under new legislation simply created different labels. This did not solve problems but reinforced the argument that it was not possible for a 'one size fits all' approach.

A 'fair system' for all was unachievable and the power given to local authorities by the 1944 Education Act meant that physical examination and I.Q. testing served as a method to exclude children from the system. The range of categories applied to disabled children, as detailed in the 1944 Act, are discussed by Alan Roulstone and Simon Prideaux in Understanding Disability Policy (2012). They maintain that whilst some children with disabilities 'were allowed, where possible, to be educated in the mainstream' they argue that the 'categorisation of disabled people was, in the main quite disturbing'. They contend that the 'most disabling feature' of the 1944 Act was the 'application of the term "ineducable"'. Roulstone and Prideaux refer to Cyril Burt's ${ }^{77}$ 'application of IQ tests to test disability' and comment how decisions made were by 'professionally trained

in Education (Oxford: Oxford University Press, 1977); C. Knight, The Making of Tory Education Policy in Post-War Britain 1950 - 1986 (London: Falmer,1990); D. Lawton, The Tory Mind on Education 1979 - 1994 (London: Falmer, 1994); D. Lawton, Education and the Labour Party: Ideologies 1900 - 2001 and Beyond (London: Routledge/Falmer, 2005); R. Lowe, Education in the Post-War Years (London: Routledge, 1988); H. Silver, Education and the Social Condition (London: Methuen, 1980); B. Simon, Education and the Social Order 1940 - 1990 (London: Lawrence and Wishart, 1991).

${ }^{76}$ Sally Tomlinson, Education in a Post Welfare Society, $2^{\text {nd }}$ edn (Maidenhead: Open University Press, 2005), pp.13-28 (p.13). ProQuest Ebook Central <https://ebookcentral.proquest.com/lib/swansea-ebooks/detail.action?doclD=295501> [accessed 2 April 2017].

77 Cyril Burt was the educational psychologist who influenced the thinking behind the 1944 Education Act through testing and the tripartite system. 
experts' which made it extremely difficult for parents to question the decisions made. $^{78}$

The idea that 'as a group, disabled children are not conceptualised as future economically-contributing citizens' and the 'rest of society [is] conditioned to believe that disability equates with tragedy, burden and dependency', is discussed by Laura Middleton. She is critical of special education arguing how it has 'attracted the most criticism for failing its pupils' and comments that 'special schools offer a poorer education than mainstream schools' as they 'rarely offer the normal range of examination subjects and inculcate social inferiority'. Middleton considers the argument that the focus for special education has been on achieving 'independence' rather than on prioritising 'educational or examination targets' to enable disabled adults not to be 'dependent on State help'. Therefore, she argues, that 'special education [became] a form of social control' ${ }^{79}$ Literature discussing segregated schools is strongly focused on the shortcomings of the system and there is little recognition of the early achievements of parent-led 'spastic' associations and the systems they pioneered. This thesis demonstrates aspects of the positive outcomes of a segregated education where being with one's peers, in an educational setting, may have been empowering. Individuals were not judged on their perceived failings in an environment where their peer group faced similar issues and so were not singled out as being different. Whilst this environment was not perfect, and long-term outcomes raise questions, achievements need to be considered in the context of the period.

Michael Oliver's experience of special education is not as a pupil but as a lecturer and he points out that his critique of special education comes from a 'conceptual, analytical and political' stance and not from any 'unfortunate personal experiences in special schools'. He uses the work of Thomas Kuhn (1970) on

\footnotetext{
78 Alan Roulstone and Simon Prideaux, Understanding Disability Policy (Bristol: The Policy Press, 2012), pp.21-40 (p.28). ProQuest Ebook Central <https://ebookcentral.proquest.com/lib/swansea-ebooks/detail.action?doclD=3030239> [accessed 27 May 2019].

${ }^{79}$ Laura Middleton, p.44.
} 
'knowledge paradigms' from The Structure of Scientific Revolutions to illustrate his thinking. Kuhn said that:

knowledge paradigms replace one another, not through the gradual evolution of understanding and the accumulation of facts about the world but through the emergence of what he called anomalies in the existing paradigm. ${ }^{80}$

As these anomalies grow, they 'force a shift to an entirely new paradigm through nothing more or less than a complete revolution in our thinking'. Therefore, in 'Kuhn's terms', a shift is being made from a 'special to an inclusive education paradigm'. 81

The move towards a more inclusive education system is discussed by Jennifer Harris and Alan Roulstone in Disability, Policy and Professional Practice (2011), as they consider the terms used in the 1981 Education Act. They reflect on the attempt to introduce new, less medicalised approaches to "special education" by rejecting the ESN terminology that came out of the 1944 Education Act'. The term 'special needs' was attached to 'high achievers as much as to pupils with learning difficulties'. Harris and Roulstone maintain that disabled children 'remained constrained by the low expectations and notions of difference' which continued to be attached to them. In order to achieve support within the system 'disabled children and their families had to emphasise what they could not do in order to receive the highest levels of support'. This was often by obtaining a Statement of Special Educational Needs. ${ }^{82}$ Harris and Roulstone make an important point. For those children who had been born with cerebral palsy in the 1940s and 1950s an assessment had also focused on what they could not do but this was for categorisation purposes and not for extra support. From a modern perspective, achieving inclusion remains impossible as there is still a need to

${ }^{80}$ Thomas Kuhn, The Structure of Scientific Revolutions, $2^{\text {nd }}$ edn. (Chicago: University of Chicago Press, 1970) cited in Michael Oliver, Understanding Disability (Basingstoke: Palgrave Macmillan, 2009), p.73.

${ }^{81}$ Michael Oliver, Understanding Disability (Basingstoke: Palgrave Macmillan, 2009), p.73.

82 Jennifer Harris and Alan Roulstone, Disability, Policy and Professional Practice (London: SAGE

Publications Ltd., 2011), p.18. 
focus on what individuals cannot achieve, rather than on what they can do, but for slightly different purposes.

In Worth Saving, Disabled children during the Second World War (2013), Sue Wheatcroft considers the Statement of Special Educational Needs (SEN) ${ }^{83}$ and whilst her main study is on the experiences of disabled children in England during the Second World War she also reflects on post-war change in the longer term. She examines the impact of the 1978 Report of the Committee of Enquiry into the Education of Handicapped Children and Young People (Warnock report) ${ }^{84}$ and says that it 'put the issue of integration of disabled children in ordinary schools onto a national agenda for the first time'. She discusses that whilst there was a 'considerable decline in the number of children attending special schools during the 1980s and 1990s' this was countered by a 'gradual increase in the proportion of children both identified as having special educational needs and receiving statements'. She discusses how long delays and questionable assessments, 'devalue[d] the process' and local education authorities could not guarantee 'specific levels of provision'. ${ }^{85}$ Wheatcroft's analysis reveals how, as with the 1944 Education Act, subsequent legislation still meant inadequate planning and a lack of understanding of individual needs which let disabled children and their families down.

The Warnock report and subsequent legislation meant that parents were now formally recognised as advocates for their children. Laura Middleton considers the 'pitfalls' of this and contends that as children develop their own point of view it is not necessarily that of the parent. She acknowledges that this can be applied to any young person but is paramount for the disabled child as 'in most families, the disability is an experience their parents will not share'. ${ }^{86}$

\footnotetext{
${ }^{83}$ SEN 'detailed the individual child's special needs and the specific help which should be provided to meet those needs'.

${ }^{84}$ Mary Warnock, Special Educational Needs: Report of the Committee of Enquiry into the Education of Handicapped Children and Young People (London: HMSO, 1978).

${ }^{85}$ Sue Wheatcroft, Worth Saving, Disabled children during the Second World War (Manchester: Manchester University Press, 2013), p.173.

${ }^{86}$ Laura Middleton, p.46.
} 
Katherine Runswick-Cole and Nick Hodge ${ }^{87}$ consider the discourse of special education and contend that whilst the 'terminology of "special educational needs" was broadly welcomed in the 1970s' and continues to be the 'dominant discourse used in education today' they maintain that this term has 'increasingly come to be seen as problematic'. They refer to Sally Tomlinson (1985), cited in David Skidmore's book Inclusion: The Dynamic of School Development (2004), and the argument that:

the terminology of special educational needs still "masks a practice of stratification which continues to determine children's educational careers by assigning to them an identity defined by an administrative label"'.88

Runswick-Cole and Hodge maintain that the "language of "special educational needs" within current policy and legislation continues to locate the "problem" within the child' and they 'advocate for the abandonment of the phrase 'special educational needs' and for the adoption of the phrase "educational rights"' ${ }^{89}$ They consider the power of language in education, citing several scholars, ${ }^{90}$ and discuss how 'language is able to create positive and negative images of children which, in turn, impact on the policy and practice of education'. They comment that the abandonment of the eleven categories of handicap' in the Warnock report was a "key change which was allied to the shift in policy that "wherever possible" children should be educated in mainstream schools'. However, they argue that the term "special educational needs" has "come to sustain and construct exclusionary practices within education' and through the focus on 'individual needs' the 'contribution of the social model of disability and the focus on the

\footnotetext{
${ }^{87}$ Katherine Runswick-Cole, and Nick Hodge, 'Needs or rights? A challenge to the discourse of special education', British Journal Of Special Education, 36.4 (2009), 198-203 $<$ https://doi.org/10.1111/j.1467-8578.2009.00438.x>.

88 D. Skidmore, Inclusion: the dynamic of school development (Maidenhead: Open University Press, 2004) cited in ${ }^{88}$ Katherine Runswick-Cole, and Nick Hodge, 'Needs or rights? A challenge to the discourse of special education', British Journal Of Special Education, 36.4 (2009), 198-203 (p.198).

${ }_{89}$ Runswick-Cole \& Hodge, refer to the work of the early years educators at the Reggio Emilia schools in Northern Italy. Information on this approach to education can be found here: $<$ https://www.reggiochildren.it/identita/reggio-emilia-approach/?lang=en>

90 Runswick-Cole and Hodge refer to: Discourse Analytic Research: repertoires and readings of texts in action, ed. by E. Burman \& L. Parker, I. (London: Routledge, 1993); M. Foucault, The Birth of the Clinic (London: Routledge, 1973); J. Corbett, Bad-Mouthing: The Language of Special Needs (London: Falmer Press, 1996).
} 
removal of barriers to learning and participation' is ignored. ${ }^{91}$ These issues are pertinent to this thesis as labelling and the use of language has had a significant impact on the lives of many with cerebral palsy. It has continued to set them apart in terms of education, choice and independence.

\subsubsection{Towards Independence}

During the 1970s the social model of disability emerged which was the antithesis of the medical model and argued that disability was caused by social and environmental factors. Responsibility for 'disabling situations' was shifted from the individual to wider society. Disability campaigner, Michael Oliver declared that the publication Fundamental Principles of Disability (1976) by The Union of Physically Impaired Against Segregation (UPIAS), was the starting point of the social model. A distinction between impairment and disability was made where impairment was defined as:

lacking part or all of a limb, or having a defective limb, organism or mechanism of the body'; and disability as the disadvantage or restriction of activity caused by a contemporary social organisation which takes no or little account of people who have physical impairments and thus excludes them from the mainstream of social activities. ${ }^{92}$

The social model has been widely discussed in academic literature by a number of scholars. Harris and Roulstone consider 'pivotal moments in the development of disability policy' and examine the influence of the social model. They consider that the social model was the innovation of a collection of hugely influential disability activists' but argue that it is 'largely recognised as the seminal work of Michael Oliver' who contended that disabled people were '(excluded/oppressed) by a non-disabled majority'. Harris and Roulstone maintain that the social model was a 'mandate for political and societal change' and 'was of key interest to social workers' and they argue that it is still 'influential'. ${ }^{93}$ Disability activists challenged society, and Carol Thomas, who also refers to Oliver, argues that the social model

\footnotetext{
${ }^{91}$ Runswick-Cole, and Hodge, 36.4 (2009), 198-203 (pp.201-202).

92 Oliver, Understanding Disability, p.42.

${ }^{93}$ Harris \& Roulstone, p.36-37.
} 
opened up the possibility that the 'restrictions of activity and myriad disadvantages experienced by people with impairments could be placed at the door of society' and be 'seen as a consequence of the social relationships between the impaired and the non-impaired', as opposed to being caused by 'impairment per se'.94 Barnes and Mercer argue, the social model broke the 'traditional causal link between impairment and disability' where the 'reality' of the impairment was not denied but was not viewed as 'necessarily a sufficient condition of disability'. 95

Tom Shakespeare and Nicholas Watson discuss how the social model of disability was 'massively important in the British disability movement, in two main ways'. Firstly, they contend that it 'enabled the identification of a political strategy, namely barrier removal' and argue that, 'rather than pursuing a strategy of medical cure, or rehabilitation, it is better to pursue a strategy of social change, perhaps even the total transformation of society'. Secondly, they say that the impact of the social model was 'very liberating for disabled individuals' as the 'social model view' defined that 'problems arose from social oppression' rather than 'from deficits in the body' as in the medical model. They maintain that:

people were able to understand that they weren't at fault: society was. They didn't need to change: society needed to change. They didn't have to be sorry for themselves: they could be angry.

They liken this awakening to other social movements of the 1970s, such as the rise in feminism or with 'lesbians and gays "coming out."' Disabled people became 'empowered to mobilise, organise, and work for equal citizenship' and 'demand their rights' instead of being reliant on 'charity or goodwill'. ${ }^{96}$ In his chapter in The Disability Studies Reader (2010), Shakespeare discusses the weaknesses of the social model, arguing that 'its authorship by a small group of activists' was a problem, as the 'majority' had 'spinal injury or other physical

${ }^{94}$ Carol Thomas, 'Disability Theory: Key Ideas, Issues and Thinkers', in Disability Studies Today, ed. by Colin Barnes, Mike Oliver and Len Barton (Cambridge. Polity Press, 2002), pp.38-57 (p.40).

${ }^{95}$ Barnes \& Mercer, Exploring Disability, p.30.

${ }^{96}$ Tom Shakespeare and Nicholas Watson, 'The social model of disability: an outdated ideology'? Research in Social Science and Disability, 2 (2002), 9-28. 
impairments and were white heterosexual men'. Although he contends that UPIAS had included a range of other disabilities, including those with learning disabilities, 'it could not have produced such a narrow understanding of disability'. ${ }^{97}$ The growing disability movement reflects a reality that would have applied to many disabled people. However, for individuals with cerebral palsy the medical model continued to strongly influence their lives.

Shakespeare's critique of the social model in Disability Rights and Wrongs, ${ }^{98}$ further explored the link between disability and impairment. Dan Goodley comments that Shakespeare's views:

cast shockwaves through British disability studies. Disability studies godfathers branded the book an act of treason that gave up on the political ambitions of the materialist social model, replacing them with a conservative turn to the realities of the medical model. ${ }^{99}$

Reviewing his critique in Disability Rights and Wrongs Revisited (2014), Shakespeare maintains that he "demonstrated that the "strong" social model [was] not the only progressive account of disability' 100 and whilst he recognises its contribution, he argues that it 'define[d] disability in terms of oppression and barriers' and '[broke] the link between disability and impairment'. ${ }^{101}$ Therefore, disability could not simply be viewed as a political experience and be 'removed' by social change as 'even in the most accessible world practical, there [would] always be residual disadvantage attached to many impairments'. ${ }^{102}$

A ‘Review Symposium' published in Disability and Society $(2007)^{103}$

\footnotetext{
97 Tom Shakespeare, 'The Social Model of Disability', in The Disability Studies Reader, ed. by Lennard J. Davis (New York: Routledge, 2010), pp. 266-73.

${ }^{98}$ Tom Shakespeare, Disability Rights and Wrongs. (Oxon: Routledge, 2006).

99 Dan Goodley, 'Disability rights and wrongs revisited' in Disability and Society, 29:4, (2014), 659-661 (p.659) < https://doi.org/10.1080/09687599.2013.864874>.

${ }^{100}$ Tom Shakespeare, Disability Rights and Wrongs Revisited, 2nd edn (Oxon: Routledge, 2014), p.1.

${ }^{101}$ Ibid., p.26.

102 Ibid., p.42.

103 Alison Sheldon, Rannveig Traustadóttir, Peter Beresford, Kathy Boxall and Mike Oliver, 'Review Symposium' in Disability and Society, 22:2, (2007), 209-234

$<$ https://doi.org/10.1080/09687590701195274>.
} 
brought together responses to Shakespeare's critique in Disability Rights and Wrongs (2006). A number of scholars strongly defended the social model, as Alison Sheldon comments 'disability and impairment are of course interconnected' and the 'distinction between them less than clear' but she argues that 'in order to identify political strategies' then it 'makes sense to separate the two analytically, treating them not as concrete objects but as abstractions'. ${ }^{104}$ A paper by Michael Oliver in 2013 reflects on criticism of the social model, stating that he had never claimed that it was an 'all-encompassing framework within which everything that happens to disabled people could be understood or explained'. He said how it 'became the vehicle for developing a collective disability consciousness and helped to develop and strengthen the disabled peoples' movement' that subsequently emerged. ${ }^{105}$

Shakespeare's critique makes sense when considering a range of impairments where an individual may always need support, regardless of any number of social interventions. This thesis highlights the continual barriers that people with cerebral palsy have faced, despite progress being made in understanding the complexities of the condition and the efforts that were made to raise its profile. It is only in more recent years that engagement with disability activism, on a 'political' platform, began in earnest for people with cerebral palsy.

In their book People with Intellectual Disabilities - Towards a good life? (2010), Kelley Johnson, Jan Walmsley and Marie Wolfe reflect on the 'influence of the social model of disability thinking' and how it began 'with people with physical impairments'. They maintain that it has 'more recently been applied to people with cognitive impairments' and they include 'intellectual disabilities' as part of this change. They argue that its:

emphasis on citizenship rather than care as the proper goal, on reducing external barriers to participation and on reclaiming a positive sense of identity as an oppressed minority has been influential in moving the

${ }^{104}$ Alison Sheldon, 'Disability Rights and Wrongs'? in Disability and Society, 22:2, (2007), 209234 (p.210) < https://doi.org/10.1080/09687590701195274>.

105 Michael Oliver, 'The social model of disability: thirty years on', in Disability and Society, 28:7, (2013), 1024-1026 (p.1024) < http://dx.doi.org/10.1080/09687599.2013.818773>. 
debate on from the somewhat paternalistic vision of an ordinary life articulated by parents' groups in the mid-20th century to a more individualised rights-based discourse. ${ }^{106}$

During the 1970s, parent-led 'spastic' associations were more focused on maintaining their organisations and, as this thesis demonstrates, the users of their services were either not politically engaged or encouraged in this way. The theory of the social model of disability did not lead to a level of emancipation as many individuals remained shielded within society and there was an inference that they were a separate group of disabled people and as such, could not really appreciate the implications of the social model.

Borsay and Dale argue that 'children were historically targeted for interventions that were meant to promote independence'. They compare children and adults with a physical or sensory disability and argue that 'a child with a hearing or visual impairment' was 'increasingly classified as having special needs' and yet the same issue would be 'unremarkable in an older person'. Therefore, they argue that disabled children have had to 'navigate their way through a larger array of services than disabled adults' and so 'a variety of experts historically claimed jurisdiction over the disabled child'. ${ }^{107}$ Jan Walmsley and Dorothy Atkinson similarly argue that the medical model 'has been seen to hold hegemonic sway in [the] understandings and treatment of disabled people [that] are not essentially historical'. However, they maintain that there is an 'historical dimension' and they draw on 'examples of the way the "medical model" operated in past practices', referring to the example of Leonard Cheshire Homes ${ }^{108}$, founded in the post-war era'. ${ }^{109}$ The level of control and intervention in individual lives meant that children and adults within parent-led 'spastic' associations remained segregated and defined by their disability.

\footnotetext{
106 Kelley Johnson and Jan Walmsley with Marie Wolfe, People with Intellectual Disabilities Towards a good life? (Bristol: The Policy Press, 2010), p.94. ProQuest Ebook Central $<$ https://ebookcentral.proquest.com/lib/swansea-ebooks/detail.action?doclD=619185> [accessed 27 May 2019].

${ }_{107}$ Borsay \& Dale, p.2.

${ }^{108}$ Leonard Cheshire is a not for profit organisation which supports disabled individuals to become as independent as they choose in their lives. Information at: https://www.leonardcheshire.org/ ${ }^{109}$ Walmsley and Atkinson, p.185.
} 
If there was to be a 'revolution', and the social model of disability embraced, it had to come from within and be led by those who attended associations. Borsay and Dale refer to the 'triangular relationship between service providers, their parents and themselves' which they maintain was 'fraught with difficulties, resulting in conflicts that shaped the experiences of many disabled children'. The emotional impact of cerebral palsy affected family relationships as, 'research suggests that parents tended to parent their disabled children differently'. ${ }^{110}$ Such relationships are seen in this thesis through primary source material and oral history testimonies. The difficulties that some disabled young people faced when making the 'transition from childhood to adulthood to take control of their lives' is discussed by Swain, French and Cameron. They argue that 'educational and social opportunities are more restricted because of hostile attitudes and an inaccessible environment' and some individuals 'may be over controlled by their parents and carers and denied opportunities for experimentation and choice'. There are some who 'may find it hard to initiate change and parents and carers may be reluctant to [accept change] because of upheaval, risk and a threat to existing sources of support'.111 These arguments could not be easily overcome by the social model as demonstrated in this thesis. The views of those 'in control' were embedded in ideologies which had influenced, not just families and individual lives, but also wider society. Many individuals with cerebral palsy were neither equipped nor supported to fully explore the implications of the social model and what it could mean for them at that time.

The issues raised through the social model should not be examined in isolation. For example, Oliver considers the problem of unemployment for disabled people. He maintains that it 'does not just entail intervention in the social organisation of work and the operation of the labour market' and says issues should be looked at in conjunction with transport, education and culture. ${ }^{112}$ Environmental barriers such as steps, stop wheelchair access. However, if such barriers were adapted to the needs of the disabled person, whilst they would still

\footnotetext{
110 Borsay \& Dale, p.4.

111 Swain, French and Cameron, p.80.

112 Michael Oliver, Understanding Disability, p.45.
} 
have their impairment, they would no longer be disabled. Changing the environment and removing physical barriers did not necessarily have a significant impact on improving access to employment, for individuals with cerebral palsy, as negative perceptions prevailed.

The literature review highlights a lack of information about the social impact of cerebral palsy on individual and family lives. Similarly, there is little recognition of the achievements made by parent-led 'spastic' associations in providing education and employment opportunities. This thesis brings a new perspective to disability history through discussing the role of associations in conjunction with the history of education and employment. My research uses oral history testimonies from people with cerebral palsy to give a voice to those previously unheard. The effect of language relating to disability is a contentious topic and this thesis discusses the historic language used to describe people with cerebral palsy. It adds to the debate by demonstrating that language, now viewed as offensive, was once used in a positive way to bring about change. There is a growing body of literature relating to the history of learning disability and elements of that history parallel the history of parent-led 'spastic' associations. This thesis complements that literature, adding to a productive dialogue about parent-led advocacy movements.

\subsection{Methodology}

Research undertaken for this thesis includes a rigorous analysis of materials held at archives, charitable organisations and libraries, together with suitable on-line sources. Included in the primary source materials are the Year Books (MSA 1972 to 1998 and SDSA 1959 to 1967 and 1978 to 1999), association minutes and a variety of other official reports and correspondence relating to MSA and SDSA; NSS Annual Reports (1952 to 1997); publications of Spastics News (1960 to 1974 as well as the 1985 edition which, by that time, had been renamed Disability Now); and BCWS Reports (1946 to 1959); films produced by MSA and also the NSS; newspaper articles; reports of parliamentary debates and official government reports; a variety of primary printed sources, including books written by key individuals of the time. 
The examination of oral history interviews provided an insight into the reallife experiences of individuals. It is only in recent years that the views of people with cerebral palsy have begun to be represented. Although the number of participants is not large, interviews have been invaluable in providing an insight into the feelings and experiences of those central to the development of parentled 'spastic' associations. The use of oral history research in this thesis is discussed separately in this chapter.

The range of material enables analysis of the changing attitudes towards individuals with cerebral palsy, born in the mid-twentieth century, while oral history testimonies reveal the wider impact of change.

\subsubsection{Challenges presented by the source materials}

One of the main sources of primary materials is Cerebral Palsy Midlands (CPM), Harborne, Birmingham which is a charitable organisation, originally known as MSA, which holds its archive. The other main source is West Glamorgan Archive Service (WGAS) in Swansea which holds the collection of SDSA, deposited there after the association closed in 2011. These collections hold items dating from the inception of the associations and have therefore been invaluable in researching their history. There has been no previous academic study of the history of MSA or SDSA.

As discussed in the previous chapter, a personal connection with SDSA was part of my motivation for embarking on this project. Undertaking a study of an organisation, where I had direct experience of the close community that had grown around it, developed my understanding of what the association meant to individuals and their families. I was aware of the potential for bias in the way I interpreted research materials relating to SDSA and I ensured that all research materials were considered objectively. Also, a consideration of other parent-led 'spastic' associations, specifically a comparison with MSA, allowed me to place SDSA within a wider context. It was unique in the fact that it established the first local parent-led day school in Wales, dedicated to the education of children with cerebral palsy. Research has shown how MSA shared its experiences, gained 
following the establishment of that organisation and Carlson House school. This school was the first local parent-led day school in Britain. Therefore, in the history of local parent-led 'spastic' associations, MSA and SDSA are of significant importance as pioneers in the field of educational provision for children with cerebral palsy.

The collection at WGAS is relatively small and the closure of SDSA may have led to the disposal of some items of importance to the historian. In contrast, the archive held at CPM is not formally archived. Materials are housed mainly in a series of boxes and files where items of a like nature are grouped together. In addition to materials relating directly to MSA, the archive contains a diverse range of sources. These include a selection of BCWS reports, memos from the Ministry of Health, correspondence with the NSS along with numerous publications, reports and papers from the 1940s and 1950s. The diversity of this archive was unexpected and having direct access to it was exciting but also challenging due to the sheer volume of information. An initial scrutiny of the materials concluded that all could not be easily examined even in multiple visits. It was helpful that there was some order to the materials and this proved a useful starting point in applying a framework to my research methods. Photographic records were made during several visits, with the agreement of CPM, in order for meticulous research to be carried out away from the premises leaving time for a broader investigation of other materials.

Since undertaking extensive research at CPM further boxes of archive materials have been located but became available too late to be incorporated in the analysis undertaken for this thesis. The formal archiving of documents has not been a priority within the association and this is a concern. There is a risk that historical documents could be inadvertently destroyed or lost through a misunderstanding of their importance to the historiography of disability history. It has been strongly suggested that the collection be professionally archived or deposited in an official archive where it can be catalogued and referenced to be more easily available for future research. Key individuals in the organisation are aware of this issue but CPM is a busy organisation with currently little resource to undertake extensive archiving due to competing priorities. 
There is a lack of documentary evidence relating to the structure of the curriculum in the school set up by SDSA. Documents pertaining to this organisation provide evidence that a teacher was employed and photographs show children in a formal setting, but detailed lesson content is not apparent. The CPM archive, whilst not revealing a curriculum provides more of an insight into the subjects taught and the structure of Carlson House school. This is provided through oral history, Year Book articles, and two school inspection reports, (H.M Inspectors for the Ministry of Education 1952; Department of Education and Science 1965). Other documents include a survey of school leavers, as part of handwritten records from the school, for the period 1960 to 1975 and administrative records detailing how the school was staffed. The gap in this information does not easily allow for a comparison to be made of the curriculum offered at 'spastic' schools with that provided by mainstream schools. A wider study of schools established by the NSS may reveal more detailed information but that is outside the scope of this thesis. However, through the medium of film, depicting life within Carlson House school, activities can be contextualised in relation to the documentary evidence.

The importance of transnational networks in the development of research into cerebral palsy, prior to the establishment of MSA and SDSA, was a revelation for me. This prompted wider research, leading to a successful search for primary printed materials by key individuals referred to in the CPM archive.

\subsubsection{Analysis of source materials}

The source materials researched for this thesis have been analysed using a broadly thematic approach. This required a methodical approach to data analysis and management of the high volume of source materials.

Organisational publications such as those produced by the BCWS, NSS Annual Reports, association Year Books and Spastics News magazine were key historical sources for this thesis. A close study of these revealed that publications were not only designed for publicity and awareness raising, but also to generate 
a financial return. One of the main challenges presented in analysis was separating the public façade from the actual lived experiences of individuals with cerebral palsy. A descriptive text together with a variety of images revealed much of the history of these associations. However, publications also raised some fundamental issues including how individuals with cerebral palsy were portrayed and what level of choice they may have had within associations. This naturally led me to consider the impact of associations on individual lives, family lives and wider society.

In applying a research framework for an initial analysis of organisational publications, I arranged them in date order by organisation and considered the following:

- the primary function of the publication and its relationship to the aims of the organisation

- the portrayal of people with cerebral palsy and use of language

- the range of topics discussed

Becoming more familiar with the organisational publications also provided an insight into the subtle differences of perspective between groups, and how the representation of people with cerebral palsy changed over a period of time. A distinction that can be made between local and national publications is that the national perspective was more political. Ultimately, national organisations had more resources available to enable a more proactive stance. However, the range of articles in BCWS publications demonstrate that they did not include the overt marketing that became more apparent following the establishment of the NSS. The use of these publications provided context to the history of the organisations studied and factual details of particular events or significant moments, in an organisation's history, could be verified. It was the richness of qualitative data within publications that provided the basis for meticulous research. 
Dividing articles according to type enabled me to see at a glance the prominent themes contained within publications. Generally, articles fell under the following headings:

- history of associations

- fundraising activities

- medical matters

- education and employment

- local and national networks

- transnational influences

- developments in research

- dissemination of research

- social activities

The qualitative evidence revealed how the enactment of policy and practices impacted on a sector of society which had hitherto been largely unknown. Similarly, films made by MSA and NSS provided another source for research and critical analysis. The media brings the organisations to life and some of the people referred to in primary literature have an on-screen role. As a body of primary research material, these sources are invaluable as they provide rich subject matter for analysis and discussion.

There is a particular celebratory element to certain aspects of publications and films which reinforces how important belonging to organisations was for many individuals. This thesis reveals how individuals and families invested time and energy in their organisations thereby developing communities and a supportive network. Information includes contributions from medical officers, educators, NSS officers and other professionals. These contributions broaden the range of subject matter giving a unique insight into the approaches taken towards cerebral palsy at a particular point in time. However, the representation of individuals with cerebral palsy and the use of discourse, encompassing labelling, led me to examine the dynamic approach taken towards marketing and the ethos of using 'tragic imagery' for monetary gain. 
A challenge presented to the historian is that, as historical sources, these materials may present a distorted picture. For example, in association Year Books, the particular style of presentation remained fairly static for much of the period covered by my research. Parents were the editors and so had the relative freedom to promote views and opinions from their perspective. Individuals with cerebral palsy are rarely heard in the historiography of 'spastic' associations established in post-war Britain. This is reflected by the limited number of articles published by individuals with cerebral palsy and, apart from a few exceptions, contributions are insubstantial. It is only in later years that their voices become more prominent. Whilst films were often made for training purposes, it is important to also consider them as promotional tools. They may therefore not accurately reflect day-to-day school life in the true sense, as the people on screen were playing out their parts for the camera. The narrator directs viewers to reach particular conclusions on what is being played out before them. However, these sources pinpoint a moment in time where history is played out and the past is brought to life through both commentary, discussion and images on screen. They present aspects that cannot be gleaned through the scrutiny of organisational minutes alone. By their nature minutes are more factual, often simply recording key decisions made, and any debate that would likely have taken place before a resolution is not always evident. In order to further contextualise the conclusions being drawn from these primary source materials, research findings were measured against other resources pertaining to parent-led 'spastic' associations.

Newspaper archives provided different perspectives on the history of 'spastic' associations. Key points in legislation and more factual reporting was a feature of The Times newspaper, sourced through The Times Digital Archive. Research of the British Newspaper Archive revealed more promotional content in tabloid newspapers, such as the Daily Mirror. These sources provided additional evidence of how prominent the BCWS and the NSS were in initiating a discourse on cerebral palsy. These resources provided a national viewpoint which was in contrast to local newspapers, who provided an almost ongoing commentary linked to the day-to-day activities of associations, as well as reporting on the more critical aspects of parent-led campaigns. Features in local newspapers facilitated fund-raising activities and invited the public to support 
associations. This put local groups at the heart of the community and kept them prominent in the media. The wide range of newspaper articles uncovered demonstrates how important maintaining newspaper coverage was for these organisations. It also confirmed how proactive groups were in campaigning.

This energetic approach, particularly after the formation of the NSS, advocated that parents joined together in lobbying their local MP's, gaining their support, and so widening the debate concerning the exclusion from education of children with cerebral palsy. A study of Hansard, in the post-war period shows how an almost crusading campaign led to issues being raised for parliamentary debate. What is not evident, in these reports, are some of the tensions that emerged in the relationships between local associations and the NSS. Further analysis of source materials, particularly those held at CPM has provided an insight into the dynamics between the local groups and the national body, as discussed in this thesis. However, in order to present a more critical analysis of the politics between local groups and the national body, a wider study would need to be undertaken.

My research identifies key people who made a significant contribution to the action taken towards the treatment of the key symptoms of cerebral palsy. These individuals included Dr. Winthrop Phelps, Dr. Earl Carlson and Dr. Jean Macnamara as well Eirene Collis, Dr. Eleanor Schonell and Marjorie I Dunsdon. A number of the organisational publications I examined in addition to official government sources referred to their work. This led me to source their original publications and undertake wider research into their lives. In this way I verified the claims being made in organisational publications and other sources regarding the importance of their work and the impact they had on development of services for individuals with cerebral palsy.

\subsubsection{Oral history sources}

Oral histories examined in this thesis originate from three distinct sources. The Speaking for Ourselves project, funded by the Heritage Lottery and administered by the national charity Scope, captured the life histories of people 
with cerebral palsy with the aim of showing how society's perception of disability had changed during the twentieth century. The final collection included thirty-six people born between the 1930s and 1950s from a wide geographical area. Many of the participants spoke of how they had lived beyond the expectations given at the time of their birth, as told to them by their parents or other family members. This project has created a valuable resource which reveals how individuals experienced social isolation and were also subject to economic factors which imposed limitations on their lives. It has examined how attitudes towards individuals with cerebral palsy have changed and their individual recollections contextualise documentary evidence uncovered through research.

Interview transcripts from the Cerebral Palsy Midlands Heritage Project Fulfilment through Achievement captured some of the memories of those individuals who had a connection with the organisation. Twenty-six people were interviewed and included people with cerebral palsy, family and staff members and friends of the association. Open questions were used and were broadly structured around the following themes; the role or connection that the individual had to the association; details of the association's history and its achievements; the impact on individual and family lives and the activities which took place in the school and the workshop.

The final source comprises my own interviews, conducted with individuals who had a connection to SDSA, which also contributed to the Heritage project, Legacy of Longfields. (Longfields Association was the new name adopted by SDSA in 2000). Interviewees included people with cerebral palsy who had been members of the association, staff members, parents and family members, and friends of the organisation. When planning my thesis, I gained ethical approval at the start of my study from the Research Ethics and Governance Committee in the College of Arts and Humanities at Swansea University. (Information and consent form at Appendix 9.1). The main purpose of the interviews was to research the impact that SDSA had on individual lives, the wider community and what the organisation had meant to those involved. All of the individuals I approached agreed to take part and there were no issues of obtaining consent. Before interviews took place, I ensured that I took the time to explain the study 
so participants were reassured and had the opportunity to ask questions. The extracts from three interviews at Appendix 9.2 come from a parent, a sibling and a student.

The interviews were semi-structured with interviewees being asked mainly open questions. The range of topics included:

- impact of the association on individual life/family/community

- range of activities offered/undertaken at association

- training, learning and employment opportunities

- fund raising activities

- role of the local authority/health service

- recalling the physical layout of the buildings

- transport provision

The total number of interviews conducted was twenty-four between June 2016 and August 2018, four were with service users; nine with family members, parents or siblings; four staff members, one committee member and six friends of the association. (Participant demographics are at Appendix 9.3).

\subsubsection{Challenges of obtaining oral history testimonies}

The sources discussed demonstrate how Heritage Lottery Funded Projects have documented 'hidden histories' through the activities of community projects and oral history interviews. Heritage Projects have enabled groups to produce material that can prove useful for academic research purposes. In the introduction of The Oral History Reader (2006), editors, Robert Perks and Alistair Thomson discuss how the 'most distinctive contribution of oral history' has been to 'record the experiences and perspectives of groups' who might otherwise have been 'hidden from history'.113 Opportunities for diverse groups to conduct interviews means that it is not only historians who are the drivers for research

\footnotetext{
${ }^{113}$ Robert Perks and Alistair Thomson, 'Introduction to the second edition', in The Oral History Reader, ed.by Robert Perks and Alistair Thomson $2^{\text {nd }}$ edn (Abingdon: Routledge, 2006), pp. ixxiii (p. ix).
} 
and, as Perks and Thomson argue, oral history is no longer the 'privileged preserve of academic or professional historians'. ${ }^{114}$

Linda Shopes discusses the concern over project outcomes being just an 'accumulation of facts'. She maintains, 'interviews are typically structured around the life histories of individual narrators, rather than around critical questions about broad themes of social life that cut across individuals' experience'. She states this is less likely to happen in 'scholarly' led projects, yet the 'specific research questions' of the investigator can have a 'narrow focus' and so their work is of 'limited value to other researchers with other research agendas'. ${ }^{115}$

As historians, is it not more beneficial to have the output, generated through community projects, available as resources? By their nature, community projects involve local people and they often can be best placed to engage with such initiatives and contribute to project outcomes. In engaging with marginal groups there are many factors which can be cited as barriers, such as isolation, a lack of individual confidence, or the failure of others to see or value an individual's contribution. Jan Walmsley considers the question, 'what is history'? She cites a life history research project in which people with learning disabilities were interviewed and argues that it would have been unrealistic to 'expect people with learning disabilities to record their history unaided' due to literacy problems and the lack of formal skills needed to undertake the task. Her interviewees were not aware of legislation such as the 1913 Mental Deficiency Act which would have impacted on their lives. This she said made 'relating people's accounts to the history, and using [her] own knowledge of that history to prompt questions, somewhat problematic'. A significant challenge to Walmsley was the need to employ a different approach to oral history as the low literacy skills of the interviewees meant that 'mainstream research methods advocated by oral historians' had to be adapted. ${ }^{116}$

\footnotetext{
114 Perks and Thomson, p. ix.

${ }^{115}$ Linda Shopes, 'Oral History and the study of communities. Problems, paradoxes, and possibilities', in The Oral History Reader. ed. by. Robert Perks and Alistair Thomson (Oxon: Routledge, 2006), pp.261-270 (p.263).

${ }^{116}$ Jan Walmsley, 'Life history interviews with people with learning disabilities', in The Oral History Reader. ed. by. Robert Perks and Alistair Thomson (Oxon: Routledge, 2008), pp.126-139 (p186).
} 
It is important that safeguarding issues relating to vulnerable adults be considered and adhered to. It is only relatively recently that interest has grown in discovering the real lived experience of people with cerebral palsy, and also people with learning disabilities. Dorothy Atkinson, Mark Jackson and Jan Walmsley cite the 'emergence of advocacy' and self-advocacy amongst the reasons why 'people with learning disabilities (and other marginal groups)' have been encouraged 'to explore their own lives in and out of institutions and state care'. ${ }^{117}$ For many individuals in health and social care settings, personal support is key to enable them to fully participate in projects. To allow researchers and vulnerable individuals the opportunity to interact and undertake project activities, due diligence requires a formal approach. This was an important consideration when conducting my research as some individuals were in social care settings.

Many individuals who had been part of the SDSA community attended a local day centre following the closure of the Association. Despite having the advantage of knowing many of these individuals, through my previous involvement with the association, I had to approach the day centre on a formal basis to obtain access. After providing written information about my research a series of meetings took place with the individuals I wanted to speak to. I needed to use a range of communication methods in order to facilitate discussion with some individuals including visual aids, such as photographs and articles from Year Books. I decided to adopt this approach, inspired by Jan Walmsley, where she described her methods of collection and the interview process she undertook to accommodate the needs of individuals with a learning disability. Walmsley used visual prompts in order to stimulate conversation which evolved into 'life maps' and 'network diagrams', as well as photographs. She said that the diagrams enabled her to try and make sense of the information provided from the point of view of the interviewee and the photographs 'helped establish some kind of chronology'.118

117 Dorothy Atkinson, Mark Jackson and Jan Walmsley, 'Introduction: Methods and Themes', in Forgotten Lives: Exploring the History of Learning Disability, ed. by Dorothy Atkinson, Mark Jackson and Jan Walmsley (Kidderminster: British Institute of Learning Disabilities, 2003), p.3.

118 Jan Walmsley, 'Life history interviews with people with learning disabilities' in The Oral History Reader. ed. by. Robert Perks \& Alistair Thomson (Oxon: Routledge, 2008), p.191. 
The methods I employed did prove useful in generating discussion within a group situation but this may have hindered the collection of individual memories. 'Ways of listening' are discussed by Hugo Slim and Paul Thomson, where they examine how a group interview can bring out both the 'best and the worst in people'. They claim that as the focus is not on the individual then the participants may become less inhibited. However, in contrast they argue that the group may 'subtly pressurise' their peers into delivering a 'socially acceptable testimony' or present a 'mythical representation of the past'. ${ }^{119}$ The range of communication methods meant that a few individuals, who had good verbal skills, tended to speak on behalf of the group. However, there was also a benefit as these individuals also helped their peers to communicate more easily their point of view. In managing a group, care needs to be taken in order to give everyone a chance to relate their story. On reflection, the group situation was not conducive to successfully gathering oral history as there were too many competing voices. This was not simply down to group dynamics but was impacted by the relative noisiness of the day centre and the physical space. It is also important to note that some individuals were reluctant to be interviewed separately. There was no definitive reason given but each time I attended the day centre, they came to me as a group. The closure of Longfields Association (previously SDSA) became a discussion point which the group frequently returned to as they shared their feelings about this. As I had been part of their organisation and was familiar with its long history, they felt able to share their anger and frustrations as to its closure. However, the sessions also allowed people to remember their community in a positive way, through its history and achievements. I felt that it was just as important that my study provided a unique space for individuals to reflect about the community they had been a part of and understand its significance.

In order for me to collect individual memories, I needed additional support from day centre staff to help me interpret what individuals with more profound verbal impairments were saying. Communication aids were not available to assist me and I did not have enough knowledge to interpret the subtle intricacies

\footnotetext{
${ }^{119}$ Hugo Slim and Paul Thomson with Olivia Bennett and Nigel Cross, 'Ways of Listening', in The Oral History Reader. ed. by. Robert Perks \& Alistair Thomson (Oxon: Routledge, 2006), pp143154 (p147).
} 
some individuals employed to communicate. This was disappointing for me as it limited the potential number of interviews I could undertake with people with cerebral palsy. I also felt that the timetabling of activities within the centre were prioritised over individuals having 'time out' to take part in an interview. In one situation, I engaged with an individual with good verbal skills, who had been at SDSA, to be interviewed as part of my study. As we were going to find a quiet space, a member of staff asked this individual where they were going as a music session was timetabled. My potential interviewee immediately told me that they could not take part in the interview as they 'had to go to music'. This raises issues of the level of choice afforded to individuals in social care settings and their freedom to participate in activities that are not timetabled.

The other oral history interviews conducted were with family members, staff and friends of the association. Not all of the interviews took place at the individual's home and this did impact on the sound quality of the recording. However, meeting with the individual was more important to me from a research perspective. I conducted another group interview of three people, who were the daughter and granddaughters of Laura Rumbelow, the first works supervisor at SDSA. This scenario had positive outcomes, through reminiscing together as a family, they gave a detailed insight into the day-to -day life of the association.

\subsubsection{Analysis of oral history sources}

Oral history as a method of research has now become an accepted area of study. In Oral History Theory (2010), Lynn Abrams maintains that it is important to remember that memory recollections should be considered as 'primary evidence' in the same way as a 'medieval manuscript' or other historical documents. ${ }^{120}$ Oral history accounts are not simply life anecdotes and can reveal hidden histories, as is demonstrated through work done with marginal groups. In undertaking an analysis of oral histories, an important consideration is that life experience may colour memories over time and the recollection of stories could be emotionally charged through recalling a traumatic time in a person's life. By

120 Lynn Abrams, Oral History Theory (Abingdon: Routledge, 2010), p.78. 
their nature, the 'recounting of life stories, individual or shared, autobiographical or biographical, is a social process. It occurs within a relationship between the teller and the listener'. ${ }^{21}$

Abrams considers that the oral historian wants to discover four things when interviewing people, 'what happened, how they felt about it, how they recall it and what wider public memory they draw upon'. Memory recollections form part of the 'primary evidence' for oral historians and Abrams maintains that oral historians have considered research from a diverse field in order to understand how 'memory works in the individual and within the collective or group'. She poses a number of issues that need to be considered when using oral history sources; how memory changes with ageing or with gender; reliability of memory as an historical source; and how individuals relate their memories to themselves and to others. ${ }^{122}$ Drawing on Portelli, Abrams argues that:

memory is not a storehouse where one can search around and find a ready-formed story. 'What is really important is that memory is not a passive depository of facts, but an active process of creation of meanings' ${ }^{123}$

She states that this 'oft-quoted' statement of Portelli is 'just another way of saying that memories are not pure; they are contingent. They are as much about the present as about the past'. ${ }^{24}$

Analysis of interviews used in this thesis offers a personal insight into how the perception of people with cerebral palsy has evolved. I did not set out with any preconceptions of which interviewees to select from the Speaking for Ourselves or the Fulfilment through Achievement collections. However, I was familiar with Valerie Lang, through her contribution to SDSA Year Book articles and the resource pack produced by Scope proved useful as a starting point. I initially browsed interview summaries and transcripts from these projects, making

${ }^{121}$ Atkinson, Jackson and Walmsley, p.8.

122 Abrams, p.78.

123 Ibid, p.79.

124 Ibid. 
notes of who the contributors were; their date of birth; place of birth; and the main themes which emerged out of their interview. This was a time-consuming process but it allowed me to select the most appropriate extracts for my thesis. However, such was the similarity of life experiences relating to education and employment I could have chosen from many more examples, particularly from the Speaking for Ourselves collection. The richness of this collection allowed me to select individuals born in different decades and from a wider geographical area. I was able to demonstrate that the discrimination against people with cerebral palsy was a national and not a local issue. The themes I identified through my analysis of written materials, discussed earlier in this chapter, emerged as common themes in the oral histories. This was also broadly true for the content of the interviews I had personally conducted.

This thesis illustrates, through the use of written primary sources, how children with cerebral palsy were denied educational opportunities which led to the growth of parent-led 'spastic' associations. The use of oral history reveals the personal impact on individuals, families and wider society, which brings this history to life. Despite my frustrations, discussed earlier with regard to the group interviews at the day centre, there is a positive outcome. There was recognition of the part that SDSA had played in history and it was good for individuals to talk about this. As Atkinson, Jackson and Walmsley discuss, 'the study of history can contribute to a sense of identity'. They argue that 'our own history as individuals is important for a sense of personal identity; a sense of the history of the group to which we belong, whether we like it or not, by virtue of our label, may be equally important for a sense of group identity'. ${ }^{125}$

Interpretation of life experiences, of those connected to 'spastic' associations, informs our understanding of the present and how services evolved. One of the areas I wanted to explore as part of my research was the changing use of language towards people with cerebral palsy. Such was the infiltration of the term 'spastic' in society, it became a collective term by which people with cerebral palsy were known. Discussions of the use of that term uncovered both

${ }^{125}$ Atkinson, Jackson and Walmsley, p.12. 
positive and negative life experiences. Whilst oral history sources cannot always be said to be objective, they can yield surprising hidden views or forgotten histories. These can relate to personal experiences or can be considered in a wider context where communities or places no longer exist.

A pertinent example is the project Hidden Now Heard ${ }^{126}$ which uncovered the history of long-stay institutions (now closed), in Wales, and captured what it was like to live and work in that community. As Paul Hunt of Mencap Cymru says:

The oral histories may not be reflective of the history of the hospitals, but rather they are reflective of people's attitudes towards the hospitals today . . . positive stories [heard] from former patients of friendships, of holidays, of positive risks taken by staff to increase patient independence, holidays, day trips and intimate relationships. In meeting former patients, the project uncovered people who [felt] isolated socially in their communities; longing for the friendships they once had and freedom to roam large open spaces. ${ }^{127}$

Without initiatives like these histories would be lost but, as Abrams contends, the 'process of remembering' has to be put into context and conveyed through a 'narrative or story' that is shaped in part by 'social and cultural' factors. ${ }^{128}$

This discussion on methodology identifies the range of primary source materials used for this thesis and considers the challenges posed in my research. Examination of my analytical approach identified my reasoning behind the selection of items pertinent to this thesis.

\footnotetext{
${ }^{126}$ Hidden Now Heard was a three-year Heritage Lottery Funded project, launched in 2014, that researched the history of long-stay institutions (now closed), in Wales.

127 Paul Hunt, Hidden now Heard - unearthing stories (2017), < https://www.ldw.org.uk/hiddennow-heard-unearthing-stories/ > [accessed 26 August 2019].

${ }^{128}$ Abrams, p.79.
} 


\section{The exclusion of 'spastic' children: collective action by parents challenges the implementation of legislative change}

Most people accept that education is an experience which we all share, with outcomes as diverse as the range of people engaging in the process, but what if that opportunity was denied to an individual? Making education accessible to all was one of the key political aims, following changes to legislation, implemented after the Second World War. However, educational reform, together with a lack of awareness of the symptoms of cerebral palsy, meant that many children with the condition were judged by their impairment and were deemed to be 'ineducable'. This chapter considers how post-war educational reform impacted on the lives of these children, their families and the wider community. A growing realisation of the number of children with cerebral palsy, who had been categorised as 'ineducable', began to draw attention to the problem of their education, and led concerned individuals to speak out to raise the issues faced by these children and their families. The chapter questions why educational reform failed so many children with cerebral palsy and argues that the lack of a coherent provision of service exacerbated the problems they faced.

Medical professionals and education providers often had contradictory views on the best way to meet the needs of children with cerebral palsy and this chapter considers how limited research contributed to a lack of understanding of the condition. The apparent failure to consider it as a separate 'disorder' is discussed in the journal of the Japanese Society of Child Neurology which contended that from the end of the nineteenth century to the mid-twentieth century there had been 'persistent confusion between cerebral palsy and poliomyelitis'. It claimed that a 'marked medical disinterest towards cerebral palsy' grew in part because of a 'lack of clinical classification'. ${ }^{1}$ Central to how cerebral palsy was perceived was the medical model of disability and this chapter

\footnotetext{
${ }^{1}$ Christos Panteliadis, Panos Panteliadis and Frank Vassilyadi, 'Hallmarks in the history of cerebral palsy: From antiquity to mid-20 ${ }^{\text {th }}$ century', Brain and Development, 35 (2012), 285-292 (p.287)

$<$ https://doi.org/10.1016/i.braindev.2012.05.003>.
} 
examines its influence, questioning why, despite new research, did children come under the jurisdiction of the health authority, rather than the local education authority.

The emergence of new research carried out by pioneering individuals, $\mathrm{Dr}$ Winthrop Phelps and Dr Earl Carlson from the USA and Dr Jean Macnamara from Australia meant cerebral palsy began to have a higher profile within professional circles. Dissemination of this research, strengthened transnational networks and enabled individuals and groups to confront prevailing attitudes. The need for change was advocated in the understanding and treatment of cerebral palsy, and this chapter contends that transnational networks were key to how the improved provision of services developed in Britain.

Against this gradually changing background there emerged a network of parent-led 'spastic' associations. Parents embraced new research and through their initiatives they drew public attention to the limited services that were offered to 'spastic' children. This chapter argues that these associations created communities which provided support and advice to many families and the strong ties that were forged held these together. Families gained the assurance and confidence to challenge medical opinion and question discriminatory attitudes. The associations grew to be a significant force within the voluntary sector, and became part of the fabric of modern society.

The organisations discussed in this chapter include the BCWS which engaged with a range of professionals in medical research into cerebral palsy; MSA, a local parent-led group which pioneered educational provision; SDSA, a local group which established the first school in Wales for children with cerebral palsy; and the NSS which led at a national level, co-ordinating a dynamic campaign to raise awareness of cerebral palsy. 


\subsection{Catalysts for change}

Making education accessible to all was one of the key aims of the 1942 Report on Social Insurance and Allied Services by Sir William Beveridge (Beveridge Report). A desire to create greater opportunity, in a better-educated post-war society, was its optimistic vision and the 1944 Education Act was at the heart of this change. It was seen by many as a turning point in the delivery of education. The Times heralded the introduction of the 1944 Act as the 'outstanding event of the year'. The statutory responsibility for providing education under the Act would rest with the local authority; The Times article confirmed that 'county and county borough councils [were to] become the sole local education authorities ... to work under the control and direction of a Minister of Education'. ${ }^{2}$ This model appears to have suited the aim of educationalists and policy makers to produce a generation of well-educated individuals to form a new workforce in post-war Britain, but this structure was too simplistic in its approach. Children with cerebral palsy did not fit neatly within the model. The 1944 Education Act streamed pupils according to 'age, aptitude and ability' and the methods of testing employed, such IQ testing, effectively streamed out many children with cerebral palsy by categorising them as 'ineducable'. Testing and the expectations placed on individual children and their families are discussed later in this thesis. Educational reform brought to the fore a growing realisation that there were a significant number of children with cerebral palsy, some of whom with complex needs, who were being deprived of an education.

The Handicapped Pupils and Medical Services Regulations 1945 defined eleven categories of 'handicapped pupils' and aimed to provide specific facilities to enable disabled children to attend mainstream or special schools. Anne Borsay describes some of the provisions which included allowing disabled children to have 'a favourable position in the classroom' or 'special furniture, aids and equipment'. ${ }^{3}$ However, many children with cerebral palsy fell outside the

2 'Educational Reform The New ACT', The Times, 2 January 1945. Gale Cengage The Times Digital Archive < http://tinyurl.galegroup.com/tinyurl/BYFbE5 $>$ (p.14).

3 Anne Borsay, Disability and Social Policy in Britain since 1750 (Basingstoke: Palgrave Macmillan, 2005), p.110. 
range of categories determined under the 1945 Regulations and provisions were either not suitable or made available.

Several individuals who raised the issue of 'ineducable' children and instigated a more general debate included Henry P. Weston, a founder member of the British Council for the Welfare of Spastics (BCWS), which was constituted in October 1946. An article in The Times informs us that, at that time, the 'term cerebral palsy was virtually unknown', apart from within a 'small circle of doctors and teachers'. Weston was aware that those 'generally known as spastics, presented a special problem different from that of other physical handicaps'. He argued that 'special provision should be made for them' and he saw his 'first step' as finding out the 'extent of the problem', enlisting the 'help of local authorities in his neighbourhood' to ascertain 'how many spastics there were in their areas'. In the first survey it was shown that 'spastic children were at least as numerous as the blind' which was said to be a 'totally unexpected result'. Weston visited about 100 'spastics' at home and concluded that services were needed to 'secure some treatment' for 'sufferers', and, to help parents 'whose burden seemed to him wellnigh impossible to bear'. He maintained that 'half the battle would be won if he could bring the parents together so they could share their problems and no longer feel frustrated and isolated'. ${ }^{4}$ It is not clear of the time period or specific locality in which this initial survey was conducted. However, the minutes of the BCWS inaugural meeting (1946) question the incidences of cerebral palsy in Britain, stating that these were 'difficult to estimate', suggesting that the figure was 'much larger than had hitherto been realised'. ${ }^{5}$ Crucially, Weston had identified the isolation and frustration felt by the parents of children with cerebral palsy.

The BCWS adopted a professional identity and this was reflected through its diverse members who came from 'various branches of the medical profession; representatives of the medical ancillary services; educational, local government, and social welfare bodies'. There were also international members of the

\footnotetext{
${ }^{4}$ N. D. Bosworth-Smith, 'Mr. Henry P. Weston', The Times, 31 December 1953. Gale Cengage The Times Digital Archive < http://tinyurl.galegroup.com/tinyurl/BYGFF1> (p.8).

${ }^{5}$ Harborne, Cerebral Palsy Midlands, Minutes of inaugural meeting of the British Council for the Welfare of Spastics, held 12 December 1946.
} 
organisation. The foundation of the Council had followed a 'series of informal Conferences' where a Working Party had emerged and, developed a 'Scheme and a Constitution for a representative Body', to 'address itself to the several aspects of the complex problem of the rehabilitation' of sufferers of cerebral palsy. ${ }^{6} \quad$ The Working Party of eight people was made up of professionals from the fields of education and medicine, a legal advisor and Steven Quayle, who had a son with cerebral palsy, and later became one of the founders of Midland Spastic Association (MSA). Paul Cadbury ${ }^{7}$, also a founder of MSA who had a daughter with cerebral palsy, attended some of the meetings of the Working Party. Through this mix of people, a debate began about cerebral palsy and the main object of the Council became:

to act as the central advisory, co-ordinating and consultative body for all activities within the British Isles directed to the well-being of sufferers from spastic paralysis and its allied conditions.

They also worked to "provide, cause to be provided, or assist in providing facilities' for the 'training of suitably qualified persons in the techniques required for the comprehensive treatment and education of those so handicapped'; the 'establishment of special schools, clinics and centres' to facilitate 'clinical and educational research'; to offer 'vocational training of suitable cases' with regard to employment; to offer 'general social welfare' to all 'sufferers - advising and assisting parents' and carers; and to 'assist those handicapped' so that they could 'take their normal place in the community - to become physically, socially and economically independent'. The BCWS was not just focused on Britain as it aimed to:

establish and maintain contact with Cerebral Palsy Research and Treatment Centres in all parts of the British Commonwealth and Empire and in other countries, and to act as a "Clearing House" for the

\footnotetext{
${ }^{6}$ Harborne, Cerebral Palsy Midlands, The Medical, Educational \& Social Aspects of The Cerebral Palsy Problem, British Council for the Welfare of Spastics first annual report, April 1948, (p.11).

${ }^{7}$ Paul S. Cadbury was part of the philanthropic Cadbury family who were Quakers and social reformers. They set up the Barrow Cadbury Trust of which Paul S. Cadbury became Chair in 1958.
} 
collection, classification, and distribution of information bearing upon the problems of Cerebral Palsy. ${ }^{8}$

As an overarching body, the BCWS developed many links as detailed in the minutes of the inaugural meeting. The action of the Cerebral Palsy Unit at Carshalton is said to have done 'so much pioneer work for the cerebral palsied child' and the Association for the Care of Sufferers from Cerebral Palsy (ACSCP) is also discussed. The ACSCP 'consist[ed] chiefly of parents of such children' and Henry Weston had been the Honorary Organising Secretary for this Association. On the formation of the BCWS, ACSCP merged 'itself and its assets into the new organisation'. Recognition was given, in the minutes, to the work of Dr Winthrop Phelps and also to the 'great privilege and value' of the visit to Britain by $\mathrm{Dr}$ Earl Carlson from America. ${ }^{9}$ In order to carry out their work the BCWS was mainly funded through donations and subscriptions. As an organisation they also applied to funding bodies in order to carry out research. Through their activities they began to formalise a debate about cerebral palsy and, as far as can be determined, were the first organisation to gather statistical evidence on the incidences of the condition at a national level. A 'Diagnostic Survey Form' intended for nationwide use was developed as an aid for data gathering and this did not go unnoticed, The Times newspaper reported that:

an effort to relieve the plight of children suffering from spastic paralysis ha[d] been made by the Ministry of Education through the newly formed British Council for the Welfare of Spastics, and it ha[d] drawn attention of local education authorities to the work of the council. ${ }^{10}$

The BCWS reached out to parents but primarily it engaged with professionals in seeking a solution to the 'cerebral palsy problem'. The focus of debate was wideranging and considered many aspects of the condition, in addition to the medical

\footnotetext{
${ }^{8}$ The Medical, Educational \& Social Aspects of The Cerebral Palsy Problem, April 1948, (p.9).

${ }^{9}$ Harborne, Cerebral Palsy Midlands, Minutes of inaugural meeting of the British Council for the Welfare of Spastics, held 12 December 1946.

10 'News In Brief', The Times, 2 August 1947. Gale Cengage The Times Digital Archive $<$ http://tinyurl.galegroup.com/tinyurl/BYH231> (p.2).
} 
symptoms, but these were central to the research co-ordinated by the BCWS. Education for children with cerebral palsy was an area of debate within the organisation as reflected in the title of their first one-day conference, held in April 1948, where the 'Medical, Educational and Social Aspects of the Cerebral Palsy Problem', were considered. The full impact of the 1944 Education Act was not clearly evident at the time of the inception of the BCWS but the denial of education, to children with cerebral palsy, became the catalyst, drawing people from diverse backgrounds to work together for one cause.

Academic achievement was central to the 1944 Education Act which meant that investment in those deemed to be 'ineducable' was not viewed as worthwhile. The profile of the BCWS and its interaction with professionals meant that issues being discussed, concerning the educability of 'spastic' children, was raised in Parliament, in July 1949, during a House of Commons debate on education. The Member of Parliament for Rushcliffe, Florence Paton, raised the issue of 'spastic' children and argued that 'no class of child [was] more handicapped or in greater need of special attention'. She raised criticisms of the 1944 Education Act and the tripartite system, asking members to consider whether it was better to have an 'integrated, harmonised child' with a 'happy outlook' rather than one who 'under[went] education merely to earn a big salary'. She referred to the need to provide 'medical, psychological and occupational' aid to 'spastic' children based on results that had been achieved in America and urged MPs to consider the need for co-operation between the Ministries of Health, Labour and Education to achieve this. She stressed that she was not talking about 'mentally deficient children' but of 'children some of whom [were] highly intelligent' and said that these children felt the 'frustration occasioned by their spastic condition even more than if they were mentally deficient or unintelligent'. ${ }^{11}$ The issues raised by Florence Paton highlighted a number of areas of concern which included the lack of commitment, in financial terms, to the investment in

\footnotetext{
${ }^{11}$ House of Commons, Hansard's Parliamentary Debates: Education (5 July 1949, vol 466, col 2057-2062) [Online] $<$ https://api.parliament.uk/historic-hansard/commons/1949/jul/05/education> [accessed 24 October 2016].
} 
education services for children with cerebral palsy and the difficulties they faced in everyday life.

Many examples can be quoted which reflect the realities of coping with cerebral palsy but the poignant memories of Alan Counsell, born with cerebral palsy in Lancashire in 1937, encapsulate this. Alan recalled happy memories of his childhood and talked of a family tradition where 'each child [was] allowed to pick up the post from the lobby on their birthday'. On the occasion of Alan's birthday, he said that as his father carried him downstairs, he asked him if he could pick up his own birthday cards but as Alan said:

It [was] no good. Why, oh why, can father never tell what I say? The words are so clear in my mind. Why does father always have to answer so inappropriately. I try again. "No, I'm not asking if John will have time to feed me this morning. I just want to pick up my cards". Why does father have to quarrel with mother and shout at John each time I speak to him? Of course, he is not the only one who cannot tell what I say. No one ever answers me correctly, and yet the words are so clear in my mind. ${ }^{12}$

A lack of firm statistical evidence contributed towards the general unsympathetic approach, exacerbated if children were being kept out of sight at home, or institutionalised. Organisations such as the Central Council for the Care of Cripples, British Council for Rehabilitation and the Invalid Children's Aid Association had been at the inaugural meeting of the BCWS. Whilst these organisations provided aid for disabled children, they were not dedicated solely to providing support for children with cerebral palsy, and so did not progress their cause. The BCWS acknowledged in its first annual report that there had been, no 'comprehensive system of registration' within the UK, and so the 'exact incidence of cerebral palsy' was unknown. However, through its initiative, the BCWS advocated that a systematic survey be carried out in order to establish both the number, and the needs of children with cerebral palsy. ${ }^{13}$ A survey

\footnotetext{
12 Alan Counsell, So Clear in My Mind (London: Hutchinson \& Co. (Publishers) Ltd., 2007), p.18. ${ }^{13}$ The Medical, Educational \& Social Aspects of The Cerebral Palsy Problem, April 1948, pp.612.
} 
carried out in 1948 recorded details of returns made by local authorities to the BCWS. The figures related to the 'Child Population' aged sixteen and under in England and Wales. Out of 147 authorities, 107 responded to the survey. There were anomalies in the returns which included concerns about the 'efficiency of ascertainment', and whether children in Orthopaedic Hospitals were included, but the overall incidence figure was reported as 0.92 per thousand. ${ }^{14}$

A more detailed survey was undertaken by Patria Asher and F. Eleanor Schonell, between November 1947 and March 1949. Asher and Schonell were from the Department of Paediatrics and Child Health, University of Birmingham and the Birmingham Institute of Child Health. Their study of children from the Birmingham and neighbouring county areas resulted in a report entitled, $A$ Survey of 400 cases of cerebral palsy in childhood (1950). This study aimed to discover the number of children, within the community, who had cerebral palsy and the exact nature of their 'physical and mental handicap'. In gathering data, doctors from the relevant county areas were asked to 'report any cases of cerebral palsy known to them'. From the data received, Asher and Schonell estimated that the 'incidence of cerebral palsy' in school age children was 'in the region of 1 per 1,000 '. ${ }^{15}$ While this report did not represent statistics on a national scale the estimate of 1 per 1,000 shows consistency with the BCWS survey. These findings were subsequently corroborated by the report of the Chief Medical Officer of the Ministry of Education (1950/51). It was said that the incidence of cerebral palsy was estimated to be about ' 1 per 1,000 of the population aged 016 years'. The report draws attention to the fact that incidences in some areas were higher, with the figure reported being ' 4.4 and 2.4 per 1,000' and in some areas the incidences were as low as ' 0.1 per 1,000 '. The statistics provided do not give information of incidences in specific areas, but present an overview. This report declared that until 'more detailed investigations can be carried out', the quoted statistic of ' 1 per 1,000' was to be officially used to 'indicate the size of the

\footnotetext{
${ }^{14}$ Harborne, Cerebral Palsy Midlands, Incidence of Cerebral Palsy, British Council for the Welfare of Spastics, (1948).

${ }^{15}$ Patria Asher and F. Eleanor Schonell, 'A Survey of 400 Cases of Cerebral Palsy in Childhood', Archives of Disease in Childhood, 25 (1950) 360-379 <http://dx.doi.org/10.1136/adc.25.124.360>.
} 
problem'. This statistic was said to equate to 'between 5,000 and 6,000 children, of compulsory school age with cerebral palsy, in England and Wales'. ${ }^{16}$

Statistics began to give more weight to the argument that there were a significant number of children with cerebral palsy, and importantly the condition was beginning to be viewed in isolation, rather than being absorbed into other categories of disability. However, statistics were just an indicator of the number of children and statistics alone did not reflect the realities of individual situations. Whilst a higher incidence of cerebral palsy in a concentrated area needed more resource, it may have been more cost effective than supporting an individual in an area where the incidence was low. Financial pressures meant that services provided were not consistent. Different geographical areas would have had conflicting priorities, and so it was often too easy to overlook 'spastic' children, and the sweeping categorisation that they were 'ineducable' prevailed. The newly formed Ministry of Education had obligations to fulfil which did include adequate provision for disabled children. Children with cerebral palsy often became trapped within the negotiations of the education authority, the health authority and other organisations.

The following three examples, taken from the oral history collection Speaking for Ourselves, describe some of the early experiences of individuals born with cerebral palsy, between 1939 and 1942, from different geographical areas. Joan Ross, born in Anglesey in 1939, recalled how her mother was told that Joan would 'probably never recognise [her] parents and that [she] really wouldn't be able to do much at all'. When Joan was five a consultant drew her mother's attention to an article in The Lancet which talked about 'a new treatment for [Joan's] type of handicap' which Joan said wasn't referred to as cerebral palsy, 'but that's what they were talking about'. She said the waiting list was so long to have a consultation that she did not get it until she was aged nine. During the intervening years, she had learnt to crawl, and her mother decided that she would

\footnotetext{
${ }^{16}$ Ministry of Education, The Health of the School Child: Report of the Chief Medical Officer of the Ministry of Education for the Years 1950 and 1951 (London: His Majesty's Stationery Office, 1952), p.82.
} 
try and get her into school as 'she took it for granted that [Joan] was entitled to an education like everyone else'. Joan recalls how her mother had:

\begin{abstract}
saved for [her] to go to a little private school very near where [they] lived, but [the school] refused to have [her] so [her mother] tried the local infants' school that was all on one level, and they were very reluctant. The headmistress did want to take [Joan] . . . but the education authority [wasn't] happy about [it]. . . [her] mum decided to go to the education offices every day to ask them when they were going to find a place for [Joan] at this school ... and one day when she went, her mother heard one of them say, "That Ross woman is here again", and so her mother said, "Yes. And I'll be here again tomorrow until you offer me a place for my daughter at school".
\end{abstract}

Eventually they did offer Joan a place at the school but with conditions attached. Her mother had to go in to take Joan to the toilet and feed her at lunchtime. She said that the teachers would teach [her] but nothing else, no personal care. ${ }^{17}$ It is debatable whether the teacher's remit would have included such extra tasks but Joan's experiences demonstrated the need to have suitably qualified staff in place to support both Joan and the teaching staff.

Pat Entwistle, born in Colne, Lancashire in 1940 went into care, in a convent, at the age of two and was not able to go to school with other children. He used to spend most of his time alone until he went to a school opened by Lancashire County Council in 1946 called Bleasdale House. He described how this was the 'first school ever in the county to deal with multi-handicapped children'. The school provided physio and speech therapy but Pat described how education was 'very limited, because they were more concerned about gettin' you walking and things like that'. ${ }^{18}$ Despite the reference made by Pat concerning the lack of education, the fact that he had access to physio and speech therapy

\footnotetext{
17 Interview with Joan Ross by Samuel Burch, 14 July 2005, 25 August 2005, 27 September 2005, Speaking for Ourselves: An Oral History of People with Cerebral Palsy, reference C1134/21/0103, British Library.

18 Interview with Pat Entwistle by Richard Smith, 4 April 2005, 25 May 2005, 9 August 2005, Speaking for Ourselves: An Oral History of People with Cerebral Palsy, reference C1134/24/0104, British Library.
} 
was progressive, but this demonstrates that the main focus was on physicality and cognitive development was not a priority.

David Edwards, born in Glastonbury in 1942, recalled how the 'education authorities were in a dilemma as to what they could provide' when he reached school age. It was eventually decided that he 'could attend the infants' school in Dorchester' where his family had moved to. He described how that 'experiment' worked well for him as the head teacher 'was very intuitive and she helped, supported and encouraged [him] a great deal'. As soon as she discovered he could 'control [his] arms and hands better, standing up and leaning against a table at the right height' she allowed him to stand up whenever they had to write anything and 'write on a cupboard at the side of the classroom'. He only attended this school for about a year as the education authority decided that they 'didn't have any provision at all for schooling for children such as [himself]'. His parents were advised to send him to a special school which he said they 'reluctantly agreed to' as 'there was really no alternative because no upper school would accept [him]'. ${ }^{19}$ It can be argued that the adoption of a more radical approach within mainstream education, to facilitate learning through practical solutions, could prove problematic. Adopting a more utilitarian approach could solve a problem in the short term but as this thesis discusses, a lack of resource and limited understanding of the symptoms of cerebral palsy had a direct impact on how each child was perceived. These factors should be taken into consideration during analysis of research materials.

These examples are a snapshot, which demonstrate how the longer-term impact of the 1944 Education Act had yet to be understood. The experiences of these three individuals were very different with no consistent approach towards their education. There was pressure from the local authority to label a child in order to place them somewhere or reinforce a decision made, and the Handicapped Pupils and Medical Services Regulations of 1945, allowed health

\footnotetext{
${ }^{19}$ Interview with David Edwards by Jill Mahler, 13 January 2005, 2 February 2005, 3 March 2005, 10 March 2005, 14 April 2005, 19 April 2005, 26 May 2005, 8 June 2005, Speaking for Ourselves: An Oral History of People with Cerebral Palsy, reference C1134/18/01-13, British Library.
} 
professionals to define disability under medical terms. The experiences of Joan, Pat and David demonstrate how an education was not viewed as important in their lives. It was the state which held the power to decide on the appropriateness of the services provided. This meant the needs of children with cerebral palsy, like these three individuals, were compromised by differing views of professionals, influenced by the particular approach being taken in their local authority area. Children who had been categorised as 'ineducable' were effectively segregated from education and, as an 'ineducable' child, remained under the control of the health authority. It is not surprising that parents' frustrations came to the fore as it seemed they had little or no redress against the system, despite the efforts of the BCWS to encourage a more inclusive attitude. Children and their families faced many and varied situations in order to gain services, particularly education. In order to examine in more detail why children with cerebral palsy were excluded, it is necessary to examine the influence of the medical model of disability.

\subsection{Medical model of disability}

Underpinning the developments of post-war legislation was the increased involvement of the medical profession in the lives of disabled people. Roger Cooter discusses how 'medical practitioners were involved with the physically disabled for the most part of the twentieth century' and considers 'what that involvement consisted of in practice'. He questions whether the 'disabled were "medicalized" and argues that this matter concerned not only 'sociologists and administrators of welfare services, but the disabled themselves and those who became politically active on their behalf'. ${ }^{20}$ Arguably children with cerebral palsy were medicalised, not just from the involvement of medical professionals in their lives, but more from the practice of categorisation. They were singled out as being different from other children, through being placed under the jurisdiction of the health authority, rather than Ministry of Education. The classification of cerebral palsy as a medical condition, and the apparent lack of shared or

\footnotetext{
${ }^{20}$ Roger Cooter, 'The Disabled Body', in Companion to Medicine in the Twentieth Century, ed. by Roger Cooter \& John Pickstone (London: Routledge, 2003), pp.367-383 (p.368).
} 
informed expertise about its affects, meant that the condition was often misunderstood, and 'administrators of welfare services', effectively excluded many children from education. Physical impairment was viewed as a primarily medical problem.

Interviewees in the Speaking for Ourselves collection talked about a lack of support for their parents, and how the medical profession was viewed with suspicion. John Hawkridge, born in Leeds in 1948, said that when his parents were told that they had a child who was 'spastic' there was very little support for them, 'you just had to get on with it'. He gave a view on the level of authority held by the medical profession when he was a child:

Well they just behaved like God, did doctors in them days, when you saw one, you know. You were put in front of a doctor and if he said whatever he said, that's what happened. So, if he said, 'Oh we'll take that leg off,' he took that leg off, and nobody said, 'Oh you can't do that,' or this that or the other - everybody just trusted them. ${ }^{21}$

Lin Berwick, born in London in 1950, recalled how her mother fought for her to see a neurologist in 1952 when she was 18 months old. She said that on watching her body movement the neurologist said, 'this child is spastic. Take her home, forget about her, she'll never be any good. You're wasting my time, your time, and everybody else's'. She said how angry her mother was, quoting her reaction:

How dare this man say that you're no good, and that you are to be taken home and forgotten about? We're going to try and help you to make your way in the world', and, basically, that's what she did. ${ }^{22}$

\footnotetext{
${ }^{21}$ Interview with John Hawkridge by Richard Smith, 15 February 2005, 1 March 2005, 21 March 2005, 16 May 2005, 9 June 2005, 27 June 2005, 27 July 2005, 30 August 2005, 6 September 2005, 4 April 2005, Speaking for Ourselves: An Oral History of People with Cerebral Palsy, reference C1134/20/01-15, British Library.

22 Interview with Dr Lin Berwick MBE by Philip Mann, 8 November 2004, 11 November 2004, 14 February 2005, Speaking for Ourselves: An Oral History of People with Cerebral Palsy, reference C1134/04/01-07, British Library.
} 
David Mills born in Lambeth in 1953 said how during that time people did not know much about cerebral palsy and explained, 'that's why [he could] understand why there was so much confusion what [he] had'. He described how he came across a piece of paper, when his father died in 1999, which would have been given to his parents when David was four years old. It said that David was 'spastic' and that he was going to be 'mentally-retarded' which, looking back, David found a 'very laughable thing' as he had 'done so much' over his lifetime. He said:

\begin{abstract}
it was different times, they didn't fully understand the needs. I got the general feeling, looking back on it, that they didn't really want people to achieve anything, because it was easier that way, and I still think that is still the case, in some cases today. . . and I think there's a lot of people who've got cerebral palsy, who are, let's say, 40 or even 30 plus now, that could have done better. All right, fair enough, some might have learning difficulties, or other disabilities, the thing is that people did not evaluate the people. ${ }^{23}$
\end{abstract}

These narratives illustrate the misperception of cerebral palsy and how a medical framework was used to discover what was wrong with the individual's body. The complexities of cerebral palsy, coupled with a lack of research into the condition, contributed to the confusion of its categorisation. Physiotherapist, Eirene Collis ${ }^{24}$, spoke at the BCWS conference in 1948 where she reflected on how descriptions of cerebral palsy, had 'conveyed the impression that deformity and some degree of mental retardation [were] an essential part of the condition'. She believed that many children who had been 'labelled mentally deficient' were 'really those who [had] been mentally deprived from infancy by reason of their physical incapacity'. Collis argued that early intervention, in the form of treatment was essential. She acknowledged that there would always be a 'small number of mentally defective cerebral palsied children' who would need to attend a 'special' school but argued that 'capacity for physical education indicate[d]

\footnotetext{
${ }^{23}$ Interview with David Mills by Samuel Burch, 14 January 2005, 21 January 2005, Speaking for Ourselves: An Oral History of People with Cerebral Palsy, reference. C1134/29/01-02, British Library.

${ }^{24}$ Eirene Collis had been a student of Dr. Winthrop Phelps and was central to the work of the cerebral palsy unit at Queen Mary's Hospital for Children in Carshalton. She became respected in the field of the treatment of cerebral palsy and published widely.
} 
capacity for academic education' where 'only the physical aspect' needed to be 'special'. Collis maintained that in order to prevent a 'new generation of educationally retarded cripples' the medical profession needed to be educated and the intervention of treatment started at a young age. ${ }^{25}$ Families were at the mercy of professionals, as children were labelled, and intellect and intelligence not regarded as important. Therefore, children were either streamed into categories or were deemed to be 'ineducable', and effectively taken out of the educational system.

A consideration when examining the categorisation of these children, is that in the immediate post-war years, there was a primary focus on the rehabilitation of the body. This dominant view can be said to have influenced the way in which the physical symptoms of cerebral palsy were perceived. Arguably, for those more severely affected, they would have been measured against a perceived normality which was not appropriate to them. Julie Anderson discusses how 'inter-war developments in medicine provided new ways for injured bodies to be treated', and the 'experience of mass warfare from the First World War was disinterred from medical journals and mingled with new medical practices and innovations'. Anderson argues the 'practice of rehabilitation was adopted by the State'. She describes a system where the hospitalised patient was "prescribed a regime, which consisted of a combination of medical, occupational, sporting and social therapy'. ${ }^{26}$ Robert Drake argues that the "overriding aim of welfare was to "rehabilitate" or "normalise" disabled people and policies reflected these goals. ${ }^{27}$ The focus of assessment, was more on the limitations of the body and what the person could not achieve rather than on what they could do. These practices were difficult to challenge and so strengthened long-held, archaic beliefs that individuals with cognitive impairments were 'ineducable'. In a critique of rehabilitation services, Vic Finkelstein maintains that 'medicine is basically concerned with curing illness and injury and helping the

${ }^{25}$ The Medical, Educational \& Social Aspects of The Cerebral Palsy Problem, April 1948. pp.2834.

${ }^{26}$ Julie Anderson, War, disability and rehabilitation in Britain (Manchester: Manchester University Press, 2011), p1.

${ }^{27}$ Robert F. Drake, Understanding Disability Policies (Basingstoke: Macmillan Press Ltd., 1999), p.54. 
patient to be as normal as possible'. However, for people who are 'permanently impaired' their role as a 'patient, with a problem', endures and the 'search for a cure carries on' ${ }^{28}$

A broad categorisation and non-consideration of mental capacity, based on physical impairment, was hugely upsetting for parents, and also for those children who were more aware of what was happening. Judy Smart, born in Oxford in 1945, was diagnosed by a specialist when she was three, undergoing a psychology test at home. She said that 'although [she] couldn't speak much' the psychologist was 'able to detect that [she] was highly intelligent, so that meant that [her] county had to find some way of educating [her]'. Judy attended a mainstream school but only stayed there for two terms as she was badly bullied. She recalled how the 'County provided [her] with a home tutor' which was 'hopeless, because she wasn't patient'. She said how at the end of her sessions with the home tutor her 'mother would find [her] in tears' and the tutor referring to her as being a 'very naughty girl'. Her mother tried to tell the tutor that Judy needed time to answer, which was not being adhered to, and so told her not to come back. The tutor's response was 'that she would write to the education authority' to inform them that 'she would not [go] back to Judy, because [she] was not educable'. ${ }^{29}$

Joan O., a parent from SDSA described her seven-year-old daughter's assessment by a doctor in 1957. She was asked to describe what the child could do; her daughter could just about sit comfortably but couldn't stand at all as her legs were very twisted. She explained what happened:

one of the questions was 'can she feed herself'? Well, that was a no and what can she do physically, 'can she stand and can she walk'? That was a no and then the next question was 'can she walk backwards'? I

\footnotetext{
${ }^{28}$ Vic Finkelstein, 'Rehabilitation Services', in Reclaiming the People's Health, ed. by T. Lobstein and Namibia Support Committee Health Collective (Namibia: AON Publications, 1984), $<$ https://disability-studies.leeds.ac.uk/wp-content/uploads/sites/40/library/finkelsteinRehabilitation.pdf> [accessed 19 August 2019].

${ }^{29}$ Interview with Judy Smart by Alex White, 18 November 2004, 16 December 2004, 13 January 2005, 27 January 2005, Speaking for Ourselves: An Oral History of People with Cerebral Palsy, reference C1134/05/01-12, British Library.
} 
said no! Then lots of questions, 'could she play with her toys'? That was a yes, she could do that and the sort of questions you would ask of a child, you know. And then I had a letter and I always remember what it said. It said, 'your daughter, has been deemed to be ineducable'. I will never forget those words. ${ }^{30}$

As a result of this outcome, her daughter remained under the jurisdiction of the health department until she had an opportunity to be transferred to education, with the opening of a local authority special school. The child had just learned to feed herself, and to walk, which resulted in her frequently wanting to stand. She was declared as being too disruptive and so was removed from the school. This meant her being returned to the control of the health authority. No exception was made to accommodate a perceived deviation from the norm, and the fact that the child was making progress was irrelevant. However, lack of resources within the classroom may have dictated the response to the situation. As for her daughter's education, Joan taught her many things at home such as 'colours and number' as she said 'Chris could learn and she could remember'. ${ }^{31}$

Reflecting on how things were at that time, Joan thought that generally the 'main thing was to get [children walking]' which she said is different now, as 'intellect' is thought about and 'people can stay in wheelchairs all their lives' but she said 'it wasn't like that in those days'. 32 The memories of Judy Smart and Joan $O$. endorse those of many families who argued that, education for their children was generally considered to be unimportant and they were viewed as 'medical cases', to be improved, in the physical sense. Michael Oliver argues that the 'pursuit of restoring the ability to walk or nearly walk is better understood as a millenarian movement rather than the logical application of modern medical knowledge'. He is applying the term 'millenarian movement' to charities, their fundraising and 'pursuit of scientific research', stating that 'the number of cures found' to 'chronic and crippling diseases' are minimal. However, he says the 'idea of restoring the function of walking ... reigns supreme' and is also evident in the

30 Joan O., interviewed by Teresa Hillier about the history of Longfields Association, $2^{\text {nd }}$ June, 2016.

31 Joan 0 .

32 Joan O. 
'enterprise of rehabilitation'. He argues that 'central to the problem of rehabilitation is the failure to address the issue of power and to acknowledge the existence of ideology'. This, he maintains, applies to both state intervention and the provision of services by the voluntary sector. Oliver refers to 'terms set by the rehabilitation enterprise' where 'not-walking can be tolerated when individuals are prepared to undergo rehabilitation in order to nearly walk or to come to terms with their non-walking' ${ }^{33}$

Aspects of Oliver's argument have valid points, when considering therapy treatment given to children with cerebral palsy, but it must be remembered that decisions to undergo treatment are made on the children's behalf. A study of promotional and information films made by MSA and NSS demonstrate children undergoing varying treatments, including 'walking' with leg callipers and using other aids. Much emphasis is given to the achievement of walking, even when, in some cases, the child is barely moving and arguably would get around more quickly by other means. It is the concept of 'normality' that is being maintained. Parent Elsie R. said, 'it upset her to think about the time when she was advised that her son should wear his callipers and boots all day and all night, even wearing them to bed'. She thought that it was 'cruel' and that there was more of a focus on the body and not much else. She said, that was how it was at the time. ${ }^{34}$ Similarly, parent Molly B. said how her son wore 'leg braces' but she did not 'persevere with them . . . as he couldn't walk'. She describes:

the heavy boots and that ... [to] stand him up, and lifting him up, he was dead weight, with the weight of all that as well. And I looked at him and I thought, "No, why should he, you know, have these on?" So I, I stopped using them - he couldn't walk, he never walked so it was pointless, as far as I was concerned anyway. ${ }^{35}$

\footnotetext{
${ }^{33}$ Michael Oliver, 'What's so Wonderful about Walking'? Inaugural Professorial Lecture, $9^{\text {th }}$ February 1993. <https://disability-studies.leeds.ac.uk/wp-content/uploads/sites/40/library/OliverPROFLEC.pdf> [accessed 19 August 2019].

${ }^{34}$ Elsie R., interviewed by Teresa Hillier about the history of Longfields Association, $22^{\text {nd }}$ April, 2017.

${ }^{35}$ Molly B., interviewed by Teresa Hillier about the history of Longfields Association, $3^{\text {rd }}$ February 2017.
} 
However, it must be noted that without intervention, children with cerebral palsy would have lost aspects of their movement, as therapy exercised those muscles affected by their condition. Therapists were also developing a greater understanding of the best treatments to apply in order to gain results.

Anderson argues, the system of 'care and rehabilitation had by necessity produced a large-scale bureaucracy that tended to the needs of the war disabled' and this 'carried over to peacetime Britain'. ${ }^{36}$ The dominance of the medical model influenced the approach of treatments applied to children with disability. Using a medical framework meant that opportunities for education, as provided by the state, were secondary. The Report of the Chief Medical Officer for the Ministry of Education (1946/47) acknowledged that whilst some children had benefited from therapeutic treatment and were not 'completely neglected', there were many children whose 'treatment was on the lines of "there's nothing we can do except to try and keep them happy"'. 37 Equality of opportunity, as afforded through educational reform did not happen universally. Colin Barnes considers the impact of educational reform, and government intervention, arguing that in order to ensure the new system was a success, 'it was considered essential to weed out as many children as possible who might inconvenience or obstruct its implementation'. ${ }^{38}$ The Handicapped Pupils and Medical Services Regulations of 1945 justified the 'weeding out' of those perceived to be 'abnormal'. More may have been done to improve opportunities but limited resources of time, money, and skilled staff, meant that progress was slow. Time, money, and staff were key resources and lack of these is a common theme when discussing the delivery of services.

Of these resources, it was the investment of time that proved crucial in the assessment process. This was highlighted by Dr. Philip Evans of Guys Hospital,

\footnotetext{
${ }^{36}$ Anderson, p.10.

${ }^{37}$ Ministry of Education, The Health of the School Child: Report of the Chief Medical Officer of the Ministry of Education for the Years 1946 and 1947 (London: His Majesty's Stationery Office, 1949), p.98.

${ }^{38}$ Colin Barnes, Disabled People in Britain and Discrimination (London: C. Hurst \& Co. Publishers Ltd., 2000), p.29.
} 
in the Report of the Chief Medical Officer (1946/47). He acknowledged the difficulties in assessing the educability of a child with cerebral palsy and said:

on intelligence testing I can do no more than repeat the warning that ordinary testing is unfair to these children with motor, sensory and speech defects, and that it may be impossible to assess the intelligence without some weeks of observation. The response to treatment is thus more useful than a single psychometric session. ${ }^{39}$

Without an investment of time, children with the condition could not be fairly tested and so individual capabilities were overlooked, as the focus remained on what they were not achieving. The assessment process was discussed by Asher and Schonell in their study, a Survey of 400 cases of cerebral palsy in childhood (1950). They argued that an assessment of the intelligence of the cerebral palsied child [was] a more difficult task than testing the intelligence of normally equipped children'. Assessment required 'more time, patience, and understanding of the psychological background and attitudes of these children'. ${ }^{40}$

Developing an understanding of the needs of 'spastic' children, and disseminating this knowledge, was paramount in giving them an opportunity to participate in society. Schonell maintained that little attention had been given to the 'psychological or educational needs of the cerebral palsied child'. She said that those with 'slight handicaps' could attend ordinary schools but those with greater disabilities, either stayed at home, with no educational support, or "were put into an institution for mentally defective children'. ${ }^{41}$ Searching for an explanation to justify your child's lack of progress in reaching 'normal' developmental milestones did not alleviate parent's fears. Roy Hull, a parent from MSA reflects how in 1946, he and his wife were 'anxious about their sevenyear-old handicapped son' who had been 'excluded from normal school as ineducable' and with 'little prospect of his being admitted to a special school'. A visit to Birmingham's School Medical Officer led to his son being labelled a

\footnotetext{
${ }^{39}$ Ministry of Education, The Health of the School Child: 1946 and 1947, p.98.

${ }^{40}$ Asher and Schonell, p.374.

${ }^{41}$ F. Eleanor Schonell, 'What is a spastic?', Educational Review, 1:3, (1949), 158-160 (p.159).
} 
'spastic'. ${ }^{42}$ The medical model coloured the approach taken towards cerebral palsy and the great promise of the 1944 Education Act was not a driver for success, but was instead the catalyst that challenged society to deal with the 'spastic problem'.

\subsection{Transnational influences}

Of great significance, at this time, was new research into cerebral palsy. This began to emerge through the work of pioneering doctors, such as $\mathrm{Dr}$ Winthrop Phelps of Baltimore, USA. His research had a major impact on how services developed in Britain, together with the input of other key individuals, $\mathrm{Dr}$ Jean Macnamara from Australia and Dr Earl Carlson from the United States. Before examining the impact of this new research in the post-war period, it is useful to consider the impact of developments that were made prior to the Second World War. In 1931, The Crippled Child's Bill of Rights had been presented to a 'Committee at the Second World Conference on the Problem of the Cripple', organised by the International Society for Crippled Children. In a paper written for the journal Disability \& Society, Nora Groce discusses the events which led to the creation of two documents. One was a Bill of Rights and the other, a request to establish an International Bureau of Information on Crippled Children. Groce argues that these initiatives reflect 'early attempts to place disability within wider social contexts'. The Bill was disseminated widely to 'politicians, medical experts and leaders of civil society' and Groce said, it showed the 'strong medical/rehabilitative roots of those who drafted it'. She summarises the Bill as follows:

It contain[ed] 10 rights. Beginning with the need for good prenatal, perinatal and newborn care to prevent disability where possible, the Bill then goes on to acknowledge that disability is not always preventable and to advocate for the right of children with disabilities to adequate medical care, education and vocational training that would allow them to become 'independent adults.' It also calls for the right to selfdetermination and to 'considerate treatment' (what

42 Harborne, Cerebral Palsy Midlands, Roy Hull, 'A Parent's Experiences in the Early Days', in Midland Spastic Association Year Book 1972, p.17. 
today would be social inclusion), as well as the right to spiritual, physical and intellectual development.

Groce maintains that documents produced and submitted to the League of Nations 'foreshadow[ed] a number of key disability rights ideas', and that these ideas would 're-emerge' in later decades. One of the goals of the Society was to 'serve as a clearinghouse for information on medical, social and educational issues' and as Groce argues, from the earliest days, members of the Society were highlighting issues which continue to be significant today. She considers how the International Society worked on a 'shoestring budget', utilised volunteers and 'came to wield influence greater than its size would indicate'. Edgar $F$. (Daddy) Allen, the founder, used 'the press, the pulpit' and 'the new medium of radio to teach an increasingly interested public'. 'Daddy' Allen had courted 'international publicity' and had 'national leaders and famous politicians', in the USA and Europe, as personal friends. Groce suggests that a pattern had been established 'that would be followed in the [post-war] era by many disability advocacy groups'. 43

Whilst the focus of the International Society was mainly on physical disabilities, the approach taken does have remarkable parallels with actions taken by parent-led 'spastic' associations in post-war Britain. Through its status, the International Society had started to challenge opinions and highlight issues that affected many disabled children. Economic issues, such as the 'deepening Depression on both sides of the Atlantic, drastically limited the work of the International Society, as funding for travel and international advocacy shrank'. It was the onset of war that halted progression, as Groce comments, the failure to continue this initiative can be explained by the 'national delegations' pulling out due to the threat of the Second World War. Groce reflects on the two documents discussed and argues that they 'represent[ed] a moment - and a lost opportunity - in disability history'. The ideas presented did not reappear for many years. This, Groce said should 'serve as a warning' as 'ideas and policies can move

\footnotetext{
${ }^{43}$ Nora Groce, 'Disability and the League of Nations: the Crippled Child's Bill of Rights and a call for an International Bureau of Information, 1931', Disability \& Society, 29.4 (2014), 503-515. <http://dx.doi.org/10.1080/09687599.2013.831752>.
} 
backwards as well as forwards'. Loss of 'significant advances in thinking' can happen quickly without 'consistent vigilance and adequate follow through'. ${ }^{44}$

An appreciation of the economic climate and cultural values are essential in order to put the apparent lack of progress, towards changing attitudes to disability, into context. A changing approach to physicality, in post-war Britain, did not adequately address the wider issues of those with cerebral palsy. Society had many competing priorities, aside from recovering from the horrors of war, economic restrictions and the challenging situations of daily life, influenced everyday concerns. Britain had been left with huge financial debt, housing shortages and continued rationing. Post-war reforms attempted to address these issues as they encompassed all aspects of life in the restructuring of society. This meant that there was also opportunity for fast-moving social change. However, implementing a tailored approach towards disabled individuals needed more resource, which was not provided by the state, as investment in those not seen as future contributors to the economy, was not a priority. The BCWS actively cultivated emerging transnational relationships and promoted developments into new research. Therefore, it took initiatives driven by organisations such as the BCWS, to push for a change in attitude, placing 'disability within a wider social context'.

Dr Winthrop Phelps, Dr Jean Macnamara and Dr Earl Carlson were pioneers in their research of cerebral palsy. They were not the only professionals with an interest in this area, but they were leaders in their field. An increased awareness of their work happened in parallel with the growing realisation of the numbers of children with the condition. The implications of their research were to have a significant impact on the approach to cerebral palsy in Britain. It is useful to reflect on the philosophy of these three individuals before considering their influence.

As orthopaedic surgeons, Phelps and Macnamara were focused on therapy treatments over education although they still thought that education was

${ }^{44}$ Groce, pp.503-515. 
important. Writing in 1941 in the Journal of the Southern Medical Association, Phelps had said how cerebral palsy had become of interest to orthopaedic surgeons, as it had 'been studied in the past probably the least of any of the major handicaps in point of frequency'. ${ }^{45}$ In an extract from the Medical Journal of Australia and the Australian Orthopaedic Association Dr Jean Macnamara had written about spastic paralysis and intelligence in children with cerebral palsy. She felt that 'orthopaedic surgeons should be the leaders in the eradication of an attitude still prevalent among doctors, that there was little to be done to help the spastic child'. ${ }^{46}$

The approach taken by Dr Earl Carlson was slightly different to Phelps and Macnamara. He had been born with the athetoid form of cerebral palsy and had to fight for his education and the right to study, particularly at university level. Born into a poor family, he had received no therapy treatment as a child and his life experience made education extremely important to him. In his 1948 report, to the New Zealand Government, and the New Zealand Crippled Children's Society, he maintained that the treatment of cerebral palsy was an 'educational problem as well as a medical problem'. He argued that the 'stiffness of movement, tremors, writhing motions and grimaces', as experienced by those with cerebral palsy, were 'intimately tied up' with 'thought processes'. He argued that it was 'difficult to think of the movements as being something apart from the feelings. To illustrate his point, he said that it was difficult to 'conceive of a smile as being something separate from the thoughts that evoked it'. He believed that emotions played an 'enormous role' in the 'motor economy of the cerebral palsied'. 47 In Carlson's autobiography, Born That Way (1952), he recalled life experiences which related to his theories and therefore spoke from personal experience. Many of the difficulties that families faced were not dissimilar to those experienced by him and, as a renowned expert in cerebral palsy, he held a unique position enabling him to influence attitudes and treatment.

\footnotetext{
45 Harborne, Cerebral Palsy Midlands, Dr. Winthrop Phelps, M.D. Baltimore, Maryland, 'The Rehabilitation of Cerebral Palsy', in the Journal of the Southern Medical Association, 1941.

${ }^{46}$ Harborne, Cerebral Palsy Midlands, Mr and Mrs J.L. Williams, St Margaret's School, Croydon, Treatment of cerebral palsy in Australia, May 1947, p.9.

47 Harborne, Cerebral Palsy Midlands, Dr Earl Carlson, Report to the New Zealand Government and New Zealand Crippled Children Society on the Problem of Cerebral Palsy, March 1948.
} 
The emerging research of these key individuals advocated that a holistic approach be adopted to the condition, and that physical therapy treatment be part of an established routine. In order to deliver such treatment on a wide scale there needed to be a co-ordinated approach. The BCWS and parents wanted this, as it was said that a significant difference could be made to both the mental, and physical symptoms of cerebral palsy. In a publication prepared under the direction of Phelps, for the National Society for Crippled Children and Adults in America, there is an 'outline of the cerebral palsy problem'. It is reported that 'with proper teaching and training' children with the condition 'often can and do improve physically'. The 'variation in the degrees and complexities' of the condition were said to be almost 'entirely impossible' to be put into categories. The report stressed the importance of 'constant teamwork', by a range of professionals, in order to make progress with the child. It was said that the 'happiest results' could be obtained if the 'parent [was] brought in as a member of the team'. 48 However, parents had been excluded in Britain and were not viewed as 'part of the team'. This was a new concept, which needed to be developed. An article in a Year Book of Swansea and District Spastic Association (SDSA, 1960), written by Orthopaedic Surgeon for South West Wales, Gordon Rowley, reflected on the role of parents. He said how 'many years ago, an eminent Orthopaedic Surgeon' had said that in order to 'obtain the best results in the treatment of spastic children, a minimum of one physiotherapist for each child would be necessary'. Rowley considered the impracticalities of implementing 'such a situation' but spoke of the need of 'establishing confidence and continuity of treatment'. He said that the 'best results [were] obtained' where there were 'co-operative parents'. ${ }^{49}$ The philosophy that Phelps promoted was one which began to be considered as services slowly evolved in Britain. However, therapy treatment was sporadic and, for some, non-existent, but it was still developing in the early twentieth century, and speech therapy was a relatively new profession

\footnotetext{
${ }^{48}$ Harborne, Cerebral Palsy Midlands, The Farthest Corner - An outline of the cerebral palsy problem, prepared under the direction of Winthrop M. Phelps, M.D. for The National Society for Crippled Children and Adults, Inc., 11 South La Salle St., Chicago 3, Illinois.

${ }^{49}$ Swansea, West Glamorgan Archive Service, D/D LA 5/1, Gordon Rowley, M.Ch. Orth., 'Parent remains the most important link', in Swansea and District Spastic Association Year Book 1959/60, p.9.
} 
The BCWS was dedicated to new research and it actively promoted its dissemination. At its first one-day conference in 1948, the 'level of Americanism' in the room was remarked on, as the merits of practical intervention through therapy treatments were debated. Serious consideration of cerebral palsy as a condition and not simply as a medical disorder for research, was essential. The multi-disciplinary audience were from all parts of Britain, enabling details to be shared of transnational developments, with the links which had been established with specialists in other countries. The address by Professor Alan Moncrieff ${ }^{50}$ highlighted reasons why the 'problem' of cerebral palsy was being viewed as a 'new thing'. He said the 'degree to which such children could be educable' had not been appreciated, and he described a series of symptoms, which had led to the classification 'ineducable'. He declared, that it was through the 'merit of the work of Carlson and Phelps', that had shown 'you could take such a person who look[ed] like an idiot and train him for something'. Moncrieff stressed that children with the condition had not been neglected in Britain, but said the approach 'was not perhaps co-ordinated or organised' and so, 'to some extent was a little aimless because one was not quite clear as to the ultimate purpose'. The financial cost of implementing an organised approach to treatment was highlighted, as was the concern that there were insufficient trained staff. ${ }^{51}$ Literature from the conference reflects on the developments made in America towards cerebral palsy, as prior to this, advocating such a change had not been apparent to medical professionals in Britain, borne out by testimonies in oral history interviews. However, lack of time invested, money and trained staff were again cited as barriers to making progress and these issues were to form part of the coming wider campaign.

The presentation of this enlightened approach at the conference, towards the treatment of children with cerebral palsy, was a ground-breaking event. Transnational relationships were being forged and these allowed new ideas to be

\footnotetext{
${ }^{50}$ Professor Alan Moncrieff was the Director at the Institute of Child Health, University of London, and Nuffield Professor of Child Health.

51 The Medical, Educational \& Social Aspects of The Cerebral Palsy Problem, April1948, pp.1825.
} 
discussed. Whilst there were still many issues to overcome, a small network of professionals was talking about cerebral palsy in a different light and with a certain level of positivity. These key people drew on a high level of expertise. The 1948 conference was reported on in the Times, where it said that early diagnosis and treatment for children with 'spastic paralysis', was 'urged' by speakers at the conference. The article explained how specialised treatments had been discussed, which included 'physio and occupational therapy, training in correct speech, and the instruction of parents on how to get the best out of their crippled children'. The Minister of Education, whilst emphasising that 'treatment of the handicap' was still at the 'experimental stage', pledged his support and that of ministry staff. ${ }^{52}$ This conference was a particularly pivotal moment for parents, they had previously been made to feel that any effort made for their child would not have been worth the bother, and now the focus of discussion began to change.

Nurturing this change was Paul Cadbury, a notable and influential figure in business and as a parent of a child with cerebral palsy, Cadbury could identify with the despair felt by so many families. Cadbury had met Carlson on a trip to America and expressed his wish that Carlson be called upon, to advise on a proposed development of a school, for 'spastic' children, in the Birmingham area. ${ }^{53}$ Cadbury was in a fortunate position, he was able to directly seek Carlson's expertise but used his influence, not just for his advantage, but for the wider purpose of improving the lives of those with cerebral palsy. Colleague, Stephen Quayle, remembered Cadbury, and spoke of his 'great qualities' and how he used his 'organising power, his drive and many vital contacts in the field of Education and Medicine'. He said how Cadbury 'planned a tour of Britain for Dr. Carlson so that in a number of key centres he could address and confer with Doctors and Educationalists'. ${ }^{54}$ Philanthropy and life experience became interwoven. As part of an influential Quaker family Cadbury was a reformer, but it was through his personal circumstances that he became so involved in the lives

52 'Aid For Handicapped Children', The Times, 15 April 1948. Gale Cengage The Times Digital Archive < http://tinyurl.galegroup.com/tinyurl/BYbHP1> (p.3).

${ }^{53}$ Harborne, Cerebral Palsy Midlands, Paul Cadbury, letter to Stephen Quayle, 11 July 1946.

${ }^{54}$ Harborne, Cerebral Palsy Midlands, Stephen K. Quayle, 'Paul Strangman Cadbury 1895-86', Midland Spastic Association Year Book 1986 p.8. 
of those with cerebral palsy. In a similar way, Earl Carlson, through his achievements and life experience, was a remarkable role model for families who had children with the condition. A reference was made to Carlson in the book Every Eight Hours (1964) ${ }^{55}$, where it said that Carlson's strong personality and 'great triumph' over his disability won over audiences. His 'difficult speech and gait' was overlooked and his addresses made 'hundreds of spastics' parents raise their heads and think "if he [can] do it, why not my child?"'56

These effective relationships strengthened transnational links and relationships between organisations and individuals. A renewed impetus for change, built on the progress already achieved, and promoted a new approach to include therapy treatment, as standard practice for children with cerebral palsy. In Worth Saving (2013), Sue Wheatcroft discusses such a new approach and considers the influence of practitioners such as Phelps. She comments that they had shown, that for children with cerebral palsy, 'in a high proportion of cases a considerable improvement in the mental and physical condition could be effected'. Such was Phelps's influence, Wheatcroft describes how the Ministry of Health proceeded with a line of treatment and training in June 1945, which had been advocated by Phelps, and undertaken at the Cerebral Palsy Unit at Queen Mary's Hospital in Carshalton. ${ }^{57}$ Through the astuteness of the BCWS and individuals such as Cadbury, transnational influences began to filter into the practices undertaken in Britain. This meant that the developing campaign for better services, for children with cerebral palsy, did not just focus on education, but went hand-in-hand with the argument for a multi-disciplinary approach to be employed. These developments demonstrate that the proposals for change were based on evidential experiences with proven results and so were not just a quick fix for a complex problem.

\footnotetext{
${ }^{55}$ This book accompanies the film Every Eight Hours (1960) which tells the story of the NSS.

${ }^{56}$ Richard Dimbleby, Every Eight Hours (London: Hodder \& Stoughton, 1964), p.20.

${ }^{57}$ Sue Wheatcroft, Worth Saving, Disabled children during the Second World War (Manchester: Manchester University Press, 2013), p.157.
} 
Such was the strength of transnational links that a series of study tours were embarked upon by key individuals from Britain to observe pioneering doctors at work and visit a variety of centres to see new practices in action. These individuals were educational psychologist, Marjorie I Dunsdon, Director of Research, National Foundation for Educational Research (NFER) in England and Wales; physiotherapist Eirene Collis; and educational psychologist, Dr Eleanor Schonell. There are no direct references in the primary source materials which detail how the study tours were funded. Collis had previously been a student of Phelps whilst she was in America and Schonell was an Australian citizen and so may have had links with Macnamara, prior to working in Britain. The fact that all embarked on tours which lasted three months demonstrates that they were respected in their subject areas and a significant financial investment was made in their research. Also, of note is that all three were women. Dunsdon, Collis and Schonell published reports and books of their findings which also included practical information for dealing with the symptoms of cerebral palsy. Therefore, the influence of Phelps and others began to have a direct impact on the delivery of services in Britain. This will be discussed in more detail in the next chapter together with the study tours of the 1940s.

Aspects of such new developments are reflected in the work begun by the International Society for Crippled Children, as discussed by Groce. Cerebral palsy was starting to become a social issue, through the exclusion of children from education and those involved in delivering expertise had 'strong medical/rehabilitative roots' 58 . The dissemination of new research was targeted at those professionals who could make a difference through the implementation of new practices. However, as shown, providing support posed a challenge to some local authorities, but as parents became more informed a continual denial of opportunities simply reinforced their resolve to achieve change. A relatively small campaign began to grow, strengthened by the emergence of transnational networks, and the campaign was to become a single-minded crusade, to raise awareness of attitudes towards children with cerebral palsy.

58 Groce, pp.503-515. 


\subsection{Parents' frustrations}

Whilst the BCWS had made great strides, its report for the period 19481952 stated, they 'continued to draw attention to the need for more ample provision' than was in place for the 'treatment and education of cerebral palsied children'. The report said that many children known to them were not 'receiving regular treatment and education'. It maintained that there was still a lack of 'conclusive evidence' to give an 'accurate estimate' of the 'number of cerebral palsied children who need[ed] and [were] capable of benefiting from special treatment and education'. Other concerns highlighted included the lack of facilities for the 'severely handicapped adolescent and adult spastics of average intelligence'. At the time of the report, parents in twenty-six areas had formed local associations to which the BCWS gave 'advice and assistance'. 59 In order to engage with an increased number of families a more dynamic approach was called for, but the BCWS, with its professional membership, inevitably had a greater focus on research activities as opposed to practical help.

Continual inconsistencies in the interpretation of children's needs exacerbated parent's frustrations. Individually, parents lacked the power to successfully challenge authority. Jennifer Harris and Alan Roulstone reflect on the 'powerlessness of parents to reject the labels' which were 'attached to their children' and state how this 'was evident in the outcomes of the appeals process, with only four successful appeals registered out of 4,000 parental appeals between 1951 and 1960'.60 Discourse was led by professionals and whilst the work of compiling statistics and stimulating debate, through the dissemination of research, was essential, it did little to address the dominant 'tragic' view of impairment and the immediate needs of families.

The need for a co-ordinated approach was acknowledged in the Chief Medical Officer's Report (1946/47), in a discussion on the integration of treatment and education. It stressed, that it was 'essential that treatment and teaching be

\footnotetext{
${ }^{59}$ Harborne, Cerebral Palsy Midlands, 1948-1952 Report, British Council for the Welfare of Spastics.

${ }_{60}$ Jennifer Harris and Alan Roulstone, Disability, Policy and Professional Practice (London: SAGE Publications Ltd., 2011), p.14.
} 
co-ordinated', rather than a child being 'subjected to bombardment by a battery of specialists working independently', which may have had a detrimental effect on the child. The report stated that 'clear-cut guidance' could not emerge immediately as 'information of value [could] be gained only by observation of the children over a lengthy period'. ${ }^{61}$ It is not unreasonable to agree with this argument as it acknowledged that systems needed to be created and tested, in order to develop a viable solution that met individual need. However, many families needed immediate intervention and could not afford to wait whilst 'systems were created'.

Parents wanted direct action but their involvement is referred to, in the Chief Medical Officer's Report (1946/47), in a rather negative way as it stated, 'handicaps', were 'formidable for therapists to cope with', but were said to be 'much more formidable for parents'. The report considered the 'danger of giving parents too much hope' and said that this 'must be avoided at all costs', particularly as the parents would have had an 'outlook deeply tinged with emotion'. ${ }^{2}$ This thinking went against the philosophy of involving parents, as part of a team of people, involved in the care and treatment of children with cerebral palsy. Lack of time, money and staff were continually cited as barriers to moving forward, and yet parents could fulfil a role which would help such situations. The lack of credibility regarding parent involvement typified the general attitude which they had railed against. There was no denial that the symptoms of cerebral palsy could be challenging, and some children had more complex needs, but the continued, widespread attitude of 'little or no hope' being afforded to children, charged parent's emotions.

\subsection{A changing climate}

Anderson argues that prior to the new 'welfare state' the voluntary sector had 'often been the only recourse for disabled people to receive assistance' and argues that the State, continued to rely on this sector 'to provide rehabilitation

${ }^{61}$ Ministry of Education, The Health of the School Child: 1946 and 1947, p.99.

62 Ministry of Education, The Health of the School Child: 1946 and 1947, p.100. 
services'. ${ }^{63}$ As discussed, the BCWS which was leading in the development of research into cerebral palsy, therefore the State was being guided by the initiative of a voluntary body. The state had created the problem of the 'ineducable' child and as Anderson comments, 'the voluntary sector grew in the wake of both the limitations and the achievements of the welfare state for it was the achievements that revealed the limitations'. ${ }^{64}$ Sue Wheatcroft argues the 'implementation of the NHS was the single most pivotal event to affect voluntary organisations in the immediate post-war period', as the Ministry of Health took over 'many responsibilities previously met by the various voluntary societies'. This, she maintains, allowed many charities to 'expand their services by working on new initiatives' ${ }^{65}$ Whilst this thesis is focussed on cerebral palsy, as a condition, other organisations that were formed at about the same time as parent-led 'spastic' associations, such as MIND (1946), British Epilepsy Association (1951), Multiple Sclerosis Society (1953) and the Muscular Dystrophy Group (1954), demonstrate that there was a desire to lobby for change, and advocate on behalf of those living with a variety of different conditions.

Maureen Oswin discusses how 'a strict classification of children's conditions [had] influenced what sort of services were developed for them'. She gives the example of how children with epilepsy were sent to 'epileptic colonies' and by ' 1945 thousands of disabled children were separated from their families because of rigid adherence to categories'. Oswin discusses how those children, in 'mental handicap hospitals' with 'cerebral palsy or other physical disorders', were isolated and kept in 'baskets' or 'cots'. As a result, they 'never received help to improve their posture, so their bodies grew twisted' and they were often kept in wards referred to as 'back-wards, and were rarely seen by outsiders'. Many children with learning disabilities were also institutionalised in 'mental handicap hospitals', classified as 'ineducable' as were children with cerebral palsy. Oswin quotes how, by 1950, there were over ' 10,000 children living in long-stay hospitals, 6,000 of whom had learning difficulties'. ${ }^{66}$

\footnotetext{
${ }^{63}$ Anderson, p.185.

${ }^{64}$ Anderson, p.185.

${ }^{65}$ Wheatcroft, p.171.

${ }^{66}$ Maureen Oswin, 'An Historical Perspective', in Growing up with Disability, ed. by Carol

Robinson \& Kirsten Stalker (London: Jessica Kingsley Publishers Ltd., 1998), pp.29-41 (p.36).
} 


\subsection{Development of local parent-led associations}

What did a changing climate mean for the families of those who had children with cerebral palsy? Heightened awareness of the condition meant that local parent-led 'spastic' associations began to be established in Britain. One of the first was MSA, linked to Paul Cadbury. In a report to the trustees of the Paul S. Cadbury Charitable Trust in 1969, Cadbury said how his daughter's 'problems were naturally the reason for [his] interest in Cerebral Palsy, and [his] visit to the United States' when he first met Earl Carlson, 'started a chain reaction'. Prior to the establishment of MSA, he described how during the period 1920 to 1940 he was 'closely identified with work for the Blind', and for 'most of [that] period was Chairman of the Trade Committee' and a 'member of the Education Committee of the Birmingham Institution. He also served as a member of the Health Committee of the City Council for the period 1940 to $1943 .{ }^{67}$ His background and experience inspired a confidence in the association that led Birmingham Education Department to support the work of MSA and their proposal to open a school. They provided financial support through a building grant and met the fees, covering the cost of tuition and treatment, for Birmingham children. Subsequently, other local authorities agreed to pay the fees of children sent by them to the school.68 As a local organisation, backed by the local authority and led by Cadbury, MSA was, in some respects, a model organisation. Roy Hull captured the essence of what parent-led 'spastic' associations meant, recalling how liberating it was, when he met with other parents at MSA who had the same 'frustrating experiences'. He described how they discussed their problems and said the meetings were:

a tremendously liberating experience for many of us and for many of our children who until then had been housebound. Many parents felt embarrassed and even angry at the curiosity shown by passers-by at the contortions and grimaces of our children and we realised the need to educate the general public to recognize spastics and accept them in society. This

\footnotetext{
${ }^{67}$ Birmingham, Wolfson Centre for Archival Research, MS 1579/1/4/6/3, Records of the Cadbury Trusts, A report to the trustees of the Paul S. Cadbury Charitable Trust.

${ }^{68}$ Harborne, Cerebral Palsy Midlands, Annual Report of Midland Spastic Association, 1949.
} 
we did by addressing meetings and by arranging outings to public places. ${ }^{69}$

The first annual report of the association details the terms of reference of MSA which were based on those of the BCWS. As part of these it is stated that MSA was to:

Act as the central advisory, co-ordinating and consultative body for all activities in the counties of Warwick, Worcester, Stafford, Salop and Hereford or other adjoining counties directed to the well-being of sufferers from spastic paralysis and its allied conditions. ${ }^{70}$

As can be seen, the provision of service was focused on a regional area, as they were fundamentally a local organisation. However, they established the first parent-led day school in Britain, Carlson House, which was to have a national impact, and will be discussed later in the thesis. Having a level of financial security enabled the association to develop its services and incorporate the philosophy of Earl Carlson.

One of the outcomes of the survey, by Asher and Schonell, enabled effective planning of services. Prior to the study, figures surrounding the incidences of cerebral palsy 'ha[d] been scanty' with figures estimated and 'based on the numbers found in institutions' or children already diagnosed and presenting for treatment. Publication of the survey's findings drew attention to the need for plans to be implemented for the 'treatment and education of affected children'. For example, attainment in reading of 'normally intelligent and bright children' revealed a 'very considerable degree of retardation'. Therefore, there was a recommendation to make a provision for special education as the 'lack of stimulus' would not allow 'capacities' to be developed 'beyond mediocre levels'. ${ }^{71}$ The publication of the report gave hard evidence to the many theories that were being discussed even though it did not clarify the national scale of the problem. Parents were involved and being part of the process, they supported the

\footnotetext{
${ }^{69}$ Roy Hull, 'A Parent's Experiences in the Early Days' p.17.

70 Harborne, Cerebral Palsy Midlands, Annual Report of Midland Spastic Association, 1949.

${ }^{71}$ Asher and Schonell, p.360.
} 
implementation of new theories, and through their advocacy they helped to pioneer a different approach.

Schonell authored a report (1949) on the suggested forms of educational provision for children with cerebral palsy, considering the intellectual level of the child; their physical disability; their level of emotional adjustment; and the nature of their home background and family relationships. Schonell listed two criteria to be considered when examining children who needed extra support:

- To what extent [was the] child capable of being made self-supporting?

- To what extent [could the] child be helped to a normal intellectual and emotional life?

She considered criticism that has been made of the research, mainly concerning the first criteria. It is not stated in the report who the critics were. A question was asked, 'why waste money on children who will never contribute to the nation's productive powers'? Schonell argued that critics were 'ignorant of the fact that an appreciable proportion of the cerebral palsied [were] of average or above average intelligence'. In consequence it was said that many could be made self-supporting. This criticism highlighted the prevalent negative attitude towards people with cerebral palsy and, in response, Schonell pointed out that not all those who are educated 'make a contribution to national prosperity', and there are 'some who actually hinder it'. ${ }^{72}$ Through working with Schonell and her contemporaries, MSA was able to address some of the criticisms raised. Demonstrating progress established the association as one of the leaders in the development of education and a supporter of wider research.

Whilst professionals became heavily involved in MSA and Carlson House school, parents were predominantly the advocates who campaigned and raised the association's profile, led fundraising activities and developed subsidiary services. It can be described as an association with two tiers, at one level the

\footnotetext{
72 Harborne, Cerebral Palsy Midlands, F. Eleanor Schonell, Suggested forms of educational provision for cerebral palsied children with varying degrees of mental and/or physical disability, $31^{\text {st }}$ October 1949.
} 
association was forging ahead in medical research and new educational practices, whilst at another level more traditional charitable activities were taking place.

MSA reached out to other organisations, parents and professionals to share its knowledge and best practice, but could only actively support individuals within its particular geographical area. However, local groups became linked by their common aims and objectives, together with a shared ethos and parent involvement. These common goals had originated from the philosophy endorsed through organisations such as the BCWS. However, each group had to strive for their own success and achieving this was no mean feat as Bill Paton, a founder member of SDSA, said of the challenges of forming an association that parents were like:

pioneers who blazed the trail centuries ago, they had faith in God, faith in their offspring, and faith in mankind. Through that indomitable faith was born a resolve to first educate the public in a problem that not even the State or local government had really appreciated. ${ }^{73}$

A particular strength of local groups was that they knew their communities, their members lived and worked there and, through intense campaigning, a clearer idea began to emerge of the number of children who needed support. This enabled the campaign to be more effectively targeted within local areas. Sharing of resources and knowledge is demonstrated through the support given to SDSA at an initial meeting in 1952. In addition to parents and representatives of educational, health and social organisations, a representative from Carlson House School attended to give a 'special lecture'. ${ }^{74}$ Later that year, it was reported that nearly 200 people attended a meeting where films had been shown depicting 'spastic' children being educated and treated for their physical disabilities, whilst at school. A 'sound film' from America was shown, illustrating

\footnotetext{
${ }^{73}$ Swansea, West Glamorgan Archive Service, D/D LA 5/1, Bill Paton, 'Through Indomitable Faith was Born a Resolve' in Swansea \& District Spastic Association Year Book 1959/60, p.6.

${ }^{74}$ Swansea, West Glamorgan Archive Service, Longfields Association Records DD LA 3/1, Management Committee and AGM minutes, 1952-1954.
} 
the early diagnosis of cerebral palsy and Enid Davies, of Carlson House School, provided a commentary. ${ }^{75}$ This support boosted confidence and gave SDSA an added impetus to achieve. Bill Paton spoke of the expertise MSA shared and their support in the argument to provide a school for approximately 30 children which would offer speech therapy and physiotherapy, in line with other schools. ${ }^{76}$ A network had begun which created a foundation for future generations to build on with parents becoming vocal advocates, in the area of disability where they challenged the situations, in which they and their children found themselves.

As can be seen, prior to parent-led 'spastic' associations becoming active, a lot had been achieved in terms of greater understanding of cerebral palsy. However, a lack of co-ordination of services, on a national scale, meant that achieving progress was limited so parents were needed to drive things forward. Jan Walmsley, Liz Tilley, Sue Dumbleton and Janet Bardsley discuss the 'changing face of parent advocacy' and argue that it 'has been at its most dynamic and powerful in periods of immense perceived challenge'. They maintain that the 'heyday of parent advocacy was in the immediate post-war era, with the founding of parent-led campaigning organisations' ${ }^{77}$ As local groups grew and achieved charitable status so they became more professional and, as independent charities they adopted an official structure to comply with the formal obligations placed on them. This change strengthened their governance, giving a clear focus to their work, whilst the legality of charitable status also gave an authority which they would otherwise have lacked. The fundamental aim to provide education and develop services for children with cerebral palsy remained a priority.

Apart from campaigning for policy change, a significant impact on families was the strength that parents gained from one another and the development of a community through their associations. In order to make these a success parents had to work together; they undertook a variety of tasks where they raised funds

\footnotetext{
75 Swansea, West Glamorgan Archive Service, Longfields Association Records, D/D LA 11/1-4, newspaper cuttings relating to Longfields Association, 1954-2007.

${ }^{76}$ Paton, 'Through Indomitable Faith was Born a Resolve', p.6.

77 Jan Walmsley, Liz Tilley, Sue Dumbleton \& Janet Bardsley, 'The changing face of parent advocacy: a long view', Disability \& Society, 32.9 (2017), 1366-1386 (p.2) <http://dx.doi.org/10.1080/09687599.2017.1322496>.
} 
through targeted initiatives. They developed sub-groups, like the 'Parents Circle' or the 'Ladies Guild', which focused on different aspects of the Association's work, such as fund-raising, social activities and volunteer work. This energy united parents in their efforts and, as parent, Joan O. said, the organisation 'was the start of life' for her family, they were involved in so many ways. She describes how there was always an 'appeals organiser' who arranged events and who was one of the parents. They were instrumental in organising an annual garden fete, a flag day and various things linked with parent's interests. She reflected that some members of the Association did not want to go on committees, but felt that they would like to be doing something. Some of the mothers suggested starting a Ladies' Guild. She said how

it was another strand of social life as people got together. They met once a month and they did their own fundraising, coffee mornings, Easter bonnet parade and other things as the seasons changed. They made a lot of money, bought the first ambulance. They 'rejigged' the kitchen in the house (made a kitchen where there was not one before) and they had a lot of fun. They had a day out every year and then some of the staff used to stay on so that they could stay out a little bit longer. Guild carried on for many years, until [the association] closed. ${ }^{78}$

These activities may seem mundane, but through such activities bonds were strengthened between people and the association became central to individual lives. The realisation that there were other families with 'spastic' children gave parents an added strength to face up to problems, and work together to confront these. Ron D., a parent, talked of his family involvement with SDSA, saying it turned out to be a 'godsend':

not only because there was somewhere for [their daughter to go] but also somewhere for [them as parents]. It was not a case of simply 'handing over' Jane but they took an active part in [the association] because of the way it was run as a charity and the

78 Joan $\mathrm{O}$. 
parents were involved and were expected to be involved. 79

The resilience of these communities did not go unnoticed as can be illustrated through the first impressions of former staff member, Pat P. when she began work at the Centre in Swansea in 2007. She said:

I was quite taken with everybody. But as I started there ... the realisation of what the organisation meant, the input of the parents, how passionate they were about their children, 'cause they were still children to them. You know and the hard work, looking back on all the photographs and how dedicated they were and, such passion. I haven't seen to be honest, everybody loves their own family and loves their children, but you know most of the parents there dedicated their whole lives in tryin' to keep this centre going. It was-, you know, it was amazing - the feats that they went through to raise money to keep everything just as it was. ${ }^{80}$

It was not just fund-raising activities that bonded families together, practical issues such as making buildings habitable were things parents had to tackle. As autonomous organisations, they did not have the sources of funding that local authorities would have been able to access or the infrastructure to do jobs. For example, the building that became Carlson House School needed extensive renovation and David Barnsley, one of the first children to attend, described it. He said the house had a large garden and stables, and parents got together and set up working parties to convert the house. He said they worked together, as 'parents didn't get grants', so they 'banded together'. In order to give the scale of the size of the house, Barnsley said how there were ' 17 windows along the side'. This was the part of the house which was converted into the physiotherapy department ${ }^{81}$ A series of photographs from November 1947 to summer 1948 reveal building work being undertaken including the entrance ramp being laid; a group clearing the garden and adapting the stables; images of the

79 Ron D., interviewed by Teresa Hillier about the history of Longfields Association, 11 August 2017.

${ }^{80}$ Pat P., interviewed by Teresa Hillier about the history of Longfields Association, 14 August 2018.

81 Peter Millington, An interview with David Barnsley (2014), <http://www.disability.co.uk/blog/2014/01/28/interview-david-barnsley> [accessed 2 November, 2016]. 
Saturday working parties; and a group of children and parents picnicking on the lawn (Appendix 9.4). ${ }^{82}$ These pictures illustrate the sense of community and the lengths to which parents went in their endeavours. Practical problems were tackled through voluntary effort. They also lacked specialist transport for their children and parents worked together to provide this, or enlisted the help of volunteers. David Barnsley remembers how he travelled to Carlson House School in vehicles provided by the 'All Electric Garage' in Harborne. These were 'pre-war Austin taxis', which Barnsley says were a 'dubious vintage', but he describes the journey to and from school as exciting, as the vehicles would break down frequently. He says 'the cars became symbols; we were attached to them and recalled them by their registration plates'. ${ }^{83}$ Being able to overcome such issues is significant as without having solutions to practical matters, parents could not effectively tackle the wider goals of their respective associations. The time and energy invested secured a safe environment and cemented friendships, which was a good foundation for the wider campaign. Whilst philanthropic support and a wide volunteer network helped them to pursue their agenda, they were the architects of their success.

\subsection{National Spastic Society (NSS)}

In order to make progress, on a national scale, an organised and coordinated approach was needed. As discussed, the BCWS did reach out to parents but primarily it engaged with professionals. They had highlighted the fact that there were still a significant number of children who were not being reached. This demonstrated that despite an increasingly enlightened view towards cerebral palsy, it did not automatically lead to inclusion for all. Exclusion from education and lack of support continued to be cited as common frustrations by parents. The early 1950s saw a small group express their concerns, over a lack of progress to include more 'spastics' in schools. This group consisted of parents Alex Moira, Ian Dawson-Shepherd and Eric Hodgson and social worker Jean Garwood. They were the founder members of the National Spastic Society (NSS) and their suggestion, of a fundraising campaign to establish a new specialised

82 Harborne, Cerebral Palsy Midlands, Photographs.

${ }^{83}$ Millington, An interview with David Barnsley. 
school, was frowned upon by the BCWS. Their response is detailed in the book Every Eight Hours (1964), ${ }^{84}$ which records the history of the NSS, compiled by journalist and broadcaster Richard Dimbleby with the assistance of Mary Hobbs. ${ }^{85}$ It said that the BCWS became alarmed when this group 'outlined their plan for raising money by an appeal to the public', as they felt that they 'were the experts', and not the parents, and 'advertising methods were all very well for commerce', but were thought to be 'perhaps rather vulgar ... when it came to charity'. ${ }^{86}$ This hints that a level of elitism had crept into the BCWS which was slightly at odds with their aims and objectives. However, being research focused, with a more professional membership, arguably meant that individuals were one step removed from the realities of day-to-day life, and the impact of cerebral palsy.

The founders of the NSS advocated a dynamic approach, which put parents and the needs of their children at the forefront of a campaign. The diverse backgrounds of this group worked in their favour. Their personalities and skills are recounted; Moira, a trained accountant and architect described as being 'thoughtful [and] intelligent with a quiet strength and determination'; DawsonShepherd had a 'special flair for advertising' and had overcome challenges in life by his 'exhilarating enthusiasm and the incisive forcefulness of his personality'; Hodgson described as a 'determined Yorkshireman' was a local government officer in Croydon who wanted to 'give spastics their rightful place in society'; and Garwood who is described as 'something of a natural rebel [who] saw beyond the official view' and was a strong advocate for the society. This group is described as having the 'power [that was] needed to bring spastics to the notice of society'. ${ }^{87}$ A 'supremely confident' Dawson-Shepherd committed the group to raising one million pounds in five years and they started their campaign via widely distributed leaflets and a letter sent to the Daily Mirror 'Live Letter Box' saying,

a new and powerful society has been formed to press, argue and fight to get better treatment for spastic

\footnotetext{
${ }^{84}$ This book accompanies the film Every Eight Hours (1960) which tells the story of the NSS.

${ }^{85}$ There is no information relating to Mary Hobbs.

${ }^{86}$ Dimbleby, pp.23-24.

${ }^{87}$ Dimbleby, pp.22-23.
} 
sufferers. Would you ask all sufferers or their relatives to write to the National Spastics Society at the above address and start helping the Society? ${ }^{88}$

From the start, the founder members, who would have been engaged with other families at a local level, set themselves apart as an autonomous group. In order to reach their target, the NSS had to cast a wide net to gain support and get the nation talking about 'spastics'. An article from the Daily Mirror, in March 1957, said that the National Spastics Society was not a 'polite charity', it reported that its approach was 'blunt', its methods 'unorthodox' and its progress 'phenomenal'. Within five years, it became one of the 'top six charities in Britain', educating the public about 'spastics'. The article suggests that 'two words' explain its success and these were 'parents and pennies'. Alex Moira, honorary treasurer, said 'a parent [didn't] have to look for an incentive in this. It [was] right there before his eyes every morning - when he [saw] his child'. Honorary chairman, lan DawsonShepherd said:

when we started, we had to face the fact that we were a new charity, breaking into a competitive field. We had no influential friends. The big cheques were not for us. So we went after the pennies. And anyway, people with only a penny to give are much more sympathetic than someone with a fat cheque book. It is easier to raise a million pounds in pennies than in fivers. 89

In employing this attitude, they reached out to families, on a national scale, and used the popular media of the day to do this. This, is in comparison to the BCWS who, arguably, were more reserved in their engagement with the public. However, both groups shared a common purpose even if they had contrasting goals. The inspiration of the BCWS had stemmed from a research principle and whilst research was still integral within the aims and objectives of the NSS, they were more focused, at that time, on promoting an understanding of cerebral palsy in the public domain and giving practical assistance to families.

\footnotetext{
88 'Live Letters' The Daily Mirror, 22 January 1952. NexisUK < https://www.nexis.com/> (p.9).

${ }^{89}$ Tony Miles, 'The Penny Crusade has boomed into a $£ 1,000,000$ charity!' The Daily Mirror, 12 March 1957. NexisUK < https://www.nexis.com/> (p.11).
} 
They employed a simple but effective way to get the public talking through running a series of comic strips, in the Daily Mirror in May 1952, which featured a fictional family, the Ruggles. Journalist Chris Davies said that:

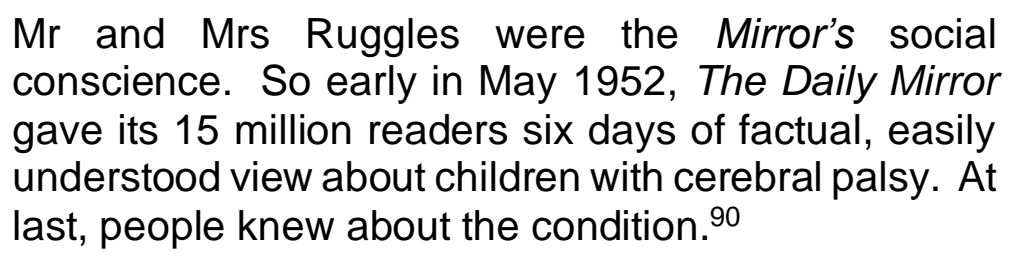

At their first public meeting, it was reported that they had nationwide representation and:

parents from all over the room jumped up with stories of lack of facilities, unsympathetic authorities, downright tragedy. The four members could only sit back and let them have their say. They had wanted a national society - now they were learning the extent of the national problem. ${ }^{91}$

A wider realisation of the number of families who had children with cerebral palsy, and an understanding of their needs, gave the NSS the impetus to be creative in their ways to 'teach the public about spastics, interest the authorities, give advice over setting up local centres, and try to set up more groups throughout the country'. ${ }^{92}$ The NSS Annual Report of 1953 records how over a million leaflets and posters were distributed, and thousands of collecting tins were provided throughout the community. There were nearly three million penny Coronation seals sold with the inscription 'Please help Spastics'. Their monthly newspaper went to thousands of parents, as well as being sent to every Medical Officer, Education Officer and Hospital Almoner in England and Wales. ${ }^{93}$ This direct approach targeted people in ordinary, everyday life situations which was a very different approach to that of the BCWS, that took a much more authoritative stance and cascaded knowledge through a strict hierarchy.

${ }^{90}$ Chris Davies, Changing Society A personal history of Scope 1952-2002 (Chippenham: Scope Creative Services, 2002), p.29.

${ }^{91}$ Dimbleby, p.27.

92 lbid.

${ }^{93}$ National Spastics Society Annual report (1953). 
Davies details the five guidelines that were agreed which were to become the initial aims and objectives of the society:

- To provide and promote facilities for the treatment, training, education and residential care of men, women and children with cerebral palsy.

- To foster understanding of cerebral palsy as a disorder, and to help toward the acceptance of people with cerebral palsy in their homes and by society.

- To provide help and support for disabled people and their families.

- To show how authorities at all levels can and should help people with cerebral palsy.

- To promote research into the causes, treatment and prevention of cerebral palsy. ${ }^{94}$

These objectives have elements of those agreed by the BCWS and MSA. However, there is a distinct focus on promoting the acceptance of cerebral palsy, by wider society, and the society advocated strongly for a united approach from those in authority. It was quickly realised, by the NSS, of the marketing value of their local associations. Without their support, their national campaign would not have been as effective. The 1953 Annual Report recorded that the number of parents in groups had risen from 700 to over 3,000 and the number of parent-led groups had risen from 15 to 60 . Their message was that 'strength [lay] in numbers, nationally as well as locally'. ${ }^{95}$ These statistics demonstrate that the approach taken by the NSS was effective in increasing membership numbers and, more importantly, in identifying the number of people with cerebral palsy.

As an organisation, the NSS had a stronger political agenda, compared to local associations, which focused mainly on their own communities. The high profile of NSS campaigns raised concerns at a local level. Associations such as MSA and SDSA feared that these campaigns could deflect attention from fundraising activities in the local communities, or even suggest that the associations were not autonomous, relying on support of the NSS. The 1955

${ }^{94}$ Davies, pp.20-24.

${ }_{95}$ National Spastics Society Annual report (1953), pp.3-6. 
Annual Report of MSA stated how a meeting had been arranged with the Chairman and Secretary of NSS to 'discuss ways and means of co-operating' with the organisation in the Midlands area. ${ }^{96}$ The 1957 Annual Report focuses on a discussion concerning publicity, with a fear that people in the area were not aware that MSA was a separate organisation from NSS. ${ }^{97}$ Loss of reputation was also a fear of MSA, as they were pioneers in what they had achieved. As a national organisation, the strength of the NSS lay in motivating parents to become active, raising funds and supporting a wider campaign, led by them. A discussion, held in December 1957, between representatives for the NSS, including lan Dawson-Shepherd, Dr. Stevens (Director of Medical Research Committee) and Dr. Wheeler (Chairman of the BCWS Executive Committee) considered a point of particular interest to this thesis. The role of parents was discussed and Wheeler referred to his personal opinion on the importance that the NSS 'attach[ed] to the role in its constitution which parents of spastics [were expected to] play'. He felt that the NSS should look upon that matter as a 'pioneering phase' which he said, had passed and he thought the NSS 'should learn gracefully to accept this fact'. Wheeler argued that as both organisations had done so much:

to make the nation aware of the problems and also to do something about them that it can be no longer be the case that just because someone is a parent of a spastic child, he or she can necessarily make a greater contribution now to the wellbeing of spastics.

To Wheeler's surprise, representatives from the NSS agreed with him and a lack of parents with 'sufficient knowledge and ability to handle the affairs of the NSS' was viewed as a problem. He suggested that they 'did, in fact, need what might have be[en] called outside help'. ${ }^{98}$ The NSS had built the aims and objectives of their association around the role of parents, and their active involvement had contributed to the rapid growth of the organisation. At the time

\footnotetext{
96 Harborne Cerebral Palsy Midlands, Minutes of Midland Spastic Association, Annual General Meeting 17 January 1955.

${ }^{97}$ Harborne Cerebral Palsy Midlands, Minutes of Midland Spastic Association, Annual General Meeting 25 October 1957.

98 Harborne Cerebral Palsy Midlands, Record of a discussion over lunch on Tuesday, 18 December 1957.
} 
of the discussion the NSS was receiving about ' $£ 2-£ 3,000$ a day on their Christmas seals programme' but this was a 'diminishing return' due to others adopting a similar scheme. ${ }^{99}$ However, this not insignificant amount of money demonstrates their fundraising success but, in reality, parents were more focused on local issues. For the size and structure of the NSS, employing 'outside help' was not an unreasonable position to adopt, but they needed to hold on to the support of parents as without their input, then arguably the organisation would not be as prominent, or as financially well off. To a certain extent, the NSS was beginning to adopt some of the characteristics of the BCWS, as they became more involved in research. The 'enormous field of research still to be tackled' was discussed and was thought to be an area where the two organisations could work together. ${ }^{100}$ It was the means of approaching this that set the two organisations apart. They did eventually merge in the early 1960 s and became one organisation, The Spastics Society.

\subsection{Conclusion}

This chapter has shown how the Beveridge report, and subsequent postwar reform, were catalysts which revealed inequalities in the provision of services for children with cerebral palsy. The focus on academic achievement, in order to create a better educated workforce, meant that employment was a driver for the 1944 Education Act. This chapter has discussed how such an expectation failed to adequately address the needs of those with cerebral palsy. The influence of the medical model of disability in decision making, and subsequent categorisation of many children with cerebral palsy as 'ineducable', often left parents feeling as if they did not have the skills, or knowledge, to question these decisions. However, it has been shown that a lack of research into the condition, and limited understanding, meant that there was an ambiguity surrounding it, which led to confusing diagnoses. In addition, the preoccupation with rehabilitation of the body, in post-war Britain, meant that children with cerebral palsy were judged by their physical impairment first, and their cognitive ability was largely ignored.

99 Ibid.

100 lbid. 
A growing realisation of the scale of the problem led to the formation of the BCWS, which engaged with pioneering research emerging from America and Australia. They facilitated the development of transnational networks, which proved advantageous in developing a changing approach towards the treatment of cerebral palsy. This chapter has discussed how a multi-disciplinary approach, through the application of therapy treatments, such as speech therapy or physiotherapy, in conjunction with education, improved individual wellbeing and facilitated learning. As an organisation, the BCWS forged links with professionals from varied medical disciplines, educationalists, voluntary organisations and government departments and so created a climate which promoted a new way of working. Despite these developments, this chapter has highlighted how the postwar economy, together with a lack of suitably trained staff with a knowledge of cerebral palsy, meant that change was slow to happen, and so children with the condition continued to be failed by the system.

The chapter has discussed how the BCWS had a greater focus on research, which meant that the practicalities of day-to-day living with cerebral palsy, were not fully addressed by the organisation. This frustrated parents who needed more immediate help. A combination of circumstances proved conducive for the development of parent-led 'spastic' associations; the categorisation 'ineducable' was the catalyst for change; the emergence of new research demonstrated that children could learn and achieve physical improvement; the BCWS had facilitated a network for these changes to occur. The development of the National Health Service, within the welfare state, provided for an individual's health needs and, as discussed in this chapter, this created opportunities for voluntary groups to specialise in the support they offered to their members and to develop new approaches.

The establishment of parent-led 'spastic' associations and their rapid increase in number meant that they could begin to educate the public and wider society about cerebral palsy, and the injustices experienced by their children. The formation of the NSS created a driving force behind the campaign to raise awareness and, as a national body, it quickly realised the value of affiliating with local groups. In addition to having a greater impact on public awareness, being 
able to campaign on a national scale was of significant financial benefit. The NSS had a political agenda, and challenged authority about their inconsistent approaches towards children with cerebral palsy and the inadequate guidelines from central government for the implementation of devolved power. At a local and national level, parent power sought to confront society's prejudices, attitudes were questioned and the need to consider the individuality of children with cerebral palsy was highlighted. Historical beliefs, ingrained in society may take many years, if not centuries, to change, yet parents directly confronted issues around the negative attitudes taken towards many children with cerebral palsy.

This chapter demonstrates how parent groups created support networks for families, as part of their local community, and were able to obtain financial support to continue their work. As Stanley Segal maintained, the failure to include 'ineducable children' in the new post-war climate gave desperate parents new energy and organisations such as the National Association of Parents of Backward Children (Mencap 1946) and NSS (Scope 1952) 'erupted into the light, giving inspiration and emotional release to thousands of unfortunate parents throughout the country'.101 From this basis parent-led groups challenged outdated and narrow perceptions.

${ }^{101}$ Stanley S. Segal No Child is Ineducable (Oxford: Pergamon Press Ltd., 1974), p.5. 


\section{Providing education for children with cerebral palsy: the impact of transnational influences furthers the understanding of individual capabilities}

Providing educational opportunities for children with cerebral palsy was a challenge in post-war Britain. Despite the intense campaign of parent-led 'spastic' associations, progress towards the inclusion of these children in state education was either disjointed or non-existent and this chapter examines why this was so. Reform, although well intentioned, had reinforced social inequalities, reproducing them in the new education system. The words of Bill Hall, born in South Lanarkshire in 1936, reflect this, as he declared that education was a 'dream machine, as far as [he] was concerned' a 'flat tyre'. He spoke of how he 'was led to believe that [he] would get a job in the cinema, or [as] a cobbler, not being aware you still needed education to do that'. ${ }^{1}$ The concept of a meaningful education, linked to the goal of employment, was not one that was attributed to many children with cerebral palsy. During the initial phases of parent-led campaigning, they had focused on securing a provision for education and did not campaign specifically under an employment banner. Initially, parents were dealing with multiple issues, of which securing an education was the most pressing. The problem of employment was to become more apparent as children with cerebral palsy reached adulthood. Having achieved the goal of education, parents took a step back to consider other issues which included a longer-term outlook, and the future direction of the associations they had created.

Without the goal of employment seen as the driver behind educational reform, the very purpose of education was brought into question. The largely negative attitude that had been displayed towards children with cerebral palsy, in terms of their future aspirations, led to often conflicting views between professionals and parents. Discriminatory attitudes had effectively badged many disabled children as 'non-achievers', and opportunity to prove otherwise was

\footnotetext{
1 Interview with Bill Hall by Philip Mann, 25 January 2005, 11 April 2005, 5 May 2005, Speaking for Ourselves: An Oral History of People with Cerebral Palsy, reference C1134/11/01-05, British Library.
} 
limited. Maureen Oswin, ${ }^{2}$ who had worked at the cerebral palsy unit at Queen Mary's hospital in Carshalton, undertook a study of various 'institutions' during the 1960s and 1970s. She observed the everyday lives of children who were housed there, and the conditions in which they were kept. Her subsequent publications $^{3}$ attracted widespread publicity, as she spoke out on behalf of children and the deprivations they suffered. Disability advocacy for these children was virtually non-existent, as a lack of medical knowledge and misunderstanding of their impairments had effectively condemned them. It was too easy for doctors to dismiss children's prospects and the medical model continued to hold sway over cerebral palsy.

The multi-disciplinary approach towards education, was advocated through the emergence of new research, promoted through transnational links. The direct impact of these links on the provision of services, for children with cerebral palsy is examined in this chapter. The argument that parent-led 'spastic' associations had more freedom to offer alternative approaches and incorporate new research, is considered, as they were not restricted by aspects of bureaucratic legislation which affected state-run organisations. This is evident through the achievements of Midland Spastic Association (MSA) and their school, Carlson House. A case study of this school is presented and demonstrates how it was influential in driving forward change, at a local and a national level. The practicalities of implementing a new approach are considered in the chapter, together with the issues of economic constraints and with a lack of suitably qualified staff, which presented problems to both voluntary and state-run services.

This chapter also argues that parent-led schools effectively segregated their pupils from wider society and this impacted on the future prospects of pupils. Therefore, to some extent, segregation compromised the core aims and

\footnotetext{
2 Terry Philpot, 'Maureen Oswin: Singlehandedly, she exposed the scandal of children's hospitals', Guardian, 1 August, 2001. <https://www.theguardian.com/news/2001/aug/01/guardianobituaries1> [accessed 1 May 2019].

${ }^{3}$ One of her most significant publications was: Maureen Oswin, The Empty Hours: a Study of the Week-End Life of Handicapped Children in Institutions. (London: Allen Lane, 1971).
} 
objectives of parent-led 'spastic' associations as their children remained isolated from wider society, not viewed as full citizens.

\subsection{The challenges}

Education for children with cerebral palsy did not conform to society's norms in the same way as that provided by mainstream schools. This thesis has shown that the need to adopt a different approach had been raised by a number of individuals, particularly those connected to the BCWS which led to matters being raised in parliamentary debates on 'spastic' children and education. ${ }^{4}$ Recruiting local Members and Councillors to become members of association committees or governing bodies, ${ }^{5}$ added to their lobbying power. While the involvement of prominent individuals raised the profile of associations, it did not address the many challenges that remained difficult to overcome. In order to fully participate in education, the physical limitations of cerebral palsy posed a barrier for some, and the need of practical support, to aid participation, was limited.

The following narrative of Valerie Lang illustrates this. Valerie was born in Cheshire in 1939, and recalled her time at St Margaret's School, the first residential school, dedicated to the education and treatment of children with cerebral palsy. Valerie attended this school from the age of about seven. She

\footnotetext{
${ }^{4}$ House of Commons, Hansard's Parliamentary Debates: Education (5 July 1949, vol 466, col 2057-2062) [Online] $<$ https://api.parliament.uk/historic-hansard/commons/1949/jul/05/education> [accessed 24 October 2016].

House of Commons, Hansard's Parliamentary Debates: Spastic Children

(28 June 1954 vol 529 col1061-72) [Online]

<https://api.parliament.uk/historic-hansard/commons/1954/jun/28/spastic-children> [accessed 24 October 2016].

House of Commons, Hansard's Parliamentary Debates: Spastic Children (Education)

(14 February 1955 vol 537, col132-58) [Online] <https://api.parliament.uk/historic-hansard/commons/1955/feb/14/spastic-children-education> [accessed 24 October 2016].

House of Commons, Hansard's Parliamentary Debates: Spastic Children, Wales

(31 March 1955 vol 539 col48) [Online]

<https://api.parliament.uk/historic-hansard/commons/1955/mar/31/spastic-children-wales> [accessed 24 October 2016].

5 For example, SDSA had local M.P. and Mayor of Council as representatives of the association and they spoke on association's behalf in council meetings.
} 
spoke of her fellow pupil Glynn Vernon ${ }^{6}$ and said:

I remember Glynn Vernon saying how awful St Margaret's was, and poor Glynn, he must have been bored out of his mind because children at the weekend, or sunny days, were wheeled out and put in the garden in a row, but they just sat there for long periods, because there really were not enough staff to entertain, or give us all activities. Because I could walk, I used to go off on my own and do things, but even for me, my chief memory of St Margaret's is of being bored, and the children who couldn't walk must have frightful memories of that school. I think they were on the edge of knowledge. They were doing their best, and they made some terrible mistakes, but I think they really were trying their best. I don't think they had enough staff, but economics were different, and the ideas of what is acceptable have changed over my lifetime, out of all recognition. ${ }^{7}$

St Margaret's School, was established in 1946, when land and buildings for the development of a school was made available by the Garwood family, who 'owned several large houses in the Croydon area'. The family is that of Jean Garwood, who became one of the founder members of the NSS, as discussed in the previous chapter. The house had previously been used for war wounded soldiers and was let at a 'nominal rent'. ${ }^{8}$ It is assumed that it was run by staff connected to the Cerebral Palsy Unit at St Mary's Hospital in Carshalton, but it has not been possible to substantiate this. As one of the first schools there was a high demand for places and the extract by Valerie, gives an insight into the difficulties arising from providing the level of practical support needed in order for children to fully participate. As St. Margaret's was a residential school, a support network of parents, as volunteers, was not available to provide support. Therefore, a shortage of suitably trained staff would have been keenly felt. Judy

\footnotetext{
${ }^{6}$ Glynn Vernon was a disability campaigner. His obituary: <https://www.theguardian.com/society/2003/jan/07/disability.guardianobituaries> [accessed 16 December 2016].

7 Interview with Valerie Lang by Philip Mann, 10 February 2005, 17 February 2005, 22 February 2005, 2 March 2005, 11 March 2005, 17 March 2005, 22 March 2005, 18 April 2005, 29 April 2005, 4 May 2005, 8 June 2005, 15 June 2005, 22 June 2005, 1 July 2005, 22 July 2005, Speaking for Ourselves: An Oral History of People with Cerebral Palsy, reference C1134/10/0125, British Library.

${ }^{8}$ Richard Dimbleby, Every Eight Hours (London: Hodder \& Stoughton, 1964), p.18.
} 
Smart, who attended St. Margaret's, recalled how treatments were disruptive to her education as 'they didn't always link together'. There were three treatment sessions a day and after one session, she said, how you would 'have to go back to the classroom and come out again at a later time'. ${ }^{9}$

In his book, Education and the Handicapped 1760 - 1960, D. G. Pritchard commented on the 'generous staff-pupil ratio', needed 'because of the difficulties involved in educating cerebral palsied pupils' and therefore financial costs were high. He referred to 'the work of voluntary bodies' and the 'foundation of schools solely for children suffering from cerebral palsy'. ${ }^{10}$ For government departments, justifying the cost of such an investment proved problematic. This was due, in part, to the influence of the medical model of disability, as the value of using up precious resources on those who had been deemed to be 'ineducable' was questionable, particularly with employment as the driver for educational reform. Economic sustainability was then, as it is now, a key factor in the development of services. Local education authorities lacked the expertise that was being developed by parent-led 'spastic' associations, through a growing network. As Sue Wheatcroft argues, the 'education of children with cerebral palsy', particularly in the years immediately following the 1944 Education Act, meant that local education authorities 'relied very much on the co-operation and resources of voluntary societies'. ${ }^{11}$ The previous chapter highlighted the lack of clarity over the number of children with cerebral palsy. This, coupled with a further lack of statistical evidence to support an estimate of the true costs of educating these children, makes it understandable why local authorities would have initially approached these issues with caution.

Economic issues highlighted in the Chief Medical Officer's Report (1946/47), on the Health of the School Child, stated that the 'staffing of special schools' for children with cerebral palsy, would have to 'be on a scale which for

\footnotetext{
9 Interview with Judy Smart by Alex White, 18 November 2004, 16 December 2004, 13 January 2005, 2 January 2005, Speaking for Ourselves: An Oral History of People with Cerebral Palsy, reference C1134/05/01-12, British Library.

${ }^{10}$ D.G. Pritchard, Education and the Handicapped 1760 - 1960 (London: Routledge \& Kegan Paul, 1963), p.219.

${ }^{11}$ Sue Wheatcroft, Worth Saving, Disabled children during the Second World War (Manchester: Manchester University Press, 2013), p.157.
} 
other types of school would be considered more than generous'. The staffing model suggested by Dr. Winthrop Phelps, highlighted in the report, was envisaged as not being acceptable 'by everyone in the country' due to the financial cost even if there was a 'substantial reduction' to the figures. It concluded that such expense went to 'show that the care and education of cerebral palsied children [was] a costly business'. ${ }^{12}$ Comparison of economic costs with different 'types of schools' are reasonable in this report, as obviously, a school which needed more resource to meet pupil needs would be relatively more expensive. However, economic concerns masked the underlying misgivings about the value of education, for children with cerebral palsy. The report stated that, 'when dealing with human suffering one cannot express profit and loss in terms of pounds, shillings and pence' but said there was 'an economic side to the picture'. It advocated more research by which it would become apparent, 'what [was] the most profitable way to use energy and money'. ${ }^{13}$ Adopting this official approach was of little use to parents and insulting to those children caught up in the bureaucracy. Parents had wanted practical and financial support from the Ministry of Education, and its lack was precisely why they had taken up their campaign. The educational needs of their children were not being given due consideration, and were overshadowed not only by economic costs, but also the issue of 'what sort of future' these children could anticipate, even with investment.

At the BCWS conference in 1948, financial matters were raised by Professor Alan Moncrieff, as he referred to the 'magnitude of the facilities required', in order to provide support to children with cerebral palsy. Moncrieff said that it would likely cost 'a great deal more to educate a spastic than an ordinary child, but nevertheless [was] an obligation [of] which [could not be] escape[d]. ${ }^{14}$ The BCWS would have been more enlightened in their understanding of what these children needed. In raising this issue, Moncrieff

\footnotetext{
${ }^{12}$ Ministry of Education, The Health of the School Child: Report of the Chief Medical Officer of the Ministry of Education for the Years 1946 and 1947 (London: His Majesty's Stationery Office, 1949), p.99.

${ }^{13}$ Ministry of Education, The Health of the School Child: 1946 and 1947, p.99.

${ }^{14}$ Harborne, Cerebral Palsy Midlands, The Medical, Educational \& Social Aspects of The Cerebral Palsy Problem, British Council for the Welfare of Spastics first annual report, April 1948, (p.22).
} 
reinforced the need to plan for the future and develop services, giving due consideration to pioneering research and economic costs. Gaining unequivocal support was not a straightforward matter. In order to make progress, economic issues had to be confronted, and this required a level of negotiation. This raises the question of whether children with cerebral palsy had become a commodity. They were measured against their peers in mainstream education, and the financial costs weighed up against possible future economic returns. However, it can also be said that these children were the commodity of parent-led 'spastic' associations, as their images were used to endorse their 'problems' in order to gain financial support. Achieving a way forward, acceptable to all, did not appear to be an easy option and this fuelled the drive of associations. Exemplified in the 1953 Annual Report of the NSS, it stated that one of their aims was to 'raise money to help set up treatment, schooling and social centres more quickly than if the job were left entirely to Local Authorities'. ${ }^{15}$

These economic concerns demonstrate the inequity created by the 1944 Education Act, as children with cerebral palsy were singled out as 'special cases'. The emphasis on 'improving prospects' for employment was driving the agenda for government led organisations, but a set curriculum would have been too restricting and not appropriate for many children with cerebral palsy. The fact that they were categorised under the health authority meant that balancing the connotations of 'care over education' was difficult, particularly with regard to education. The physical impairments of cerebral palsy were masking the true capabilities of individuals, and a distinction between the 'mind' and the 'body' needed to be made in the development of education services. Education is not simply about passing exams or tests. Focusing only on academic achievement, excluded exploring and discovery in areas which may have been of more interest and possibly of longer-term benefit to some children.

For children with cerebral palsy, who had been isolated by their disability, interaction with their peers was limited. Dan Goodley reinforces the argument that education is not just concerned with learning, but for children to 'learn to

\footnotetext{
${ }^{15}$ National Spastics Society Annual report (1953), p.6.
} 
become social citizens through their dealings with the educational system'. ${ }^{16}$ However, if the wider focus remained solely on employment, as the driver for education, then the very purpose of education is brought into question. Isolating children at home or through being institutionalised had segregated them from wider society. Being hidden away can be said to have influenced how others saw such individuals as 'social outcasts' with nothing useful to contribute to society. Also, as the following experiences of Bob Williams-Findlay and Sheila M. demonstrate, limited social interaction impacted on individual life experiences.

Bob Williams-Findlay, born in Buckinghamshire in 1951, recalled his first experience of school:

after I went to school - I realised there were other children like me and that there was a difference between non-disabled people and disabled people. Up to that point it hadn't really dawned on me, I don't think. ${ }^{17}$

Sheila M., born in mid Wales in 1957, recalled when she went to school:

to be honest, when I went to school, it didn't dawn on me that I couldn't walk, 'cause I didn't know. . . and when I went to my school, I thought 'Oh God' I must be like that. It didn't dawn on me that... I knew I couldn't walk and I couldn't do but it wasn't until I went to school that I thought, well I must be like them, because my mum and dad didn't talk about it. ${ }^{18}$

If Bob and Sheila had continued to live their lives in isolation then, arguably, they would have become more of a 'burden' to society, rather than being able to achieve a level of independence. All children need time and support to develop their experience in an educational setting. The isolation of children with cerebral palsy intensified the lack of expertise of many professionals, at this time, in their

\footnotetext{
${ }^{16}$ Dan Goodley, Disability Studies An Interdisciplinary introduction (London: SAGE Publications Ltd., 2017), p.170.

17 Interview with Bob Williams-Findlay by Anne Austin, 25 September 2009, 20 November 2005, 5 February 2006, 25 February 2006, 14 May 2006, Speaking for Ourselves: An Oral History of People with Cerebral Palsy, reference C1134/15/01-08, British Library.

${ }^{18}$ Sheila M., interviewed by Teresa Hillier about the history of Longfields Association, 16 August 2017.
} 
dealings with these children. The 'educators' needed to be educated and the haphazard approach experienced by many individuals and their families emphasised the lack of expertise. The isolation from peers did not simply affect children with cerebral palsy but was something that was also experienced by siblings. Cedric Q., son of one of the founder members of MSA, recalled his brother Alasdair:

My elder brother Alasdair who couldn't walk; severely disabled, but that didn't seem unusual because that's how it was. And children accept these things so it was, sort of, for me, normal life. I couldn't play with my brother, because he couldn't do things like that. So I missed playing with other children and there weren't many around. ${ }^{19}$

The parent-led campaign for educational rights incorporated a range of issues, which included combating isolation and challenging stereotypes, as well as considering the possibility that some 'spastic' children were academic. The following examples represent early educational experiences of individuals born between 1937 and 1957. These recollections represent a range of attitudes and inconsistent approaches experienced by individuals, and their families, as they tried to participate in education. Alan Counsell, was initially not accepted in his local school but was kept home, which prompted a visit by a School Inspector. The school was then forced to take him and he remained there for about two years until the Headmistress suggested that he 'went to a school for retarded children, because [her] mainstream school couldn't cope with [him]'. ${ }^{20}$ Alan recalled how angry his family were and he didn't go to school for eighteen months. Following a tribunal and testing, he had a certificate to say that he had been found to be of 'above average intelligence, and of sane mind'. Despite this the Headmistress at this school remained unsupportive.

Valerie Lang recalled her mother's attempts to get her into a local school,

\footnotetext{
19 Interview with Cedric Q., 21 May, 2014 as part of a Heritage Fund Project, Fulfilment through Achievement, Harborne, Cerebral Palsy Midlands.

20 Interview with Alan Counsell by Dean Thomas, 26 January 2005, 16 February 2005, 23 February 2005, 30 March 2005, Speaking for Ourselves: An Oral History of People with Cerebral Palsy, reference C1134/08/01-08, British Library.
} 
as her 'brain was the only bit that was working properly'. Her mother was 'determined that [Valerie] would get a decent education'. Valerie described how her mother went to the local primary school near Manchester with Valerie in her arms. When she got there the door was shut in her face and her mother said that this 'memory really seared her badly'. ${ }^{21}$

Barry Morgan, born in the Midlands in 1945, recalled how his father made him 'sit, and showed [him] how to write, and read, and various other things'. When Barry was of school age his father said, he was 'not going to have [his] son put away in an institution'. Barry said that he was 'very lucky' as his father 'found a headmaster that was prepared to give [him] the opportunity of going to a normal school'. ${ }^{22}$

John Hawkridge went to a boarding school for 'spastics' run by Leeds Education Authority. He described how it was a 'new experiment', and the local authority 'took 20 children with cerebral palsy that they thought they could develop'. John said how 'everything you had was supposed to be shared', and there was 'no such thing as personal possessions'. He did not think much of this and said for a small child, away from home, 'you need to have some personal possessions for your own emotional security'. John did not think that he got a 'normal education' at the school although subjects included maths, English, history and geography. He said that whilst they got a 'good basic education' there were a few who could 'probably have moved forward a lot quicker' as they had to work 'at the rate what the majority of the slower ones [were] moving at'. ${ }^{23}$

Sheila Middleton went to a local authority school in Penarth, aged six. Her parents did not tell her that she was going to board at the school. She said how there was 'one thing that always stuck, in [her] mind'. The Headmaster always

\footnotetext{
21 Interview with Valerie Lang.

22 Interview with Barry Morgan by Anne Austin, 24 January 2005, 7 February 2005, 21 March 2005, 18 April 2004, 9 May 2005, Speaking for Ourselves: An Oral History of People with Cerebral Palsy, reference C1134/07/01-08, British Library.

${ }^{23}$ Interview with John Hawkridge by Richard Smith, 15 February 2005, 1 March 2005, 21 March 2005, 16 May 2005, 9 June 2005, 27 June 2005, 27 July 2005, 30 August 2005, 6 September 2005, 4 April 2005, Speaking for Ourselves: An Oral History of People with Cerebral Palsy, reference C1134/20/01-15, British Library.
} 
used to say 'ah, you've got to be tidy because you're disabled, people stare at you'.24

These examples illustrate an enduring level of inconsistency and misunderstanding which raise questions about the purpose of education. Could some children with cerebral palsy be educated and integrated into society through employment? Was 'education' being delivered just in order for them to maintain a level of independence? Progress in the modern, post-war welfare state was not straightforward, and these recollections show that services for children with cerebral palsy were frequently delivered in an 'ad hoc' way. This was the challenge that families faced. Whilst it was acknowledged that many disabled children needed to experience learning in a less conventional way, the historic focus on having a medical diagnosis impeded progress.

A paper written on cerebral palsy (1946), by E. Stanley Evans, the Medical Superintendent at Queen Mary's Hospital in Carshalton, illustrates an attitude typical of the time. Evans detailed his observations on how teachers in the orthopaedic hospital school, viewed children with cerebral palsy. He said that they saw them as an 'encumbrance', and were thought of as being 'mentally retarded'. He described how they were 'kept in a corner of the ward and given walking exercises' and treatments. Results were varied, but a 'poor result was generally attributed to the lack of co-operation on the part of the mentally retarded patient'. ${ }^{25}$ Blame was laid firmly with the child with little consideration given to wider influences. In highlighting the attitudes employed by teachers, Evans demonstrated the dominance of the medical model of disability and the ignorance of teachers through a lack of training. It was following the appointment of Eirene Collis that a program of treatment and training was implemented. Evans outlined certain features of this training which 'applied the principles enunciated by Winthrop Phelps'. At the time of Evans' report, the results had not been fully analysed. However, his general conclusion was that the results 'far exceeded his

\footnotetext{
${ }^{24}$ Sheila M., interview $16^{\text {th }}$ August 2017.

${ }^{25}$ Harborne, Cerebral Palsy Midlands, E. Stanley Evans, F.R.C.S., 'Cerebral Palsy', [Reprinted from Proceedings of the Royal Society of Medicine, April 1946, Vol. XXXIX, No.6, pp.317-320 (Section of Orthopaedics, pp. 15-18)].
} 
expectations and [were] better than [he] personally could have obtained by orthodox methods' ${ }^{26}$

For teachers working in a medical setting, their perception of pupils' abilities would have been influenced by the diagnosis and treatments administered by medical staff. However, teachers working within a more traditional educational setting could also have been influenced in this way, if they came into contact with medical professionals, in relation to some of their disabled pupils. A fine balance had to be achieved to give health professionals time to deliver their sessions, but due consideration was also needed for the demands of teachers. It continued to be the medical diagnosis and definition which determined the fate of the child, and proved critical to their future. As Robert Drake argues, 'it is in the crucial decision about which child is educated where that we may observe the pivotal role of the medical profession'. ${ }^{27}$ The outwardly physical aspects of cerebral palsy determined whether a child was 'educable' or not, and was led by medical diagnoses and this placed cerebral palsy, firmly under the heading of a medical banner.

The expansion of medical disciplines to include psychology, as a tool in defining disability, was a significant development for children with cerebral palsy. Goodley discusses how the 1950s were the 'halcyon days for special educators and psychologists', with the 'emergence of a psycho-medical view of the disabled child'. ${ }^{28}$ Educational psychologists did not suddenly become experts in the condition but, through the work of people like Eleanor Schonell, expertise in testing began to be disseminated. The limited experience of professionals, interacting with children with cerebral palsy, meant that during an assessment process there was an increased chance of a poor result, misinterpreting the ability of the child. Stanley Segal discusses the complexities of diagnosing a 'spastic child', with the 'majority regarded as being mentally deficient'. He gives an example of a child with athetoid cerebral palsy and said that 'an athetoid with

\footnotetext{
${ }^{26}$ Harborne, Cerebral Palsy Midlands, E. Stanley Evans, F.R.C.S., 'Cerebral Palsy'.

${ }^{27}$ Robert F. Drake, Understanding Disability Policies (Basingstoke: Macmillan Press Ltd., 1999), p.49.

${ }^{28}$ Goodley, p.171.
} 
jerky, involuntary movements of the body and who was also deaf was frequently regarded as an imbecile'. ${ }^{29}$ IQ tests used as a 'scientific' measure of intelligence were not appropriate for children with cerebral palsy when used without due consideration being given to individual needs. It was essential to give children time to complete tasks and to ensure the tasks were appropriate, otherwise children were summarily denounced as 'ineducable'.

The Ministry of Education, Pamphlet No. 5 Special Educational Treatment (1946), intended to 'afford some help and guidance to teachers who [found] handicapped children in the schools in which they work[ed]'. ${ }^{30}$ However, this pamphlet demonstrates that the Ministry of Education did not address the needs of children with cerebral palsy, and they sat outside the mainstream structure and special education. The range of categories listed in the 1945 Handicapped Pupils and School Health Regulations define those children who need 'special educational treatment'. The complexities of cerebral palsy have been discussed in this thesis and, as a condition, it did not easily align within the 1945 categories. However, some of the symptoms listed could be assigned to many of the symptoms of cerebral palsy. It is easy now to be critical of this publication, but it was published at a time when dissemination of new research, relating to cerebral palsy, was in its infancy. 'Ineducable' children are referred to in the 'educationally sub-normal' category which states that if these children were to be 'retained either in special schools or ordinary schools' then 'not only [would it be] impossible to teach them' but also they would 'take up an undue share of their teachers' time and energy'. ${ }^{31}$ This statement again reflects a lack of understanding and teachers, with a lack of expertise and insufficient resources to do their job effectively, would likely have experienced difficulty. However, this may be said to be true in teaching all children and not just those with disabilities. Children with cerebral palsy were singled out as being different from other disabled children, as were children with cognitive impairments which included learning disabilities. However, opinions expressed did not stop at cognitive ability, and in a most

\footnotetext{
${ }^{29}$ Stanley S. Segal, No Child is Ineducable (Oxford: Pergamon Press Ltd., 1974), p.246.

${ }^{30}$ Ministry of Education, Pamphlet No. 5: Special Educational Treatment, (London: His Majesty's Stationery Office, 1946), p.5.

${ }^{31}$ Ibid., p.19.
} 
personal way the pamphlet continued, 'children with so low a degree of ability', were said to 'often have undesirable social and personal characteristics' including their appearance. It said that 'it [was] not fair either to the other children or to their parents to make them associate with ineducable children'.32 From a modern perspective, it is difficult to comprehend the advice given in this pamphlet but ignorance of a condition gave way to ungrounded fears.

Difficulties arising from insufficient resources to support both teacher and pupil, laid the blame firmly with the child and the so-called admittance into school, 'on sentimental grounds', was a practice to be immediately 'ceased'. The pamphlet said that:

one detrimental or low-grade child [could] create havoc in a class, distract the children, occupy the full attention of the teacher, and bring the school into disrepute amongst the parents and the public. [This was] too great a price to pay for kind-hearted acquiescence [and] continued attendance. ${ }^{33}$

The solution offered, was to refer 'ineducable' children to the 'local mental deficiency authority' so that the individual could be dealt with under the 'Mental Deficiency Acts'. ${ }^{34}$ This would have effectively kept such 'undesirables' out of sight. Laura Middleton reflects on this view, where both disabled and nondisabled children could, 'suffer from being educated together'. She maintains that 'such arguments focus on the disabled child as the locus of difficulty'. It is they who were:

deemed to be unable to cope, to be subject to undue bullying, to require an unfair amount of teacher time, or to be disruptive, or conversely to succeed better if educated in specialist facilities ${ }^{35}$

It is not surprising, that in such circumstances relationships between medical

$32 \mathrm{lbid}$.

${ }^{33}$ Ibid., p.20.

${ }^{34} \mathrm{lbid}$.

${ }^{35}$ Laura Middleton, Disabled Children: Challenging Social Exclusion (Oxford: Blackwell Science Ltd., 1999), p.43. 
professionals, educators and families could be confrontational. Whilst it is understandable that some parents had difficulties in coming to terms with the negative labelling of their child, the lack of effective communication between professionals and family, simply made the dynamics of a 'triangular' relationship more problematic.

At an Oxford seminar, conducted by the Spastics Society in 1966, on The Spastic School Child and the Outside World, K. Wedell, an educational psychologist, discussed the often-fraught relationship between family, the psychologist and those responsible for 'diagnosing and treating children'. She commented on the parent's 'interpretation of diagnosis', arguing that a parent's first thought was one of 'no hope for their child', then the possible feelings of guilt that they may have been responsible for the child's condition. This, Wedell said, frequently turned the parents against the person providing the diagnosis, and 'sets them against accepting the findings'. Wedell said that it was not just the parents who had difficulties about cognitive impairment, as 'decisions about the educability of a child [were] seldom clearcut'. She reflected how a 'physically handicapped' child had probably seen a number of specialists in their early years, 'each concerned with one or other aspect of [the child's] condition'. When parents ask about intellectual development, Wedell argued that a specialist, because of the 'limitations of his competence', tended to reassure parents that the 'child would grow out of [their] difficulties' or tell them to 'wait and see'. These doubts, Wedell said, were frequently accepted by parents as they were 'only too glad to accept [a] lack of information as reassurance' ${ }^{36}$ This view by Wedell provides a patronising image of most parents. Whilst her comments are valid, at no point does she give parents the credit of being able to understand their child's condition.

\subsection{Development of a transnational network}

The lack of clarity, support and resources had significant impacts as

\footnotetext{
${ }^{36}$ K. Wedell, 'Intelligence and Educability: The Communication of Prognostic and Diagnostic Information to Parents' in The Spastic School Child and the Outside World, ed. by James Loring and Anita Mason (Oxford: William Heinemann Ltd., 1966), pp. 67-73 (p.68).
} 
evidenced in this thesis, but the challenges of obtaining an education were not insurmountable for a significant number of individuals. Progress was made when professionals began to consider the wider picture and the development of a transnational network began to impact on the delivery of services. The emergence of new research and therapy treatment programs, as advocated by pioneering doctors Phelps, Macnamara and Carlson, has been highlighted in the previous chapter. In order to consider the significance of the transnational network, on the provision of services for children with cerebral palsy, it is essential to examine the study tours and research trips made by pertinent individuals. These were undertaken with the purpose of observing people, such as Phelps and Macnamara, at work enabling first-hand examination of their methods and expertise. Individual study tours discussed in this chapter include those of educational psychologist, Marjorie I Dunsdon, Director of Research, National Foundation for Educational Research (NFER) in England and Wales; physiotherapist Eirene Collis; and educational psychologist, Dr Eleanor Schonell.

Dunsdon was supported by the Ministries of Health and Education, in a three-month research trip to America, in 1946. She observed Winthrop Phelps at work looking specifically at education, 'to observe the types and methods of education particularly adapted for children' with cerebral palsy. Her subsequent report was to inform a debate 'to determine the place of special institutional treatment in a wider plan of education' for children with the condition, aiming to 'approximate their educational treatment as closely as possible to that of normal children'. Her report is very detailed and contains information on staffing and domestic arrangements; the types of equipment used or needed; the provision of therapy; and educational aspects. The schools, centres and institutions she visited varied in size and type of location, from urban to rural. The nature of her observations meant that it was inevitable that a 'proportion of the time was spent observing the work of therapists'. Dunsdon therefore had a view of the holistic approach that was being taken. She also attended the Conference of the International Council for Exceptional Children, which gave her 'personal contacts with specialists in various fields of special education' and so was able to add to her expertise through discussion, and arranged visits to other educational 
institutions. ${ }^{37}$

As a resource, Dunsdon's report provided critical information, and as an impartial observer she reported on the best practices and also those which were not as successful. The content of her report influenced the Report of the Chief Medical Officer (1946/47), which stated that the recommendation for the integration of treatment and education came following the publication of Dunsdon's report. Despite her recommendations, the Medical Officer's Report advised that 'clear-cut guidance' would not be immediately available due to the need for the 'observation of children over a lengthy period. ${ }^{38}$ As a 'not-for-profit' organisation, NFER arguably had more freedom to allow Dunsdon to develop her own research. Links were in place with the BCWS who were at the forefront in promoting the connection with Phelps and the NFER. Research, led by Dunsdon, resulted in the publication The Educability of Cerebral Palsied Children (1952) which she had started at a time when 'there existed no schools exclusively for cerebral palsied children'. 39

The cerebral palsy unit at Queen Mary's Hospital for Children in Carshalton, was modelled on the approach taken by Winthrop Phelps. Collis had been a student of Phelps, and in the foreword of her book, $A$ Way of Life for the Handicapped Child (1947), Member of Parliament, Somerville Hastings, ${ }^{40}$ described how he had heard of the 'good results', in the treatment of cerebral palsy at Carshalton, and said that, following a visit by him to the unit, London County Council recommended that Collis was given 'every reasonable facility', for her to 'put into operation, on an extensive scale, a method of treatment which she had studied under the direct supervision of Dr W M Phelps in the USA'. ${ }^{41}$ The resource put into this unit was significant, and Collis referred to the 'principles laid down by Dr. Phelps' who had been her teacher and whose work she

\footnotetext{
${ }^{37}$ Harborne, Cerebral Palsy Midlands, Marjorie I. Dunsdon, B.A., M.A., (Lond.), An account of a three months visit paid to the United States of America for the purpose of observing the work being done there for children suffering from cerebral palsy, June 1946.

${ }^{38}$ Ministry of Education, The Health of the School Child: 1946 and 1947, p.99.

${ }^{39}$ M.I. Dunsdon, The Educability of Cerebral Palsied Children (London: Newnes Educational Publishing Co., Ltd., 1952), p.vi.

40 Somerville Hastings, a surgeon and Chairman of the Hospitals and Medical Services Committee of the then London County Council (LCC).

${ }^{41}$ Eirene Collis, A Way of Life for the Handicapped Child (London: Faber \& Faber, 1947), p.14.
} 
'endeavour[ed] to follow'. She aimed to 'give practical help, from the therapeutic point of view, to those interested in the welfare of children with cerebral palsy'. Of her book, A Way of Life for the Handicapped Child (1947), she claimed that it had no bearing on the political, ethical or administrative running of cerebral palsy schemes. ${ }^{42}$ This statement by Collis portrays a climate where difficulties had been experienced in providing services, and a lack of funding and expertise had hindered progress. She believed that as a result of her work at Carshalton, a 'new approach [was] being made generally to the problem of cerebral palsy in England'. ${ }^{43}$

Schonell visited the 'spastics centres' in the capital cities of the Australian states in September 1948. Her work is of particular importance in how services developed in Britain. As a member of staff at the Birmingham Institute of Child Health, she conducted major research on children in the West Midlands, as discussed in the previous chapter. As an educational psychologist at Carlson House School, a 'flagship' school for children with cerebral palsy, Schonell's views were very much part of the ethos employed by MSA and Carlson House School. She singled out the centres at Melbourne and Mosman, as being well established and contributing greatly to the improvement in the physical and psychological wellbeing of 'spastic' children. Schonell viewed renowned doctor Jean Macnamara, at work, and said how she inspired her. Schonell wanted to 'infuse' centres in the UK with the 'spirit of considerate, intelligent co-operation between all those dealing with Cerebral Palsy cases'. She argued that the way to success, in the organisation of a Spastic Centre, was down to certain actions. These included recruitment of 'personnel' with specific qualities and the need for co-operation 'between everyone involved in the care and development of 'spastic children'. She argued that 'long term success' depended 'considerably on the guidance that [could] be given to parents and the way in which [they could] be help[ed] to help their children'. Help was seen as not just physical but also emotional. ${ }^{44}$

42 Collis, p.17.

43 Ibid., p.163.

${ }^{44}$ Harborne, Cerebral Palsy Midlands, F. Eleanor Schonell, M.A. (Lond.), Report of a visit to the spastic centres of Australia. September 1948, p.10. 
Dunsdon, Collis and Schonell were stimulated through the opportunities afforded them in their international study tours. The knowledge they gained through observation and discussion was disseminated to select groups in Britain, and shaped the way in which services developed. The tours were undertaken within a relatively short timescale, between 1946 and 1948, and therefore findings were contemporary. Being from distinct disciplines and backgrounds would have been a strength, as each individual brought different qualities to their research and its interpretation. All three had a wide reach in the dissemination of their research and subsequent recommendations, so their work added to the growing drive for a change in attitude towards cerebral palsy. They did not just reach out to professionals and organisations, their work impacted on individuals and their families, as aspects of their research was put into practice. Armed with knowledge and new practical applications in the treatment of cerebral palsy, parents could view the future of their children in a more positive light, and press for change in their treatment. If an investment had not been made in Dunsdon, Collis and Schonell, an opportunity would have been lost to address the integrity of treatment of children with cerebral palsy.

Close examination of the BCWS Annual Reports, during the period 1948 to 1958, reveals the commitment of the BCWS to furthering transnational relationships. As an organisation, they reported on the work of international experts and disseminated widely through conferences where delegates included those from the disciplines of health and education. Through these transnational links, a 'body of information' was gathered on cerebral palsy, offering expert advice and promoting good practice. Having access to information strengthened the network of support for many families, not only in Britain, but internationally. The BCWS Annual Report 1955-1956, stated that 'requests for information and advice ha[d] been received from overseas organisations and individuals'. Translations had been made of the Parent's Handbook into German, French and Italian and it was noted that a 'good deal of literature' was received from the U.S.A. ${ }^{45}$ There was a flow of information between countries, groups from other ${ }^{45}$ Harborne, Cerebral Palsy Midlands, Annual Report 1955-56, British Council for the Welfare of
Spastics, pp.8-9. 
countries accessing the 'body of information' included organisations such as:

- The Dutch Confederation of Parents of Spastic Children

- The Italian National Association for the Welfare of Spastics

- Belgian Association Nationale d'Assistance aux Enfants Estropiès

- The High Commissioner for India in London had been supplied with copies of BCWS publications to forward to the Indian Department of Health

Other requests for BCWS publications came from Eire, Holland, France, Northern Ireland, Union of South Africa, USA, Italy, Turkey and Mauritius. Copies of Spastics Quarterly were sent to 32 overseas countries or territories. At the seventh World Congress of the International Society for the Welfare of Cripples (1957), BCWS had an exhibition of its publications, including those which had been translated into other languages ${ }^{46}$ Parents' campaigns, at a local level, had fuelled a desire for information. The implementation of new procedures, based on original research, had demonstrated visible results. Parent-led and voluntary organisations became a driving force at a local, national and international level. The energy of parent-led groups and their desire for change, linked parents in many different countries. Shared resources included films such as, $A$ Day in the Life of a Cerebral Palsied Child (1948) from the Children's Rehabilitation Institute in Maryland, USA and Here is a Plan about the work of the Mosman Spastics Centre, Sydney, Australia. ${ }^{47}$ The NSS also produced publicity and information films such as Chance of Their Lives (1952), and Door to Freedom (1956), which depicted life inside schools and centres established by the NSS. MSA also produced a range of films which became influential nationally and internationally.

There was a growing realisation that this sector was becoming more informed and influential and, where appropriate, could take the lead. An article in Spastics News (1960), by R Howlett, Under Secretary for the Ministry of Education, reflected on 'the most ambitious course that ha[d]s ever been run' in

\footnotetext{
${ }^{46}$ Harborne, Cerebral Palsy Midlands, Annual Reports 1948 to 1958, British Council for the Welfare of Spastics.

${ }^{47}$ Harborne, Cerebral Palsy Midlands, Annual Reports 1948 to 1958.
} 
Britain. He was referring to a two-week course on cerebral palsy, for some 90 teachers and therapists, held at St Edmund Hall, Oxford. Topics under discussion included 'Education of the Severely Handicapped and Activities for Life'. Those attending had been invited to present papers on their 'special knowledge and experiences'. Amongst the delegates were individuals from nine European countries; Britain, Sweden, Norway, Denmark, France, Holland, Germany, Italy and Czechoslovakia. ${ }^{48}$ Howlett, as a government minister, was praising the voluntary sector, and at this time it is unlikely that the government would have been able to achieve such an event. Parent-led 'spastic' associations had the motivation, the contacts, the knowledge and more than that, they had the relative freedom to act on these issues. Through a combination of circumstances, which included the outcomes of the study tours and the drive for information, the voluntary sector was able to take advantage of a gap in the market, to pull all the different strands together and provide a service, to which there was a ready-made audience at a local, national and international level.

\subsection{Carlson House School}

Carlson House School was established by MSA in 1948, and was one of the first to pioneer a collaborative approach in the delivery of education and therapy, and also to showcase achievements made with its disabled pupils. At the outset, this venture had the support of the Education Department of Birmingham Council and, as discussed, the school worked closely with Birmingham Institute of Child Health, benefiting through the involvement of Paul Cadbury and the philanthropic work of the Cadbury Trust. The first Headteacher of the school recalled the early days of the school and said how, 'in those days spastics were looked upon as ineducable and we wanted to prove that they could be educated and benefit from almost normal schooling plus treatment'. ${ }^{49}$ The film Children at Carlson House (1950), provides a visual insight into school activities and children are pictured in a 'traditional' setting, taking part in lessons and other

\footnotetext{
48 London, Wellcome Library, R. Howlett, 'The most ambitious course that has ever been run in this country', Spastics News Magazine of the Spastic Society, September 1960, p.12.

49 Interview with Christine B., 14 October, 2013 as part of a Heritage Fund Project, Fulfilment through Achievement, Harborne, Cerebral Palsy Midlands.
} 
activities that you would expect in any school. The film also has a strong focus on the range of therapy treatments that were given to children in order to treat the symptoms of cerebral palsy. Of the children shown, the range of physical symptoms were diverse which proved that jerkiness of movement or inability to speak was not a bar to being chosen for the school. ${ }^{50}$

The children were selected via a streaming process, and the School Inspection Report of 1952, gives a more detailed analysis of life within the school. The report stated that 'great care ha[d] been taken to measure, as far as possible, the ability of children' and they were selected within a particular range of IQ tests. ${ }^{51}$ This statement appears to contradict the very cause that parents were railing against, but potential pupils of Carlson House appear to have had a rigorous and fair assessment, unlikely to have been replicated, at that time, through local authority provision. Initial testing took place at Birmingham University, Department of Education, by an educational psychologist. This was then followed by a series of assessments at the school by a number of professionals, including an orthopaedic specialist, physiotherapist, speech therapist, teaching staff and welfare officer of MSA. The report stated that 'selection [was] based chiefly on the child's need for treatment' and their IQ and said 'it was rare for a child to be turned down because of the severity of his physical disability'. ${ }^{52}$ Whilst the report does not give specific detail of the procedures undertaken during the assessment, all those involved in the selection process had a professional interest in cerebral palsy. Therefore, they were uniquely placed to assess the child, giving them the investment of their time, for the best outcomes of the process. This immediately gave children selected for testing an advantage. The impact of continued treatment was closely monitored by the school, and outcomes were charted. For example, progress made in movement, aided the development of activities needed for everyday living and voice recordings made, over a period of time, demonstrated the impact of speech therapy.

\footnotetext{
${ }^{50}$ Children at Carlson House, dir.by Staff of Carlson House (Morland Braithwaite Ltd., 1950), online film recording, You Tube, 3 April 2016,

<https://www.youtube.com/watch?v=VBUOw99rivE> $>$ [accessed 14 August 2017].

${ }^{51}$ Harborne, Cerebral Palsy Midlands, Carlson House School Inspection, March 1952.

52 Ibid.
} 
The report considered the procedure of record keeping, which included 'precise information on the child's physical attainments in the skill of everyday living' in addition to educational progress that you would expect in a school. The records kept were said to be 'full' but staff had 'avoided the danger of recording at the expense of teaching and treatment'. ${ }^{3}$ Individual progress was being made as the teaching was balanced against the needs for treatment, 'interruptions for treatment' were minimized so that the class had 'certain periods when children [were] not withdrawn for treatment'. It said that this 'allowed the teacher to plan the time-table in such a way that the withdrawal of individual children [was] as little disturbing as possible'. The standard of teaching was said to be good and the 'curriculum balanced'. ${ }^{54}$

The structure of the school included a 'a nursery unit . . . about 3 other classes of older children ... it was based on an ordinary school, as far as possible, plus the treatment - speech therapy and physiotherapy. ${ }^{55}$ Angela $\mathrm{H}_{\text {., }}$. whose mother worked as a secretary at the school recalled how well staffed it was and said:

from a Speech Therapy point of view, I think they had two speech therapists working just for the School, at the time, which is unheard of, you don't get that anywhere really. And certainly, within its era they were definitely years ahead. It's not replicated anywhere the level of expertise and the level of staffing that that the children had then. And it was small - it didn't have a huge number of pupils so everybody knew each other and, I think, the staff knew the children inside out and knew exactly where they were going, and the classroom was set out so that the children were very clear what they were working on, what they were striving for, what they were trying to improve and everybody worked together; so the Physio, the Speech Therapist and the class Teacher, although the Speech and Language Therapist did have their own

\footnotetext{
${ }^{53} \mathrm{lbid}$.

54 Ibid.

${ }^{55}$ Interview with Christine B., 14 October, 2013.
} 
little department as well. ${ }^{56}$

This description of the school's structure demonstrates how it was built around supporting new research and the early intervention of appropriate treatment to improve a range of the symptoms of cerebral palsy. This approach was unique and arguably could not have been replicated in state run schools. State schools were not dedicated solely to the education of children with cerebral palsy and so would simply not have had the resources or the level of understanding of children with the condition.

Nineteen of the fifty-one children, who had started when the school opened had left at the time of the 1952 Report. The majority of those children had left because they had 'become fit for a less specialised type of school' while one was said to be 'educationally subnormal' two were to be educated at home and one was 'referred to the Mental Health Authority as ineducable'. ${ }^{57}$ This statistical evidence proved that the approach taken by the school was generating successful outcomes, and the number of children who did not progress as anticipated was relatively small. The level of planning undertaken in the school's development meant there was a high level of professional expertise in place. This would have been of direct benefit to the pupils, and was a strength of the school, as they demonstrated what could be achieved if sufficient resources were employed.

Carlson House provided a segregated education but without this approach, at this time, it is questionable how quickly progress would have been made. Segregation in education was not a new concept as 'disability specific' schools and institutions dedicated to blind or deaf children demonstrate. Gordon Phillips, in his book The Blind in British Society (2004) debates the history of education and the blind and comments how in 1920, 'both the state and the voluntary sector saw the blind as a group of distinct character and finite proportions'. As such they 'demanded specialised treatment and appropriate

\footnotetext{
56 Interview with Angela H., 7 May, 2014 as part of a Heritage Fund Project, Fulfilment through Achievement, Harborne, Cerebral Palsy Midlands.

${ }^{57}$ School Inspection, March 1952.
} 
knowledge'. Phillips refers to the 'special institutions' that were formed for 'education, training and employment'. ${ }^{58}$ Similarly, in her discussion on education for disabled children, Anderson states that, 'generally blind and deaf children were sent to schools specifically catering for them'. The Board of Education, Annual Report of the Chief Medical Officer of the Board of Education (1921) shows that there were a 'higher proportion of residential facilities for blind and deaf children than for other disabilities'. The reasons behind 'removal from home and segregation' are considered by Anderson and she comments that parents were not perceived to 'possess skills necessary to provide a solid education for a sensory deprived child'. Anderson argues that 'educational services for blind children were most advanced' and many schools 'concentrated on preparing students for the job market'. 59 Whilst both groups were segregated, the main difference was that parents of children with cerebral palsy did not have state support as afforded through legislation. Philips makes an important point in his consideration of the role of charities and the blind, as he refers to the 'heyday' of charities where they 'formed a medium between the blind and the sighted, designed to convey messages between them'. He says, 'the resulting communications may have been distorted and unduly constrained, but they were and remain an audible dialogue'. ${ }^{60}$ This point is pertinent to this thesis as organisations such as MSA, through their efforts, were making progress independently of any state provision. Segregation enabled schools, such as Carlson House, to utilise different approaches to cerebral palsy and learn from these approaches and share progress.

Parents had been the driving force and had taken the lead in forging ahead with experimental new treatments. The expansion of MSA, through the development of Carlson House, meant that the association became respected in the field of education and treatment of 'spastic' children. An article in Educational Review (1949), by the Headteacher of Carlson House, reflected how from the beginning, the school kept detailed records which included reports from

58 Gordon Philips, The Blind in British Society: Charity, State and Community c.1780-1930 (Hampshire: Ashgate Publishing Limited, 2004), p.409.

59 Julie Anderson, War, disability and rehabilitation in Britain (Manchester: Manchester University Press, 2011), p.20.

${ }^{60}$ Phillips, p.419. 
'teachers, physiotherapists, occupational therapists and speech therapists'. ${ }^{61}$ Therefore, they created tangible evidence of progress made and shared their experiences as they opened their doors to welcome visitors and personnel from a variety of fields, including education and medicine. The sharing of outcomes, strengthened and gave credence to the theories of leading experts in cerebral palsy, which created more of an impact. Identifying issues and providing solutions, contributed to a growing bank of knowledge, made available for the future planning of services. This meant that, in time, citing a lack of information about cerebral palsy would not be such a viable argument to justify the denial of services.

An article in the 1977-78 Yearbook of MSA, by the Headteacher, reflected on the 'pattern of progress' since 1947 and she said that from the school records 'a pattern began to emerge of the specific difficulties that some spastics seemed to encounter when learning to copy shapes of letters and spacing their work' ${ }^{62}$ Spatial difficulties were experienced by many children with cerebral palsy and it was noted how individual 'spatial problems' impacted on a child's ability to develop literacy skills and undertake practical tasks such as dressing. Continuous monitoring highlighted the progress made and demonstrated that, with early intervention, difficulties could be improved or overcome. Through hard evidence it was proved that children with 'severe spatial problems' could go on to develop literacy skills. ${ }^{63}$ Spatial difficulties are just one example; the same principle was applied to all aspects of cerebral palsy and the application of education and therapy treatment.

There is no definitive material available regarding the curriculum that was followed in Carlson House but a range of primary sources give an insight into subject matter and how treatment was incorporated into the school day. Annette Jackson, born in 1942 was six when she started in the 'newly opened Carlson

${ }^{61}$ Christine Woodall, 'Carlson House, Harborne: An experimental school and treatment centre for spastic children', Educational Review, 1:3, (1949) 161-163 (p.162).

62 Harborne, Cerebral Palsy Midlands, Christine Woodall, 'The Headmistress of Carlson House School talks of the Pattern of Progress since 1947' in Midland Spastic Association Year Book 1978, p.28.

63 Harborne, Cerebral Palsy Midlands, Carlson House records 1948 - 1975. 
House School' and recalls her days there:

I began my school life in the infants' class, where, much to my joy, I learned to read and do simple sums. I was also able to play with children of my own age. The part of the day which I did not enjoy when I first went to school was going to physiotherapy, but in due course I grew to like it because it taught me to be independent. . .. As I made my way through the school, I learned the usual subjects such as, English, history, geography, needlework... I learned to type and how to write Pitman's Shorthand. ${ }^{64}$

However, Annette was told, by her teacher, that 'she would never be able to find a job in an office because [she] was not fast enough at either shorthand or typing'. ${ }^{65}$ Indeed, Annette did not find employment outside of MSA and as a school leaver she began work in the MSA Work Centre. Her duties included craft activities and light industrial work. A 1959 school report of a pupil, born in 1941, lists history, French, English essay \& current affairs, arithmetic, algebra \& geometry as subjects studied. He achieved success in passing state examinations in English literature \& language, French and history, arithmetic \& mathematics results were unknown at the time of the report. Also detailed is information about his therapy treatment and remarks from the Headteacher. ${ }^{66}$

These narratives demonstrate that conventional subjects were studied and the standard of education was adhered to as pupils made progress. However, it is not obvious how this standard compared to the education experienced by contemporaries in mainstream school. David B., reflected on his education at Carlson House and said:

my education was reasonable, apart from these lengthy - bouts in hospital, I was able to progress into what was called 'The Study Group', where, at that time, Anthony Sutton, ... . was really the star pupil, because he and John Lines were taught by $\mathrm{Mr}$ Doughty, who came in ... 2 or 3 times a week, read

\footnotetext{
${ }^{64}$ Harborne, Cerebral Palsy Midlands, Annette Jackson, 'A younger Spastic - then and now' in Midland Spastic Association Year Book 1972, p.36.

${ }^{65}$ Annette Jackson, 'A younger Spastic - then and now', p.36.

${ }^{66}$ Harborne, Cerebral Palsy Midlands, A school report of a pupil at Carlson House, July 1959.
} 
the chapter in front of the books we were looking at and then we were left to do homework - Anthony, as I said, did particularly well, as he progressed to ALevel, which he did at home under the auspices, privately, of Mr Doughty and he was, in fact, a-athe first disabled person to go to Birmingham University, where he taped the seminars and then went back home and whatever. He had a speech defect, which was rather strange, because he was studying Spanish and Russian. Of course, during that period he was supposed to spend time away - at the country for 6 months, but he was not able to do that, so that was tailored $-I$ think he went to Portugal and he actually passed a BA honours and what have you, so he was really the star pupil of Carlson House. . . I managed to obtain a few O Levels, but because - the Oxford and Cambridge board allowed us extra time, but the Northern Matriculation Board, where I took Maths, Geometry and whatever, didn't, so I - although I knew the questions I didn't pass because I didn't fill 'em all in! In a - instead of that, I took Arithmetic and Maths at the London Chamber of Commerce and passed that ${ }^{67}$

Despite having a level of financial security, Carlson House school did not have a huge budget to spend on specialised equipment and did not have particular special aids as are available today, so everyday items were adapted for use. Such was the success of their innovation; a film was made in 1956 entitled Special Equipment. This was distributed both nationally and internationally, to schools and centres attended by children with cerebral palsy. Simple innovations shown in the film include the adaptation of cotton reels, to become 'number pegs', or 'letter pegs', which pupils could pick up more easily and develop their numeracy and literacy skills; using clamps to attach paper to desks; different coloured 'cylinders' made from painted wooden dowelling which made it easier for pupils to pick up and develop colour matching skills; the addition of wheels to the back of wooden chairs so pupils could be manoeuvred more easily to sit at a desk; modified desks with a cut out section to accommodate different types of chairs; and the use of a frame on a typewriter keyboard to make

${ }^{67}$ Interview with David B., 22 January, 2014 as part of a Heritage Fund Project, Fulfilment through Achievement, Harborne, Cerebral Palsy Midlands. 
it easier for pupils to use a 'stick' to push down on the keys. The film's narrator said how these innovations had been gradually developed at Carlson House and how each solution was unique to each child. This meant that they could all work at a similar pace even though they were affected in a variety of ways through the symptoms of their condition. ${ }^{68}$ (Images at Appendix 9.5 shows children at work in Carlson House school).

A series of other films were made: Steps to Independence (date unknown), ${ }^{69}$ Carlson House a Day School for Spastics (1954) and Physiotherapy for Four Spastic Children (1965) which demonstrated changes in the approach to treatment given to children with cerebral palsy. ${ }^{70}$

The work undertaken with pupils was frequently used in lectures and talks to illustrate progress made and good practice. In addition to more generalist films such as Children at Carlson House, individual recordings were made of each child 'from admission to leaving school' and these were said to have been 'invaluable for training the many students' who had visited the school. David Barnsley recalled how he and his fellow pupils were:

whisked off to Physio, etcetera on a daily or weekly basis, depending on the sincerity - the severity of our disability. Now, of course, we didn't realise that we were - really, it was an experiment and we were asked to appear on a film - films - cinefilms, which was done by Moore and Braithwaite of Moseley and he took pictures of us all in our figleaves and goodness knows what, showing all our deformities, and they were supposedly to $\mathrm{pr}$ - to show the progress that was made then. These films were given by Mr Paul Cadbury, at a much later date, to Woodlands Hospital for their archives. ${ }^{71}$

A criticism that can be made, is that the children at Carlson House were paraded

\footnotetext{
68 Special Equipment, dir.by Staff of Carlson House (Morland Braithwaite Ltd., 1956), online film recording, YouTube, 22 November 2013, <https://www.youtube.com/watch?v=Xv9jV0JDVs0> [accessed 14 August 2017].

69 Steps to Independence, dir.by Staff of Carlson House (Morland Braithwaite Ltd., (date unknown)) [DVD].

70 Harborne, Cerebral Palsy Midlands, Carlson House records $1948-1975$.

${ }^{71}$ Interview with David B., 22 January, 2014.
} 
in front of others, photographed and filmed at a time when treatment administered was very much at the experimental stage. The narrative of David Barnsley informs us of the images taken at Carlson House for clinical purposes. This can be said to be a throwback to the 'eugenics era' as discussed by Martin Elks. He comments how, in the eugenics era, the 'feebleminded' were photographed and portraits had the subject of the photograph 'depicted as specimens, examples of types of mental defectives, or carriers of particular diseases or conditions'. 72 There is no suggestion that Carlson House had eugenic tendencies. It can be surmised that the images were used for teaching purposes as well as for monitoring progress. Rosemarie Garland Thomson considers the genre of medical photography, which she says was 'one of the major photographic modes used to shape our modern notion of disability'. She discusses how the 'clinical photograph materialised what Michel Foucault call[ed] modernity's "medical gaze", which define[d] the norm by picturing the deviant'. ${ }^{73}$

Through the use of clinical images, the children were being depicted as being something other than 'normal' and so the images were akin to those used for fundraising purposes. Garland Thomson considers the impact that photography has had on the medicalisation of disability and argues that it has 'contributed substantially' through its 'extensive use in diagnosing, documenting, identifying, treating and pathologizing disability'. ${ }^{74}$ The children at Carlson House and other similar establishments could not escape public gaze due to their being perceived as different. Tom Shakespeare discusses the concept of 'othering' and how the 'separation into able-bodied and disabled is an artificial process'. He argues that the 'idea that the world neatly divides into people with physical limitations and 'normal' people who have perfect bodies is an illusion'. He says that 'only by projecting their frailty and vulnerability onto the Other -old people, disabled people -can non-disabled people maintain the illusion of their own strength and wholeness' ${ }^{75}$ To consider the viewpoint of professionals and

\footnotetext{
${ }^{72}$ Martin Elks, 'Clinical Photographs: "Feeblemindedness" in Eugenic Texts', in Picturing Disability (New York: Syracuse University Press, 2012), pp.75-98, p.77.

${ }^{73}$ Rosemarie Garland Thomson, 'Seeing the Disabled: Visual Rhetorics of Disability in Popular Photography', in The New Disability History: American Perspectives, ed. by Paul K. Longmore and Lauri Umansky (New York: New York University Press, 2001) pp.335-374 (p.336).

${ }^{74}$ Rosemarie Garland Thomson, p.336.

${ }^{75}$ Tom Shakespeare, Help: imagining welfare (Birmingham: Venture Press, 2000), pp.1-20. (p.7).
} 
others connected to Carlson House, from a modern perspective, they were doing their best in the circumstances and were utilising resources of what was deemed acceptable at the time.

The resources produced by the school proved to be excellent teaching aides, not just for professionals, but also for parents. Parents could learn through observation and practical experience how to continue with treatment at home and so benefit their children. Through the use of visual media, in conjunction with written reports, the assumptions of how cerebral palsy was viewed were challenged. There was no denial that such children needed more practical help to enable them to achieve a level of independence but through the work of Carlson House it was proven that they could also take part in education. Through voluntary efforts and active involvement parents had developed a scheme and were rewarded through the positive impact it made on the lives of their children. An article in the 1977-78 Yearbook of MSA reflected the views of parent, Marjorie Jeramiah, who said how before MSA, the various doctors she visited with her daughter gave 'often conflicting opinions' but she said 'no one told [her] how to stimulate her [daughter's] inactive legs or how to train and co-ordinate arm movements'. She spoke of the 'tremendous debt' that parents owed to MSA for their 'practical help, and to those who with courage and foresight planned to make all this possible'. ${ }^{76}$

After the first school inspection in 1952, copies of its report were sent to medical professionals of various disciplines, Directors of Education of a number of local authorities, the Education Department of the United Nations and Dr Earl Carlson as well as parents and others who had been involved in setting up the school. ${ }^{77}$ The initiatives they had developed had an impact at a local, national and international level. The changing relationship with the local authority reflects how progress was made. In an article in a 1977-78 MSA Yearbook, the Headteacher reflected on how the local authority had given 'support and encouragement' to Carlson House school. Over the years they had sent them

\footnotetext{
${ }^{76}$ Harborne, Cerebral Palsy Midlands, Marjorie Jeramiah, 'Three Parents Look Back to the Early Days' in Midland Spastic Association Year Book 1978, p.16.

${ }_{77}$ Harborne, CP Midlands, Carlson House School Inspection March 1952.
} 
many children but from 1976, they felt that they could 'make provision within their own special schools for cerebral palsied children'. ${ }^{78}$ This was a turnaround from the exclusion of 'cerebral palsied' children from education and the Headteacher said this change meant that Carlson House 'began to play a different role in the field of special education and focused on language and speech impairment as they had the 'expertise, knowledge and experience'. This change of focus helped young children to 'overcome their difficulties' so that they could eventually go to 'ordinary schools' ${ }^{79}$

As well as providing a level of education to so-called 'ineducable' children, those with more profound disabilities also needed to be considered. Research has shown that disabled children generally had a different and separate experience of school to that of non-disabled children, but an article written in Spastic News, in February 1963, discussed how the Spastic Society's schools had grown to provide an 'established pattern of educational facilities recognised nationally and internationally as meeting the needs of the very severely handicapped pupil in particular'. National Spastic Society schools began to be established just a few years after Carlson House (1947). These schools were said not to be 'a duplication of facilities already provided by the State or other organisations but a vital, necessary and highly developed service designed specifically for the cerebrally palsied'. 80 The change that started with Carlson House led to other independent schools being established, including Percy Hedley School for Spastics, in Newcastle Upon Tyne, and Grove School in Swansea which by 1964 had twenty-two children on their roll, with an age range from three to eighteen years. In an article written by the matron, Gloria Watts, she described how she and her team worked to develop 'the child's physical, social and educational abilities' in a 'friendly and happy environment'. ${ }^{81}$ Within its first eight years, the National Spastics Society had set up nine national centres which included four schools. From small beginnings, the establishment of these

\footnotetext{
78 Harborne, Cerebral Palsy Midlands, Christine Woodall, in Midland Spastic Association Year Book 1978, p.28.

${ }^{79}$ Christine Woodall, p.28.

80 London, Wellcome Library, C A Clifton, 'The Changing Emphasis of the NSS Schools Programme', Spastics News Magazine of the Spastic Society, February 1963.

${ }^{81}$ Swansea, West Glamorgan Archive Service, D/D LA 5/5, Gloria M. Watts, 'A friendly and happy environment', in Swansea \& District Spastic Association Year Book 1964, p.29.
} 
schools started a revolution in the access to education for children with cerebral palsy.

Research had shown that a 'one-size fits all' approach was not appropriate as the unique capabilities of each individual had to be assessed independently. Many children with the condition had little or no experience in an educational setting and had not started school, at an age comparable to their peers, where their lack of educational experience, did not go unnoticed. Paediatrician $\mathrm{Dr}$ Robert Wrigglesworth discussed, at the Oxford seminar in 1966, how the 'handicapped child' may be 'deprived most of all of early contact with his peers'. He argued that any contact with children of the same age would probably have been 'his superiors in physical and/or mental ability'. Wrigglesworth said that 'this [could have been] a damaging experience'. ${ }^{82}$ Innovative ways of teaching needed to be adopted, in order to complement developing research and incorporate multi-disciplinary working. This required a degree of flexibility towards the delivery of education and also in the treatment of cerebral palsy.

\subsection{A time of change}

Discrimination had segregated children with cerebral palsy from their peers, and in order to progress then a 'trial period' was needed to discover which systems worked best. As with all children, those with cerebral palsy had a range of abilities and some were more academic than others. Michael Oliver reflects on his view of education, not as a pupil but through his experience as a teacher, having a 'supportive mentor'. He maintains that this is where he learnt that 'the 'art' of teaching was to create the right conditions for people to learn for themselves' ${ }^{83}$ Through creating the 'right conditions', there could be a period of discovery and debate, inclusive of all children within the range of cerebral palsy symptoms. A report by Paul Cadbury, to the trustees of the Paul S. Cadbury Charitable Trust in 1969, illustrates how organisations such MSA had the

${ }^{82}$ Robert Wigglesworth, 'The Value of Early Part-Time Developmental Training' in The Spastic School Child and the Outside World, ed. by James Loring and Anita Mason (Oxford: William Heinemann Ltd., 1966), pp.1-12 (p.1).

${ }^{83}$ Michael, Oliver, Understanding Disability (Basingstoke: Palgrave Macmillan, 2009), p.70. 
opportunity to be 'experimental' in their approach. Cadbury reflected on the time when the idea of starting a school, Carlson House School, specifically for children with cerebral palsy, had started to become a reality. Cadbury described that following his meeting with renowned doctor, Earl Carlson, he 'inevitably' became a 'prime mover in education and welfare of spastics'. Cadbury's original idea had been to start a school 'along the lines of Cropwood and Uffculme' ${ }^{84}$ which were open air schools, for 'delicate' children, established by the Cadbury family. Cadbury had expected the local authority to run Carlson House School but following a meeting with the Chief Medical officer of the Ministry of Health and Education this changed. It was said that if local government ran the school it would be 'too restricted' as they wanted an 'experimental' school and Cadbury to run it. ${ }^{85}$ This approach, forward thinking for the time, demonstrated what could be achieved.

Post-war parents had created a solid foundation to further develop educational services and, with the formation of the NSS, change accelerated at a local, national and international level. The list below demonstrates the range of education provision for children with cerebral palsy in September 1956. It is taken from a list compiled by the BCWS and reproduced in Spastics in Cheyne Walk (1957). Cheyne Walk was the location of the Centre for Spastic Children, established in 1955 and dealt primarily with pre-school children. The details are:

- schools in England \& Wales and 1 in Scotland under voluntary administration providing education and treatment approved by the Ministry of Education (these included Carlson House School and St Margaret's)

- schools in England \& Wales and 2 in Scotland provided by Local Education Authorities (children were only accepted from the local authority area)

- 10 special units in England \& Wales for cerebral palsied children in schools for physically handicapped children, provided by local education authorities

- Hospital units providing education as well as

\footnotetext{
${ }^{84}$ Details for these schools can be found online:

$<$ http://www.formerchildrenshomes.org.uk/birmingham open air schools.html>

${ }_{85}$ Birmingham, Wolfson Centre for Archival Research, MS 1579/1/4/6/3, Records of the Cadbury Trusts, A report to the trustees of the Paul S. Cadbury Charitable Trust.
} 
treatment (included Queen Mary's Hospital, Carshalton)

- 8 private schools and teaching units in England \& Wales and 1 in Scotland (under the umbrella of the Spastics Society $)^{86}$

This list demonstrates the level of progress that had been made stimulated by the ethos of 'spastic' associations. From small beginnings, parent-led organisations rose to have a level of authority to inform and educate and through their increasing professionalism they diverged into training becoming experts in their field.

The eventual merger of the BCWS and NSS in the early 1960s, led to the creation of the Spastics Society, which was proactive in providing training that included solutions, tailored specifically to the needs of families. Spastics News (1960), reported on a new training course for parents in Cardiff, designed to give parents practical help to learn 'the correct ways of handling their child, to make family adjustments easily, and to gain, in the process, as normal a life as possible.' It was a small group, six mothers, but they were said to become 'the pioneers of a new method whereby they might understand and contend with their problems of day to day living'. They were taught how to use 'therapeutic apparatus' by attending demonstrations, and could discuss issues with speech therapists, physiotherapists and teachers from Craig-Y-Parc School, Cardiff. Talks and films were said to be one of the main features of the course, as well as the opportunity for them to freely discuss 'individual problems with experts'. It is reported that the course 'had been entirely practical and geared to actual personal home situations' and its success had created an 'enthusiasm' amongst others to join the next one. ${ }^{87}$ In 1961, Craig-Y-Parc was the setting for the 'first regional course for teachers and therapists dealing with cerebral palsied children', which included lectures from eminent specialists in cerebral palsy, as

${ }^{86}$ Spastics in Cheyne Walk, ed.by Joan Saunders \& Marjorie Napier (London: Pitman Medical Publishing Co. Ltd., 1957), p.65.

87 London, Wellcome Library, 'N.S.S. New Venture, Parents' Training Course' Spastics News Magazine of the Spastic Society, May 1960, p.15. 
well as practical sessions, eighty people attended. ${ }^{88}$ Parents were included as valued contributors, and did not encounter the level of exclusion that had been experienced in immediate post-war Britain.

This was a positive step forward, but a more widespread diverse approach to education remained elusive. The practice of leaving some children under the jurisdiction of the health authority continued and so a sense of hopelessness still remained. The continued power of the medical model of disability and ill-informed medical practitioners; a lack of suitably trained teachers; and insufficient funding were still issues to be addressed. An article in the February 1963 edition of Spastics News, considered how there was still a 'divide' between the Ministries of Health and Education in the categorisation of the child. It was argued that this 'divide' gave 'an unevenness in the provision of education and training throughout the country both as regards quantity and quality'. The article acknowledged that there would 'always be a gap between what society [could] afford to provide and what [was] really needed'. Whilst it stressed the importance of charity as a means to 'bridge the gap' it also emphasised the need for specialised planning. The Society expected to spend 'at least £8 million on new schools and centres alone' in the coming years, ${ }^{89}$ which it stated was not an insignificant amount of money.

Segal discusses the training of teachers and how publications 'increasingly drew attention to work with handicapped children'. He says how special schools were of 'particular concern to the National Union of Teachers (NUT) Advisory Committee'. By 1965, 'only the special schools for the blind and for the deaf could expect their staff to be specifically qualified for their work' and for new staff in 'other special schools' specific training was not a condition of entry' at that time..$^{90}$ The period following the end of the war had been a time of uncertainty and change, when relationships between professionals and parents had been complex. Parents had dared to question the authority of experts, challenging long established conventions and, in many cases, parents were

\footnotetext{
${ }^{88}$ London, Wellcome Library, 'Course on Cerebral Palsy for Wales and the West', Spastics News Magazine of the Spastic Society, September 1961, p.11.

${ }^{89}$ London, Wellcome Library, J. A. Loring, 'The Role of Charity in the 1960s', Spastics News Magazine of the Spastic Society, September 1963, p.4.

${ }^{90}$ Segal, No Child is Ineducable, p.125.
} 
better informed than the 'experts'. Culturally, people had trusted and respected doctors, but now there was an element of discord for the families of children with cerebral palsy. Alan Counsell, quoted earlier, who had been given his certificate to say that he was 'above average intelligence, and of sane mind' had a letter from the Headmistress to suggest he and his family saw her friend, an army doctor. Alan said how the doctor:

thought it would be better if my right arm was amputated, and I had a false limb. Well, this sent my Dad into orbit. And then I had to go and meet this orthopaedic man in the local hospital; and there were issues about that, because, apparently, he talked to me like I was mental, and Mum and Dad weren't having that ${ }^{91}$

This highlights the difficult situations that individuals and families faced, and needed to overcome in order to make significant progress. In 1953, at a BCWS conference, Sir Frederick Messer M.P. had spoken of the essential roles that parents, medics, educationalists and therapy providers all had to play and how they needed to 'be prepared to work as a team' for the benefit of the child. ${ }^{92}$ This was often difficult to achieve and this difficulty has endured over time.

\subsection{Conclusion}

This chapter shows that despite the challenges, new research and the actions of parents had proved that children with cerebral palsy could be educated. Parents had driven an intense campaign, challenging the medical model of disability, which had overshadowed progress. The paradox was, the emotive images used, also perpetuated aspects of the medical model. However, parents were driven by a desire to bring about change, where the lack of an education had imposed social exclusion and deprived their children of opportunity. The use of images which promoted their associations, brought them financial gain and allowed them to continue with the campaign processes.

\footnotetext{
91 Interview with Alan Counsell.

${ }_{92}$ Harborne, Cerebral Palsy Midlands, Addresses given at a one-day conference on The Cerebral Palsy Problem Today, British Council for the Welfare of Spastics, November 1953, p.4.
} 
The development of transnational networks, and implementation of new approaches towards cerebral palsy, had a positive impact on how services developed in Britain. Incorporating therapy treatment as part of a holistic approach, was helped by the advancement of subsidiary branches of medicine, which included speech and physiotherapy. This chapter has demonstrated how parents and parent-led 'spastic' associations embraced a new approach, although the struggle to view parents as equal partners, is also considered. Wrigglesworth argued at the Oxford seminar, 'a skilled therapist, on economic grounds alone, can only be available for a fraction of the time'. ${ }^{93}$ Parents, with guidance, could continue treatment at home, which addressed some of the concerns around economic sustainability.

Carlson House School has been used as a case study in this chapter, and it has been shown how it challenged the educational system with innovative approaches. Through educating pupils with cerebral palsy, the purpose and value of education was brought into question. Matters raised included, whether children were worth the investment, as they were not perceived to be future contributors to the economy; whether employment outcomes were feasible; or whether education for these individuals should simply be focused on preparing them to achieve a level of independence. These questions demonstrate that despite progress made, the reality for many was still inequality and segregation, where a stereotypical view of a 'spastic' child remained dominant. However, this chapter has shown Carlson House School achieved significant success, and shared its knowledge widely with other organisations and individuals. It has been argued that the advancements made could not have been achieved if left entirely to local and national government interventions. Similarly, the progress made by the NSS, through their schools, also proved what could be achieved by coordinated campaigns.

At the heart of change, parental involvement remained constant; their role did not end with the establishment of schools as they continued to fundraise,

${ }^{93}$ Wigglesworth, p.3. 
provide support and campaign. Continued involvement meant new relationships, forged with key professionals in education and health, were complementary in the development of services. A sense of community linked parents closely together, adding strength, to work as one, against a perceived unjust system. The drive behind progress of parent-led 'spastic' associations had come from 'parent power', and it is understandable why they may have felt a sense of possessiveness for what they had achieved. 


\section{Sheltered employment: the development of Work Centres and the limited opportunities for school leavers with cerebral palsy}

In achieving independence, employment is a natural next step after leaving education but for many individuals with disabilities, this was not immediately attainable. Owen Davies, a member of Swansea and District Spastic Association (SDSA), reflected on the achievements of the association, and how they had 'educated the public in understanding the needs and long-term potential of spastic persons.' He said that individuals of 'reasonable physical and mental ability should be encouraged to become far more independent', and to 'socially integrate with able bodied people and in general strive for a far higher degree of individuality and self-respect'. He argued that the 'existing attitude of always mixing with your own sort, [was] antediluvian and entirely unnecessary'. ${ }^{1}$ It can also be argued that continued parental intervention, as children reached adulthood, inhibited independence. This, together with the development of sheltered employment meant that many individuals continued their lives within the same environment. Whilst parent-led publicity campaigns had raised the profile of 'spastic' children, they had also cultivated an attitude which evoked pity. Employment, together with financial security, can support a person in becoming a full member of society but not all individuals with cerebral palsy were able to take steps to independence in this way. This raises the question, to what extent a level of independence had been achieved. Public expectation of what a person with cerebral palsy could achieve had been adversely influenced by the actions of associations.

This chapter examines independence and employment, arguing that employment opportunities for 'spastic' school leavers in the 1960s and 1970s, were limited. It was challenging to find employers who were willing to accept a 'spastic' person as part of their workforce, despite the campaign co-ordinated by the National Spastics Society (NSS). This campaign included a series of films made by the NSS which challenged employers to give 'spastics' a chance. The

\footnotetext{
1 Owen Davies, 'A shift of emphasis' in Swansea \& District Spastic Association Year Book,
} 1979/80. 
NSS 1961 Annual Report stated that the Employment Department of the NSS had made a documentary to show 'individual spastics in a variety of different types of jobs'. It was hoped that the film would generate interest 'amongst employers and the general public' and so create more opportunities for work. The film also reported on the activity of 'spastic' Work Centres and the 'variety of sub contract work' that could be undertaken. ${ }^{2}$ Local association campaigns had contributed to the limitations of opportunities, offered to 'spastics', through the continuance of parental intervention in their adult child's life.

The opening of Work Centres did provide a valuable contribution to the problem of providing employment for people with cerebral palsy. This chapter examines the variety of work available, considering the impact it had on the lives of those attending Work Centres. 'Spastic' Association Year Books and other primary sources reveal a narrative which is mediated by the views of parents, educators, medical staff and other professionals. Limited academic analysis has been undertaken to discover whether Work Centres for 'spastics' were viewed as a success, or whether they perpetuated a negative view of people with cerebral palsy.

This thesis has discussed how the voices of disabled children have been largely hidden from history; this remained the case for many individuals with cerebral palsy, as they moved into adulthood and struggled to make their voices heard. As the original children of the post-war era became school leavers, the level of choice available during the 1960s and 1970s, is questionable. This chapter argues that it was limited by a number of factors, which included parental intervention, negative attitudes in society, and a lack of life and work experience. The medical model of disability still influenced attitudes, despite the emergence of the social model of disability in the mid-1970s.

\subsection{Prospects for school leavers}

As pupils with cerebral palsy reached school leaving age, it became

\footnotetext{
${ }^{2}$ National Spastics Society Annual report (1961), p.20.
} 
apparent that there were limited opportunities for employment. An article written by M.R. Morgan, Employment Officer of the NSS (1960), considered the options available for school leavers and said that in the coming 'few years' there would be a peak in the number of 'spastic' school-leavers and therefore more competition for jobs. She said that as more children with cerebral palsy were now receiving an education then it was 'quite understandable that they should have the same ambitions and desires for work as any other young people leaving school.' ${ }^{3}$ Whilst theoretically this was true, achieving those 'ambitions and desires' was another matter. An article in 1961 by the Headteacher of the Thomas Delarue School in Tonbridge, Kent, a school established by the NSS, posed the question about what was the 'true function' of 'spastic' schools'? His answer was that it was their 'duty' to 'ensure that those who [were] employable' to be as 'well prepared as possible to go either straight to work or to training or employment'. He argued that the schools 'must endeavour to equip all pupils to live as full and interesting lives as may be possible within the limits imposed by their physical disabilities'. Learning to be independent was viewed just as importantly as literacy and numeracy skills with both genders undertaking occupational therapy to learn to cook, sew, shop and handle money, undertake household tasks and maintain their living areas. ${ }^{4}$ However, Colin Barnes and Geof Mercer state that the 'historical experience of disabled people within industrial capitalism has been of significant exclusion from, and marginalisation in, the labour market'. ${ }^{5}$ Historically, people with disabilities obtained jobs that were often below their capability or did not match their aspirations.

Aside from the limited opportunities on offer, the failure to see individuals as being able to work, further exacerbated the situation. Alan Counsell, had a career which included nursing and social work before he became a teacher, but expectations were not high for him on leaving school, as he recalled:

Well, we had a career advisor called Mr Jolly, and he's

\footnotetext{
${ }^{3}$ Swansea, West Glamorgan Archive Service, D/D LA 5/1, M. R. Morgan, 'After School - What'? in Swansea \& District Spastic Association Year Book 1959/60, p.20.

${ }^{4}$ H. B. Davies, 'Preparation for School Leaving', Spastics News Magazine of the Spastics Society, July 1961.

${ }^{5}$ Colin Barnes \& Geof Mercer, Exploring Disability (Cambridge: Polity Press, 2010), p.113.
} 
one of the people I would love to meet today. He must be dead now; he must be long gone. But he gave no hope: me in work? You know, and then all, everybody in my form at school had got jobs, but not me. ${ }^{6}$

Alan is just one example of a range of individuals with cerebral palsy who defied expectation and had successful careers outside sheltered employment.

There are limited statistics to support analysis of school leavers with cerebral palsy, but a small sample is available through MSA. A survey from Carlson House School, provides an indication of outcomes for school leavers. It covers the period 1960 to 1975 , where less than half of 36 pupils found employment, with the remainder either staying at home or attending a day centre. Eight females and seven males found employment, but not all of these were recorded as being 'likely to find' employment, when they started school. The survey reports on the job roles of the males, which included a lift attendant, a market stall trader, a factory worker and clerical jobs including an accounts clerk. Of the eight females, two were in employment as a clerk and a typist. The remaining six had worked but no details of the type of work is recorded other than the fact that they were now married, some with children. ${ }^{7}$ Another source comes from a Midland Spastic Association (MSA) report in 1961 of 17 Birmingham school leavers with cerebral palsy. There were 12 who were said to have 'normal intelligence' with the remainder being classed as 'sub-normal.' These pupils had attended a variety of schools, including schools for the physically handicapped, residential schools and 'normal' schools. The range of jobs for those of 'normal intelligence' included shop work, a motor mechanic, clerical and assembly work whilst the remainder attended day centres. ${ }^{8}$ Despite the specialist attention given at Carlson House, where resources had been geared towards individual needs, the statistics demonstrate that the majority of school leavers did not progress into paid employment in the 'outside' world. Of the Birmingham school leavers who

\footnotetext{
${ }^{6}$ Interview with Alan Counsell by Dean Thomas, 26 January 2005, 16 February 2005, 23 February 2005, 30 March 2005, Speaking for Ourselves: An Oral History of People with Cerebral Palsy, reference C1134/08/01-08, British Library.

${ }^{7}$ Harborne, Cerebral Palsy Midlands, Handwritten report detailing a survey of Carlson House school leavers, 1960-1975.

${ }^{8}$ Harborne, Cerebral Palsy Midlands, Details of Birmingham school leavers, 1961.
} 
had attended a variety of different schools, a higher proportion found employment. However, these figures are just a snapshot, contained within the same geographical area. To establish whether these results are nationally significant would require further research beyond the scope of this thesis.

A range of variables would have affected individual prospects in addition to educational experience, such as: life experience; type of cerebral palsy; individual outlook and determination; intelligence; and support network. The 'collection box' culture, used to evoke feelings of sympathy for monetary return, was difficult to shake off. An attempt to change attitudes is depicted in the opening scenes of the film The Right to Work (1974). The narrator, who has a disability, stated that the people in the film were:

a group of people who, if society were honest with itself, would probably say [were] more of an embarrassment than anything else. For we reflect a peculiar kind of hypocrisy, while everyone seems prepared to accept us when we are children, once we grow up, they seem totally unprepared to accept the possibility, that we have the same aspirations as everyone else. ${ }^{9}$

Individuals had been defined by their impairments, and aspects of this continued into adulthood, despite a concerted effort to change opinion. The immersion of parents in all aspects of their child's life, meant that they had invested a lot of time and energy in their desire to bring about change. However, the dynamic marketing approach which had been employed, reinforced a model of dependency. Being transported daily, door-to-door, from home, to school or centre, and back again, left little opportunity for an individual to branch out and undertake social activities, and such activities form part of independent living.

At this time, there was little or no representation on the governing bodies of 'spastic' associations by those who attended them, and this limited the contribution to decisions made by those who wanted to make their voice heard.

9 The Right to Work, dir. by Nigel Evans (A Randel Evans Production for The Spastics Society, 1974), online film recording, Wellcome Library

$<$ https://wellcomelibrary.org/item/b16744421\#?c=0\&m=0\&s=0\&cv=0> [accessed 9 March 2018]. 
Instead they were often treated in a childlike way. For example, the idea of a Social Club formed at SDSA came from a suggestion by the Management Committee and the activities reported on were organised by parents. ${ }^{10}$ Some individuals with cerebral palsy had designated roles on the Social Club committee but it appears that they were 'figureheads' and did not have any real power in organising events themselves. A report of activities in 1965 reveals events which include a conjuror, film shows and a day trip to the Gower. They are reported on as if those taking part were children. It was stated that the 'ladies of the Inner Wheel Club' had provided sweets to 'replenish' the Tuck Box. ${ }^{11}$ Whilst these articles are succinct and simply give an overview of events, there is a distinct lack of representation from individual members of the Social Club. We do not hear their voices, comprehend the level of involvement they may have had in the organisation of activities or how they may have viewed the activities.

It is likely that individuals, who had been in residential schools, would have faced similar situations in getting their voices heard or being represented on governing bodies. Significantly, they were still segregated from wider society, and their choice of activities was driven by those in authority. Sheila M., born in mid Wales in 1957, described school activities at Ysgol Erw'r Delyn, a residential special school in the Vale of Glamorgan. She said:

\begin{abstract}
You 'ad to go to Brownies, you 'ad to go to Guides, you 'ad to go to youth club, you, you didn't have a choice, you 'ad to do it. And you 'ad to eat your food. You couldn't say you don't want no-, I remember on a Friday, when I was in school, I didn't like fish and the headmaster made me eat it. So, you couldn't say you didn't want anything; you were forced to eat it, which was a bit cruel but you 'ad to 'ave it. You 'ad to have everything. Yeah ${ }^{12}$
\end{abstract}

A more traditional approach to education may have encouraged full participation

\footnotetext{
${ }^{10}$ Swansea, West Glamorgan Archive Service, D/D LA 5/2, Ethney Rasbridge, 'Trainees Organise Social Club' in Swansea \& District Spastic Association Year Book 1960/61, p.19.

${ }^{11}$ C. Pridmore \& L. Rumbelow, 'Our social clubs' round of activities' in Swansea \& District Spastic Association Year Book 1964/65, p.33.

12 Sheila, M., interviewed by Teresa Hillier about the history of Longfields Association, 16 August 2017.
} 
in activities, but the level of intervention in the lives of children with cerebral palsy, was significant. Arguably, individual lives had been more regimented than those of their peers, as they underwent rigorous therapy treatments, and were subjected to strict monitoring processes. Positive benefits were outweighed by the culture of dependency which allowed others to influence key decisions in individual lives.

Lack of life experience and maturity was highlighted as an area of concern in relation to 'spastic' school leavers. This negative view towards employment prospects was reiterated in a paper given at a seminar, held by the Spastics Society at Oxford in 1966. M. Peacey, a Careers Advisory Officer of the association, argued that 'inexperience of life' was a 'major problem which confront[ed] one in discussing work with young cerebral palsied school-leavers'. She stated how it was not 'uncommon to find young men and women who ha[d] never worked out for themselves a bus or train journey, or perhaps even made decisions about their own clothes'. She argued that 'exposure to calculated risks [was] probably the only chance some of these young people [would] ever have of pitting their wits against some of the realities of life'. ${ }^{13}$ Lack of life experience was difficult to address, many individuals needed a level of support to undertake some activities, but having a level of choice and the ability to make your own decisions is also part of achieving independence.

Having the means to break free from controlling influences was not easy and the following narrative from Pauline Johnson is representative of how sheltered some individuals were from the 'realities of life'. Pauline, born in Handsworth in 1949, recalls how she 'wasn't allowed to do quite a lot of things that [she] should have been'. She said of her parents, they were:

more cuddled-up with the notion that, you know, "We're not going to let them, you know: keep them as young as possible", that sort of attitude. "Don't let them, you know, lead, slap the lead", you know. It's in a way, it's very sad in a way.

${ }^{13}$ M. S. Peacey, 'Unrealistic Aspirations', in The Spastic School Child and the Outside World, ed. by James Loring and Anita Mason (Oxford: William Heinemann Ltd., 1966), pp.106-112 (p.110). 
Pauline said that she was not 'allowed to cross the road on her own' nor 'walk the bloody streets alone'. She thought her parents were frightened that she might hurt herself and said that she 'lost a lot of [her] teenage years' although she understood her parent's concerns and her mother apologised to her 'long before she died'. Pauline thought that she did not 'really blossom' until she was in her early forties when she left home. She said, 'now l'm a middle-aged woman and I think about my own childhood, and the years I could have lived on my own'. She referred to her father who said 'some hurtful things' and when asked during an assessment if Pauline could make a cup of tea, he denied this and Pauline said she 'sat there and thought to [her]self, "No, because you won't even let me try"'. As a woman now in her sixties she thought that 'young parents' should be taught not to be 'so afraid' and to 'let the[ir] child[ren] experience something with cerebral palsy' rather than think, 'he or she won't be able to cope to do this: they won't be able to take it in; they won't be able to do this, that or the other'. ${ }^{14}$

Owen Davies provides an ironic analogy on the long-term effects of segregation which is descriptive of how some viewed the consequences of being grouped together for 'unhealthy long periods of time':

Just think what exactly happens to a Spastic person from the moment he or she leaves their mother's womb. For the initial eighteen years of life you are systematically processed and graded, like Frozen Peas, by the Medical and Educational Professions. This processing environment is created for convenience sake. Unfortunately, it has to be this way, otherwise if Surgeons or Teachers had to assess the true potential of each Spastic Child, it would take longer than eighteen years and its highly possible that they would still reach the wrong conclusions. Having reached eighteen, you are then passed on, because even now you are not an individual, more the 'booby' prize in an endless game of 'Pass the Parcel' and the music is playing so fast that no-one has time to find out what you can do, so you are plonked in a Work Centre with yet another group of Spastic people. After a while the next stage of 'processing' will take place,

\footnotetext{
${ }^{14}$ Interview with Pauline Johnson by Anne Austin, 13 March 2006, 10 April 2006, 25 May 2006, Speaking for Ourselves: An Oral History of People with Cerebral Palsy, reference C1134/30/0105, British Library.
} 
an offer of a vacancy in that nice Residential Home just around the corner from the Work Centre. Thus, the circle of conformity is complete, you are now living and working with the same Spastic people which you went to school with. ${ }^{15}$

There can be no denial that segregation and parental anxieties contributed to the failure of some individuals to achieve a level of independence. However, parental anxieties have to be considered in context. To a certain level, parents had also experienced a high degree of social isolation and had overcome significant challenges in parenting their child. As one parent from MSA said, 'far fewer will know just what [the] new beginning meant to those of us who had travelled painfully through that early period, when the word "spastic" was unknown'. ${ }^{16}$ Sharing parental concerns, with others in similar situations, gave credence to actions undertaken.

Perceptions of ability to live independently, as a person with cerebral palsy, are contrasted through the following differing views. A hostel, managed by the national association, opened in Swansea in the late 1960s. People who lived there attended the Work Centre at SDSA. Two individuals, Andrew S. and Sheila M., recalled positive memories of their time living in the hostel. They both thought that they had more independence when compared with their peers, who lived at home in a family environment. They said how people living in the hostel were able to go out into the local community, socialise, and do everyday tasks such as shopping. Andrew and Sheila had also been pupils at residential schools. Their life experience, and the fact that they lived independently, reveal a different attitude taken towards them by some at SDSA. Sheila recalled how they weren't allowed to go on any holidays organised by that association, 'because [they] didn't have any people to go with' such as a family member and so could not be 'looked after'. Those individuals who went on the holidays, lived at home and their families were either founder members of the association or were heavily involved in its running. Sheila thought that those who lived at home

\footnotetext{
15 Owen Davies, 'What's in a name ..., Swansea \& District Spastics Association Year Book, $1984 / 85$, p.24-25.

${ }^{16}$ Harborne, Cerebral Palsy Midlands, The Whitbread Family, "Three Parents Look Back to the Early Days' in Midland Spastic Association Year Book 1977/78, p.17.
} 
were 'more sheltered'. ${ }^{17}$ Andrew said, some at the Work Centre were a little bit 'mentally handicapped', and he saw his peers at the hostel as being different. He said they 'were not being awkward' because those living at home 'were nice people', but those from the hostel 'did not want to end up like them' because they valued their independence. He said it was a struggle to maintain independence but they got on with things. ${ }^{18}$

A discussion between Gillian Y., Helen H. and Sarah T., who were the daughter and granddaughters of Laura Rumbelow, the first 'works supervisor' at SDSA, reiterate these views. They all thought there was a difference between the group living in the hostel and those living at home. They thought parents were 'very protective' and Helen said that 'often parents [stood] in the way of people achieving their potential . . because they [had] been so protected'. Sarah recalled that when the hostel was opened there was a 'lot of conversation' about individuals 'coupling up' and how this was 'probably a great worry to everybody' and concern was expressed as to how 'people would cope' living more independently. Sarah said that they:

coped absolutely marvellously. Looked after themselves and had a really good time ... they had the freedom if they wanted... 'cause they were grown men and women.

They all commented that it was not until the group from the hostel began attending SDSA that people 'actually began to realise how independent they could be'. Sarah described how there was a realisation that individuals:

had their own minds, and saw what they wanted to do. Before that they were very controlled. And they couldn't do, you know they weren't allowed to do anything. They were barely allowed to sit next to each other. ${ }^{19}$

17 Sheila M., interviewed by Teresa Hillier about the history of Longfields Association, 16 August 2017.

${ }^{18}$ Andrew S., interviewed by Teresa Hillier about the history of Longfields Association, 12 February, 2018.

${ }_{19}$ Gillian Y., Helen H. and Sarah T., interviewed by Teresa Hillier about the history of Longfields Association, 15 March, 2018. 
However, despite this realisation letting go was not easy. The complexity of roles and relationships is discussed in Making Connections (1989). A mother of a child with Down Syndrome reflected on her feelings when her son left home to live in a hostel. She said:

there is the emotional side of you which loves your child dearly and you don't want to part with him. There is the other side, common sense, which says now is the time. If you love him let him go. ${ }^{20}$

An appreciation of the difficulties experienced by parents gives a level of understanding to their motives and how hard it was, for some, to relinquish the level of responsibility they had in their children's lives.

Tom Shakespeare considers parents who continue to provide care for their older disabled children and argues that they 'may be unable to see them as adults in their own right'. He discusses their need to 'provide emotional and social support' as well as physical support which also involves making decisions for their adult child. ${ }^{21}$ However, as shown, experiences of isolation and discrimination left a lasting impact which did not diminish, but rather re-energised parents to take up a new cause in their adult child's life. Barry Morgan recalled how his parents wondered what he would do for a job when leaving school. He said:

they started thinking 'What is he going to do when he's
left school?' You know, 'What's he going to do for a
job?' and, it just goes to show what they was like, you
know: 'What is he going to do as a job?' you know.
And my dad had the daft idea... well, it ain't a daft idea,
but, he had the idea that l'd become a vicar. Honestly.

One of Barry's first experiences of trying to find employment involved his father who had taken him to the labour exchange and asked if they could find Barry a 'nice little job'. He was offered an interview for work in a factory that made tents

${ }^{20}$ Ann Richardson, 'If you love him, let him go', in Making Connections: Reflecting on the Lives and Experiences of People with Learning Difficulties, ed. by Ann Brechin and Jan Walmsley (London: Open University1989), pp.5-12 (p.9.).

${ }^{21}$ Tom Shakespeare, Help (London: Venture Press, 2000), p.47. 
and camping equipment. He recalled his first job interview, which he did not attend alone:

me dad sat with me in the interview, and, sort of, the man behind the desk said, 'What? How old's Barry?' and all this sort of thing, and 'He's just left school' and this sort of thing, and 'We'll give him a job in the stores, you know. Ten and six a week.' So me dad says 'All right. ${ }^{22}$

Parents' actions had been key in the campaign for education and often, they had been the only people providing advocacy for family members. Therefore, a level of understanding can be afforded to their seemingly controlling attitudes, but this meant a continuation, faced by many, of the same limitations experienced as children.

In their paper discussing parent advocacy, Jan Walmsley, Liz Tilley, Sue Dumbleton and Janet Bardsley reflect on the history of families advocating for relatives with learning disabilities. They argue that 'families are the most consistent individuals in the lives of most people with learning disabilities'. This same argument can directly apply to the families of those with cerebral palsy as both groups of parents had to 'fight for support and resources' and this has continued into today's society as Walmsley et al illustrate through 'contemporary family testimony'. They argue that whilst it is not:

de rigueur in disability studies to include the voices and experiences of family members alongside those of disabled people ... for those . . . whose voices may go unheard, or for those who do not speak at all, and in the absence of consistent advocacy, families can be an important route to publicising their concerns and needs. ${ }^{23}$

The issues of cerebral palsy, cannot be simply addressed through employing the

22 Interview with Barry Morgan by Anne Austin, 24 January 2005, 7 February 2005, 21 March 2005, 18 April 2004, 9 May 2005, Speaking for Ourselves: An Oral History of People with Cerebral Palsy, reference C1134/07/01-08, British Library.

23 Jan Walmsley, Liz Tilley, Sue Dumbleton and Janet Bardsley, 'The changing face of parent advocacy: a long view', Disability \& Society, 32.9 (2017), 1366-1386 (p.5) <http://dx.doi.org/10.1080/09687599.2017.1322496>. 
social model of disability. Whilst this model did have an impact in terms of accessibility and attitudinal change, individuals required support in ways which the social model could not easily address, therefore achieving the right balance was difficult. The role of parent advocacy in the lives of people with a learning disability or cerebral palsy, sets these disabilities apart from purely physical conditions.

Post-war reforms had a focus on paid work, where gaining full employment was viewed as a driver for success. The jobs detailed under the 1944 Disabled Persons Employment Act, gave credence to the assumption that disabled people were only capable of a certain type of job, namely unskilled work. Anne Borsay argues that the 1944 Act had a 'narrow scope' and did not 'cater for all types of disabled people'. She discusses the 'invidious designated employment scheme', highlighting job roles deemed as suitable, such as lift operators and car park attendants. She contends that Disablement Resettlement Officers and the Employment Rehabilitation Centres were 'orientated towards manual jobs and so failed to deliver rehabilitation across the full occupational range'. ${ }^{24}$ This approach was one which still clouded the vision of many employers who could only see problems to be overcome if they gave a job to someone with cerebral palsy. Ken Blakemore and Robert Drake argue that the Beveridge Report and the 1944 Disabled Persons Employment Act were 'predicated upon the belief that disabled people were prevented from working by their medically defined, physical or cognitive impairments'. ${ }^{25}$ Cerebral palsy remained defined by the medical model of disability, and this impacted on the range of opportunities available to people with the condition, which added to the difficulties in pursuing employment.

The following experiences of Lin Berwick and Desmond Cox illustrate how perception of them, as individuals, disparaged the view of their true capabilities. Lin Berwick recalled her experiences of trying to find work when she left school in 1968 and said how difficult it was to get 'gainful employment' and if you had a

24 Anne Borsay, Disability and Social Policy in Britain since 1750 (Basingstoke: Palgrave Macmillan, 2005), p.136.

${ }^{25}$ Ken Blakemore \& Robert Drake, Understanding Equal Opportunity Policies (Hemel Hempstead: Prentice Hall Europe, 1996), p.143. 
'multiple disability, well then you're regarded as a non-starter'. Lin was visually impaired as well as having cerebral palsy and on applying for training at the RNIB College the 'tutor there said she was paid to teach visually-impaired people, not spastics'. Lin eventually had an interview for a job, as a telephonist at the Commonwealth Trading Bank of Australia, at which she was successful but it did not get off to a very good start as she recalls:

I remember, when I got to the bank, it was one of these banks with these horrible revolving doors, which wasn't easy, going through on a pair of tripods: but, anyway, eventually, found my way into the bank, and made my way to the accountant's office, and when he opened the door he, said, "Oh, I know they told me you were disabled", he said, "but I didn't realise you were that disabled, but you might as well come in and sit down anyway", and I thought, 'God, this is a really good start to your first job interview!'26

Despite having undergone training and achieved at a high-level, Lin's experience highlights how the value of this training was questioned by potential employers as often they could not see beyond her disability. Desmond Cox, born in Wolverhampton in 1955 recalled the skills he had learnt through 'different training schemes' and said how some employers 'as soon as they heard the word disabled' would not give him an interview. He said how he had 'only had full-time employment, twice' as all other work had been 'placements' and at the end of these the 'employers [felt] that they [couldn't] take [him] on for reasons of their own' 27

William (Bill) Hargreaves, Industrial Liaison Officer of the NSS, considered the dilemma that many 'spastics' experienced when compared to their ablebodied contemporaries and said that many employers did not give them a chance, mainly 'from a very definite lack of understanding'. He believed that a 'climate of understanding' was needed between employer, trained 'spastic' and

\footnotetext{
${ }^{26}$ Interview with Dr Lin Berwick MBE by Philip Mann, 8 November 2004, 11 November 2004, 14 February 2005, Speaking for Ourselves: An Oral History of People with Cerebral Palsy, reference C1134/04/01-07, British Library.

27 Interview with Desmond Cox by Anne Austin, 25 May 2005, 6 June 2005, 6 December 2006, Speaking for Ourselves: An Oral History of People with Cerebral Palsy, reference C1134/12/0103, British Library.
} 
employee. He argued that 'for so long, the spastic ha[d] not been understood and somehow his awkward movements ha[d] given the wrong impression of his mental abilities'. He referred to the sheltered life that some 'spastics' led because of special schooling and suggested that as a result they were 'unrealistic about the sort of job they were able to do'. He asked the reader to consider this and 'face a few facts'. He pointed out that employers were in business to make money, and would expect a worker to 'pull his weight alongside his fellow workers' in order to give a 'reasonable return for the payment received'. ${ }^{28}$ Hargreaves is generalising in his statement, as it is inferred that the majority of potential employees, were destined to become manual workers of some description. It would have been inevitable that some individuals, in certain jobs, would not have been able to keep pace with their non-disabled counterparts, due to the physical limitations of their disability. However, this can be said of other people with physical disabilities, but those with cerebral palsy were viewed as having 'multiple handicaps', due to perceived cognitive impairments. Hargreaves himself had cerebral palsy, and whilst his statement is slightly at odds with promoting employment in a positive way, he was probably being realistic in reflecting the attitudes of some potential employers.

Hargreaves described his role as Industrial Liaison Officer in his biography Can you Manage Stares? (2001), a job he did for five years, and he said how he travelled every day, 'into industry', spreading the message:

I'm a spastic, look at me, you may think that I look odd; but I don't feel odd. I stagger about, but I don't fall down or drop things. My hands wave about but I still do a good job of work. I just need a chance. That's what spastics need - a chance to prove themselves. We are just normal people locked in disobedient bodies. ${ }^{29}$

Hargreaves' statement chimes with the type of marketing consistent with the more provocative style, adopted by the NSS, at this time. However, it is

\footnotetext{
${ }^{28}$ Swansea, West Glamorgan Archive Service, D/D LA 5/2, William Hargreaves, 'Over 300 Placed in Employment' in Swansea and District Spastic Association Year Book 1960-61, pp.23-24.

${ }^{29}$ Can You manage stares? The life of Bill Hargreaves, ed. by Alex White (Cambridge: Black Bear Press, 2002), p.70.
} 
questionable how this statement reflected positivity in promoting the view of 'spastics', as individuals with a range of talents. Indeed, Hargreaves' statement seems rather flippant, and he is guilty of representing his peers in a stereotypical way, as objects of pity in need of charity, or as people who did not mind being ridiculed. In his role, Hargreaves described how he 'came to the conclusion' that apart from speaking to 'top management' he needed to speak to the 'foremen, chargehands and workers' to 'educate' them 'to accept the sort of disabled employee they would rarely have met before'. ${ }^{30}$ At one level this can be said to be a sensible approach, but may also have conditioned potential work colleagues to expect a 'freak', who you needed to be warned about, and be prepared before meeting them.

'Emotional immaturity', is cited by Hargreaves, as a weakness of the 'people he was trying to place', and whilst this may have been true, his representation of individuals, does not appear to encourage emotional development. He referred to failures in placements as being a result of this immaturity, and described how when this happened he would go and see the employee and 'tear strips off this person, saying. "What the hell have you got me to come in for? You're doing this job, not me. Pay attention to what you're being asked to do."'31 There may be an element of exaggeration by Hargreaves, as he told his story, but the actions quoted reflect a paternalistic attitude, as was adopted by the NSS and parent-led 'spastic' associations. At this time, Hargreaves was unique in his status within the NSS, as many disabled people did not generally have positions of authority within the association. It was run and staffed by non-disabled people, and he was a man with cerebral palsy. In this recollection, Hargreaves seems to set himself apart, in his attitude, from his contemporaries.

One of the fundamental aims, of parents in the 1950s, had been to 'educate' the public and wider society about cerebral palsy, so that individuals with the condition could be accepted, enabling them to participate in everyday

30 Ibid., p.71.
31 Ibid., p.73. 
life. However, during the intervening years it would appear that little tangible progress was made, in the achievement of 'spastics', particularly with regard to employment. It was still only a 'select group' who had an understanding of the abilities of individuals with cerebral palsy. A continued negative perception is illustrated in the following narrative by Valerie Lang. She said how during most of her career 'people [had] largely accepted her' but she had come across 'jealousy from time to time'. This she said had 'been from people' who had achieved 'lower grades' than her in education and she said occasionally, 'people have thought it was not fair that [she] should have got the level of job that [she] did achieve because of [her] disability'. She described how she 'was attempting to get jobs at a level where people in those days were not used to meeting someone with [her] level of disability'. She said that it was:

a hell of a lot harder then to get work, than to get an education. It's one thing to offer a disabled person a place in a university, it's quite another, I think, or it was in those days, quite another to look at them from the point of view of giving them a salaried position. ${ }^{32}$

The prevailing view that people with cerebral palsy could not be employed remained, and the development of Work Centres, specifically for these individuals, did not challenge this.

\subsection{Developing Work Centres}

Work Centres established by parent-led 'spastic' associations did not develop in isolation, but grew around the time of other new ventures into sheltered employment, in post-war Britain. The ideal outcome was that following a period of time in sheltered employment, the disabled individual would be able to apply to work outside that environment. One such enterprise was the development of government-run Remploy factories, for 'people whose disability precluded them from finding work on the open job market'. Julie Anderson considers their

32 Interview with Valerie Lang by Philip Mann, 10th February 2005, 17th February 2005, 22nd February 2005, 2nd March 2005, 11th March 2005, 17th March 2005, 22nd March 2005, 18th April 2005, 29th April 2005, 4th May 2005, 8th June 2005, 15th June 2005, 22nd June 2005, 1st July 2005, 22nd July 2005, Speaking for Ourselves: An Oral History of People with Cerebral Palsy, reference C1134/10/01-25, British Library. 
expansion, from the first established in 1946, to 25 by 1948 , and by 1953 there were ' 90 factories' which employed '6,000 disabled people'. Anderson describes how 'much of the work' undertaken at the factories was 'traditional' of the type of work 'undertaken by disabled people for decades, including woodwork, leatherwork, and mat and brush making'. Remploy establishments were classed as factories, and the types of disability of those employed there are described as 'pulmonary tuberculosis, congenital deformities, heart and lung disease, and epilepsy.' In addition to Remploy factories there were a smaller number of private sheltered workshops, which benefited from government grants, but Anderson comments that there were only '700 disabled people given work from 25 government grants in 1949'. She discusses the importance of 'getting disabled people back into work after the war' and cites an economic benefit, as it was 'better for disabled people to pay tax and produce goods and services', as 'Britain's economy was in a perilous position'. ${ }^{33}$ By their nature Remploy workers were segregated in their factories from the rest of society. These ventures can be viewed as social enterprises within the new welfare state, as they provided a service despite making a financial loss. However, Work Centres at parent-led 'spastic' associations, can be viewed as being distinct from other forms of sheltered employment, as they were inclusive to those individuals, with more profound symptoms of cerebral palsy, who would have been automatically excluded from other employment.

The development of association Work Centres, strengthened the community which had grown up following the inception of associations, in postwar Britain. As stated earlier, ventures such as Remploy can be viewed as social enterprises, and this term can also be applied to Work Centres, created by associations. A study commissioned in 1974 by the Spastics Society, considered 'the employment of severely handicapped people in 26 Work Centres' in Britain. The "broad terms of reference were to study "Productivity and Job Satisfaction of the Disabled in a Work Centre Environment"', where researchers were tasked with 'a view to identifying areas where improvement might be made', particularly 33 Julie Anderson, War, disability and rehabilitation in Britain (Manchester: Manchester University
Press, 2011), p.183. 
'within existing resources'. Researchers were occupational therapist, Hilary Schlesinger and clinical psychologist, Edward Whelan. In the report's introduction, they reflected on the 'traditional attitude' that had prevailed when 'providing services for disabled adults'. These had been to 'divide them into two groups - the disabled who [were] "employable" and the severely disabled who [were] not'. Of the first group, services had been 'geared towards placing them in open employment', particularly of an 'industrial nature', and their 'integration in the community has always been thought of exclusively in connection with work'. Of the 'unemployable' group, there had been 'an emphasis on providing welfare services, mostly of a social or diversionary character'. Schlesinger and Whelan maintained that little had changed within a thirty-year period, since post-war reform. They argued that 'Day Work Centres for spastics [were] unique in their approach to the multiple handicapped', as those who attended them would have belonged to the 'unemployable' group and so would have been 'eligible for welfare services'. Therefore, in these circumstances, Schlesinger and Whelan stated that it was not 'surprising to find that the first question to be raised' in the initial stages of the study, was 'directly related to the nature of the service that should be provided'. It was asked,

should the Centres be primarily places of work, or should they provide the diversionary, educational and social activities normally available to those of a similar degree of handicap and considered capable of only a 'modicum of effort and industry'?

Whilst monetary gain would obviously have been welcome to associations, generating a profit was not the key driver. ${ }^{34}$

The survey raises questions about both the meaning of and the value of work to individuals. This is a topic explored by Laura Yakas who defines work as a 'purposeful activity that builds community' which challenges the 'narrow neoliberal definition of work as "paid employment"'. She poses the question, 'what do I need, and what do I need to do, to feel fulfilled'? She argues that:

\footnotetext{
${ }^{34}$ Hilary Schlesinger and Edward Whelan, Industry and Effort, A study of Work Centres in England. Wales and Northern Ireland for severely disabled adults (London: The Spastics Society in conjunction with William Heinemann Medical Books Ltd., 1979), pp.2-6.
} 
the answer lies in the interconnected feelings of purpose and community. The feeling that one, and one's work, matters to and in a specific group of people, and ultimately, the feeling that one belongs. Hence, [she argues that her] data-driven definition of work became purposeful activity that builds community. ${ }^{35}$

Yakas' theory is pertinent when examining the environment created by association Work Centres as the community they had built, offered stability and a sense of purpose to individuals who were able to be part of a 'normal community', where their contribution was valued. As Schlesinger and Whelan reported 'workers in the Centres regard[ed] work as more than a means of achieving economic independence'. Whilst individuals realised that they could not be entirely 'supported by their own efforts', they saw 'themselves as workers' which meant a 'great deal to them'. ${ }^{36}$ Through their efforts the community survived. Statistics from the study show that $48.8 \%$ of those attending Work Centres do so to 'be with friends and meet people' $21.4 \%$ cite the 'work/doing something useful' as a reason but only $7.1 \%$ cite 'earning money' as a reason.

The strength that came from association communities had allowed them to contemplate the 'problem' of employment and adult 'spastics'. As Schlesinger and Whelan reflected, the formation by the NSS of an Employment Committee, in 1955, had considered this topic. There was a level of realisation that individuals 'needed help in habilitation to the adult world as the development of 'new services' were 'all geared towards productive employment, preferably in normal conditions'. This had 'automatically excluded the more severely handicapped' as they were not able to reach an acceptable 'level of productivity. ${ }^{37}$ The astuteness of the NSS led to the development of the 'only residential training centre exclusively concerned with the training of spastics - into regular work'. The centre was, Sherrards Training Centre in Welwyn Garden City. The 1961 Annual Report of the NSS details the type of training offered, which included 'light

\footnotetext{
${ }^{35}$ Laura Yakas, 'Work is Love Made Visible": Purpose and Community in Clubhouses', Disability Studies Quarterly, 37.4 (2017), <http://dx.doi.org/10.18061/dsq.v37i4.6096>

${ }^{36}$ Schlesinger and Whelan, pp.2-6.

37 lbid.
} 
engineering and woodwork' with a 'commercial course' and 'domestic training' soon to be 'added to the training programme'. ${ }^{38}$ The creation of dedicated training centres, such as Sherrards, arguably gave more opportunity for individuals to improve their skill set and achieve a level of independence.

Barry Morgan, who attended Sherrards, reflects on his time there and aside from the training, he saw this move as an opportunity for him to 'break out and be a little more independent'. However, there were rules employed at Sherrards, as Barry recalls as he talks about social activities in Welwyn Garden City, where he and his friends were not allowed to drink. He said how there were 'quite a few people from the Midlands - and, [they] more or less all stuck together, and used to go to ... a place called 'The Wagon and Horses' in St Albans'. Whilst this level of control was employed, arguably Barry and his friends would not have had the opportunity to socialise in this way if they had continued to live at home. Barry spent three years there and 'learnt various trades' and said that you didn't have to leave until 'they'd found you employment'. Barry said that Sherrards gave him confidence and he went on to work at Walsall College of Technology. ${ }^{39}$

The book Every Eight Hours (1964), provides a narrative of life within Sherrards, but its depiction must be considered in light of the marketing activities employed by the NSS. The day-to-day running of the training centre is depicted as being very regimented. This, ordinarily would not be unusual in such a setting, production targets had to be met and health and safety, dictated many practices to be adhered to. However, the comments on the failings of 'spastics', and their attitude to work is somewhat detrimental. It is stated that 'many spastics in the past' had come to 'grief' because they had seen 'no point in factory discipline', and that this was because they 'had always been the people round whom everyone else, their families or their teachers revolved', and 'nobody expected them to do things as well as other people'. It said that 'they still wanted a normal job, although they weren't prepared to try to work at the normal standard'. It was stated that Sherrards taught them that in order to be accepted 'by the normal

\footnotetext{
38 National Spastics Society Annual report (1961), p.14.

39 Interview with Barry Morgan.
} 
world', then they also needed to accept responsibility. ${ }^{40}$ The descriptive language used would have made the reader think that all 'spastics' were objectionable and unreasonable, and the tone used did not inspire confidence. It is representative of a condescending attitude, faced by families, prior to the establishment of associations in the 1950s. However, documenting individuals in this subjective way is being done by the very people who purported to help them. The text which demonstrates the effort to generate an emotional response, remained a driving force behind this approach, as public donations were still crucial and funding a program to develop Centres such as Sherrards, would have been costly.

Keeping alive the medical model of disability was a useful tool, both in terms of finance, and in generating stories of adversity and achievement. The following, rather extreme example of life within Sherrards, illustrates this:

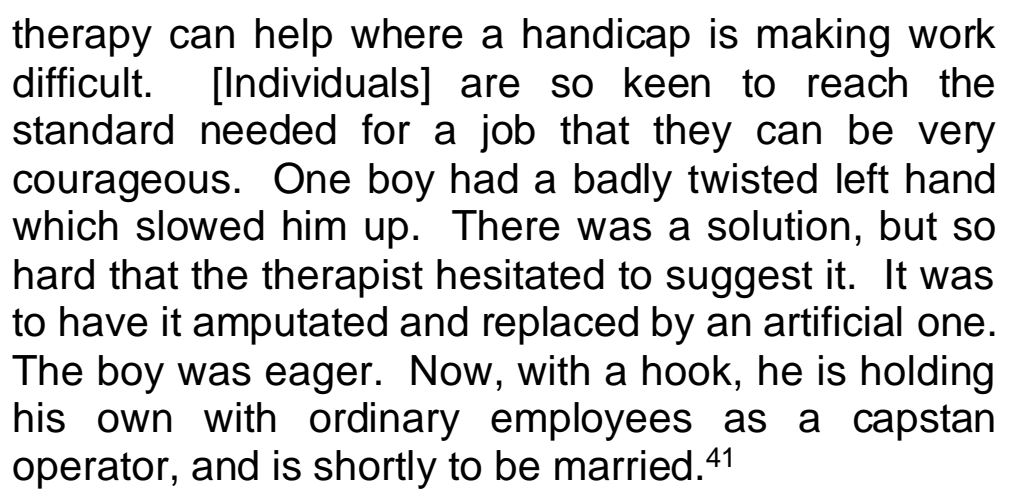

More information is not forthcoming to discover details about the individual who, apparently, had an amputation to improve productivity. However, potential employers, on reading this, may have reconsidered and thought about the 'risks' of employing a 'spastic'. The text endorsed a view that 'spastics' were obtuse and needed training to do the simplest of tasks, 'training in living' as well as in 'technical skill'. ${ }^{42}$ However, the text was not produced as part of a 'recruitment drive', but rather to tell a story and keep generating interest in the 'plight of spastics'. It would seem that, from the point of view of the NSS, it was difficult to achieve a balance between a positive portrayal of an individual, and that of

\footnotetext{
${ }^{40}$ Richard Dimbleby, Every Eight Hours (London: Hodder \& Stoughton, 1964), p.87.

${ }^{41}$ Dimbleby, p.87.

${ }^{42}$ Dimbleby, p.86.
} 
someone who needed support in everyday life.

A book review of Every Eight Hours (1964), in the British Medical Journal from 1965, gives an informed opinion on the purpose of the book, with an insight into the life of the association. The review stated how the book was easy to read and was 'clearly intended for the unscientific reader', but contended, that it would also have been of interest to 'members of the medical and auxiliary professions', in light of the 'brief account' given in the book of 'medical research into cerebral palsy'. The review emphasised that 'of much greater interest' would have been the:

description of the methods used by a group of energetic laymen in order to draw the plans and to collect the funds which have enable[d] the Society to transform the plight of many brain-damaged children.

It continued that the book was a:

remarkable chronicle of achievement in the face of adversity and frustration', and illustrated how the 'attempts of well-meaning laymen to aid their less fortunate fellows [could] sometimes be misunderstood or perhaps be treated less sympathetically than they might [have been] by members of the medical profession.

The review referred to the authors almost 'journalese' style which 'clearly aim[ed] at emotional appeal' but also stated that it was a 'serious social commentary and should be regarded as such by all those concerned with the care of the handicapped'.43 This review is helpful in placing the book in context and demonstrating that it needs to be considered in light of what the NSS was trying to achieve.

${ }^{43}$ C. Allan Birch, 'Spastics Society', in The BMJ, 1:377 (1965),

$<$ https://doi.org/10.1136/bmj.1.5431.377-b $>$. 
The film, Door to Freedom (1956), ${ }^{44}$ includes a sequence on Sherrards which highlights the achievements of 'trainees', and a few individuals who progressed to working on an assembly line with their non-disabled counterparts. At the end of the sequence, the narrator stressed how more centres like Sherrards were needed to provide for those who would need to be catered for, through sheltered employment. Thus, it is implied that employment opportunities in wider society were limited, and so it seemed a natural next step to draw on the strengths of parent-led 'spastic' associations, through the development of sheltered Work Centres, on a national basis. The operation of Work Centres, such as that opened by SDSA, engaged in light industrial work with local industry, holding contracts with The Mettoy Company, which kept the Centre 'supplied with packeting and scrap-part reclamation work', along with similar contracts with other local employers. ${ }^{45}$ This proved that there was a certain emphasis on economic output as recalled by Laura Rumbelow's family. Her granddaughter Helen said how:

As a young teenager [she] thought [her] Gran was very firm and a little bit harsh sometimes and she'd always say; "This is a workplace; people have to work; we've got contracts; we've got things to do, we have to make money and this is a workplace". And there was no messing with that, you know? But we used to think she was very, very strict; different as she was. ${ }^{46}$

However, in line with such Work Centres being considered more as social enterprises, another view is offered by Sheila M. She recalled a more relaxed attitude, and described how 'everybody could go at their own pace, because some could work quicker than others' when undertaking different tasks. She recalled how on a Friday someone used to 'come and help [her] with putting the wiring in for lamps', and she said it was staff who helped with work tasks. She described how each individual undertook different types of work, according to

\footnotetext{
${ }^{44}$ Door to Freedom, dir. by lan Sinclair, (A Sovereign Production for the National Spastics Society, 1956) online film recording, Wellcome Library $<$ http://catalogue. wellcomelibrary.org/record=b1679258> [accessed 9 March 2018].

${ }^{45}$ Swansea, West Glamorgan Archive Service, D/D LA 5/6, H McKelvie, 'A pointer to the rapid growth of our centre', in Swansea \& District Spastic Association Year Book 1966/67, p.21.

${ }^{46}$ Gillian Y., Helen H. and Sarah T., interview 15 March, 2018.
} 
their ability. ${ }^{47}$ In the disability history of work, the concept of utilising a range of skills, suited to individual ability to meet varying tasks has been referred to by Brendan Gleeson as 'somatic flexibility'. ${ }^{48}$ This type of approach is typical of a pre-industrial, economic structure, where people worked to task rather than time and production was centred on the home. This point is discussed by David M. Turner and Daniel Blackie who state that:

\begin{abstract}
although impairment might prove challenging, then, the structure, requirements and expectations of preindustrial life were flexible enough to allow permanently injured or chronically ill people to take up productive or other socially valued roles.
\end{abstract}

'Somatic flexibility' was 'significantly undermined' with industrialisation and 'impaired people were forced into less socially desirable positions' ${ }^{49}$ It was not just staff who got involved with work activities, a family member recalled one task which involved workers pulling bristles out of 'faulty brushes'. She said her brother used to bring them home because 'they had to have so many done', and very often on a Friday, a big box would come home with [her] uncle in the car and [they'd] all spend the weekend pulling these'. ${ }^{50}$ In this way, Work Centres in the local community were very much a community enterprise, with the involvement of family members and staff being more important. This is an important distinction between Sherrards and local centres, Sherrards had more 'able' individuals whilst local associations had a mix of individuals, including those with more profound symptoms of cerebral palsy.

The development of local centres is referred to in the 1961 NSS Annual Report, where it stated that 'out of 127 Groups affiliated to the National Society, 57 [were] running centres of one sort or another'. The NSS had a 'special

\footnotetext{
${ }^{47}$ Sheila M., interview $16^{\text {th }}$ August 2017.

48 Brendan Gleeson, Geographies of Disability (London: Routledge, 1999), ProQuest Ebook Central < https://ebookcentral.proquest.com/lib/swansea-ebooks/detail.action?doclD=165264> [accessed 23 July 2019].

${ }^{49}$ David M. Turner and Daniel Blackie, 'Introduction' in Disability in the Industrial Revolution:

Physical Impairment and British Coalmining, 1780-1880 (2018), (pp.1-22) $<$ https://doi.org/10.7765/9781526125774.00008>.

50 Jean H., interviewed by Teresa Hillier about the history of Longfields Association, 11 April 2017.
} 
provision in its budget for capital grants for new centres'. ${ }^{51}$ These figures demonstrate how local groups were active and had a common aim of providing sheltered employment. The NSS had successfully orchestrated a provision of a service, on a national scale. The film, The Management of Work Centres (1973), documents their history stating that the 'responsibility and initiative for assessing the need for a Work Centre' was with the 'Executive Committee of the local spastic group' which was then 'generally planned and organised with the Spastics Society'. ${ }^{52}$ The benefits of building up a network of Work Centres in this way, was that local associations were already established in the community, and had premises which they could use or develop in a relatively straightforward manner. Also, many individuals could continue to live at home and take up local employment. Local associations meant that parents continued to drive the agenda forward, and families remained part of the fabric of their local association, and this met key objectives of associations.

In primary sources detailing the history of the development of local Work Centres, it is the voices of family members, managers and observers who are dominant. An article published in the 1962 Year Book of SDSA, reproduced from a local newspaper, Herald of Wales, depicts young people, 'spastics', being trained to do a job. It reports, that they 'all know about frustration and what it means to have led sheltered lives'. The article asks the reader to make a 'close study of their faces', which reveals their 'determination' at 'having accomplished something that at one time seemed impossible'. ${ }^{53}$ Despite their achievement they are still depicted as if they did not have adult capacity for work. Richard A. Kurtz discusses how labels prevail for people with disabilities, for example, being seen as an 'eternal child'. This image, Kurtz argues, means that 'adultlike demands should not be made upon them', and all decisions must be made for them,

\footnotetext{
${ }^{51}$ National Spastics Society Annual report (1961), p.22.

52 The Management of Work Centres, dir. by Michael Holmes (Heron Film Productions for The Spastics Society, 1973), online film recording, Wellcome Library $<$ https://wellcomelibrary.org/item/b16743453\#?c=0\&m=0\&s=0\&cv=0> [accessed 9 March 2018].

${ }^{53}$ Swansea, West Glamorgan Archive Service, D/D LA 5/3, 'Courageous' in Swansea \& District Spastic Association Year Book 1961/62, p.20.
} 
adapting the environment to the 'childlike retarded person'. ${ }^{4}$ Such a label perpetuated the view that disabled people could only take low skilled, poorly paid jobs and educational achievements did not appear to be of significance. As others continued to make decisions and speak on behalf of many of those employed in Work Centres, it is not surprising that the voices of the 'employee' are not at the heart of historical records.

Bill Paton, founder member of SDSA, said that one of the aims of the new Work Centre at SDSA, was to "help Spastics to take their normal place in the community and assist them as far as possible to become physically, socially and economically independent'. ${ }^{55}$ In contrast, Owen Davies, who had cerebral palsy, saw the development of Work Centres as 'artificially safe environment[s]' which left 'little space' for individuals with 'even a minimum of ambition to spread [their] wings'. He said, the 'golden harvest of achievements' had 'sadly neglected one crop' leaving the 'average Swansea Spastic person . . . almost totally void of motivation'. ${ }^{56}$ There is no doubt that Work Centres did provide a service that the local authority could not do, particularly in the employment of those with more profound symptoms of cerebral palsy. If it were not for services offered then many individuals would have languished at home. However, local Work Centres failed in their aim of delivering independence to individuals, as associations remained governed by parents and obtaining independence, away from the home, was not easily achievable for those who wanted it.

\subsection{Inside Work Centres}

The film, The Management of Work Centres (1973), described how the Work Centre manager had to be capable of a range of roles. Listed amongst the skills needed were the ability to 'negotiate sub-contract work' with potential customers; to 'promote confidence that the work [would] be of high quality and

\footnotetext{
${ }^{54}$ Richard A. Kurtz, 'The Sociological Approach to Mental Retardation', in Handicap in a Social World, ed. by Ann Brechin, Penny Liddiard \& John Swain (Sevenoaks. Hodder and Stoughton Educational, 1983), pp.14-23 (p.16).

${ }^{55}$ Swansea, West Glamorgan Archive Service, D/D LA 5/1, Bill Paton, 'Through Indomitable Faith was Born a Resolve' in Swansea \& District Spastic Association Year Book 1959/60, p.8.

56 Owen Davies, 'A shift of emphasis' in Swansea \& District Spastic Association Year Book $1979 / 80$
} 
delivered on time;' to be adept at assessing the viability of potential jobs in order to meet production deadlines; to meet the practical and emotional needs of workers, being sensitive to problems and knowing when to 'call in parents' or the 'specialised knowledge of social workers and others;' to have 'engineering' skills so that equipment could be adapted to accommodate physical impairments. ${ }^{57}$ The role of manager needed someone with quite a diverse range of skills.

Activities undertaken at Work Centres included an extension of 'craft-based' pursuits that had been done as part of therapy treatment. MSA had begun a 'crafts class' in 1952, where they had built a 'Little Hut' on school premises to accommodate these activities, as well as promoting 'social contact' for those 'spastics' who could not attend school. ${ }^{58}$ Annette Jackson recalled how, in 1961 when she started attending the Work Centre at MSA, she 'learned to do canework ... ma[de] soft toys ... and knit[ed] shopping bags'. ${ }^{59}$ Similarly, SDSA produced a range of goods which included household items and handicraft work, which may be viewed as more therapeutic work. However, these goods provided a steady source of income for Associations. Also, selling items brought local people into the Work Centre, which built up relationships within the local community. The items produced also took workers out into the community through participation in local shows, and Trades and Industries Fairs. In an article for the 1962 SDSA Year Book, Laura Rumbelow, reflected on the success of such a venture where individuals 'gained confidence' through their work with orders being sent 'all over the British Isles'. ${ }^{60}$ Similarly, staff member Edgar Abel from MSA reflected on the 1960s, and how there was a 'hive of activity' with items being made including 'fancy goods of all descriptions, canework and woodwork'. ${ }^{61}$ Maureen Pritchard reflected on her involvement with MSA and how she was 'one of the first spastics to benefit the whole of [her] life'. Through the 'workshop', social activities

57 The Management of Work Centres, dir by Michael Holmes (Heron Film Productions for The Spastics Society, 1973).

58 Harborne, Cerebral Palsy Midlands, Harry Cocksedge Kent, 'Sir No. 1 looks back' in Midland Spastic Association Year Book 1972, p.29.

${ }^{59}$ Harborne, Cerebral Palsy Midlands, Annette Jackson, 'Three Spastics remember the excitement of progress' in Midland Spastic Association Year Book 1978, p.18.

60 Swansea, West Glamorgan Archive Service, D/D LA 5/3, Laura Rumbelow, 'New Venture which Proved a Success,' in Swansea \& District Spastic Association Year Book 1961/62, p.17.

${ }^{61}$ Harborne, Cerebral Palsy Midlands, Edgar Abel, 'Thirty Years Development in the Day Centre,' in Midland District Spastic Association Year Book 1977/78, p.23. 
increased and new interests were formed. ${ }^{62}$ An activity, once viewed as therapeutic, came to have a wider benefit to the association through financial gain and increased social contact.

Not everyone saw the employment of craft-based activities as positive, as David Mills describes, he could not do what he wanted, as he did not have the qualifications and he described his role as a printer at his local centre, a job which he said he hated. He:

stayed there for two and a half years, but [said he] couldn't do it. It was in a hut, in Erith, and there was about four other people beside me, and it was meant to keep people satisfied. It wasn't good as some, but it was, you know. It wasn't very exciting, it wasn't. ${ }^{63}$

Judy Smart said of Work Centres:

Well, it was like, you had to be one big happy family, and 'You've got to go to this workshop every day', which I hated. The jobs were so monotonous and repetitive. You had to count out screws, put them in a bag, and then pass them on to the next person, who sealed them up and then the next person packed them in a box, and it would just go on, and on and on. ${ }^{64}$

David and Judy's memories are poignant, as they are representative of a particular time, when many with cerebral palsy went through the life cycle of attending a segregated school, and then a sheltered Work Centre. Future generations would likely have different experiences to influence their views.

At the Tenth World Congress of the International Society for Rehabilitation of the Disabled, in 1966, researcher, M I Griffiths discussed 'sheltered workshops

\footnotetext{
62 Harborne, Cerebral Palsy Midlands, Maureen Pritchard, 'The Excitement of Progress,' in Midland District Spastic Association Year Book 1977/78, p.19.

63 Interview with David Mills by Samuel Burch, 14 January 2005, 21 January 2005, Speaking for Ourselves: An Oral History of People with Cerebral Palsy, reference C1134/29/01-02, British Library.

${ }^{64}$ Interview with Judy Smart by Alex White, 18 November 2004, 16 December 2004, 13 January 2005, 27 January 2005, Speaking for Ourselves: An Oral History of People with Cerebral Palsy, reference C1134/05/01-12, British Library.
} 
in a modern economy'. She argued that 'open competition enforce[d] rational productivity in sheltered workshops' and declared 'otherwise the employment of disabled workers would be mere occupational therapy.' She considered the relationship of such workshops to 'private enterprise', and argued that without developing these then 'rehabilitation centres (sheltered workshops) would be senseless (ghetto, isolation)'. Griffiths found 'the old principle of protecting disabled persons inconvenient' and recommended that 'more and new possibilities to secure further employment of disabled workers' be created. ${ }^{65}$

A study undertaken in 1977, by Margaret Davidson for the Scottish Council for Spastics (SCS), gathered the 'considered opinions, ideas and hopes of a group of young men and women whose physical handicap is cerebral palsy'. ${ }^{66}$ Their views demonstrate dissatisfaction with the opportunities available to them, where lack of experience, and over protective parents, were again cited as barriers to employment. Of the young people interviewed, varying reactions to employment were elicited. One person said that 'no one seems to think anything we do in a work centre is of any value, and yet we do work, all day long, just as hard as we are able in our own way'. Another said that he was 'not keen on work centres'. He complained about the attitude of the staff, 'they're on too high a level above us - they're not like us, not companionable enough. You should hear some of them giving orders- after all, we're grown up'! He thought that being in a Centre was where most disabled people ended up and said:

If we must have a working place for disabled people, why shouldn't we run one of our own? We could make the aids we need - we've got the knowledge. We know what we need and what will work for us - you can't really know that if you're not disabled'. ${ }^{67}$

Criticism of activities undertaken at sheltered Work Centres has to be considered

\footnotetext{
${ }^{65}$ Harborne, Cerebral Palsy Midlands, M. I. Griffiths, 'The Increasing Problem of Employment for the Cerebral Palsied - a Prospective Survey from Birmingham', in Industrial Society and Rehabilitation - Problems and Solutions ed.by Werner Dicke, Marlis Muller, Kurt A. Jochheim \& Harald Thorn (ISRD-Proceedings of the Tenth World Congress, 1966), p.123.

${ }^{66}$ Margaret B. Davidson, You Tell Me (Edinburgh: William Blackwood \& Sons Ltd., 1977), p.xiii.

${ }^{67}$ Margaret B. Davidson, p.39.
} 
in the light of what they were trying to achieve. At the time parent-led 'spastic' associations became established, there were adult 'spastics' who had not had the benefit of any education, training or treatment. These were a very distinct group when compared to other disabled people and so Work Centres created opportunities for some, which otherwise may not have been available. The type of activity in Work Centres has been reported as being tedious, repetitive and boring, but the same may be said for all factory work, or other types of work, where the 'able bodied' are required to do repetitive tasks in order to earn a living. An article entitled 'Speaking out in Support of Sheltered Workshops' argues that such workshops:

provide[d] opportunities for people with disabilities to challenge themselves, further their self-esteem and self-confidence, develop friendships and engage in their communities.

It continues that they [were] able to do this 'because of the supports and protections in place' and that those with more:

severe/profound impairments can find success in meaningful and productive activities that may not otherwise be possible for them in mainstream businesses. ${ }^{68}$

In creating Work Centres, parents had the best of intentions, and some of the types of activities grew out of what had already been in place. However, it is the failure to adequately consult individuals regarding the types of activities to be undertaken, that is more problematic.

Undoubtedly, there were new challenges to be faced by parent-led 'spastic' associations through their expansion. The staffing structure of associations became more complex, and there would have been more of a working ethic, with the production of goods. The continuation of parents as decision makers also meant that a new dynamic had to be addressed. Paid staff

68 'Speaking out in Support of Sheltered Workshops', EP Magazine, May 2017, $<$ https://reader.mediawiremobile.com/epmagazine/issues/200979/viewer?page=59> [accessed 27 January 2018] (pp.58-60). 
were needed to meet the demands of a working environment, and yet, many family members would likely have seen the Centre as providing a continuation of welfare and family support, as provided in the early days. There is insufficient evidence to document whether families impeded Work Centre activities, but anecdotal evidence from SDSA suggests that, particularly in earlier years, there was an 'open house' attitude with people dropping in when they felt like. A family member recalled how she used to drop in to SDSA, on a fairly regular basis, and '[watch] them doing their trays and their brushes' and she said, 'they had the printing shop then, yeah I used to like going down'.69 However, associations continued to flourish during these years, and the new challenges of running a Work Centre were met through the commitment of all, and by being part of the same community for the most part of individual lives.

\subsection{Conclusion}

The fact that many individuals with cerebral palsy were perceived as not being able to undertake jobs of significance to the economy, demonstrated that a negative attitude prevailed. Despite progress made in providing education, the first cohort of school leavers were faced with a limited choice in finding employment. A lack of comprehensive statistics means it is not possible to gain an accurate picture of employment achievement, on a national scale. However, influential factors that contributed to the lack of achievement, have been shown to be the continued parental intervention in the lives of individuals, which inhibited opportunity for independence. Segregation added to a lack of life experience, and also a greater likelihood of immaturity. As adults, the voices of these individuals who attended Work Centres are rarely heard, and it is more likely to hear the voices of their parents.

This chapter has demonstrated that segregation continued through the prominent promotion of Work Centres as the likely best option, for suitable employment. The history of Work Centres is fragmented and not well documented. However, this chapter has shown that many who attended centres

69 Jackie T., interviewed by Teresa Hillier about the history of Longfields Association, 17 November, 2017. 
made lifelong friends, and being a part of this community was a positive experience. Without it, many individuals could have remained isolated, which would have had a negative impact on individual wellbeing. The NSS had strongly argued that many people with cerebral palsy could take their place in 'normal' employment, but as discussed in this chapter the limitations of the 1944 Disabled Persons (Employment) Act, did not allow for individual experience and a range of work opportunities. Many jobs that were deemed suitable were of a light industrial nature, such as in sheltered Work Centres. However, some individuals obtained (full) employment, and this chapter has argued that being economically productive in a competitive sense, was not the main focus of 'spastic' Work Centres, when they were established. Peter Large, a 'handicapped worker' said, 'being useful, contributing to society through work, [was] one way of conquering disability'. ${ }^{70}$ This point was taken up by Hargreaves who argued that it was not only the 'economic and social value of work' but also the 'satisfaction' derived from it. He said that there '[were] adverse consequences when the opportunity to work is lost' as the 'community survive[d] through work, depend[ed] on it for its existence and [was] shaped by it. ${ }^{71}$

Questions have been raised about the 'tedium of sub-contract work', whether the idea of 'normality' justified the work undertaken by those who were not viewed as 'economically productive'. An alternative view would place individuals in a 'Community Centre' where they could 'be enriched and given purpose by all kinds of social and cultural activities'. ${ }^{72}$ Therefore, the singleminded determination of 'spastic' associations which has been viewed as a strength did, to some extent, undermine the very people it set out to help. Not all employers would have viewed the prospect of employing an individual with cerebral palsy in a positive light as, for so long, the overriding view portrayed of individual capabilities, was a negative one. A significant change was needed, to promote the view that individuals, with the condition, were as diverse as any other groups in society and had a range of skills to be utilised.

\footnotetext{
${ }^{70}$ Schlesinger \& Whelan, Industry and Effort, p.3.

71 lbid, p.3.

72 lbid.
} 


\section{Challenging perceptions: the legacy of the 'spastic' label}

This thesis has shown that individuals with cerebral palsy were categorised by their condition and labelled as 'spastic'. Labelling individuals in this way took away their individuality, adding a level of control to lives with the development of an institutional culture. Coming into popular use in the 1950s, the term 'spastic' was not initially regarded as offensive as it was once used as a successful marketing tool. Using an 'emotional appeal' generated income for many newly formed parent-led associations and, such was the intensity of campaigns, the term become part of popular culture, shaping society's attitude towards individuals. Many with cerebral palsy were judged against a concept of 'normality', which they could not achieve, and so remained outside the accepted societal 'norms'. Paul Longmore discusses the views of sociologist Candace Clark who said 'individuals typically deliver sympathy and acts of compassion in ways their culture and society consider socially and therefore morally appropriate'. Clark argued that 'just as social "rules and logics help shape emotions", emotions, in turn, "help shape the social structure"'. ${ }^{1}$ As individuals became categorised by their condition, the word 'spastic' gradually became a derogatory term.

This chapter examines changing attitudes towards the use of the term 'spastic', and how the meaning and emotion, linked to the term, was challenged. Phil Foreman, in an article 'Language and Disability' (2005), discusses how language is 'dynamic and ever changing' as 'words drop in and out of popularity and respectability'. He argues that 'there are probably few areas where this is more apparent than in relation to disability'. Foreman reflects on early publications of the Journal of Intellectual \& Development Disability and the descriptive language used such as 'the retarded' or 'the mentally subnormal'. He comments how such terms now 'seem so terribly out-dated' but they were in 'current usage' at the time. ${ }^{2}$

${ }_{1}^{1}$ Paul K. Longmore, Telethons: Spectacle, disability and the business of charity (Oxford: Oxford University Press, 2016), p.84.

2 Phil Foreman, 'Language and Disability', Journal of Intellectual \& Development Disability, 30.1 (2005) 57-59 (p.57) <https://doi.org/10.1080/13668250500033003>. 
The development of the social model of disability during the 1970 s attempted to address the negative portrayal of disabled people. However, it would be some time before noticeable change began to be realised. This chapter examines how far the 'collective experience' of disability of many individuals with cerebral palsy, inhibited their participation in the growing campaign for change. Issues which were of growing importance to those with cerebral palsy, such as discourse and representation, proved difficult to address. Parent-led action had created an identity which significantly disempowered many of those for whom they had campaigned. 'Spastic' associations needed to transform and promote a different ethos.

This chapter examines the transition from parent-led 'spastic' associations, to organisations where individuals began to campaign in their own right, and move towards losing the word 'spastic'. Foreman argues that the change in 'language usage' was not just a matter of 'political correctness' but an attempt to 'use language accurately and politely', 'so that it conveys meaning correctly and helps to create positive attitudes'. ${ }^{3}$ However, such was the authority held by founder members of associations, it was not until the 1990s that a change of name was achieved. This was not an easy transition as opinions were very much divided, and modifying the 'label' led to a period of reflection on the aims and objectives of associations.

\subsection{Developing the brand}

From the early days of parent campaigning, the use of cogent marketing had been at the centre of activities and this called for a dynamic approach, where the term 'spastic' was agreed as one that was easily identifiable with cerebral palsy. The British Council for the Welfare of Spastics (BCWS) adopted this term and it quickly became synonymous with the condition, of which spasticity is just one aspect. However, the term did not reveal the complexities of the condition. The minutes of the inaugural meeting of the BCWS in 1946, reveal that using the term 'spastic', in the name of the organisation, was not without debate. The

\footnotetext{
${ }^{3}$ Foreman, p.58.
} 
minutes state that 'reasons had been explained for using the term' to those who had questioned it. Unfortunately, neither the questions nor the 'reasons' are recorded in the minutes. Although the use of the term was 'approved by a large majority', it is pointed out that 'the use of the term "spastics" in the main title [was] not technically correct' but preferable to using 'cerebral palsy'. ${ }^{4}$ It may have been that there was a certain simplicity to using that word over the term 'cerebral palsy', and it was already in use in other countries where the BCWS had links. The formation of the NSS in 1952, saw the term come into widespread use. Chairman, lan Dawson-Shepherd, 'perceived the word 'spastic' as one that would catch the public's imagination'. Other members of the inaugural committee advocated the use 'cerebral palsy' in the Association's name, as 'it was the proper medical term'. It is suggested that it was the 'force of Dawson-Shepherd's character', a man who worked in advertising, that pushed for the use of the word. ${ }^{5}$ The term 'spastic' became a brand, which quickly became identifiable with cerebral palsy and particularly with children who had the condition. As a word, 'spastic, is quicker and easier to say when compared to cerebral palsy. Whilst not definitive, it would appear that the decision to use the term 'spastic' was driven by marketing and through endorsement, this one word invoked the ethos of the organisations it served. Therefore, in terms of marketing, it can be considered a success.

The NSS, referred to as the 'ordinary people's charity', promoted its innovative methods of awareness raising and fundraising to local, affiliated parent-led groups who adopted similar approaches. This significantly raised the overall profile of 'spastic' associations. Their rapid growth was remarkable, aided by the changing climate of post-war Britain, where opportunities were created for voluntary organisations to be innovative. Parents, in the 1950s, raised enough money to ensure the durability of their associations. The image of a 'spastic' child provoked an emotional response and, as one parent recalled, 'you only had to say Swansea Spastics if you were on a flag day in town and [people] would turn

\footnotetext{
${ }^{4}$ Harborne, Cerebral Palsy Midlands, Minutes of inaugural meeting of the British Council for the Welfare of Spastics, held 12 December 1946.

${ }^{5}$ Chris Davies, Changing Society A personal history of Scope 1952-2002 (Chippenham: Scope Creative Services, 2002), p.21.
} 
around and come back' to give money to the organisation. ${ }^{6}$ Targeting 'ordinary people' secured a steady stream of income, with money being raised in the heart of the community. Whilst individual amounts were not huge, they were regular, and so cumulatively became a more substantial sum. Examination of early SDSA Yearbooks ${ }^{7}$ reveal detailed lists of donations received from local business, churches, sports clubs and social groups in addition to individual donations. Interacting with public-facing organisations meant that parent-led 'spastic' associations benefited in different ways, aside from financial gain, there was free advertising and promotion of their work, as giving to a 'good cause' generated publicity.

A developing consumer-based society of the 1950s arguably led to a more individual outlook. This was an opportunity for charities to remind people about a sense of community, to which they could belong, doing something 'positive' for others. This concept is discussed by Longmore as he argues that becoming a 'giver', as promoted through telethons, was a message that was 'more than a ploy to prod donations'. He maintains that it 'drew an important moral boundary' which 'contrasted humane concern for one's neighbours with selfish preoccupation with one's private interests'. ${ }^{8}$ In considering the ritual surrounding fundraising events, including telethons, Longmore argues that these 'defined people with disabilities as dependent on the moral fitness of their benefactors'. ${ }^{9}$ There was an unspoken message that if you did not contribute to society, through some altruistic act, then you may be viewed as being less morally committed and responsible than your peers.

Using overt messages was a tactic employed to appeal directly to an individual's 'moral responsibility', to give to those supposedly less fortunate, and be rewarded through being virtuous. This is illustrated in an article written by Councillor Percy Morris, a trustee and supporter of SDSA, in their 1961 Yearbook. Morris described a Dr. Barnardo advertisement which 'depicted a healthy happy

\footnotetext{
${ }^{6}$ Joan O., interviewed by Teresa Hillier about the history of Longfields Association, 2 June, 2016.

${ }^{7}$ Swansea \& District Spastic Association Yearbooks from 1959 to 1967.

${ }^{8}$ Longmore, p.59.

${ }^{9}$ Longmore, p.64.
} 
boy, with an infectious smile' pointing to a caption which read 'my happiness depends on you'. Morris used this as a tool to appeal directly to readers for funds, and claimed that the message delivered was 'very relevant' to the children of SDSA, as the "happiness of spastic children depend[ed] entirely upon [him and the readers]'. To emphasise his point, he quoted lines from 'Everlasting Mercy', a poem written by John Masefield, Poet Laureate 1930 to 1967.

He who gives a child a treat

Makes joy bells ring in Heaven's streets

He who gives a child a home

Builds Palaces in Kingdom come.

Morris stresses that the benefits that could be achieved through increased financial donations would help spastics 'achieve a measure of independence', 'add zest to their lives and make them supremely happy'. ${ }^{10}$ Thus, the religious overtones meant that you were able to redeem yourself by becoming a 'giver'.

Adopting these methods continued to reinforce the way in which disabled people were viewed and, as Longmore argues, it had an impact on how the 'social identities of people with disabilities' were shaped'. ${ }^{11}$ The commitment of parents contributed to this as they campaigned, within their family and wider circle of friends, through social events. Molly B., a parent from SDSA said how their Ladies Guild used to meet 'once a week' where they would:

either be organising the Easter parade thing, or doing Easter baskets and Easter eggs, or just have a meeting and have a collection and in the summer we would - do strawberry and cream, teas - and invite all the parents and drag in all the neighbours, my neighbour next door and Jan across the road. It was lovely because the grounds down in [SDSA were] really lovely, and we used to raise money that way, you know and I would go out and give talks to various

\footnotetext{
10 Swansea, West Glamorgan Archive Service, D/D LA 5/2, Councillor Percy Morris, 'Their happiness depends entirely upon you' in Swansea and District Spastic Association Year Book 1960/61, p.9.

${ }^{11}$ Longmore, p.59.
} 
groups and ... they'd always give you a cheque at the end of the evening - which was marvellous. ${ }^{12}$

As a supporter of SDSA, Roggan B. described her involvement with regular 'Sunday lunches' at the local Yacht Club, where the Ladies Guild would have free use of the premises to put on a 'Sunday lunch event'. She said how she used to 'sell tickets to [her] friends in church and have a crowd coming'. She described how everyone involved 'used to do well' and there was a high demand for tickets. ${ }^{13}$ The activities described by Molly and Roggan are not 'high level' fundraising activities but simple events which focused around day-to-day life. These activities kept people interested and talking about parent-led 'spastic' associations at a community level. This was essential as maintaining a high degree of involvement with donors was crucial to success and holding social events, which involved community participation, was an excellent way of doing this. The individuals involved may not have realised the significance of their actions at the time, as more high-profile events would have overshadowed them. However, associations relied on their local communities for regular support to promote their cause, and keep them in the public eye. These events remained at the core of association activities, as the first Year Book of SDSA reports. It stated a reliance on the 'generous public' for their main source of revenue, and said that to this cause 'considerable time and effort [was] given by the officers and members', as well as friends, in organising various functions. The accounts of 1959/60 reveal that the highest proportion of public money raised was through holding a flag day, which demonstrate[d] the generosity of the public to the Association. ${ }^{14}$ As can be seen, in adopting such methods, it meant that the recipients of the funding continued to be viewed as dependent beings, in every sense.

In developing their brand, parent-led 'spastic' associations campaigned relentlessly in the local and national press and, through the promotion of their

\footnotetext{
${ }^{12}$ Molly B., interviewed by Teresa Hillier about the history of Longfields Association, 3 February 2017.

${ }^{13}$ Roggan B., interviewed by Teresa Hillier about the history of Longfields Association, $21^{\text {st }}$ June 2017.

${ }_{14}$ Swansea, West Glamorgan Archive Service, D/D LA 5/1, 'Organised Events in 1959-60' in Swansea \& District Spastic Association Year Book 1959/60, p.24.
} 
activities, a montage of photographs and headline grabbing stories were generated. In the early days of campaigning, the focus of stories centred on the injustices of segregation and the misperception of cerebral palsy. A local newspaper article from April 1953, included a contribution from founder member of SDSA, Bill Paton, who said:

As a parent I never dreamt that I should have to spend most of my leisure time trying to move heaven and earth to see that my child is educated . . . because in this Welfare State there is very little provision for our offspring, who, through a cruel stroke of fate, are victims of cerebral palsy - better known by the coined term Spastic - unless they get specialised treatment, they grow to stagger about like a drunken man because they have no sense of balance, drool like babies, and often talk unintelligibly. Yet the amazing feature is that most of them are intelligent ... regular treatment and attention in the early stages has worked wonders in many cases. In Britain today there are about 10,000 Spastic children - more than twice as many as there are blind and deaf. Less than one child in ten gets a chance. The rest grow up to join the grim army of adult Spastics condemned to a lifetime of disability. ${ }^{15}$

The images used in this article present a very depressing picture of what a 'typical spastic' may have to endure over a lifetime. It may well have provoked negative assumptions about individuals with cerebral palsy. Relatively little is said to refute these assumptions in the form of intelligence and the effect of early treatment.

The methods employed in charity advertising are discussed by David Hevey in an article written for New Internationalist in July 1982. Hevey contends that 'most disability charity ads carry at least two messages - one in the photo, one in the text' where the 'image posits futility and hopelessness, while the text suggests methods of cure, care or eradication'. ${ }^{16}$ This method was adopted by the NSS and local associations, notably in their early days. The NSS Annual Report 1953/54, contains two images of 'helpless children'. The first is of an

\footnotetext{
${ }^{15}$ Swansea, West Glamorgan Archive Service, D/D LA 11/1-4, Newspaper cuttings relating to Longfields Association, 1954-2007.

${ }_{16}$ David Hevey, 'Fear for sale', New Internationalist, 5 July 1992.

<https://newint.org/features/1992/07/05/fear> [accessed 20 May 2019] (para 4 of 13).
} 
apparently healthy child, 'little David', who sits in an adapted chair but we are told that 'he can't crawl - he can't stand - he can't even use his arms and hands properly'. It states that 'unless he gets years of skilled treatment, his arms and legs will grow thin and wasted' and he will end up like 'the pathetic boy in the wheelchair', who is called John. John is an older boy, who does not look as robust as David, and he has a caption over his head which says 'why let a lovely child grow up like this?' The object of the advert was to gain financial support for the NSS to set up treatment centres as 'you can't tell David, or his Mummy and Daddy, to wait . . . and wait . . for the State to set up more treatment centres'. The text conveys a sense of urgency and states that 'for David and John and thousands of Spastic children like them it is a desperate race against time', (see Appendix 9.6). ${ }^{17}$ This was a model which endured in the portrayal of children with cerebral palsy.

Once a level of progress had been made by associations, there was a slight shift in emphasis to stories of good news and success. However, within these features, it was stressed that 'spastics' were being helped through the efforts of other people, and the individual efforts of those with cerebral palsy, were not at the fore. The 1985/86 Year Book of SDSA, contains an advertisement for the 'Annual Garden Fete' where an appeal was made for 'saleable goods of any description' in order to raise funds. The 'reward' for doing this was to know that 'you helped to make a Spastic Persons Life a little brighter'. ${ }^{18}$ As this appeal illustrates, the iconic image of a 'spastic' was maintained. However, the use of emotive images in marketing campaigns did raise awareness and generated increased funds. As the campaign grew, the number of local associations increased, and this prompted more activity at a regional level. The NSS developed new regional Associations, the South Wales Association was established in 1966. This region saw the development of three new Work Centres in Cwmbran, Merthyr Tydfil and Sully. Two large houses had been acquired, one in Penarth and one in Mumbles, for 'spastics' to live in. A 'Family Help Unit' was being developed in Cardiff and a new 'Day Centre' had been built. An extension

\footnotetext{
17 National Spastics Society Annual report (1954), p.8.

18 'Advertisement' in Swansea \& District Spastic Association Year Book 1985/86. p.19.
} 
to facilities was also underway in Swansea. ${ }^{19}$ By this time, the NSS had significantly increased their financial resources and were able to offer grants to affiliated groups, as well as continuing to invest in their own properties. The 'spastic' banner, under which they campaigned, became the label attributed to people with cerebral palsy. The actions of parent-led 'spastic' associations created the identity of a generic 'spastic' and this creation was central to all activities

\subsection{Social Model of Disability}

The emerging disability movement of the 1970s put disability on the wider political agenda with the emergence of the social model of disability and the publication, Fundamental Principles of Disability (1976) by The Union of Physically Impaired Against Segregation (UPIAS)..$^{20}$ Chapter two discussed the concept that disability was caused by social and environmental factors. Colin Barnes and Geof Mercer argue the 'spotlight shift[ed] to how far, and in what ways, society restrict[ed] opportunities to engage in mainstream economic and social activities'. ${ }^{21}$ Therefore, it was society that disabled people, while social and environmental factors were the barriers which denied citizenship and excluded individuals from full participation in society.

Closer examination of the social model reveals how it was focused more on the disabled body and not on the brain as the locus of disability. Anne Louise Chappell argues that 'one of the most important features of the emergence of the social model has been the relevance of personal history and experience to the writing that has been produced'. She refers to a number of individuals (Mike Oliver, Jenny Morris, Sally French, Lois Keith and Paul Abberley) and argues that they have 'theorised their personal experiences as disabled people to develop political insights into the meaning of disability' which focused on 'physical/sensory impairment'. Chappell argues that 'it is this that has tended to shape the analysis

\footnotetext{
${ }^{19}$ Swansea, West Glamorgan Archive Service, D/D LA 5/6, B. Kingsley-Davies, 'A look at the South Wales Region' in Swansea \& District Spastic Association Year Book 1966/67, p.9.

${ }^{20}$ Michael Oliver, Understanding Disability (Basingstoke: Palgrave Macmillan, 2009), p.42.

${ }^{21}$ Colin Barnes, and Geof Mercer, Exploring Disability (Cambridge: Polity Press, 2010), p.30.
} 
which has developed' and maintains that 'for people with learning difficulties, the issues are more problematic'. ${ }^{22}$ Similarly, Jan Walmsley argues, 'it is hard to locate a discovery of barriers in what are, admittedly, the quite limited writings by people with learning disabilities'. Therefore, as a consequence of not fully considering cognitive impairments, in the social model, the 'understanding of the barriers people with learning disabilities experience is far less well developed'. ${ }^{23}$ It is helpful to restate the point that cerebral palsy, as a complex condition with a wide spectrum of symptoms, does not necessarily include learning disability. However, the fact that many people with the condition, were perceived in a similar way to those with a learning disability, is relevant. As with people with a learning disability, the experiences of those with cerebral palsy are not widely documented in the historical record.

Structural and environmental changes, as challenged by the social model, were practical considerations in the physical sense. Challenging attitudinal barriers, has arguably proved more difficult to address for people with cerebral palsy. Imagery and language had shaped an attitude which was difficult to dispel. A study of primary sources, such as the Year Books and Annual Reports of 'spastic' associations, does not yield many references to the social model. As expected, descriptive language, used to refer to people with cerebral palsy, is powerful within this literature. At the time the social model emerged, the public image, presented by 'spastic' associations, was still centred around advertising and fundraising. This would have made it more difficult for those who wanted to challenge their situation and it was still the founder members, parents, who were in control. In order to confront attitudinal barriers, a radical overhaul of association aims and objectives had to be undertaken, which proved more challenging than simply addressing the physicality of situations.

\footnotetext{
${ }^{22}$ Anne Louise Chappell, 'From normalisation to Where?' in Disability Studies: Past Present and Future, ed. by Len Barton and Mike Oliver (Leeds: The Disability Press, 1997), pp. 45-62 (p.56). ${ }^{23}$ Jan Walmsley, 'Ideology, Ideas and Care in the Community, 1971-2011', in Community Care in Perspective: Care, Control and Citizenship, ed. by John Welshman and Jan Walmsley (London: Palgrave Macmillan, 2006), pp.38-55 (p.49).
} 
Walmsley discusses how the disability movement 'insisted on using the term "disabled people" to convey the idea that disability is created by society'. ${ }^{24}$ The situation for people with cerebral palsy was more complex, their segregation had extended from childhood into adulthood, which created a greater dependency on others. The historical language used, held so many negative connotations and, in order to fully embrace the social model, individuals within associations, such as the NSS, had to be proactive and collectively address the situation. In a sheltered climate, many individuals may not have been fully aware of the implications of the social model, or simply not interested in it. However, during the 1970s, even if they were interested, they lacked a voice, and were not politically active as a group. It was not until the 1990s, through self-advocacy groups, that the long-term effects of labelling began to be questioned. As Walmsley maintains, through 'what has been called People First language', it is the 'person first and the disability second'. Walmsley states, 'people with disabilities are people, first and foremost' and this is reflected in the People First slogan 'Label Jars, not People'. 25 To consider the reasons why the emerging disability movement, in the 1970s, could not fully engage with people with cerebral palsy, the origins of the creation of the term 'spastic' as a brand, has to be understood.

\subsection{The 'spastic' label}

The dichotomy in the use of the 'spastic' label was problematic, and was directly at odds with promoting a 'can do' attitude. Arguably, the public façade of the national charity (NSS), overshadowed progress being made by 'spastic associations' in the provision of education and other services. Advances were revealed only within a select group, as activity was more focused on raising money, so organisations needed to perpetuate the tragedy behind the 'spastic' label. Alex White, Information Content Manager of the national charity Scope, comments, 'it would be easy to say that language is just words, but in truth it

24 Walmsley, 'Ideology, Ideas and Care in the Community, 1971-2011', p.49.
25 Ibid. 
shapes, and reveals, people's attitudes'. ${ }^{26}$ The predominantly negative messages used in fundraising had focused on the difficulties encountered by 'spastics' in society. In the film, The Chance of Their Lives, directed by I. Sinclair in 1952, a young man with cerebral palsy is depicted as seeking work, but is continually rejected without being given the opportunity to demonstrate his capabilities. The narrator turns to camera and asks, 'well, would you employ him and what job would you give him'?27 Whilst the aim of the film was to highlight the prejudices that individuals faced, it also reinforced a negative image of a person with cerebral palsy, compared to society's perception of 'normality'. Similar problems may have arisen if a different term to 'spastic' was used to describe people with the cerebral palsy, or if the actual term itself was used.

Tom Shakespeare discusses how, 'labelling is a complex and paradoxical process', and argues that, in order to gain access to support services and other benefits, there is a need to identify with a label and accept it. ${ }^{28}$ The most positive outcome of attaching this label was that it created an identifiable condition within society, of which previously there had been limited knowledge. However, this public portrayal of cerebral palsy may not have been welcomed by individuals with the condition, who had grown up without the 'spastic' label, and who had reached adulthood by the time 'spastic' associations began to emerge. The marketing success of parent-led associations did not simply link the term 'spastic' to children with cerebral palsy but to anyone with the condition. Therefore, it is understandable why, as an adult with the condition, one may have taken umbrage by suddenly being labelled a 'spastic'.

One such individual was Alan Counsell who, on reaching the age of eighteen in 1955, asked his doctor to explain what was wrong with him. His doctor revealed that Alan had cerebral palsy and related the circumstances of his birth which had caused damage to his 'brain's motor system'. Alan felt shocked

\footnotetext{
${ }^{26}$ Alex White, More than words: The changing language of disability (2016), $<$ https://community.scope.org.uk/discussion/30680/more-than-words-the-changing-language-ofdisability> [accessed 15 August 2018] (para 5 of 6).

27 The Chance of Their Lives, dir. By I. Sinclair (Sovereign Productions, National Spastics Society, 1952) online film recording, You Tube <https://www.youtube.com/watch?v= IhMkm9-X9A> [accessed 18 October 2017].

${ }^{28}$ Tom Shakespeare, Disability Rights and Wrongs (Oxon: Routledge, 2006), p.72.
} 
at hearing the words 'brain' and 'damage' and could 'not comprehend that there was something wrong with [his] brain' as he had always linked it to 'intellect' and he did not think that he was 'mental'. Alan wanted to know why he had never been told about his condition and his doctor replied, 'I have never put a label on you because people react to labels and I wanted you to be treated normally or as normally as possible'. He said, 'in common language, you are a spastic'. On hearing this Alan felt extremely angry and began shouting at the doctor 'how can I be a spastic? Everyone knows spastics are imbeciles in wheelchairs'. Alan's doctor, who it can be said was better informed about cerebral palsy, told him that he was 'reacting exactly like the ill-informed majority of people'. He said that 'the words "spastic" and "brain damage" [were] very emotive because people [didn't] fully understand their meaning'. Reflecting on this, Alan began to see 'how wise the doctor [had] been' in not labelling him. ${ }^{29}$ Thinking back over his life he says:

there are still those who may laugh at me and misunderstand me, for in many situations I look peculiar. But this is only because they make comparisons which label me as 'different'. If only I could be viewed as an individual. If only people would realise that I was born the way I am and that for me to talk and use my body the way I do is normal. Were I to speak or use my hands and body like the majority of people I would not be me. It is absolutely normal for me to function the way I do. If it were not for those comparisons maybe I might be seen as a person rather than as an oddity. ${ }^{30}$

The success in marketing the 'spastic' label had obscured the fact that having cerebral palsy did not mean a lack of mental capacity. Writing in 1952, educational psychologist Marjorie Dunsdon had considered terminology, and the use of the term 'spastic paralysis', when describing people with cerebral palsy. She maintained that the term had been applied broadly, and not just to those 'exhibiting actual "spasticity"'. She argued that 'popular articles' had been 'written largely for their emotional appeal to the general public'. She spoke of the need

${ }^{29}$ Alan Counsell, So Clear in My Mind (London: Hutchinson \& Co. (Publishers) Ltd., 2007), p.15.

${ }^{30}$ Counsell, p.199. 
to establish 'facts, rather than assumptions and impressions', when establishing 'appropriate schemes for educational care'. ${ }^{31}$ Elements of Dunsdon's argument are reflected by Laura Middleton where she considers how disabled children were seen as 'non-contributing, not only in the present but also in the future'. She argues that there was 'pressure to invoke pity and hope for a sympathetic response', and contends that it was not a 'coincidence' that many services were provided by charities for disabled children. ${ }^{32}$ The dominant view of cerebral palsy, together with the lack of specialised knowledge, curtailed the involvement of professionals as they too could be misled by the term 'spastic', and what it stood for. It was a complex situation, as parents were admonishing professionals, whilst at the same time attempting to 'educate' them, through the work of associations.

It is not difficult to imagine how confusing individual situations could be, and why the level of support towards families was so varied. For example, the parents of Bill Hall were told by their doctor 'just leave him. Feed him; [but] don't let your expectations come on that he's going to grow up and be a man, and gonna be this and gonna be that'. Hall said, 'at that time, it was just; you know, that was it'. ${ }^{33}$ Barry Morgan recalled how his parents fought for him to go to a mainstream school, rather than being forced to go to a residential school. He said 'the only reason they offered a residential school, was because for the simple reason . . . it was a medical thing, that they felt I shouldn't, run around with other kids' ${ }^{34}$ Despite the contradictions associated with the term 'spastic', it is important not to lose sight of the motivation behind its use. It was precisely because of a lack of progress, shown towards these children, that parents' campaigns became political as well as emotional. A family member of SDSA recalls the early days of the Association saying,

${ }^{31}$ M.I. Dunsdon, The Educability of Cerebral Palsied Children (London: Newnes Educational Publishing Co., Ltd., 1952), pp.1-3.

32 Laura Middleton, Disabled Children: Challenging Social Exclusion (Oxford: Blackwell Science Ltd., 1999), p.58.

33 Interview with Bill Hall by Philip Mann, 25 January 2005, 11 April 2005, 5 May 2005, Speaking for Ourselves: An Oral History of People with Cerebral Palsy, reference C1134/11/01-05, British Library.

${ }^{34}$ Interview with Barry Morgan by Anne Austin, 24 January 2005, 7 February 2005, 21 March 2005, 18 April 2004, 9 May 2005, Speaking for Ourselves: An Oral History of People with Cerebral Palsy, reference C1134/07/01-08, British Library. 
I really emphasise and reiterate the fact there wasn't anywhere else for a physically handicapped, cerebral palsy person to go to. Yeah they could have been put 'em in an institution, of which many, many people before them were. ${ }^{35}$

In a letter to The Times (June 1952), the Chairman of the BCWS said that it was only when the BCWS was founded that the term 'spastic' became known. He said it was 'almost unknown' except in 'medical circles and practically no special provision was made for their education and welfare'. ${ }^{36}$ Responding to this article, Georgiana Buller (1884-1953) ${ }^{37}$ who was a campaigner and advocate for disabled people, referred to the 'widespread failure in medical circles (apart from a few specialists), to recognise' the potential of children with cerebral palsy. She discussed how a 'witless expression' through the 'effects of the disability' is 'one of the most tragic factors in the burden borne by the intelligent "spastic"'. 38 Concern had been raised about the number of 'spastic' children in 'mental institutions'. An article in The Times in October 1954, reported on the address given by C Pritchard, general secretary of the NSS, to the 'Royal Commission on the law relating to mental illness and mental deficiency'. Pritchard was critical of the assessments made of the 'mental condition of spastic children'. He declared that they were 'often made on the spur of the moment'. The process of reassessment, following complaints, very often did not happen 'for a considerable number of years' and only when 'considerable pressure [was] brought to bear on the authority'. 39

A discussion between Industrial Liaison Officer (NSS) Bill Hargreaves, who had cerebral palsy, and lan Dawson-Shepherd (NSS), who had pushed for the use of the word 'spastic', illuminates the complexities around the term.

\footnotetext{
${ }^{35}$ Peter Ba., interviewed by Teresa Hillier about the history of Longfields Association, 29 March 2018.

${ }^{36}$ N.D. Bosworth Smith, 'Education of Spastics', The Times,3 June 1952. Gale Cengage The Times Digital Archive <http://tinyurl.gale.com/tinyurl/BbJus1>.

${ }^{37} \mathrm{http}: / /$ www.exetermemories.co.uk/em/ people/buller-georgiana.php

38 Georgiana Buller, 'Education of Spastics, The Times, 13 June 1952. Gale Cengage The Times Digital Archive <http://tinyurl.gale.com/tinyurl/BbK8R7>.

39 'Spastic Children In Mental Homes', The Times, 27 October 1954. Gale Cengage The Times Digital Archive <http://tinyurl.gale.com/tinyurl/BbKEV5>.
} 
Hargreaves recalled how he was vilified for an article he had written for Spastics News. He considered the average IQ of the population, in comparison to the IQ of those with cerebral palsy, and said that $50 \%$ of spastic children were 'mentally handicapped to some degree', arguing that 'this was no different to the general population, half of whom were below par'. He maintained that of the general population,

most of them do not know that they are mentally handicapped anyway, and they plod through life sweeping roads or whatever quite happy and they rear families of more mentally handicapped and so forth. They are quite happy because that has been their way of life and no-one said, "Look you're not very bright are you?" They are earning their money and sweeping the roads. Nothing against road sweepers by the way. ${ }^{40}$

When asked who reacted so angrily to his article, Hargreaves said it was 'Mr \& Mrs Everybody' or as Dawson-Shepherd put it, 'the ordinary parents'. DawsonShepherd reflected on the term 'spastic', and how it had come to be seen 'as meaning stupid'. They agreed that it had become 'bastardised'. ${ }^{41}$

The growing confusion surrounding the label fostered a continued misunderstanding of the condition, which is at odds with the original aim of 'spastic' associations, to educate people about cerebral palsy. A study undertaken in the East Midlands between 1963 and 1968, on The Family and the Handicapped Child (1970), involved 180 interviews. An analysis in the study report states, that mothers were confused when told that their child had cerebral palsy or was 'spastic'. They asked, 'what is cerebral palsy? Is it the same as being spastic'? These two terms had begun to be 'used interchangeably', and some mothers went away 'believing that their babies had two things wrong with them'. ${ }^{42}$ In the final comments of the report it is argued, that 'the word of the

\footnotetext{
${ }^{40}$ The sound file of this discussion is held at the British Library and is part of a collection deposited by Scope of which the sound is of varying qualities. The shelf mark is C984/18/01-18. The transcript of the interview was sent to me by Scope and is undated but the discussion would have taken place before 1996 as Ian Dawson-Shepherd died in that year. Spastics News was relaunched in the 1980s and became Disability Now in 1984.

${ }^{41}$ Scope, London, transcript of interview between Bill Hargreaves and lan Dawson-Shepherd, undated.

${ }^{42}$ Sheila Hewett \& John \& Elizabeth Newson, The Family and the Handicapped Child (London: George Allen \& Unwin Ltd., 1970), p.30.
} 
label - "spastic", "cerebral palsy" or whatever it may be - bears enormous significance in itself for the mother'. It was contended that the label '[gave] a form to previously unformed fears' and that parents needed to face the 'label squarely before they [could] begin to cope constructively with the problems'. ${ }^{43}$ There is a need to look beyond the label, and consider the words that people were using in describing the condition. A lack of understanding, within the medical profession, of the symptoms and treatments available, did not offer up much hope for parents. This led to both despair and a resolution by parents, to 'do their best' by their child, regardless of what the medical opinion was.

\subsection{Living with the label}

As a generic label, the term 'spastic' ignored the diversity of people with cerebral palsy and being labelled 'spastic', as a child, stayed with many individuals throughout their lives. This influenced how others saw them and coloured their life choices. Continued parental intervention had driven forward the development of sheltered employment, which meant that many individuals, who had been children in 'spastic' schools, continued with the same organisation as they became adults. A report in the 1962 Year Book of SDSA lists its achievements:

first the School, then the Nursery, followed by a Works Centre and now a $£ 10,000$ Workshop which we are sure will prove a tremendous boon to our young people in the difficult years that lie ahead. ${ }^{44}$

These developments took place at the same site, and so did not require the individual to go elsewhere to seek other activities. That is not to say that individuals were unhappy to remain part of the same organisation, but it must be considered what level of choice they may have had. If there were other opportunities on offer, it is questionable whether they would have known about

\footnotetext{
${ }^{43}$ Hewett \& John \&Elizabeth Newson, p.200.

${ }^{44}$ Swansea, West Glamorgan Archive Service, D/D LA 5/3, Bill Paton, 'Tremendous Boon To Young People', in Swansea \& District Spastics Association Year Book 1961/62.
} 
them. The 'spastic' label formed the basis for a discreet level of social control over individual lives.

The development of Work Centres, in the 1960s and 1970s, furthered an institutional culture which fostered dependence, and the resulting discourse was overwhelmingly limited. Boyd et al discuss how discourse within health and education systems 'can often cause children with disabilities to be treated as 'problems' that need to be fixed, which can limit their conditions of possibility'. ${ }^{45}$ The continual reinforcement of this belief, made it difficult for many individuals to break away from the stereotype. At their inception, parent-led associations were focused on children. However, it can be argued that there was a lack of foresight, as despite the successes in improving their children's lives, through education and treatment, equipping them with more skills, many parents continued to make life decisions for their adult children and continued to treat them as minors.

Owen Davies, who had attended the school established by SDSA in 1953, recognised the 'valuable work' that had been performed by the founder members. However, he argued that 'among their golden harvest of achievements, the Swansea and District Spastic Association ha[d] sadly neglected one crop'. He is referring to the 'average Swansea Spastic person', maintaining that whilst the Association, in 'genuine efforts' to make 'every possible provision for Spastic persons', had in fact 'created an artificially safe environment which [left] little space for any individual with even a minimum of ambition to spread his or her wings'. He advocated change, whilst acknowledging that financial support was 'increasingly valuable' and said that 'understanding that Spastic persons are individual people of potential and not merely souls for sympathy, [was] priceless'. ${ }^{6}$ As discussed earlier, concerns had been raised about the lack of life experience of those who had attended schools and work centres run by 'spastic' associations. Reluctance by those who founded the associations to relinquish

\footnotetext{
45 Victoria A. Boyd, Stella L. Ng and Catherine F. Schryer, 'Deconstructing language practices: discursive constructions of children in Individual Education Plan resource documents', Disability \& Society, 30.10 (2015), 1537-1553 (p.1540) $<$ https://doi.org/10.1080/09687599.2015.1113161>.

46 Owen Davies, 'A shift of emphasis' in Swansea \& District Spastic Association Year Book 1979/80.
} 
control had exacerbated the situation and emotional involvement can be said to have clouded the longer-term vision of the capabilities of their children.

People with cerebral palsy had to contend with complex relationships, between families and professionals, in order to make life decisions. This needs to be considered within the context of the social model. Oliver discusses the unequal relationship between professionals and disabled people and considers how independence is viewed. He comments that professionals see self-care activities as core, whilst disabled people take a different view. He argues they would define independence, 'as the ability to be in control of and make decisions about one's life, rather than doing things alone or without help', ${ }^{47}$ Walmsley discusses the view that the 'disabled people's movement tends to regard professionals with suspicion', as the 'goal is empowerment of disabled people to take control of their own lives'. ${ }^{48}$ This ideal is not straightforward as many with cerebral palsy need extra support in daily life, not just for day-to-day living but also in decision making. This was an area not fully addressed within the social model. Achieving a level of independence is not about living in isolation, and most people, not just those with disabilities, rely on a support network in order to live their lives. Oliver considers the meaning of dependence and independence, arguing that:

no one in a modern industrial society is completely independent: we live in a state of mutual interdependence. The dependence of disabled people therefore, is not a feature which marks them out as different in kind from the rest of the population but different in degree..$^{49}$

Taking on responsibility for your own life choices, making mistakes as well as reaching the right decisions, is part of the transition from childhood to adulthood.

\footnotetext{
${ }^{47}$ Michael Oliver, 'Disability and Dependency: A Creation of Industrial Societies' in Disability and Dependency, ed. by Len Barton (Lewes: The Falmer Press, 1989), pp.6-22 (p.14).

${ }^{48}$ Walmsley, 'Ideology, Ideas and Care in the Community, 1971-2011', p.50.

${ }^{49}$ Michael Oliver, The Politics of Disablement (London: The Macmillan Press, 1990), p.84.
} 
Presumed control over individual lives and denial of opportunity to state your point of view, and be taken seriously, was a situation faced by many. Reflecting on her role as Welfare Officer in the early days of MSA, Barbara Brand said that she did not think that those who attended the association were 'seen as equals'. She felt that they 'were very much viewed as - people who - were "being helped", rather than being perhaps listened to'. However, she said that:

\begin{abstract}
it was a long time ago and there was nothing else out there, so the services that we provided were the only services really that were about at the time and we had a happy environment - I think Cerebral Palsy Midlands, or the Midlands Spastic Association as was then, has always endeavoured to be a happy environment, whether it being as a benefactor, or whether it has been 'user-led', which we strive to be now but that's the main difference. I think we are now 'user-led' as then we were 'the providers'.
\end{abstract}

Jonathon Rix maintains that 'as a society we make much of an individual's independence and in so doing we fail to recognize that we are fundamentally interdependent'. Rix argues that it is the assumption that, 'some levels of support in specified areas make a person normal and other levels make them worthy of a label'. It is this which, Rix argues, strengthens assumptions about particular labels and the 'individual[s] to whom [they are] given. The individual becomes the problem and not the level of support'. 50

The dominance of the medical model of disability, throughout the twentieth century, had influenced the way in which disability was viewed, and the powerful discourse created within 'spastic' associations was difficult to overcome. Writing during 'The International Year of the Disabled' (1981), Owen Davies of SDSA, considered the practicalities of independent living. He argued that as part of school life, the 'introduction of a "Scholarship For Living"' should be given priority over academic subjects. He called for training in cookery, social etiquette, financial matters and sex education. He said, 'it is essential to make each

\footnotetext{
50 Jonathon Rix, 'Does it matter what we call them? Labelling people on the basis of notions of intellect', Ethical Space: The International Journal of Communication Ethics, 3.4 (2006), 22-28. <http://oro.open.ac.uk/id/eprint/6515> [accessed 3 May 2018].
} 
disabled individual realise that he or she are not "Cabbages" and "Cripples" but members of a civilised society'. ${ }^{51}$ Davies makes a pertinent point and this thesis has discussed the 'purpose of education'. The teaching of more practical skills, to enable the individual to become a 'social citizen' and take their place in society, had to be considered alongside academic achievement. Living with the 'spastic' label inhibited the process of change, as called for by the social model.

The growth of the disability rights movement did challenge the portrayal of disabled people, but it was a slow process, particularly so for many with cerebral palsy. Ignacio \& Rafael Calderón-Almendros discuss the objectification of people with disabilities, 'when people with disabilities are named, catalogued and labelled, they are converted into objects'. Drawing on Vygotsky, they contend that 'this process manifests itself in language and therefore in the structure of thought'. ${ }^{52}$ They argue that 'discourse is also a major instrument of power and control which drastically limits freedom'. ${ }^{53}$ Gillman, Swain \& Heyman also consider objectification in relation to people with learning difficulties and argue that:

professional disciplines, such as medicine, clinical psychology and social work, operating within the field of learning difficulty appear to have the power to specify certain 'truths' about the worlds of those who 'consult' them.

Through the application of 'professional theories', individuals have become 'client groups' being 'objectified as "cases" and "problems"'.54 The emotional attachment of parents to 'spastic' associations, endorsed the continuation of the same methods of publicity and fundraising and by doing so curtailed progress.

\footnotetext{
${ }^{51}$ Swansea, West Glamorgan Archive Service, D/D LA 5/7, Owen Davies, 'Scholarship for Living', in Swansea \& District Spastics Association Year Book 1981/82, p.17.

52 L. S. Vygotsky, Thought and Language (Cambridge: MIT Press, 2012).

${ }^{53}$ Ignacio Calderón-Almendros and Rafael Calderón-Almendros, 'I open the coffin and here I am: disability as oppression and education as liberation in the construction of personal identity', Disability \& Society, 31.1 (2016) 100-115 (p.104) <https://doi.org/10.1080/09687599.2015.1133400>.

54 Maureen Gillman, John Swain and Bob Heyman, 'Life History or "Case" History: The objectification of people with learning difficulties through the tyranny of professional discourses', Disability \& Society, 12:5 (2010) 675-694 (p.676) <https://doi.org/10.1080/09687599726985>.
} 


\subsection{Loss of identity}

Charity advertising, and the use of the 'spastic' brand, demonstrates how people with cerebral palsy were represented, it took away individuality. An extract from the South Wales Evening Post, in 1960, reporting on individuals from SDSA at work illustrates this:

thin, pale, barely mobile fingers threaded scraps of chamois on a piece of string. Beside them, others struggled with yellow and green beads and a circle of wood. The hands were slow, stiff, often clumsy. They could hardly light a cigarette, let alone illustrate a witty anecdote with vivacity. But their hesitant groping tells a story rarely equalled in courage and hope. ${ }^{55}$

The failure to consider individuality in this extract contributes to the stereotypical image of someone with cerebral palsy. Tom Shakespeare argues that individuality may be ignored as a consequence of labelling, and 'the impairment label becomes the most prominent and relevant feature' which dominates interactions. ${ }^{56}$ Amongst the publicity concerning 'spastics', the intense marketing and the headline grabbing stories, the ordinariness of everyday life is missing.

In 1965, Rosemary Dawson-Shepherd, born with cerebral palsy, dared to suggest that a conference be held, between 'spastics' and the Spastics Society. Rosemary, who was the daughter of lan Dawson-Shepherd, a founder of NSS, campaigned in her own right and argued that there was a growing gap between 'those who work[ed] for spastics and the spastics themselves'. Her proposal for a three-day conference included discussion on:

- the services provided by the NSS and whether they met the needs and expectations of 'spastics'

- the 'future' in medical and educational fields

- how 'spastics' could do more on their own in both leisure and employment

\footnotetext{
55 Swansea, West Glamorgan Archive Service, Longfields Association Records, D/D LA 11/1-4, Jill Forwood, 'Learning to live with a handicap', in South Wales Evening Post 1960, p.10.

${ }^{56}$ Shakespeare, Disability Rights and Wrongs, p.71.
} 
- how 'spastics' were presented in the public eye as the public still believed that 'being a spastic automatically [meant] mental deficiency'57

Her suggestions were welcomed enthusiastically by Bernard Brett, ${ }^{58}$ who also had cerebral palsy, and was an active campaigner for disability rights. He said that the time had come, for 'spastics in Britain' to show that they were 'capable of accepting a measure of responsibility within the community'. He argued that the best people who 'can do the most to help spastics', were those who had cerebral palsy. He maintained that the conference would give an opportunity for people with the condition, to prove their willingness and eagerness to 'play a part in the Spastics Society which for better or worse ha[d] been dominated by the influence of parents'. Brett's proposal of items for discussion included:

- employment and whether people with cerebral palsy were 'bad employees or not'

- medical research

- an 'attack on the perceived 'built-in characteristics of self-centredness and complacency' in people with cerebral palsy

- relations with the opposite sex, marriage and disabled people

- challenges of the future

He asked people with cerebral palsy to decide, if they were 'content with a passive role in [the] Society and in the community at large.' He maintained that the proposed Conference 'should not be just another service supplied by the Spastics Society', but be organised by people with cerebral palsy. ${ }^{59}$ Parent-led 'spastic' associations and the national organisation had traditionally been the organisers of all events, doing what they thought best without necessarily consulting those who were directly affected by their actions. It is not known whether this conference took place, but the arguments put forward for it

\footnotetext{
${ }^{57}$ London, Wellcome Library, Rosemary Dawson-Shepherd, '(I) Plans for a spastics' conference', Spastics News Magazine of the Spastic Society, February 1965, p.5.

${ }^{58}$ A passing traveller: the life of Bernard Brett (1935-1982) in his own words, ed.by Dave Richards \& Anne Hosking; photographs by Dave Richards.

Brett, Bernard, 1935-1982.

https://trove.nla.gov.au/work/18444517?q\&versionld=21646891

59 London, Wellcome Library, Bernard Brett, '(II) The Opening Door', Spastics News Magazine of the Spastic Society, February 1965, p.6.
} 
demonstrate that there was an emerging need for individuals to challenge the misperception of the 'spastic' label and become decision makers rather than passive recipients.

The following extracts taken from the 1979/80 Year Books of SDSA, illustrate how keenly felt was the loss of identity. Owen Davies, of SDSA, reflected on his school life and spoke of his 'sheer anger and indignation of being programmed like a human computer for the first seventeen years of [his] life'. That, he said, made him 'determined to become Owen Davies the individual, instead of "that Spastic lad".' He spoke with pride about running his own 'small printing outfit' independently and said that financially, 'it [was] a complete failure, but psychologically it [was] great'. He said that mixing with 'able-bodied people' who treated him as a 'person with a handicap, rather than a handicapped person' was 'not merely a play on words, but the difference between happiness and misery'. 60 Valerie Lang reflected that in the early days the label 'spastic' was 'useful', as it 'served a purpose'. However, she argued that attitudes should change from within organisations themselves and she urged members not to allow 'anyone in [their] hearing, to use the words "A Spastic," or, what [was] even worse, "Our Spastics".' Of herself, she said that she was a 'middle-aged librarian, who happen[ed] to be mildly spastic'. To be called a 'spastic' she said would 'take away [her] age; [her] education; [her] career; all [her] interests, achievements, everything which distinguish[ed] [her] as a person, even [her] sex.' She said that the term 'our spastics' had become so widespread in use, that local groups had become used to talking about 'our spastics' as if they were seen as 'an undifferentiated mass' and groups had 'lost sight of the fact that each spastic person was a quite separate personality'. She said that if she was:

not seen as [herself], in [her] own right, someone who [was] fortunate enough to have a job, somewhere to live, a name, interests, likes and dislikes, [not] just another one of those "spastics", [she would] have no human dignity at all. 61

\footnotetext{
60 Owen Davies, 'Owen Davies' in Swansea \& District Spastics Association Year Book 1979/80, p.24.

61 Valerie Lang, 'The Use of the Word "Spastic" or, What's in a Name?' in Swansea \& District Spastic Association Year Book 1980, pp.33-35.
} 
In 1988, a film directed by Yvette Vanson, Stand up the real Glynn Vernon, told the personal story of Glynn Vernon, who had cerebral palsy. Vernon was a disability rights campaigner, who the first person with cerebral palsy to 'join the executive council of Scope and [was] its vice-chairman from 1993-96'62 The film summary was said to, 'challenge and disturb able-bodied people' and 'effect change on both an individual and institutional level'.63 Vanson spoke of the importance of the film as it had 'a disabled person at the centre' who 'couldn't speak' and 'when he could speak' it was 'very, very difficult to understand'. Vanson said that as Vernon opened up about his life, the 'very funny opening' in the film 'revolutionised approaches to disability'. She expected him to say that amongst the issues he had to contend with were things like, I 'haven't got access to my bathroom, or whatever, you know'. What he actually said was, 'I ain't got enough money, and I don't get enough sex'. Vanson said 'he's like all the rest of us'. ${ }^{64}$ The need to become 'an ordinary human being' is discussed by Hargreaves. He said that through the opportunity, to 'enjoy' or 'not enjoy' the 'ordinary things 'that happen throughout the course of an 'ordinary lifetime', he was able to live a 'perfectly able-bodied life, as a disabled person'. His message was that 'people with cerebral palsy have got to know about life . . . birth ... death ... sex ... love ... good ... evil. They've got to realise that they can be just as bad and just as good as any other people and that they should be treated the same as anyone else'. ${ }^{65}$ Achieving 'ordinariness' proved difficult against a backdrop which had a multitude of representations, purported to be modelled on a typical 'spastic'.

\footnotetext{
62 Anthony PM Hewson, 'Glynn Vernon, Disabled campaigner for disabled people' Guardian, 7 January 2003. <https://www.theguardian.com/society/2003/jan/07/disability.guardianobituaries> [accessed 25 June 2018].

63 Stand up the real Glynn Vernon, dir. by Yvette Vanson (Vanson Wardle Productions, 1996), online film recording, VANSON < http://www.yvettevanson.com/file/57> [accessed, 27 June 2018].

${ }^{64}$ BECTU History Project, Transcript of Yvette Vanson, Interview 569, 22 June 2007 $<$ https://historyproject.org.uk/sites/default/files/HP0569\%20Yvette\%20Vanson\%20-\%20Transcri pt.pdf> [accessed 25 June 2018].

${ }_{65}$ Can You manage stares? The life of Bill Hargreaves, ed. by Alex White (Cambridge: Black Bear Press, 2002), p.61.
} 
Jenny Corbett, Elaine Jones and Sue Ralph comment that many disabled people are 'independent, intelligent, bubbly and full of life'. However, they pose the question 'would people give money to charities if they did not show disabled people in a miserable situation?' They refer to a 1990 study by K. K. Lumb,66 which looked at 'an example of people with cerebral palsy in television advertising'. 'The sound of coins dropping onto a plate was imposed over the image of a young, white woman with cerebral palsy in a way which evoked pity and pathos'. The coins drowned out the sound of her voice which suggested that 'giving money was the key message' and 'her "ordinariness" and "humanity" were relegated to second place'. ${ }^{67}$

In a paper presented at the 'Cap-in Hand' Conference, in 1990, disability rights campaigner Jane Campbell, described the 1950s to the 1970s as a time of 'fund raising garden parties' and referred to the publicity and philanthropic nature 'titled people fund raising for the "poor unfortunates"'. She argued that there was 'more emphasis on the monied folk' doing a 'selfless deed' where 'garden party publicity portrayed the bone china and fairy cakes being consumed by the providers', with no disabled people there. A disabled friend told her, if they were there, then they were in another room, 'with a plastic mug and digestives'. Campbell contends that 'disabled people were not consulted', but 'acted on'. 68 The philanthropic nature that Campbell refers to can be illustrated through the earlier history of Spastic Associations. Headlines taken from a selection of press cuttings in 1954: The Lady from Mayfair is a Fairy Godmother; Woman buys home for spastic children; Handicapped children's chance of happiness ${ }^{69}$ reveal a philanthropic approach, resulting in the purchase of a house for SDSA. Similarly, the publicity surrounding celebrity fundraising organisations, such as Stars Organisations for Spastics is one of glamour where people with cerebral palsy are not seen, just referred to.

${ }^{66}$ K. K. Lumb, The drama of disability in charity fundraising, Coalition (1990).

67 Jenny Corbett, Elaine Jones \& Sue Ralph, 'A Shared Presentation: Two Disabled Women on Video', Disability, Handicap \& Society, 8:2 (1993) 173-186

$<$ https://doi.org/10.1080/02674649366780141>.

68 Jane Campbell, 'Developing our Image - Who's in control?' $1990<$ https://disabilitystudies.leeds.ac.uk/wp-content/uploads/sites/40/library/Campbell-DEVELOPING-OURIMAGE.pdf> [accessed 20 August 2018] (p.4).

69 Swansea, West Glamorgan Archive Service, Longfields Association Records, D/D LA 11/1-4, newspaper cuttings relating to Longfields Association, 1954-2007. 
Jane Campbell reflected on the 'traditional societal view' of disabled people and commented that historically, disabled people 'have never been allowed to take an active controlling role in the charitable organisations which purport[ed] to represent [them]'. Their 'image has been created by non-disabled people who "know" how to help those who cannot help themselves'. ${ }^{70}$ In contrast to the portrayal of the individual as part of a homogenous group, Campbell argued that the 1980s saw the rise of the image of the 'courageous and exceptional' disabled person. 'Able bodied experts' used words such as 'courage and bravery' in conjunction with disabled people and charity advertising. The 'ordinary disabled people' remained 'silent and isolated', if they didn't either achieve 'Douglas Bader-like feats of fortitude', or 'demonstrate happy smiling faces of gratitude'. Campbell said that the International Year of the Disabled in 1981, 'nurtured the myth' that disabled people 'were all so brave to undertake everyday tasks' ${ }^{\prime}$ These views are not restricted to people with cerebral palsy but also other disability groups. The business of charity is now a significant part of the economy and a major contributor in providing services for disabled people. The segregation of people with cerebral palsy, in post-war Britain, grew in part because there was no satisfactory provision of service, starting with education. Laura Middleton argues, this should not be 'an excuse' to stop us from 'seeking the reasons' for the lack of provision which was 'probably because of an unwillingness to provide for certain groups' ${ }^{72}$ The debate continues around the strategic aims of organisations and appropriate advertising.

\subsection{A 'spastic' icon}

The iconic 'spastic' collecting doll, (Appendix 9.7) is one such model of a 'typical spastic' and is representative of a particular type of attitude experienced by many. The doll drew on pity to evoke a response and shape an attitude, not by chance, but by design. Journalist, Raekha Prasad, considers the images of

\footnotetext{
70 Jane Campbell, Developing our Image - Who's in control? (p.2).

${ }^{71}$ Ibid., (p.4).

${ }^{72}$ Laura Middleton, p.60.
} 
disability in an article written in November 2002, referencing the 'troupe' of 'spastic' collecting dolls which:

stood on pavements in every town and city in Britain. Each girl's yellow hair fell around cherubic cheeks the picture of childhood, bar three crucial things. A calliper was strapped to one of her chubby legs and in one hand she held the sign "please help spastics". In the other, she clutched a teddy bear with a slot in his head to catch pity-pennies from passers-by. ${ }^{73}$

Alongside the obvious financial gain, the impact of this doll has to be considered in terms of advertising. Its public persona meant that it infiltrated society in a subliminal way, keeping alive the idea that a 'typical spastic' needed help and was to be pitied. Sharon Hughes, a trustee of the charity at the time is reported as saying that the doll 'portrayed people with cerebral palsy as pathetic cripples' and 'gave the impression that we all needed a lot of support and had nothing to contribute to society'. Prasad discusses how the doll, 'launched by the parents of children with cerebral palsy', was later 'found guilty of gross distortion by the adults they became 20 years later'. ${ }^{74}$ This view is supported through the recollections of Valerie Lang, who said that one of her 'pet objects was to get rid of the collecting dolls that the Society had, standing outside shops'. She said that her 'main contention was that in an era when the Society was attempting to foster independence - talking in terms of 'equality' - she did not think that the 'image of a begging child was conducive' with 'asking for independence, and a place in society'. ${ }^{75}$

Lang was not alone in her views and the giant sculpture of the doll, created by artist Damien Hirst, provoked a response from Kate Ansell in the BBC Ouch ${ }^{76}$

\footnotetext{
${ }^{73}$ Raekha Prasad, 'Looking Different', Guardian, 20 November, 2002. $<$ https://www.theguardian.com/society/2002/nov/20/disability> [accessed 2 September 2018].

${ }^{74}$ Prasad, (2002).

75 Interview with Valerie Lang by Philip Mann, 10 February 2005, 17 February 2005, 22 February 2005, 2 March 2005, 11 March 2005, 17 March 2005, 22 March 2005, 18 April 2005, 29 April 2005, 4 May 2005, 8 June 2005, 15 June 2005, 22 June 2005, 1 July 2005, 22 July 2005, Speaking for Ourselves: An Oral History of People with Cerebral Palsy, reference C1134/10/0125, British Library.

${ }^{76} \mathrm{BBC}$ Ouch is a website that reflects the lives and experiences of disabled people: http://www.bbc.co.uk/ouch/about.shtml
} 
blog. Ansell describes the sculpture, which was seven metres tall, in 'Hirst's interpretation she's been broken into with a crowbar and loose change is scattered at her feet'. Ansell comments that 'apparently, the statue aims to question society's historical tradition of representing disability as pitiful'. Ansell has cerebral palsy and wore callipers as a child. She states that 'it was these collection boxes which introduced [her] to the concept of disability charity when [she] was small.' When she saw donations being put into the box, she asked why and 'was told it's because they wanted to help [her] and said that she 'genuinely thought [she'd] get all the takings and it blew [her] tiny mind'. When the concept was explained to her, she said that is when she 'learnt that disability charities exist[ed], and [she] didn't much like the idea'. She continues:

A piece of me still wonders why those who want to help disabled people put money in a box rather than just help. But right now, I am wondering why people want to look at a statue and ponder an abstract situation, rather than engage with disabled people.

Ansell comments that with the 'unveiling of the statue comes the intriguing realisation that disability is something people are expected to have "attitudes towards"'. However, she argues that:

nobody seems to be encouraging anyone to pay attention to what disabled people say. Instead, it's suggested they gaze at a statue by a famous artist who isn't disabled, and think about people like us - all in the name of awareness raising.

For Ansell, the 'girl is not a redundant artefact of times gone by' and 'neither are people's attitudes towards her - they're still here'. She makes a political point that she and others 'don't need a giant statue of a miserable disabled girl in the centre of the city to encourage conversations about disability' as she says 'there are already loads of them going on' and concludes that 'it would be nice - if people were encouraged to listen to us, rather than take selfies with a statue'. ${ }^{77}$

77 Kate Ansell, Viewpoint: Does this Spastics Society statue start the right conversations? (2015), $<$ https://www.bbc.co.uk/news/blogs-ouch-33440475> [accessed 2 September, 2018]. 
Images used within charity advertising, are both male and female, and collection boxes were not wholly representative of girls with cerebral palsy. In his discussion on poster children, Paul Longmore considers the range of images presented. He argues that whilst 'agencies also used adults to illustrate their services', these generated, 'nowhere near the publicity beamed at the kids'. ${ }^{78}$ Considering Longmore's argument in relation to 'spastic' associations in Britain, the image of the child is predominant, despite associations evolving to represent adults with cerebral palsy. This is borne out through a study of the front covers of the Annual Reports of the national organisation, (1952 to 1997), which with limited exception, portray children to appeal to prospective donors. Longmore refers to a workshop held in 1986, where 'Easter Seals officials' said that 'children raise more money than adults'. They explained that 'youngsters were effective fundraising tools - because the public sympathised with images of "the most weak"'. The workshop also reported that 'girls pulled in larger amounts than boys'. Longmore reports that of the 'forty-eight national poster children chosen between 1947 and 1994, 2 out of 3 were girls' in the campaigns led by the Easter Seals. ${ }^{79}$ Of the single images on the front cover of the aforementioned Annual Reports, ten are of boys and fourteen are of girls, so not significantly higher in this instance.

\subsection{A change of name}

The 'spastic' brand had been in existence for more than four decades, with many of the same people at the helm at both a national and local level. As discussed, the social model did little for people with cerebral palsy or those with learning disabilities, in terms of attitudinal change and how they were perceived. The emotional link with the term 'spastic' had made it difficult for older parents to consider losing the term as they had created the brand and, for many, it represented their life's work. The brand image had proved to be successful, and had not only provided financial aid but also practical support and promotion of associations. Undergoing an identity change would have meant that

${ }^{78}$ Longmore, p.156.

${ }^{79}$ Longmore, p.157. 
associations, whilst keeping a support network intact, would have had to work to incorporate a changed profile and appeal to a new audience.

Increasingly, many individuals with cerebral palsy wanted to be actively involved in running their organisation, and be accepted as a person, not a stereotypical representation of a 'spastic'. The wider impact of the social model of disability forced the Spastics Society to consider a change of direction. If it was to continue, and be more inclusive to members, it had to listen to the requests made by those it supported. The citing of 'younger spastics' and 'younger parents' is interesting. Disquiet had been expressed, over the use of the term 'spastic', for many years by adults with cerebral palsy, who were the original children of the early days of associations. Their calls for change had largely gone unheeded. Jane Campbell makes a poignant statement, arguing that 'charities have been able to build their empires' based on the tragic image portrayed of disabled people. This, she says, maintains the 'image of dependency' by disabled people on charity, but she asks us to consider the dependency that charities have on disabled people. For example, their dependency for jobs, but she argues 'power is ignored in this equation. ${ }^{80}$

A period of consultation ensued, where the Spastics Society considered different views and reported that, it was particularly younger adults with cerebral palsy who 'reaffirmed their disquiet' over the use of the word 'spastic'. Also, a 'significant number of younger parents' had 'chosen not to seek the service of The Spastics Society, to avoid their child being associated with the stigmatising label'. ${ }^{81}$ The views expressed by 'younger parents', is in complete contrast to the views of 1950 s parents, who actively campaigned under the 'spastic' label.

Owen Davies of SDSA, writing in 1985, considered the views of Sir John Cox who at that time was the Director of The Spastics Society. Cox had said that the 'name spastic filled him with horror' and that most 'spastic' people who he had spoken to, also hated it. Davies wonders whether it was 'more beneficial to

\footnotetext{
80 Jane Campbell, Developing our Image - Who's in control? (p.3).

81 James Rye, The Spastics Society to Scope: The story of the name change and relaunch November 1994 (Produced by Scope's Creative Services 3431), p.5.
} 
let able-bodied people know WHO you are, rather than spend abortive hours worrying about WHAT you are'. He argued that rather than 'changing the name of the disability', changing attitudes would be of 'greater assistance'. He viewed proposals to change the name as 'purely cosmetic nonsense' as the 'environmental situation' [could not] be changed in doing this. ${ }^{82}$ Valerie Lang, who was the first disabled woman to serve on the executive committee of The Spastics Society, had campaigned for many years to change the name. As discussed, Lang had expressed her concerns over how the word 'spastic' had come 'to be used as a noun' and how emotive the term was, 'back then'. She recalled how a lot of people did not want to change the name. 'They liked The Spastics Society and they felt safe with it'. ${ }^{83}$

Eventually the name of the charity was changed from The Spastics Society to Scope but, extraordinarily, this did not happen until 1994. One of the factors cited for choosing the name Scope, was that it was a neutral term, and could not be used as a term of abuse. The term 'spastic' had been synonymous with the high-profile advertising campaigns of the charity and was therefore associated with negative imagery. In Changing Society (2002), former Chief Executive of Scope, Anthony Hewson, remembered the time when his son was diagnosed with cerebral palsy and he said to the paediatrician 'and what tablets do you prescribe for that?' The paediatrician replied, 'I don't think you quite understand $\mathrm{Mr}$ Hewson. It means he will be a spastic'. Hewson described the 'vision of the child in the wheelchair, the image that had been created when the Spastics Society had been formed, really all came quickly into view'. ${ }^{84}$ An article by Julie Pybus in Third Sector magazine (2002) features an interview with Richard Brewster, another former Chief Executive of Scope. He refers to a Blue Peter Appeal in the 1980s which featured Joey Deacon, a man with cerebral palsy. Brewster said that following the appearance, 'Joey Deacon and his disability were pounced on by schoolchildren who invented new forms of abuse based on the programme'.

\footnotetext{
${ }^{82}$ Swansea, West Glamorgan Archive Service, D/D LA 5/9, Owen Davies, "What's in a name ..." in Swansea \& District Spastics Association Year Book 1984/85, p.24-25.

${ }^{83}$ Valerie Lang, Twenty years on: Why I campaigned for The Spastics Society to change its name (2014), <https://blog.scope.org.uk/2014/03/31/why-i-campaigned-for-the-spasticssociety-to-change-its-name/> [accessed 25 June 2018].

${ }^{84}$ Chris Davies, p.106.
} 
He described how 'to be a "Joey" or a spastic was a common insult associated with committing a playground sin such as dropping a ball or tripping over'. Brewster referred to the 'Joey Deacon effect' which was not isolated but it 'resonated with wider debates about the way that disability was viewed by society'. 85

The term Scope had no obvious link to the condition, cerebral palsy. This is in complete contrast to the early days of The Spastics Society, and the passionate debate that had taken place in choosing the name of the society. At that time, it was agreed to deliberately focus on a term that was said to reflect those individuals who the charity was representing. Bill Hargreaves, who had cerebral palsy, and was the first disabled person to be on the executive committee of The Spastics Society, said that when he first heard the proposed name Scope, 'he nearly fell off the settee'. He had spent years 'campaigning for spastic children and their parents'; years campaigning for jobs whilst using the word 'spastic'; and time campaigning to support people with cerebral palsy in 'self-help groups' making 'some of them feel proud to be spastic'. ${ }^{86}$ As Chris Davies comments, pride in being labelled a 'spastic' was not unique, he recalls the time when Spastics News became Disability Now. The organisation received 'a lot of mail protesting about the change'. People said 'how dare you, I'm a spastic and I'm proud of it'. ${ }^{87}$ Actual statistics to demonstrate acceptance or rejection of the word 'spastic' are not available. However, of the views and literature considered, it can be said that, overwhelmingly people with cerebral palsy did not want to be labelled as 'spastic' and were in favour of the name change, what they all thought of the name Scope is a matter for another debate.

Chris Davies, in his personal history of Scope, discusses the opinions of Conservative MP, Tim Yeo, who became the 'Director' of The Spastics Society in 1980. Yeo had researched the organisation and its activities before taking up the post. He believed that the organisation 'had completed its first phase of

85 Julie Pybus, NEWSMAKER: A question of priorities - Richard Brewster, Chief executive, Scope (2002), <https://www.thirdsector.co.uk/newsmaker-question-priorities-richard-brewsterchief-executive-scope/article/611685> [accessed 18 September 2019].

${ }^{86}$ Can You manage stares? The life of Bill Hargreaves, p.129-131.

${ }^{87}$ Chris Davies, p.130. 
existence; a rather successful phase, in terms of enormous expansion from a very small beginning'. He argued that there followed a transitional phase 'in terms of the influence of the parents' the founders of the organisation. 'It was ready to be handed over to allow disabled people themselves to play a much bigger role in the management of the organisation'. He saw the role of disabled people as both volunteers and staff. ${ }^{88}$ Davies describes how he was at the 'historic' meeting where the change of name was made, and recalled how Hargreaves made an 'eloquent speech in favour of change'. ${ }^{89}$ Why did Hargreaves change his mind to be more accepting of the new term? He decided to be 'really positive' to see what he could do when invited to speak at the Extraordinary General Meeting in 1994. He described a 'eureka' moment after he had considered a dictionary definition of the word 'scope' which read, 'opportunity for action'. He spoke about this at the meeting and declared, 'opportunity for action to help cerebral palsied people was exactly what was needed . . . Scope means hope, Ladies and Gentlemen, vote for Scope'. ${ }^{90}$ Davies reports that Hargreaves had said an 'amalgamation of the old and the new' had to be achieved and Hargreaves was 'the person who swung opinion towards change' and did so because of 'who he was'. Hargreaves had 'always defined himself as spastic', and if he could 'see the sense behind the change' then 'there wasn't much reason not to do it'. Such was the emotion at the meeting, Davies said he 'did a lot of crying afterwards. It was a big success for The Spastics Society' but for Davies it was also a 'big personal success'. ${ }^{91}$

Alex White joined the charity as it was relaunching. He said that thankfully he never had to utter the phrase, 'I work for The Spastics Society'. He recalled the 'abiding relief' that was felt by colleagues and others that the 'old-fashioned, medical name' had finally been changed. ${ }^{92}$ James Rye, the Assistant Director/Head of Public Relations (1998-2001) at Scope, told the story of how The Spastics Society changed its name. Whilst staff and volunteers, were said

\footnotetext{
88 lbid, p.90.

89 lbid., p.122.

${ }^{90}$ Can You manage stares? The life of Bill Hargreaves, p.132.

${ }^{91}$ Chris Davies, pp.122-127.

92 Alex White, More than words: The changing language of disability, (November 2016), $<$ https://community.scope.org.uk/discussion/30680/more-than-words-the-changing-language-ofdisability $>$
} 
to 'express pride and support' for the organisation they worked for, many were reluctant to name it due to their 'reservations' about the word 'spastic'. Similarly, individual and corporate sponsors, whilst expressing support for the Society's work, 'disliked the word spastic'. ${ }^{93}$ The charity felt that the use of the word made it difficult to 'challenge prejudice and misconceptions' about cerebral palsy. It was felt that a 'barrier was being created for many people in need of the organisation's support, or who wished to get involved in various ways'. ${ }^{94}$

Dorcas Munday, born with cerebral palsy in 1947, commented, even though the term 'spastic' was 'no longer the official language' people would 'still say spastic because it's what they [were] brought up on' and 'it takes a long time for language to die'. She said, as it has taken 'an awful long time to get rid of the word cripple [then] I daresay it'll take an awful long time to get rid of the word spastic as well' . ${ }^{95}$ Comedian Laurence Clark, born with cerebral palsy, discusses the use of the term 'spastic' which he used inadvertently during his act in the Edinburgh Fringe in 2007. He said 'to [his] amazement, this was greeted with possibly the biggest laugh [he had] ever got as a stand-up comedian'. He continued:

It was as if l'd voiced the very thing that was foremost on the minds of absolutely every single audience member, yet no-one dared to say it. At that moment, I realised that whilst we may have banished this word from British culture, people with cerebral palsy, like me, will forever be subconsciously labelled spastic by a section of the public.

However, he asks: 'if anyone's got a right to use this word then surely it's [me]'? He refers to his school days, where he attended Percy Hedley School for Spastics, and said how the 'teachers, doctors, care staff... pretty much everyone there would commonly refer to [him] as a spastic'. Clark comments how in a 2003 poll for BBC Ouch the term 'spastic' was voted 'to be the second most offensive

\footnotetext{
${ }^{93}$ Rye, p.5.

${ }^{94}$ Rye, p.6.

95 Interview with Dorcas Munday by Philip Mann, 23 - 24 June 2005, 28 June 2005, 11 July 2005, 20 January 2006, Speaking for Ourselves: An Oral History of People with Cerebral Palsy, reference C1134/23/01-13, British Library.
} 
word in the English language when it came to describing a disabled person'. He argues that it 'was high time to take a stand and attempt to reclaim it'. He refers to other negative terms of the past that have been reclaimed, and says 'it's about humour, irony and taking ownership of words that were once used destructively' and he talks of his 'personal mission' to reclaim the term through his stand-up show 'Spastic Fantastic', and wonders whether his 'audiences will either be rolling in the aisles or stunned into a perplexed silence'. ${ }^{96}$ As argued by Munday, Clark's discussion demonstrates the power of language and its ability to evoke a response. This is a topic discussed by Damon Rose in respect of the importance of charity names. He reports how, Scope has 'never rebuilt its brand awareness' as previously, ' $90 \%$ of people used to know what the Spastics Society was' but following the change of name this dropped to $64 \% .{ }^{97}$

The change of name by the national charity filtered down to the local, affiliated groups, for example Swansea \& District Spastic Association changed its name to Longfields Association in 2000 following a consultation of its members in 1999. The new name was based on the name of the house in which the organisation was situated. Similar concerns were expressed about marketing and fundraising. Committee member, Peter B. recalled how the buses used to have the name Swansea \& District Spastic Association emblazoned on the side which he said, was:

a two-edged sword. It would advertise people with cerebral palsy, but at the same time, it put them a bit on a pedestal from the point of view of seeing them sitting in the buses and driving along and of course we know that the word spastic became a derogatory term. There was a lot of discussion at committee meetings about whether we should change it. Because, Longfields didn't show what we were doing, but the buses with Swansea and District Spastic Society did. ${ }^{98}$

\footnotetext{
${ }^{96}$ Laurence Clark, Spastic fantastic (2008), <http://www.bbc.co.uk/ouch/opinion/spasticfantastic.shtml>.

97 Damon Rose, Formerly known as the Spastics Society: The importance of charity names (2014), <https://www.bbc.co.uk/news/blogs-ouch-26788607>.

${ }_{98}$ Peter Be., interviewed by Teresa Hillier about the history of Longfields Association, 6 June 2017.
} 
As well as having the name 'spastic' on the side of the bus, they also had the term 'ambulance' inscribed on the bodywork. It is important to remember that this was the 1990s and the buses were relatively modern, yet SDSA still chose to refer them as 'ambulances'. Christopher P., who travelled regularly on the buses said 'I didn't like what they put on the buses. 'Cause, 'we weren't in no proper ambulance. People stopped us in the road thinking we were the ambulance, and I didn't like that'. 99 There were also general concerns over the possible loss of funding as a parent, Molly B., said, 'when we were out with our boxes -people [didn't] know, what Longfields represented'. 100 Another parent, Joan O. said:

\begin{abstract}
we had to change our name, so a great deal of thought went into that, I think we asked the youngsters as well and we became the Longfields Association . . . Well then people didn't know that you see, and people would stop and say; 'What's that then? Is it for, for old people?' you know and we did not get the public support that we had had when the word spastic was there, which was a great shame. ${ }^{101}$
\end{abstract}

Historically, the society had existed as an organisation for people with cerebral palsy, but the aim was to change to an organisation run by people with the condition. This constitutional change would force the charity to look at its aims and objectives, and employ people with cerebral palsy at the core of the organisation. This was a radical change and the society had to win over 'traditional thinkers'. Yeo maintained that the founding parents found it difficult as 'they weren't letting go' and the Executive Committee proved difficult in their 'resistance to change'. ${ }^{102}$ In order for change to happen there had to be a step away from the 'spastic' label as this, in addition to becoming a derogatory term, was overwhelmingly demeaning to people with cerebral palsy. It perpetuated a societal view that these individuals lacked ability and therefore could not be seen

\footnotetext{
99 Christopher P., interviewed by Teresa Hillier about the history of Longfields Association, 17 February 2017.

${ }^{100}$ Molly B.

101 Joan O.

102 Chris Davies pp.92-94.
} 
as being able to contribute to change by working alongside their non-disabled colleagues.

\subsection{Conclusion}

It was the motivation of the parents of children with cerebral palsy, and the actions of the NSS, that led to the birth of the 'spastic' brand which became synonymous with the condition, and the word 'spastic' becoming part of popular culture. The term was used in a deliberately confrontational way, to draw attention to cerebral palsy and also to raise money. This was successful but it endorsed a view of people with cerebral palsy as one homogenous group. As a term, it did not represent the wide range of symptoms associated with cerebral palsy. This added to the confusion and misunderstanding of the condition. However, replacement of the term 'spastic' with a new brand, 'Scope', raised different issues as this term gave no indication of what the organisation stood for.

Barnes considers the representation of disabled people in the media and the use of terms such as 'cripple, spastic and idiot', arguing that these terms had been 'substantially devalued by societal perceptions of disabled people; in short, they had been turned into terms of abuse'. He argues that disability organisations, such as The Spastics Society, 'whose name 'implie[d] that they [were] organisations of disabled people' should state in their adverts that they were 'controlled and run by non-disabled people.'103 This only began to be challenged seriously as disability activism grew, and the term 'spastic' began to be phased out of the titles of parent-led organisations.

Parental involvement in the advancement of associations, from segregated schools to sheltered employment encouraged the development of an institutional culture. Developments in the field of cerebral palsy, and the education of children with the condition were overshadowed by the 'spastic' label.

103 Colin Barnes, Disabling Imagery And The Media: An Exploration of the Principles for Media Representations of Disabled People (Halifax: The British Council of Organisations of Disabled People and Ryburn Publishing Limited, 1992), <https://disability-studies.leeds.ac.uk/wpcontent/uploads/sites/40/library/Barnes-disabling-imagery.pdf> [accessed 8 May 2019]. 
The revolution for change had to come from within, to address the dilemma of how to present people with cerebral palsy in a more positive way, whilst also demonstrating that funds were needed in order to provide help and support. This was a new dilemma as previously, the 'spastic' image was used without any obvious concerns about negativity. Such images had been at the core of organisations and helped to secure financial gain. The public façade of The Spastics Society had been built on the use of images, such as the collecting doll. The resulting emotional appeal went beyond these images, and strongly bound together the founding families. Without the growth of parent-led 'spastic' associations, many families would have struggled to overcome the isolation felt by having a child with cerebral palsy. Over time, the impact of a growth of disability activism as opposed to parent advocacy, could not be ignored.

The move to replace the term 'spastic' was an aspect of disability activism, and the organisation began to change their public image, as well as their attitude towards those who were the recipients of their charitable work. The social model of disability failed to address the blanket attitudinal barriers that individuals with cerebral palsy faced, but it did help to raise awareness of the importance of language in relation to disability. The publicity and marketing machine was a force to consider and dominant charities, such as The Spastics Society, were difficult to challenge. Campbell, writing in 1990 refers to the power of charities, citing the Spastics Society with a high number of staff and large financial turnover. She comments that charities like The Spastics Society were looking for 'POSITIVE IMAGES' of disabled people but questions whether it [was] just another PR exercise and if the new emphasis on 'ABILITY and ACTIVITY [was] reflected in organisational practices'? The five new regional managers of the Spastics Society were all able bodied which prompts her to ask whether the change was only 'POSTER deep'. ${ }^{104}$ Despite these comments, the rebranding of 'spastic' associations did lead to a period of reflection on their aims and objectives. They had to develop a level of professionalism in order to compete

104 Jane Campbell, Developing our Image - Who's in control? (p.3). 
with other organisations, and including disabled people in positions of responsibility was essential to moving the organisation forward. 


\section{Forces for change: the impact of the Warnock Report and the future of 'spastic' associations}

The often-competing views of parents, educationalists and medical professionals, with respect to education for children with cerebral palsy, has been discussed in this thesis. Differing opinions brought into question the purpose of education. The goal of securing employment and integration into society was an objective that proved difficult for some to achieve. Societal prejudices, lack of life experience and the complexities of cerebral palsy have all been cited as obstacles to opportunities. Segregation, within the education system, reinforced the concept of 'ineducability' and the new category of 'special educational needs' encompassed cerebral palsy. The 1970 Education (Handicapped Children) Act transferred the responsibility of those children who had been under the jurisdiction of health authorities to the education departments of local authorities. This chapter argues that integration did not automatically mean inclusion. Parents of the 1960s and 1970s had similar issues to parents of the 1940s and 1950s concerning prejudices towards their children and employment prospects. Associations had to adapt to a society where disability activism increasingly challenged the portrayal of disabled individuals.

In November 1973, the Secretary of State for Education, Margaret Thatcher M.P., appointed a committee, led by Mary Warnock, with the following terms of reference:

to review educational provision in England, Scotland and Wales for children and young people handicapped by disabilities of body or mind, taking account of the medical aspects of their needs, together with arrangements to prepare them for entry into employment; to consider the most effective use of resources for these purposes; and to make recommendations ${ }^{1}$

The resulting Warnock report challenged the perception of children with

\footnotetext{
1 Mary Warnock, Special Educational Needs: Report of the Committee of Enquiry into the
} Education of Handicapped Children and Young People (London: H.M.S.O., 1978), p.1. 
disabilities and their means of access to education. The 'landmark' report was to form the basis of the 1981 Education Act. This chapter argues that despite losing the 'disability categories' of the Handicapped Pupils and Medical Services Regulations 1945, labelling continued to have a negative influence. During the intervening years, from the establishment of 'spastic' associations to the recommendations of the Warnock report, a generation of individuals had grown up with the 'spastic' label.

Throughout this period of change, parent-led 'spastic' associations had remained constant, continuing to provide a service, but they were no longer at the forefront in campaigning. By the mid-1980s, with diminishing contract work, associations formed day centres, which many individuals continued to attend. It can be said that a new generation of adults with cerebral palsy, had a ready-made service awaiting them, and so there were no fears about employment. However, this prospect may not have been viewed as acceptable to a new generation.

A changing relationship with local authorities led to the introduction of more formal agreements, and inevitably this meant that associations lost a certain level of autonomy. Whilst the associations had provided a much-needed and welcomed service for many, the achievement of full citizenship within society remained elusive for those who sought it.

\subsection{Integration challenges}

Parent-led 'spastic' associations had created a safe haven and parents did not worry about their children being accepted within that environment. Jean $\mathrm{H}$. recalled how her mother wanted her brother Clive to remain at SDSA 'because he'd been so safe there, and she'd been so happy with the people there'. Following the 1970 Education (Handicapped Children) Act, Clive, who would have been in his early teens, was transferred to a 'special unit' run by the local authority, but Jean did not think that he was very happy there as 'it wasn't so ... secure ... and sort of comfortable and homely' as it had been at SDSA. She said, 'when Clive was there, we knew, we knew everybody, most of them had 
been there nearly all the time with Clive'. ${ }^{2}$ Concerns of parents about having the right provision for their children did not diminish with new legislation. Aspirations to achieve integration and inclusion were also goals, yet to be attained.

The legacy resulting from the medicalisation of disability was viewed as a problem, which society did not have the resources to deal with. The need for more resources is demonstrated through an experiment undertaken in the 1960s by Enid Marlow, headmistress of Carlson House School, Mary Thomas, educational psychologist, and Andrew Innes, consultant surgeon at the Children's Hospital Birmingham. The reported outcomes of this experiment gives an insight into the difficulties parents experienced in gaining the necessary support for their children. Experience had shown staff at Carlson House school that children who had mild physical 'handicaps' also had behavioural difficulties and 'lacked confidence'. This, it said, made it hard for them to be accepted by 'ordinary' children. The experiment, Spastics in Ordinary Schools, involved ten children who had been originally admitted to the nursery unit at Carlson House. These children, who were aged between four and six in 1960, were transferred to 'ordinary' schools. In 1966 an assessment was made of the outcomes of the experiment. Their parents were interviewed as part of the process and the majority were fairly satisfied with their child's progress, but concerns were expressed about the level of support given in 'ordinary' schools, for their child's 'specific learning problem'. A frequent comment made by parents was that they found it 'difficult to explain to teachers, in ordinary schools, that their children were slower than normal because they were "spastic" and not mentally backward'. They said, that whilst some teachers were more sympathetic, the size of the classes and lack of continuity of teaching staff, contributed to the limited understanding of each child's 'specific learning difficulties essential to their success'. ${ }^{3}$ The concerns expressed by parents illustrate that, despite a move towards integration, it could not be achieved without having sufficient resources to meet individual needs.

\footnotetext{
2 Jean H., interviewed by Teresa Hillier about the history of Longfields Association, $11^{\text {th }}$ April 2017. ${ }^{3}$ Harborne, Cerebral Palsy Midlands, A report by Enid Marlow, Mary Thomas and Alexander Innes, 'Spastics in Ordinary Schools' (1967).
} 
The authors of the report argued that 'more satisfactory progress' had been made in schools with smaller classes, and where 'teachers [had] a good understanding of specific learning problems, and how to deal with them.' 'The size of classes in ordinary schools', together with the 'spatial problems' and 'spasticity' experienced by the pupils, was said to make it 'impossible for teachers' to give them 'adequate tuition and supervision'. Whilst 'special classes in ordinary schools' were seen to be the 'ideal solution', particularly for the 'basic subjects', effective reporting on individual 'physical and educational difficulties' was also seen as essential. Realisation that the 'spastic' child's 'basic level of intelligence was at least average', meant that 'there would be less possibility of the spastic child drifting into the educationally subnormal category and ending his school career as a failure'. ${ }^{4}$ However, to meet these ideals, effective communication was needed between educational and medical professionals, as well as the parents. This has been shown to be difficult to achieve.

Streaming is a consistent component within the education system, irrespective of social or political motives, or allowances made for individual needs. Being measured, against a set of defined benchmarks, inevitably leads to failure for some and testing ability in this way may not be a true indicator of forecasting an expected level of achievement. The tripartite system was replaced in the early 1970s by non-selective, comprehensive schools, which took children according to catchment area. However, for families of children with cerebral palsy, this development would simply have perpetuated their concerns about integration and inclusion, and finding the right place for their child, with suitably trained staff. These concerns can be said to be as relevant today, as for post-war parents. Professionals remain the key 'decision makers' when it comes to the assessment and placement of children with cerebral palsy. Opportunity may be taken away from some, who have the potential to achieve at a higher level, because of streaming and the chance to achieve may never be realised.

An increase in practical resources, in order to aid in the provision of education for disabled children, is not enough. A widespread change in attitude and acceptance of difference remains paramount. Laura Conner, in her article

\footnotetext{
${ }^{4}$ Harborne, Cerebral Palsy Midlands, 'Spastics in Ordinary Schools'.
} 
for the periodical Research in Teacher Education, considers inclusion. She discusses Tom Shakespeare's argument (2006) that the social model cannot be seen in isolation, and 'focusing on disability solely as the result of social oppression does not take into consideration the role of the impairment itself'. Shakespeare argues that 'creating a world void of all barriers for all disabilities would be impossible'. ${ }^{5}$ The complexities of cerebral palsy, particularly during childhood, inevitably meant a continual involvement of the medical profession through regular therapy treatments. Separating the medical and social model of disability, for these individuals, remains almost impossible. Conner argues, either model alone is too simplistic, because to choose one would be to potentially ignore important contributions from the opposing model'. ${ }^{6}$ The study 'Spastics in Ordinary Schools', demonstrates how a fine balance is needed between the two models in order to provide more equality of opportunity, and simply having extra resources in the practical sense will not address this issue.

Reflecting on the history of 'spastic' associations, it can be said that providing specialised support achieved a level of success, but that is not to say that it was the best solution to the problem of segregation. Dan Goodley discusses 'inclusive education' and maintains that in order to understand it 'we need to probe special education'. He refers to Felicity Armstrong, who described special education as "a "wild profusion of entangled ideas" including charity, medicalisation and psychologisation'. Goodley discusses how 'proponents' of special education 'argue that special settings provide more suitable contexts for the needs of disabled children to be met'. ${ }^{7}$ The problems of segregation run through the history of education for children with cerebral palsy. A report in Spastics News in April 1970, discussed the integration of children with 'physical and mental handicaps' into 'ordinary' schools in Yorkshire and it reports that initially, the scheme was met with opposition, 'particularly from parents'.

${ }^{5}$ Tom Shakespeare, Disability rights and wrongs, London: Routledge, 2006) cited in Laura Conner, 'Reflections on inclusion: how far have we come since Warnock and Salamanca?', Research in Teacher Education, 6.1 (2016) 18-23 (p.19) <http://dx.doi:10.15123/PUB.5096>.

6 Laura Conner, 'Reflections on inclusion: how far have we come since Warnock and Salamanca?', Research in Teacher Education, $6.1 \quad$ (2016) $18-23 \quad$ (p.19) $<$ http://dx.doi:10.15123/PUB.5096>.

7 Dan Goodley, Disability Studies An Interdisciplinary introduction (London: SAGE Publications Ltd., 2017), p.171. 
However, it was not just from the mothers of the disabled children who had wanted to 'protect their youngsters from the usual rough and tumble of playtime'. Opposition also came from the mothers of the non-disabled children who were 'reluctant for their children to mix with the handicapped'. The response from the Head of the Spastic's Society's Social Work and Employment Department, M. R. Morgan, said that mixing 'handicapped and un-handicapped children' from a young age meant that they were 'more likely to be able to make meaningful relationships' with each other as they grew up. She spoke of the 'more specialised help' some children needed, and differences in the pace of work between the two groups. She argued, if such nurseries were to be successful, then it must be accepted that the 'most physically handicapped, and the most emotionally disturbed children', would always require 'special provisions, where the meeting of their needs [came] first'. ${ }^{8}$ Prior to the recommendations of the Warnock Committee and their subsequent enactment, children in special schools were denoted as having either moderate, severe learning or severely subnormal difficulties. Stanley Segal discussed the segregation of pupils who were viewed as 'educationally subnormal'. He is not specifically considering schools for children with cerebral palsy but his views are pertinent. He said that his first experience of a 'special school' left him with a 'nagging group of questions'. He argued that it was 'not sufficient to look for answers in the changes of [the] political colour of government' but the 'intentions of the decision makers' had to be considered with how they had to 'operate through existing professionals, auxiliaries, services and resources'. He maintained that:

in every case, it was easier for the decision-makers to grasp the need to remove troublesome children and to find them 'places'; rather than to concentrate upon the appropriate training of the staff into whose hands they were placed. ${ }^{9}$

Achieving a level of integration and meeting individual needs had been problematic for so long, that many families with disabled children only expected segregation, and in part, this had become the norm.

\footnotetext{
${ }^{8}$ London, Wellcome Library, 'Prejudice at first - but now school integration is a success', Spastics News Magazine of the Spastic Society, April 1970, p.11.

${ }^{9}$ Stanley S Segal, No Child is Ineducable (Oxford: Pergamon Press Ltd., 1974), p.69.
} 
The Warnock report acknowledged that 'many parents had experienced difficulties in 'convincing anyone that their children's problems [were] real' and it refers to evidence submitted to the committee, and a research project conducted by 'Professor Chazan and Dr Alice Laing of the University College of Swansea'. ${ }^{10}$ The research project had looked at 'services for parents of handicapped children under five' and had been undertaken between December 1975 and December 1976 covering five geographical areas, Hampshire, Sheffield, Suffolk, West Glamorgan and the Lothian Region. ${ }^{11}$ The outcomes of the project revealed that parents in the 1970s were faced with similar issues experienced by parents in the 1950s. Parents as partners were still perceived as problematic, as they were said to be too emotionally involved to adopt a pragmatic approach. However, without that emotional response, then arguably, the growth of parent-led 'spastic' associations could have been more restrained. Parents were part of the solution and their role in contributing to the lives of children with 'special needs' is acknowledged in the Warnock report. The 'voluntary movement', of which parentled 'spastic' associations were included, was referred to as a 'living thing'. Organisations had adapted over time and the relationships with 'statutory authorities constantly change[d] with new legislation or changes in administration'.12 However, it had taken more than twenty years, from the implementation of the 1944 Education Act, to bring 'ineducable' children out of the shadow of the medical model of disability.

As discussed, campaigning for education, employment and integration, for people with cerebral palsy, were issues which had been at the heart of parent-led 'spastic' associations. These issues were now being highlighted by the Warnock report but, despite this new initiative, associations did not cease and continued to make an active contribution. An article in the Spastics Society magazine (1974), discussed research on the 'handicapped adolescent' in education and the resulting report, 'The Closed Door'. The concept of the 'handicapped and ablebodied, sharing common schooling' had been considered and it was strongly stated that:

\footnotetext{
${ }^{10}$ Warnock, p.51.

11 lbid., p.388.

12 Ibid., p.309.
} 
It would [have been] improper and even cruel if handicapped pupils were transferred from special schools - (many of which ha[d] remarkably high standards) - to ordinary schools, many of which [were] not yet organised or designed to contain them and may [have been] functioning at an inferior level, merely to satisfy doctrinaire educational theory.

The Spastics Society ran seven schools which provided education for 500 pupils. The report argued that there was 'a need for less dogmatism and more research before a proven system of special educational facilities [was] abandoned'. A two-year study, planned with the Institute of Education at London University, was to examine the 'progress of handicapped children' who attended 'ordinary' schools. It was said that this study would 'provide valuable information and data for the special committee set up to enquire into special education'. 'The Closed Door' report concluded, that only a 'small proportion of handicapped school leavers' went on to further education. It contended that 'without that bridge to adulthood the door to even limited opportunity [was] liable to remain firmly closed to all but the minimally handicapped'. ${ }^{13}$ The concerns voiced by the Spastics Society demonstrate how they wanted to maintain a robust position in providing services, while recommendations from the Warnock report may have been seen as a threat to their role as service providers.

In theory, the integration of disabled children into mainstream schools was a positive goal, but special education classes for children with disabilities meant that they were not fully included. The focus was on the child adapting to the school rather than the school adapting to the child. Those children with cerebral palsy who did not lack mental capacity were, in many cases, side-lined. Teaching methods needed to be adapted to assess and teach all children, and in doing so teachers needed additional training. The Warnock report declared that independent schools, catering for 'handicapped children', had 'carried out useful pioneering work' in the past and continued to be innovative. However, there was

${ }^{13}$ London, Wellcome Library, 'Cruel to send all handicapped children to comprehensive schools, says new Report', Spastics News Magazine of the Spastic Society, January 1974. 
also a level of criticism towards such schools and 'two extremes' were quoted which maintained that:

some of the very best schools in the country for children with certain disabilities, particularly for spastic and for autistic children, [were] run by voluntary bodies who prefer[ed] for their schools the greater freedom which independent status confer[red]. At the other extreme, some individual proprietors appear[ed] to view the provision of boarding special education as a commercial venture which should yield a profit. Moreover, the schools are often isolated from the mainstream of education and, having few contacts with ordinary schools, they tend[ed] to accentuate the present division between handicapped and other children. ${ }^{14}$

Parent Philippa Russell, writing in the British Journal of Special Education, reflected on the hopes of some parents of 'mentally handicapped children' before Warnock where a 'brave new world' had been forecast that would 'provide appropriate education' and 'suitably trained teachers' offering a 'real future' for their children. After Warnock, Russell said parents' concerns were evident, they felt bewildered by the 'conflicting integration versus segregation battles' and as Russell commented, some parents were 'frightened that [their] children would be caught in the cross fire'. ${ }^{15}$

Parent-led 'spastic' associations confronted local authorities with their concerns as the outcomes of the Warnock report began to take effect. At the time of the Warnock report, associations were still very much focused on keeping their charitable status, providing a service to their members but not necessarily representing their views. This was to change in the coming years. The Warnock report did not really provide a viable alternative that successfully solved the issues around educating children with 'special needs' and addressing their employment prospects. This debate is still relevant today.

\footnotetext{
${ }^{14}$ Warnock, p.139.

${ }^{15}$ Philippa Russell, 'Warnock and After - A Parent's View', Special Education, Forward Trends, British Journal of Special Education, 5-3 (1978) p.29.
} 


\subsection{0s - maintaining communities in a time of change}

By the 1970s, for the first time all children were entitled to an education, which meant most children with cerebral palsy were no longer classed as 'ineducable'. This changing climate encouraged wider debate on how to teach and include disabled children in education. John Welshman considers the early 1970s as:

a watershed, the time when policy makers adopted the relatively optimistic ideas associated with researchers who made the case for regarding people with mental handicaps as able to benefit from a comfortable environment, contact with the wider world and education.

However, he maintains that 'ideas alone do not drive change' but argues that they 'can influence the direction of changes'. He says that:

the difference between what is said and done underlies our decision to separate the analysis of ideological change from the account of changes in organisations and structures. ${ }^{16}$

At this time, 'spastic' associations had become well established in the fields of education and employment and their large network had spawned thriving communities which collectively formed an influential body. The services they provided had been developed over many years and associations had supported a generation of children, through education and into some form of employment. The growth of expertise and dissemination of knowledge, delivered by 'spastic' associations, could not be disregarded within the development of new legislative policies. Associations had many years of direct experience of the challenges that had to be overcome, in order to meet the needs of 'spastic' children and their families. This body of knowledge and the established network of dedicated individuals, sympathetic to their cause, was invaluable. As Segal argued,

\footnotetext{
${ }^{16}$ John Welshman, 'Ideology, Ideas and Care in the Community, 1948-71', in Community Care in Perspective: Care, Control and Citizenship, ed. by John Welshman and Jan Walmsley (London: Palgrave Macmillan, 2006), pp.17-18.
} 
organisations such as the Spastics Society 'could not have foreseen the mileage in the high-octane emotional fuel which was to sustain their own multi-directional services'. ${ }^{17}$

The 1970 Annual Report of the Spastics Society illustrates how 'spastic' associations had extensively developed their network, through a programme of expansion in the provision of new services. The report details the development of new work centres in addition to the expansion of existing ones. These developments enabled more employment and training opportunities, forming part of an extensive list of projects which catered for 'spastics' of all ages and varying needs. ${ }^{18}$ These developments can be seen in Midland Spastic Association (MSA) where a variety of Clubs had grown to cater for teenage and older 'spastics'. ${ }^{19}$ David B., who attended MSA, recalled the importance of the youth clubs in his life and said that he 'managed to get down to the Youth Club straight from school and that was the stepping stone towards moving out and was most important in [his] life'. ${ }^{20}$ In 1969, MSA launched a Further Education Scheme for adults and as part of this initiative groups had 'visiting speakers' and took part in social outings, which included visits to 'ancient monuments; shows; theatres; wildlife reserves; and museums'. It was felt that these 'extra activities' added to the 'life of the centre'. 21

The success of 'spastic' associations was partly due to its ability to continually adapt to meet the needs of those who used their services. It is not difficult to understand why the 1970 Education (Handicapped Children) Act was greeted with a level of scepticism and concern by the national association. The Spastics Society argued that the 1970 Act would have 'a far-reaching effect on [its] services' and particularly services run by local groups. It had been the Education Department within the Society and not government bodies that had

\footnotetext{
${ }^{17}$ Stanley Segal, Society and Mental Handicap: Are we Ineducable?' (Tunbridge Wells: Costello Educational, 1984), p.86.

${ }^{18}$ National Spastics Society Annual report (1970), pp.5-8.

19 Harborne, Cerebral Palsy Midlands, 'Jottings from the Welfare Office' in Midlands Spastic Association Year Book 1973/74, p.15.

${ }^{20}$ Interview with David B., 22 January, 2014 as part of a Heritage Fund Project, Fulfilment through Achievement, Harborne, Cerebral Palsy Midlands.

${ }^{21}$ Harborne, Cerebral Palsy Midlands, 'Further Education', in Midland Spastic Association Year Book 1972, p.26.
} 
provided local groups with 'professional advice' regarding new legislation, for which 'spastic' associations had campaigned. ${ }^{22}$ The Spastics Society had been the main provider of information to parents through publications and other literature, films, and dissemination of information through its network. Utilising the network, it had targeted a large audience. Through the services it provided, local associations had also become significant providers within the welfare state. The national society said that it had 'fill[ed] some of the wide gaps in State provision for the handicapped'. ${ }^{23}$ Whilst the new legislation represented progress it also potentially threatened the level of influence that associations had. The fact that the 1970 Act moved all children to the responsibility of local education departments, inevitably impacted on systems that had been developed over a period of almost thirty years. Associations had got used to delivering such services. MSA had a team of welfare officers who dealt with the 'multitudinous problems of spastics and their families'. They not only dealt with families connected to the association but also with those in the wider county area. They worked in 'the interests of the family as a whole', which included the needs of the 'spastic' person. Throughout their work they dealt with 'hospitals; social services; education and health departments; youth employment officers; various Ministries; and other voluntary organisations'. ${ }^{24}$ The success and range of services offered, gave a level of confidence and assurance that its expertise was needed by a wider audience.

Whilst the rapidity of the growth of parent-led 'spastic' associations was phenomenal, financial concerns began to emerge in the 1970s. Education was no longer the sole focus of associations, the first generation of children from the 1940s and 1950s had become school leavers, so the emphasis had shifted slightly to campaign on employment issues. Maintaining these associations, made members look to the future, and the possibility of having a closer collaboration with the state had to be considered. Whilst finance and marketing had always been central to their operation, they had to develop a level of

\footnotetext{
${ }^{22}$ National Spastics Society Annual report (1971), p.8.

${ }^{23}$ National Spastics Society Annual report (1973), p.3.

${ }^{24}$ Harborne, Cerebral Palsy Midlands, 'Jottings from the Welfare Office' in Midlands Spastic Association Year Book 1973/74, p.15.
} 
professionalism in order to compete with other, similar organisations and include disabled people at their core. During the 1970s many of the socio-historical inequalities of race, class, sex and disability were challenged and the emerging social model of disability confronted society, provoking a changing attitude towards social and cultural values.

\subsection{The Warnock Report - a new beginning?}

Felicity Armstrong considers the Warnock report, which challenged the 'dominant assumptions', that children fell into the broad categories of 'the handicapped and the non-handicapped', with 'the categorisation of impairment' used as a 'justification for "special" provision'. This report stated that the use of the term 'handicapped' did not provide information about 'educational need' and 'disabled children were not to be seen as the recipients of therapy and care, but as learners with an entitlement to education'. She discusses this changing climate and reflects how the 'dominant assumptions regarding impairment' and the 'experiences of disabled people and their social roles' had been 'increasingly challenged by the disability movement and disability scholars' as well as 'within human rights debates and organisations'. ${ }^{25}$ Inequalities within education could no longer be ignored.

The Warnock report stated that the focus of its enquiry had been the 'education of handicapped children and young people' and it held that 'education ha[d] certain long-term goals':

first, to enlarge a child's knowledge, experience and imaginative understanding, and thus his awareness of moral values and capacity for enjoyment; and secondly, to enable him to enter the world after formal education is over as an active participant in society and a responsible contributor to it, capable of achieving as much independence as possible.

${ }^{25}$ Felicity Armstrong, 'Disability, Education and Social Change in England since 1960', History of Education, 36:4-5 (2007) 551-568 <https://doi.org/10.1080/00467600701496849>. 
It recognised that different levels of support were needed in order to achieve the long-term goals and it stated that 'for some the road they ha[d] to travel . . . [was] smooth and easy, for others it [was] fraught with obstacles'. However, it contended that a level of achievement was possible and the 'criterion by which to judge the quality of educational provision [was] the extent to which it [led] a pupil towards the twin goals'. ${ }^{26}$

One of the most striking aspects of the report was the apparent changed attitude towards the value of education for those viewed as the 'most severely disabled'. The purpose of education, and whether it was to secure employment or to equip an individual with the skills needed to maintain a level of independence, had been a continual backdrop in the discourse of education and disability. The report raised questions such as: 'Why educate such children at all? Are they not ineducable? How can one justify such effort and such expense for so small a result'? The answer given was that education was a 'specifically human good, to which all human beings [were] entitled' and that there was a 'clear obligation to educate the most severely disabled for no other reason than that they [were] human'. ${ }^{27}$ These questions and answers are almost a duplication of the same issues that were raised in post-war Britain. The difference being is that they were being raised as part of an 'official' government enquiry. Kate Wall considers this issue and the argument that all children had the right to an education and to develop their full potential. She contends that the 'fact that this basic principle needed stating reflect[ed] somewhat negatively on the education system and societal perspectives prior to 1978 '.28 An editorial in The Times in May 1978 discussed the newly published report saying that:

the argument that children with special educational problems should be taught without being segregated more than was unavoidable from their contemporaries [was] well on its way to universal acceptance as a truism.

\footnotetext{
${ }^{26}$ Warnock., p.5.

27 Warnock., p.6.

${ }^{28}$ Kate Wall, Special Needs and Early Years (London: Paul Chapman Publishing, 2003), p.12.
} 
The article reflected on how education and the provision for 'special needs' had evolved. It said that, historically, 'charitable initiative' had recognised 'new categories of need successively and separately' but 1940s and 1950s education authorities had increasingly 'set up separate schools instead of developing provision in ordinary schools'. It maintained that 'only in the past few years ha[d] the proportion of handicapped children' attending 'ordinary schools' begun to rise. ${ }^{29}$

The legacy of the assessment process had pushed children towards failure, by focusing on their apparent failings. As we have seen, many children born in the 1940s and 1950s had been written off and seen as less than human. Bob Williams-Findlay, born with cerebral palsy in 1951, said that in the early fifties cerebral palsy was 'connected to like learning difficulties'. He recalled that the doctor implied to his parents that 'if they did want to leave [him] then the doctors would understand and [his parents could] get on with their life'. He said that whilst he had a 'physical impairment - there was nothing wrong with how [he] thought and behaved'. 30 The Warnock report paved the way for change and argued that, in a 'civilised society' ways of helping [individuals] towards identified educational goals [was] better than being 'content just to look after' them. It stated that a failure to meet their educational needs would have compounded and increased their 'disadvantages'. ${ }^{31}$ A new focus began to develop towards what the child could do and what needs had to be met to enable them to achieve it.

The experience of Sara Miller, born with 'severe athetoid cerebral palsy' in 1969, illustrates how individual needs were given more consideration. Sara attended Swansea and District Spastic Association (SDSA) until 1977 when she was transferred to Morfydd House Special School. Sara used her toes, feet and legs to communicate and at Morfydd House they had tried to get her to use her hands. Following an assessment, by a 'top paediatrician and psychologist', at

\footnotetext{
29 'Handicapped Children at School', The Times, 25 May 1978. Gale Cengage The Times Digital Archive <http://tinyurl.galegroup.com/tinyurl/BZRY67> (p.17).

${ }^{30}$ Interview with Bob Williams-Findlay by Anne Austin, $25^{\text {th }}$ September 2009, $20^{\text {th }}$ November 2005, $5^{\text {th }}$ February 2006, 25 February 2006, 14 May 2006, Speaking for Ourselves: An Oral History of People with Cerebral Palsy, reference C1134/15/01-08, British Library.

31 Warnock, p.6.
} 
the Spastics Society headquarters in London, it was suggested that due to the limited use of her hands, Sara should be encouraged to use her feet. This was agreed with her school, and 'all those concerned with Sara's education and therapy, were involved' in supporting her to use her feet. Resources for Sara followed, including a bespoke table which enabled her to 'write, draw and paint using her feet', 32 and this new approach allowed Sara to have the freedom to express herself. Whilst this is an isolated example, it can be said that in the past children like Sara, with more profound symptoms of cerebral palsy, would have been overlooked and priority given to those perceived as being not so disabled. The example demonstrates how a change in attitude could achieve a more positive outcome. When compared to the many negative and demeaning experiences of the past, this can be said to be a complete turnaround. The Warnock report emphasised the importance of an early assessment of individual needs, followed by regular reviews of individual educational, psychological and social needs. These recommendations, again, reflect the arguments of earlier years concerning intervention and treatment in individual lives. Despite a new approach towards individuals such as Sara, who developed her creative skills in the use of computer technology, she did not gain employment, attending a day centre on leaving education.

Parent-led 'spastic' associations continued with the further development of their services. A report from the November 1965 edition of Spastics News discusses the importance of helping, not just parents, but the whole family in understanding cerebral palsy. The national society facilitated a series of residential assessment courses for families of children with the condition. In part, this was in response to concerns expressed by parents about the lack of time afforded them to talk and 'ask all the questions [they] longed to ask but hesitated because the doctor was "too busy" or "not interested" or [that] the questions [might] have sounded silly'. Reflecting on the outcomes of the residential courses, Betty Booth, Senior Family Caseworker, highlighted the importance of seeing the child as part of the family, and not being treated as a 'separate entity'

32 Derek Miller, 'To Sara - and Others - The Computer Brings Hope', Swansea \& District Spastic Association Year Book 1980/81, p.21. 
to 'family attitudes and relationships'. The need was stressed to look at the 'whole child, his personality, his capabilities, his potential, his position in the family, his relationships, his needs' and then 'consider ways of fulfilling [those] particular needs with due respect to what [was] realistically possible'33. This level of support given, to the families of children with cerebral palsy by associations, had been built on a wealth of experience over many years, through the initiatives of parents. It was through voluntary effort that advancement had been made and this had not been replicated by the state.

Historically, 'spastic' associations had taken the lead in developing systems for assessment and therapy programmes to improve symptoms of cerebral palsy. Schools such as Carlson House had shown, through their achievements, the benefits of having an innovative and experimental approach to the delivery of education, from an early age. The Spastics Society is listed amongst the numerous organisations and individuals who engaged with the Warnock Committee and sub-committees as part of the consultation process. However, the primary sources consulted for this thesis do not reveal the detail of the level of involvement and whether the national body consulted local groups for their views.

Astudy by Maurice Chazan and Alice Laing, published in 1982, discussed the difficulties of providing support for parents with disabled children, following the Warnock report. They focused on the early years and argued that families needed support from a 'range of professionals' and so, they argued, did teachers. Many of the professionals with whom disabled children came into contact on a frequent basis were not specialists in their child's disability. ${ }^{34}$ It would be reasonable to assume that the trend of parents gaining support from specialist organisations in the voluntary sector would continue. However, Chazan and Laing demonstrate that this was not the case. They discussed the role of 'voluntary organisations concerned with different handicaps' and how they

\footnotetext{
${ }^{33}$ London, Wellcome Library, Betty Booth, 'Why Help Parents'? Spastics News Magazine of the Spastic Society, September 1965, p.4.

${ }^{34}$ Maurice Chazan and Alice Laing, The Early Years (Milton Keynes, The Open University Press, 1982), pp. 8-12.
} 
offered a 'wide range of services to parents, from the publishing of information sheets, to the organisation of playgroups'. Their survey from 1980 revealed that of families interviewed, only $37 \%$ were members of any organisations. This they said was a 'lower percentage than was found in another survey' in 1977 which covered 'mentally or multiply handicapped children' where the figure was $54 \%$. They concluded that in their child's early years:

parents [were] reluctant to associate themselves with formal groups, often feeling that their child's handicap [was] not severe enough to warrant such association or not realising the support they could obtain from membership..$^{35}$

This trend would suggest a reduction in membership of voluntary organisations from the 1970s following their initial rapid growth in post-war Britain.

The suggestion of a decline in membership of voluntary organisations can be linked to a possible loss of camaraderie, developed amongst pioneering parents in post-war Britain, and not continued to the same extent with a new generation of parents. Education was no longer a common cause to campaign for and negativity, associated with labelling and disability, turned many parents away from associations which had been a lifeline to post-war parents.

The Warnock report attempted to address the old system of assessing and labelling individuals, according to impairment, with a move away from the stigmatising labels of the Handicapped Pupils and Medical Services Regulations 1945. The new category which emerged, of 'special educational need', originated from the contention in the report that 20 percent of all of the school population had a 'special educational need', at some time during their school life. This new category immediately widened the concept of special education and children with physical impairments were put into a broad category, which now also included those with emotional or behavioural disorders. The report makes the distinction that 'children with moderate learning difficulties and those with emotional and behavioural problems', formed the 'largest group of children with special

${ }^{35}$ Chazan and Laing, pp. 8-12. 
educational needs.' It contended that these children did not 'so readily arouse sympathy', or gain public support, as was won by voluntary organisations for 'children with other sorts of disability'. ${ }^{36}$ Therefore, the negative effects of labelling for children with more visible disabilities, such as cerebral palsy, continued.

Felicity Armstrong discusses special educational needs and whilst the term 'focused on educational needs rather than individual impairments' it meant that it 'became a globalizing category denoting difference or learning difficulty'. This she argues 'coexisted with the established categories of impairment, and alongside new ones'. ${ }^{37}$ Special education has its roots in the medical model of disability and the introduction of this global category, would have had little impact on changing societal perception of 'spastics'. The 'spastic' label was to continue into the 1980s and 1990s. The past pervaded and slowed down change. Michael Oliver maintained that taking a 'cursory glance at the history of special education' clearly showed 'how it was underpinned by notions of special educational needs as an individual problem'. He said this 'reached its zenith with the categories introduced by the 1944 Education Act'. In considering the historical categories, from early legislation for 'idiots and imbeciles', through the 1944 'medical categories through to 'special educational needs', Oliver said 'only the labels have changed' and children's needs are still not fully met. ${ }^{38}$ A lasting legacy of the Warnock report is the term 'special educational needs' and this continues to set children apart. Joan Adams discusses the 'concept of special' with a focus on 'special educational needs' and remarks how the language of the Warnock Report 'remains part of the language of policy as well as of daily discourse in mainstream as well as special schools'. ${ }^{39}$

\footnotetext{
${ }^{36}$ Warnock, p.310.

${ }^{37}$ Armstrong, p.556.

38 Michael Oliver, 'The Social and Political Context of Educational Policy: The Case of Special Needs', The Politics of Special Educational Needs, ed. by Len Barton (Lewes: The Falmer Press, 1988), pp.13-31 (p.20).

39 Joan Adams, 'Provision: Who needs special needs'? in Controversial Issues in a Disabling Society, ed. by John Swain, Sally French \& Colin Cameron (Maidenhead: Open University Press, 2005), pp.122-130 (p.126).
} 


\subsection{The Warnock Report - a loss of expertise?}

The founding of parent-led 'spastic' associations had set down practices such as therapy treatments as part of everyday life and the importance of this cannot be ignored. Whilst dedicated schools for children with cerebral palsy were in the minority, compared to state run schools, through their work they had pioneered a new approach and demonstrated the value of having in place a programme, which balanced education against, so called, 'medical' needs. The importance of maintaining this was paramount for children with cerebral palsy and arguably, the practicalities of continuing this under the auspices of local authority provision, was more complex. This was a concern that had been raised by the NSS in the 1970 Annual Report of the Spastic Society, where the organisation considered the 'pioneering methods of special education' that had been undertaken by the Society. It stated that innovative approaches towards education '[could] not be attempted by State education authorities to the same extent'. 40 Whilst it can be argued that the NSS would have been biased towards promoting its achievements in a positive light, its innovative approach taken towards education had stimulated parental awareness, informing them of new treatments and approaches towards cerebral palsy.

Wall considers how the Warnock report was 'innovative at the time' and was to 'inform subsequent legislation and significantly change the face of special needs provision' ${ }^{41}$ Parents from Carlson House had already discussed concerns about the 'future structuring of special education' and its impact on their children, at a parent's meeting in 1975. Parents were urged to attend the meeting, it was stressed that 'no parent of a handicapped child [could] afford to miss th[e] opportunity', reminding everyone that 'the parent's voice [was] an important voice'. ${ }^{42}$ Unfortunately, there is no record of the outcome of the parents' meeting, but the request for parents to attend demonstrated a level of disquiet. Concern, expressed by parent groups, of the implications of the Warnock report were real, and following its publication, the possible loss of expertise in the treatment given to people with cerebral palsy, was raised as an issue.

\footnotetext{
${ }^{40}$ National Spastics Society Annual report (1970), p.10.

${ }^{41}$ Wall, p.12.

42 Harborne, Cerebral Palsy Midlands, notice of a parent's meeting to be held on $20^{\text {th }}$ October 1975.
} 
Parents of the post-war era, were well aware of the limitations of the past, and subsequent lack of opportunity afforded to their children. Mavis Barrett, welfare officer of MSA, reflected back to the early years of associations when there was an 'inadequacy of provision - in every field' which included 'employment, assessment and training facilities'. She said that it had been a 'depressing picture' and individuals had taken on the' task to try and remedy this' through 'direct provision' or 'steady, regular pressure on responsible authorities'. She recalled how 'special equipment' had not been 'invented' or was 'too costly' and there had been no 'social clubs or day centres for teenage and older spastics'. The subsequent development of statutory services, she said, made it 'difficult to people new to the scene to believe the lack of facilities in those days'. ${ }^{43}$

In an article written in 1978, Paul Cadbury, of MSA, considered the 'direction' in which 'future voluntary and public development' was likely to change. He said that there had been a change in the level of disability of children who were referred to the association's school. Amongst these children were some who had 'more severe problems' which affected their speech and language. He maintained that there were 'many more places available in schools for the handicapped than there were 30 years ago'. In his opinion, he said that in the future Carlson House school would cover 'a wider field and serve more than one specific handicap'. ${ }^{44}$ A changing society did impact on the relationship between the public and the voluntary sector. Robert Drake argues that since 1979, the 'main thrust of government social welfare policies and the containment approach, ha[d] been guided by two principles. He refers to these as 'welfare pluralism and community care'. He defines 'welfare pluralism' as the 'notion that services should be provided not by the state alone but by a plurality of organisations from different parts of the economic and social landscape'. He argues 'in tandem with this idea' was the 'move away from institutional settings towards "care in the

\footnotetext{
${ }^{43}$ Harborne, Cerebral Palsy Midlands, Mavis Barrett, 'From a room in a School to an organised department', in Midland Spastic Association Year Book 1977/78, p.13.

${ }^{44}$ Harborne, Cerebral Palsy Midlands, Paul S. Cadbury, 'The President looks back - and forward!' in Midland Spastic Association Year Book 1977/78, p.9.
} 
community"'. ${ }^{45}$ How did these changes impact on parent-led 'spastic' associations? Drake argues that 'a consequence' was the 'Conservative government's assiduous courting of the voluntary sector'. Charities were encouraged to 'enter into partnership with state agencies' and 'take on service contracts'. Associations had been the recipients of grants from their local authorities, as we have seen in this thesis, but a service contract put relationships on a more formal footing, so Cadbury was correct to anticipate change.

Stephen P. Osborne and Kate McLaughlin discuss how relationships changed from 1979, between local government and the voluntary sector, commenting how relationships 'assumed increasing importance in the delivery of public services to local communities'. ${ }^{46}$ Arguably, associations were well used to providing services and had terms and conditions to adhere to. However, these were controlled by associations and having a formal agreement with the local authority inevitably meant other pressures. Contracts meant compliance with conditions which were not necessarily within the association's control. Osborne and McLaughlin argue 'government policy has propelled the voluntary sector from the margins to the mainstream, and often the forefront, of the delivery of a range of public services to local communities'. They refer to a 'partnership paradigm'. The 'societal value' of voluntary organisations has been 'their capacity to operate independently from government' and a partnership challenged the 'potential loss of the independence'. ${ }^{47}$

The outcome of the Warnock report had a significant impact on Carlson House School and it closed at the end of 1982. The association minutes of the Annual General Meeting in 1982 record that Carlson House was to close at the end of the year, due to economic reasons, following the recommendations of the Warnock report. The following extract from the minutes state that the Warnock report:

\footnotetext{
${ }^{45}$ Robert F. Drake, Understanding Disability Policies (Basingstoke: Macmillan Press Ltd., 1999), p.69.

${ }^{46}$ Stephen P. Osborne and Kate McLaughlin, 'Modelling government - voluntary sector relationships: emerging trends and issues', European Business Organization Law Review, 4:3 (2003), 383-401 < https://doi.org/10.1017/S1566752903003835>.

47 Osborne and McLaughlin, 4: 383-401.
} 
recommended that children who were handicapped should be integrated into schools for the able-bodied children and that preferably these schools should be situated near to their homes. In the event, three special units ha[d] been set up at State Schools and [the association was] assured that the children [would] have the same facilities as they [had] at Carlson House. It was a pioneer in the education of children suffering from cerebral palsy and [it was felt] that no praise [was] high enough for the people whose foresight and efforts made the dream come true. It [was] of course, sad that Carlson House School ha[d] closed but one must remember that when it opened so little [had been] done for people suffering from cerebral palsy [and] it was necessary thing to have education. We should be proud that the steps [taken] were the forerunners of the events that have now taken place and children who are spastic, in fact all handicapped children, [were] getting a better hearing. ${ }^{48}$

Laura Middleton considers the 'contract culture' and its impact on the role of the voluntary sector and disabled children. In line with other scholars, she argues that the impact of the 'contract culture' with an 'increasing reliance on funding tied to contracts', inevitably meant that the voluntary sector became less 'independent'. She considers how organisations, 'in exercising their campaigning and advocacy roles' have been 'engaged in adversarial relationships with government'. ${ }^{49}$ This is demonstrated within this thesis through the actions that parents took on behalf of their disabled children. Funds raised went directly to the range of costs incurred by associations. As Middleton argues, in 'giving to charity, people [had been] paying to maintain a mixed welfare system, including advocacy, campaigning and research'. However, she contends that within a 'contract culture', funds raised through campaigning, were 'increasingly used by charities to subsidise services contracted from local authorities'. Therefore, rather than being seen as independent, charities became to be viewed as being 'part of the mainstream'. 50 The impact of the 'contract culture' had both a positive

\footnotetext{
${ }^{48}$ Harborne, Cerebral Palsy Midlands, Minutes of Annual General Meeting 1982.

${ }^{49}$ Laura Middleton, 'The Social Exclusion of Disabled Children: The role of the voluntary sector in the Contract Culture', Disability and Society, 14:1 (2010), 129-139 $<$ https://doi.org/10.1080/09687599926424>.

${ }^{50}$ Middleton, 'The Social Exclusion of Disabled Children: The role of the voluntary sector in the Contract Culture'
} 
and negative effect and the relative level of security had to be balanced against a possible loss of independence.

The loss of Carlson House School meant that MSA developed in a different direction with the building of Carlson Park, which offered independent living accommodation to people with cerebral palsy. In their 1983 Year Book it was stated that the aim of MSA was to work 'towards [the] independence and integration of disabled people in the community'. They had built a 'Flatlet with a bathroom' at the centre to enable individuals to 'learn ordinary domestic skills' to equip them should they wish to live independently or as part of a 'group home'. 51 Within a few years MSA had embarked on the further development of Carlson Park, to add residential accommodation for disabled people, built on the site of Carlson House School.

In a similar vein, SDSA developed their services in different directions as school age children were transferred out of the association. They focused more on disabled adults, concentrating on improving life skills for independence and working with community groups to increase the range of activities. These included literacy and numeracy for disabled adults, computer skills and the development of a self-advocacy program. MSA and SDSA changed over their lifetime as they had started out in providing a service to children and evolved to be organisations which supported adults with cerebral palsy. As these local associations ceased to be providers of education the national charity continued, although it was not immune from the impact of the Warnock report. The 1981 Annual Report of the Spastics Society recorded that there had been a 'slight reduction in demand for places' at the Society's schools due to the 'interesting trend towards integration of the handicapped in ordinary schools'. This had led to one of the society's schools closing but it was noted that the further education centres run by the society had expanded in numbers. ${ }^{52}$

\footnotetext{
${ }^{51}$ Harborne, Cerebral Palsy Midlands, 'A Flatlet Comes To life', Midland Spastic Association Year Book 1983/84, p.13.

${ }^{52}$ National Spastics Society Annual report (1981), p.7.
} 
Prior to the appointment of the Warnock Committee, concerns had been expressed by teachers involved in 'special education'. The Education Correspondent of The Times, writing in 1975, reported that the National Association of Head Teachers claimed that 'the reality of special units for the handicapped in ordinary schools [was] often very different from the aim'. The Association wanted more 'speech therapists, physiotherapists and educational psychologists' in addition to having a satisfactory 'career structure' for teachers in special schools. It maintained that special education had been 'a poor relation in the normal education system' for too long. ${ }^{53} \mathrm{H}$. M. Brice, the Principal of Potterspury Lodge special school in Northamptonshire, also expressed concerns over the recommendations of the Warnock Committee and asked what would happen if Warnock proved to be 'yet another of [those] educational bulldozers that [swept] all before it, decimating and ignoring the real wealth of knowledge and ability that specialised educational charities [could] offer'. Brice argued that the specialist training of teachers could not happen overnight and that the 'average teacher' was not 'possessed of the necessary devotion and stamina' that was needed. She challenged commentators who seemed 'to assume that special schools of charitable status [could] be quietly run down as the national capacity for educating handicapped children [grew]'.54 The possible loss of expertise was also raised by the Educational and Social Studies Department of the Spastics Society when they 'consulted on the Warnock report' and the 'future education of handicapped children and young persons'. The 1979 Annual Report of the society said that the Department had been 'encouraged by Warnock's emphasis on the importance of early assessment of children's needs' which included their 'educational, psychological and social needs'. It stated that the society was 'ready to expand its existing work in the training of teachers and psychologists in the proper use of assessment techniques'. It was stressed that this was 'particularly important for children with severe and multiple handicaps, whose abilities and special educational needs [were] often overlooked by poorly trained staff'. ${ }^{55}$ The concerns expressed are understandable and it is of note that

\footnotetext{
53 'Heads seek schools for handicapped', The Times, 28 August 1975. Gale Cengage The Times Digital Archive < http://tinyurl.galegroup.com/tinyurl/BZSAD4> p.16.

54 H. M. BRICE, 'Handicapped children', The Times, 3 June 1978. Gale Cengage The Times Digital Archive <http://tinyurl.galegroup.com/tinyurl/BZSDm1> p.15.

${ }^{55}$ National Spastics Society Annual report (1973), p.7.
} 
they came from a more diverse group of people, rather than parents alone. The outcomes of the Warnock report could not adequately address the need for training of appropriate staff and many of the issues raised were not new, simply a continuation of questions raised by parents.

\subsection{Conclusion}

The pioneering work of immediate post-war parents was unique and the next generation of parents had different challenges to consider. The intense lobbying and campaigning that had taken place had won the right to an education for many children with cerebral palsy. The archaic practice of fitting the child to the school rather than the school fitting the child was deemed to be unacceptable, in theory.

Parent-led 'spastic' associations supporting individuals with cerebral palsy had grown to be more than 'local charities' and were in effect small businesses with charitable status. Through the services they provided they had become significant providers within the modern welfare state and were vocal in their campaigns. The importance of voluntary organisations as pressure groups was recognised in the Warnock report, which stated that such organisations had ensured that authorities 'fulfil[ed] their existing responsibilities' towards those with disabilities and had identified the 'need for new forms of provision' and mobilised 'public opinion to demand them'. It was envisaged that these roles would continue as the voluntary organisations 'exert[ed] pressure on behalf of individuals' who did not find it easy to ensure 'statutory duties [were] carried out'. ${ }^{56}$ In order to achieve this, maintaining the network of associations was essential, and it was suggested that local authorities assist voluntary organisations in carrying out their work in financial and practical ways.

The outcomes of the Warnock report had an impact on the provision of services delivered by the NSS and affiliated groups. There was more emphasis on the older 'spastic' and independent living. Many of the issues that had been

${ }^{56}$ Warnock, p.314. 
raised in the Warnock report concerning the education of disabled children overlapped with issues that had been highlighted many times by associations. 'Spastic' associations did not suddenly drop their campaign on education and employment but they were able to take a step back and re-evaluate their aims of the early days of campaigning. The government-led enquiry officially reviewed the provision of education for 'handicapped children and young people' and had a series of outcomes which would be implemented in the 1981 Education Act. The practice of categorising children as 'ineducable' due to their impairment was now a thing of the past.

Whilst it can be said that 'spastic' associations had achieved their goal, now, in order to survive, they had to adapt as they moved into the 1980s. Society had evolved into an increasingly consumer driven culture where associations would have to compete more actively for services and funds. It was during the 1980s that many charities entered into more formal contracts with local authorities. At their inception they had been established as autonomous groups and so had the freedom to make their own decisions and define their own aims and objectives. Having a closer collaboration with the state would have put them on a more secure financial footing which arguably made it easier for them to be heard in a changing climate where disability activism challenged inequalities and confronted social and cultural values. As Robert Drake argued, in order to survive 'voluntary groups agonised over the dilemma of needing funds' versus 'fearing for their independence once they signed on the dotted line'. ${ }^{57}$ There had been a shift in their main client group from children to disabled adults and as Drake contended, 'these were caught in the maelstrom of change with the new competitive ethos'. ${ }^{58}$ This challenge was taken up by parent-led 'spastic' associations as they developed their focus on life skills and independent living. They had the infrastructure in place and also had a ready-made group with which to develop their service.

${ }^{57}$ Drake, p.75.

${ }^{58}$ Drake, p.75. 
However, introducing the 'special educational need' category into the education system was a practice which further set disabled children apart and reinforced difference. This carried on into adulthood and the attainment of integration and full citizenship remained elusive within society for those who sought it. The provision of services evolved from sheltered employment in a work centre to provision in a day care setting. Whilst the range of activities on offer had improved, the prospects for many school leavers had not significantly changed. In order to move forward it was argued that greater participation was needed between professionals, service providers and disabled people in order to address the piecemeal efforts of the past. 


\section{Conclusion}

This thesis has shown that social reform in post-war Britain, intended to build a better, fairer society with improved access to health care and education, did not meet the needs of individuals with cerebral palsy. In addressing my research questions, the histories of BCWS, MSA, SDSA and NSS have revealed a unique perspective of the social impact that cerebral palsy had on individuals, their families, daily lives and on wider society. Examination of the source materials has uncovered the motivation behind 'spastic' associations and the passion of parents to achieve change. Publications researched, detail the growth of a local, national and international network and the impact of the 'spastic' brand is clearly evident in primary sources. The achievements of the founder members of 'spastic' associations have been recognised and acknowledgement given to a section of society who were resolute in their determination to effect change. These positive outcomes are balanced against the frustrations felt by those who became identified by the 'spastic' brand, and its wider impact on individual lives.

This chapter assesses conclusions resulting from analysis of a wide range of sources which address the research questions posed earlier in this thesis. The chapter also considers areas for further research.

\subsection{Key Findings}

The literature review highlights that existing literature on cerebral palsy has been mainly focused on medical aspects of the condition. The rich history of parent-led 'spastic' associations and the social impact of cerebral palsy, on individual and family lives, is missing from historiography. This thesis has addressed this omission by emphasising the importance of 'spastic' associations, not only as service providers, but also as significant contributors to the development of a body of knowledge and expertise in the understanding of cerebral palsy. 
Confronting practices that had been founded on eugenic beliefs, 'spastic' associations challenged the influence of the medical model of disability and its impact on policy making. The voluntary sector transformed during post-war Britain as the welfare state developed, and this thesis shows that 'spastic' associations were part of that revolution. Associations challenged and lobbied government bodies, campaigning for new approaches to be taken towards individuals with cerebral palsy. Analysis of the actions taken by parents and the 'spastic' associations they created, reveals parents as reformers who campaigned at local, national and international levels, on issues of entitlement and access to services, decades before the emergence of disability activists in the 1970s.

Archival research and oral history interviews have shown that securing the provision of education, for children with cerebral palsy, was the driving force behind the establishment of 'spastic' associations. Confronting preconceived notions about cerebral palsy and its effects on a person's ability to function could only be achieved through direct action. This endeavour arose from a basic humanity to challenge a system which had wronged many individuals.

This thesis shows that 'spastic' associations had clear aims and objectives from the outset and the dynamic progress made is evident through the study of BCWS, MSA, SDSA and NSS. At a time of crisis, when no other support was available to meet the differing needs of children with cerebral palsy, these associations were instrumental in raising awareness of inequities and in pioneering a proactive response. This pioneering spirit never dimmed, enduring through a spirit of friendship and unity and this has been shown to be a significant strength. Parents worked together to raise funds and establish associations, undertaking a wide variety of tasks but it was not just high-profile activities, linked to campaigning, which demanded attention. Tasks such as gardening, adapting furniture or building work were just as essential. This thesis has given examples of how the working parties at MSA, or the fund-raising activities of SDSA strengthened the relationships between families adding to the stability of associations. A strong sense of determination meant that organisations were able to achieve their core aims and objectives. Analysis of primary sources has 
revealed how 'spastic' associations developed a co-ordinated approach in the dissemination of new research into cerebral palsy and in assessing the needs of individuals with the condition. Shared resources aided the development of education services and a network was established which had local, national and international links.

An important point raised in this thesis is that 'spastic' associations had the relative freedom to be experimental and adopt different methods towards the treatment of the symptoms of cerebral palsy. This flexibility could not easily be adopted by government bodies as they were more rigidly controlled within the boundaries of legislation. Acknowledgment is given to the importance of the role that Dr. Winthrop Phelps and his contemporaries played in developing expertise in the understanding of cerebral palsy and of recognising the capabilities of individuals with the condition. His research findings advocated change through the practical application of therapy treatments as being integral to improving individual lives. 'Spastic' associations were pivotal in the adoption of these new approaches. Increased knowledge and practical research outcomes added impetus to campaigns. This thesis has shown how investment was made to support key individuals in study tours, to observe Phelps et al., at work. These individuals imparted their knowledge through publications in addition to the practical application of new skills. Adopting a more holistic approach to the symptoms of cerebral palsy created new possibilities for many and this was in sharp contrast to the discrimination and rejection previously endured.

This study has added further to Nora Groce's observation that 'early advocacy work on disability' came from people working on behalf of a disabled group rather than from disabled people where the efforts to make a difference were specifically for 'crippled' children and not those with other disabilities (for example, deaf/blind). ${ }^{59}$ Primary source material has revealed how 'spastic' associations progressed these links in post-war Britain. A growth in transnational

\footnotetext{
${ }^{59}$ Nora Groce, 'Disability and the League of Nations: the Crippled Child's Bill of Rights and a call for an International Bureau of Information, 1931', Disability \& Society, 29.4 (2014), 503-515 <http://dx.doi.org/10.1080/09687599.2013.831752>.
} 
networks paved the way for the newly formed Spastics Society ${ }^{60}$ to develop international links. A comment by the President of the World Commission for Cerebral Palsy in 1965 endorses the importance that maintaining transnational links had. He stated that 'a failure in communications' could only be 'overcome by agencies such as the Spastics News' or the World Commission, 'channelling knowledge and hope to parents' and their children 'of modern methods and of new techniques in the treatment of cerebral palsy based on up to date research'. ${ }^{61}$ Thus, it has been shown how crucial transnational links were in progressing a different approach towards the understanding and treatment of the symptoms of cerebral palsy.

In the history of education for children with cerebral palsy, it has been demonstrated that significant advancement was made primarily through the actions taken by 'spastic' associations. This thesis argues that the progress made could not have been achieved if left entirely to local and national government interventions. The purpose of education, specifically for children with cerebral palsy, had been questioned by authority and children were judged against their future economic output. This measure was not a fair or realistic benchmark for children with cerebral palsy, many of whom were not given adequate opportunity to prove their ability. The progress made in Carlson House school and in other establishments, which catered specifically for children with cerebral palsy, can be held as examples which showcase the achievements made.

A case study of Carlson House school has highlighted how inequities were positively challenged, proving that children with the condition were not all 'ineducable', simply by the nature of their impairment. The benefits of a holistic approach, as referred to earlier, were actively demonstrated. It has been shown that the school was not just an educator of children. Methods and techniques employed at the school were shared not only with parents but also with a variety of professionals in medicine and education. Literature and films generated by the

${ }^{60}$ The merger of the BCWS and the NSS to become the Spastics Society.

61 J. A. Loring, 'The Spastics Society and the World', Spastics News Magazine of the Spastic Society, September 1965, p.4. 
school, provide evidence of its impact, practices undertaken and the progress made. Recognition of schools, such as Carlson House, informs us that in postwar Britain, education was not just a matter for the state. In the historiography of education, the impact of schools established by 'spastic' associations rarely feature. If schools such as Carlson House had not been established, then what realistic chance would children with cerebral palsy have had in post-war Britain?

The progress made by 'spastic' associations is indisputable as they raised pertinent issues and succeeded in delivering a service not provided within the new welfare state. The distinctive communities which developed around 'spastic' associations, provided much needed support to families and parents were able to share concerns. The emotional connection to 'spastic' associations is revealed at a specific point in time, where parents embraced the concept of a collective effort to campaign for change. These unique communities are central to this thesis and, for many individuals and their families, remained so for most of their lives. It has been shown, particularly through the study of MSA and SDSA, that these communities supported decades of campaigning, generating a multitude of actions to ensure that services were developed and maintained. Historically, the communication methods available to post-war parents were basic when compared to today's technology. This, to a certain extent, made parents work more collaboratively to gain support and target a larger audience. Associations have been shown to be the mentors to those in authority, particularly with the formation of the NSS in 1952. This thesis adds to a body of evidence, which documents the failings of the newly created welfare state, detailing how the needs of disabled people were often viewed as problematic.

The tailored model created by post-war parents was not without its consequences and, to a certain extent, it became part of the problem. An analysis of the legacy of 'spastic' associations reveals how they contributed to the development of an institutional culture which stifled employment opportunities and inhibited the individuality of many with cerebral palsy. In tracing the chronology of 'spastic' associations it can be understood why employment issues became the natural 'next step' as the focus for a concerted campaign. Education had become a right for children with cerebral palsy but a lack of employment 
opportunities posed a new dilemma. The development of sheltered employment, through 'spastic' association Work Centres, offered opportunities specifically to individuals with cerebral palsy. However, these did not really address the wider issues of individual futures and employment. A key objective of 'spastic' associations had been to achieve integration and inclusion for people with cerebral palsy. There is no denial that Work Centres may have been the right move for some, but this environment was a segregated one and so did not address the challenges arising from integration and inclusion.

This thesis has highlighted the dissatisfaction voiced by individuals who wanted to move into different spheres of work but could not easily do so. The need to include people with cerebral palsy, as part of a consultation process, had not been taken seriously. Primary source documents have shown how parents continued to exert a level of control over their adult child's life. One of the goals of parent-led organisations had been to enable a level of independence through education, but continued parental intervention brings into question how far this had been achieved. Lack of confidence and life experience have been cited in this thesis as barriers to employment. However, in reality, what did the future hold for many school leavers with cerebral palsy? Individuals had been faced with little choice as children and despite achievements and progress, many were faced with similar situations as they became 'unemployable' school leavers.

Achieving equality was not easy. Remaining with the same association for the whole of your life may have been the desire of some individuals. However, not being able to make your own choice to seek independence, through the actions of overprotective parents, did not chime with the initial aims of 'spastic' associations. Such was the connection to the associations they had created; parents could not relinquish control and step away. Arguably, they had become inflexible in their attitude to the abilities of their adult children. This echoed the approach that had been adopted by many professionals when considering the ability of children with cerebral palsy, before associations were formed. 
Contradictions between the private and the public façade of 'spastic' associations, were prevalent from the start. Condescending and paternalistic attitudes were not compatible with promoting the capabilities of individuals in a positive way. Prejudices and assumptions towards people with cerebral palsy were seen as commonplace. Examination of the reasons behind this reveals how the public façade of associations and the creation of a generic 'spastic' hid, to a certain extent, progress made. The true capabilities of individuals with cerebral palsy became largely overshadowed by the marketing influence of the 'tragic child' which 'spastic' associations employed in order to raise funds. This thesis has demonstrated how the 'spastic' label had been important in the early days of campaigning as a successful marketing tool, resulting in the term becoming part of popular culture. The use of the label was at odds with a 'can do' objective that the focus on access to education originally set out to achieve. Positive individual stories could not compete against how people with cerebral palsy were represented. Personal stories highlighted in this study, have challenged this portrayal and have revealed how a growing dissatisfaction eventually challenged how people with the condition were depicted. However, the reforms which followed the Warnock report and subsequent 1981 Education Act, generated another label which continued to single out children who were perceived to be different. They became marginalised by the 'special need' category and whilst this may not have been the intention, the new label has prevailed. In the history of education and disability the legacy of 'spastic' associations can be used to highlight longstanding inequality and issues that are still faced today.

It is not possible to study the legacy of 'spastic' associations without due consideration of the creation of a generic 'spastic' as this adds to our understanding of why historic attitudes are still prevalent in today's society. The historical imagery and language used effectively limited many futures, where individuals were thought of as being incapable of taking on responsibility and living what is usually referred to as a 'normal' life. This is a paradox which is sometimes difficult to reconcile. 


\subsection{Further study}

The focus on parent-led associations specific to cerebral palsy has revealed how effective they were in raising awareness, disseminating information and providing practical solutions. A comparative study with The National Association of Parents of Backward Children (established in1946 and now known as Mencap) would present opportunities for research into commonalities in their approach, identify differences in their methods, reveal difficulties they have faced and how they may have been overcome.

Transnational networks were not confined to consideration of cerebral palsy. A wider examination of the impact of other transnational networks, alongside the research already undertaken for this thesis, may provide a useful addition to disability history.

Earl Carlson, who had cerebral palsy, was one of the leading doctors who influenced changes to treatment of cerebral palsy. He published his autobiography Born This Way (1952) which was translated into several other languages. An academic study of his life and achievements would provide a significant addition to disability historiography.

This thesis has considered the influence the NSS had as a national organisation. It campaigned on many different levels with various strands to its activities and decisions made have had a significant impact on the lives of people with cerebral palsy. The NSS archive has remained largely inaccessible as it is yet to be fully catalogued. Once this is complete, historians will have the opportunity to further explore the relationship between local parent-led associations and the national umbrella organisation. This will permit further comparative studies that will help to contextualise the case studies examined in this thesis. 


\section{Appendices}

\subsection{Information and consent form}

\section{Participant Information Sheet}

You are invited to take part in a research study. Before you decide you need to understand the purpose of the research and what it will involve for you. Please take time to read the following information carefully. Talk to others about the study if you wish.

Study Title: Providing education for children with cerebral palsy and related disabilities: how policy and collective action brought about change during the second half of the twentieth century. (Note: this was the original title for my thesis which subsequently changed).

Research undertaken by: Teresa Hillier

Department of History and Classics, Swansea University

\section{What is the purpose of the study?}

To research how legislation and policy implementation affected education for children with cerebral palsy and related disabilities during the second half of the twentieth century. As part of the research the history of Longfields Association (formerly known as Swansea and District Spastics Association) will be examined. West Glamorgan Archives hold the Longfields collection which has already been researched. Oral history methods will be used to gather the memories of individuals who have been involved with the Association. These will give the researcher a greater understanding of the impact Longfields has had on individual lives and the wider community.

\section{Why have I been invited?}

You have been invited to take part in this study because of your link to Longfields. This may have been as a service user, a parent/carer, a friend of Longfields, a staff member, a management committee member, a ladies guild member or a combination of these roles.

\section{Do I have to take part?}

Taking part in the research is entirely voluntary. It is up to you to decide when you have read this information sheet. If you agree to take part you will be asked you to sign a consent form. You will be free to withdraw at any time without giving a reason.

\section{What will happen to me if I take part?}


If you consent to take part Teresa Hillier will arrange a suitable time and place to conduct an oral history interview with you. The interview will be recorded and it may be necessary to meet more than once.

What about confidentiality?

The researcher has ethical and professional responsibilities to keep all information confidential. Interviews necessarily contain personal information and if you wish, segments of the interview - or the entire interview - can be given anonymously. You may also inspect the transcript of your interview when it is completed. You may at any time choose to discontinue your collaboration with the research, in which case your information will be removed from the interview collection and from any written materials relating to the research.

\section{What happens with the results of this study?}

Information gathered by Teresa Hillier will be used in her thesis and will be anonymised within the report. This will prevent identification of the participants. All tapes and transcriptions will be stored securely.

West Glamorgan Archives would like to hold the research interviews (sound files and transcripts) to add to the Longfields collection. Your interview would only be deposited with your consent.

\section{Has the study been reviewed and approved?}

The study has been reviewed by the ethics committee of the College of Arts and Humanities, Swansea University.

Thank you for considering this information. If you have any further questions, please contact the student researcher or her supervisor as detailed below:

PhD Research student: Teresa Hillier

Email: Mobile:

Supervisor: Professor David Turner Email:

Tel: 


\section{Consent Form}

- I confirm that I have read and understood the information provided and have had the opportunity to consider this and ask questions.

- I understand that my participation is voluntary and that I am free to withdraw at any time without giving a reason.

- I understand that interviews will be recorded and that anonymised direct quotes may be used within the final thesis.

- I understand that my interview and the information I provide anonymously if I wish - may be stored in West Glamorgan Archives after completion of the research, and may be available to other individuals, on request.

- I agree to take part in the research and I understand that I may withdraw from this at any time by informing Teresa Hillier of this decision.

\section{PARTICIPANT}

Name:

Signature:

Date:

Date:

\section{RESEARCHER}

Name: Teresa Hillier

Signature: 


\subsection{Oral history interview extracts}

Extract from interview with Joan O. (parent)

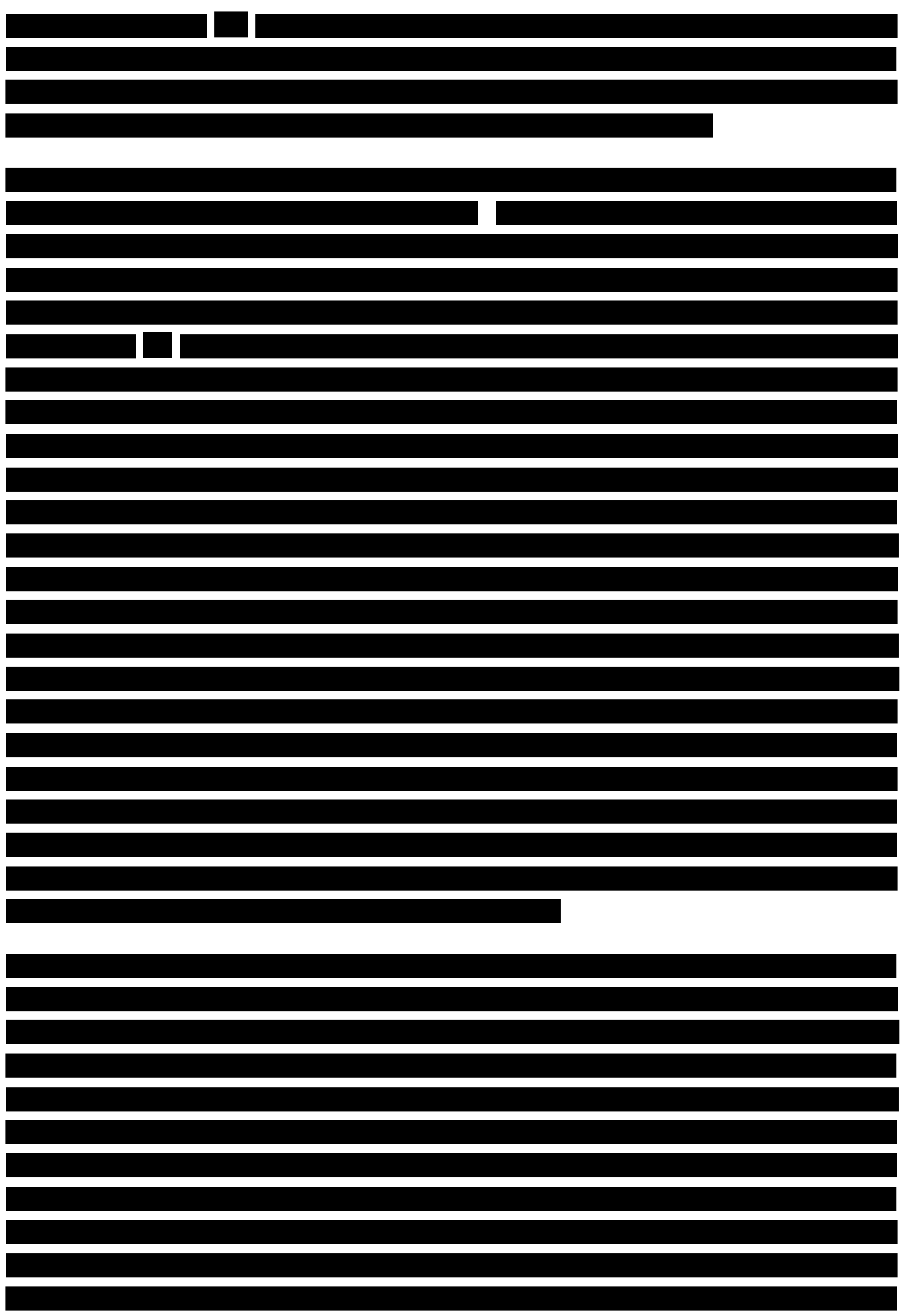




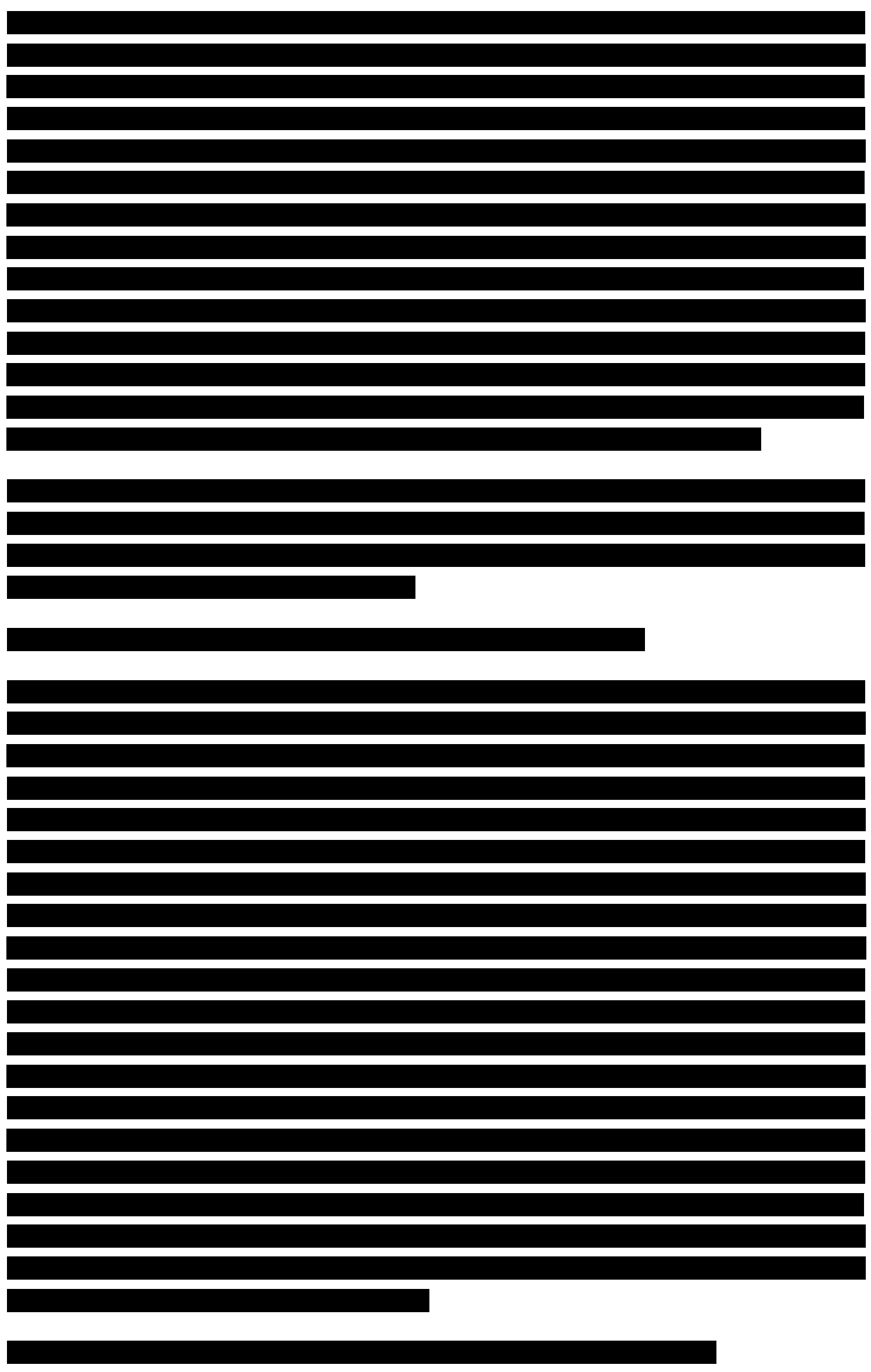



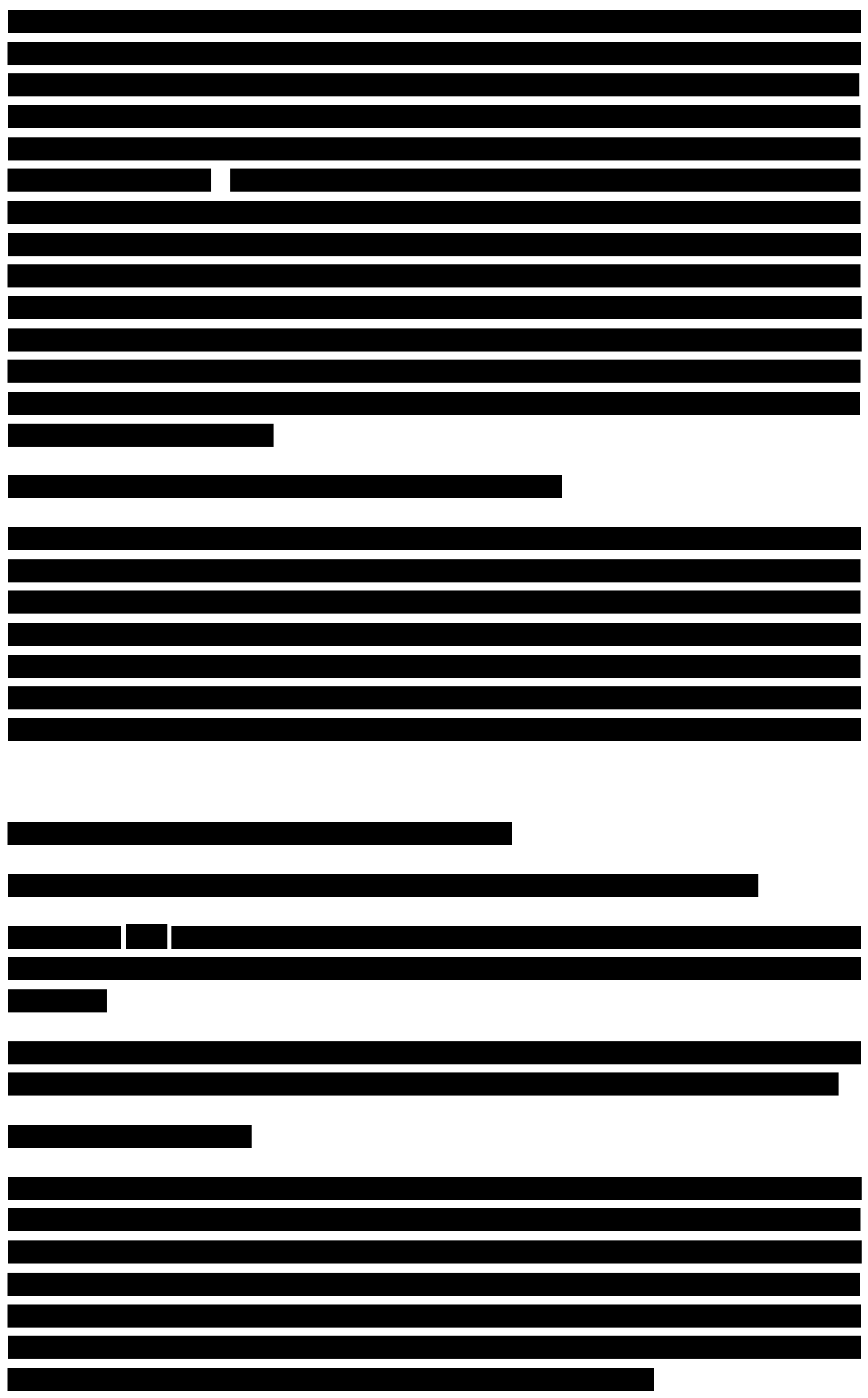


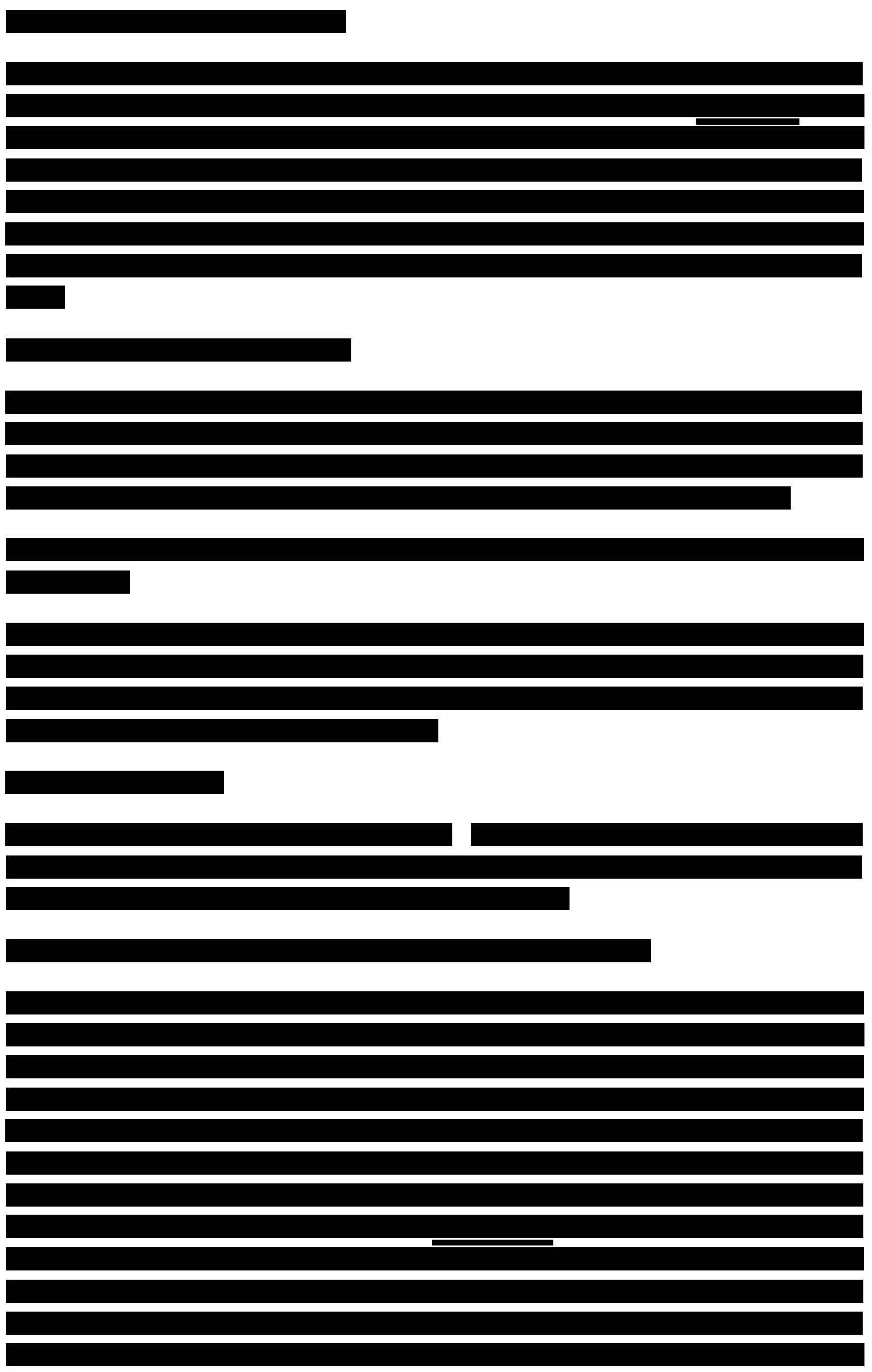




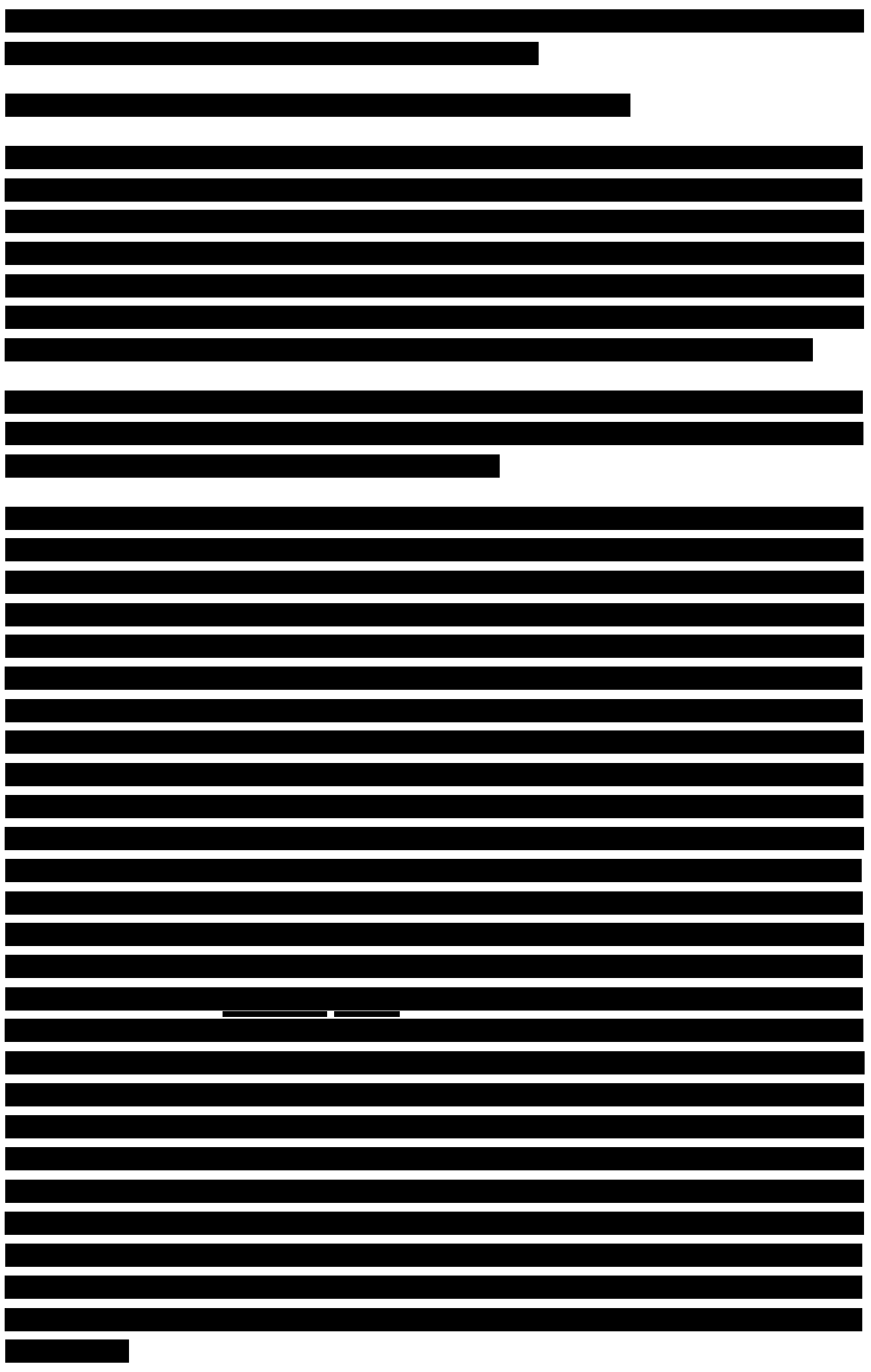




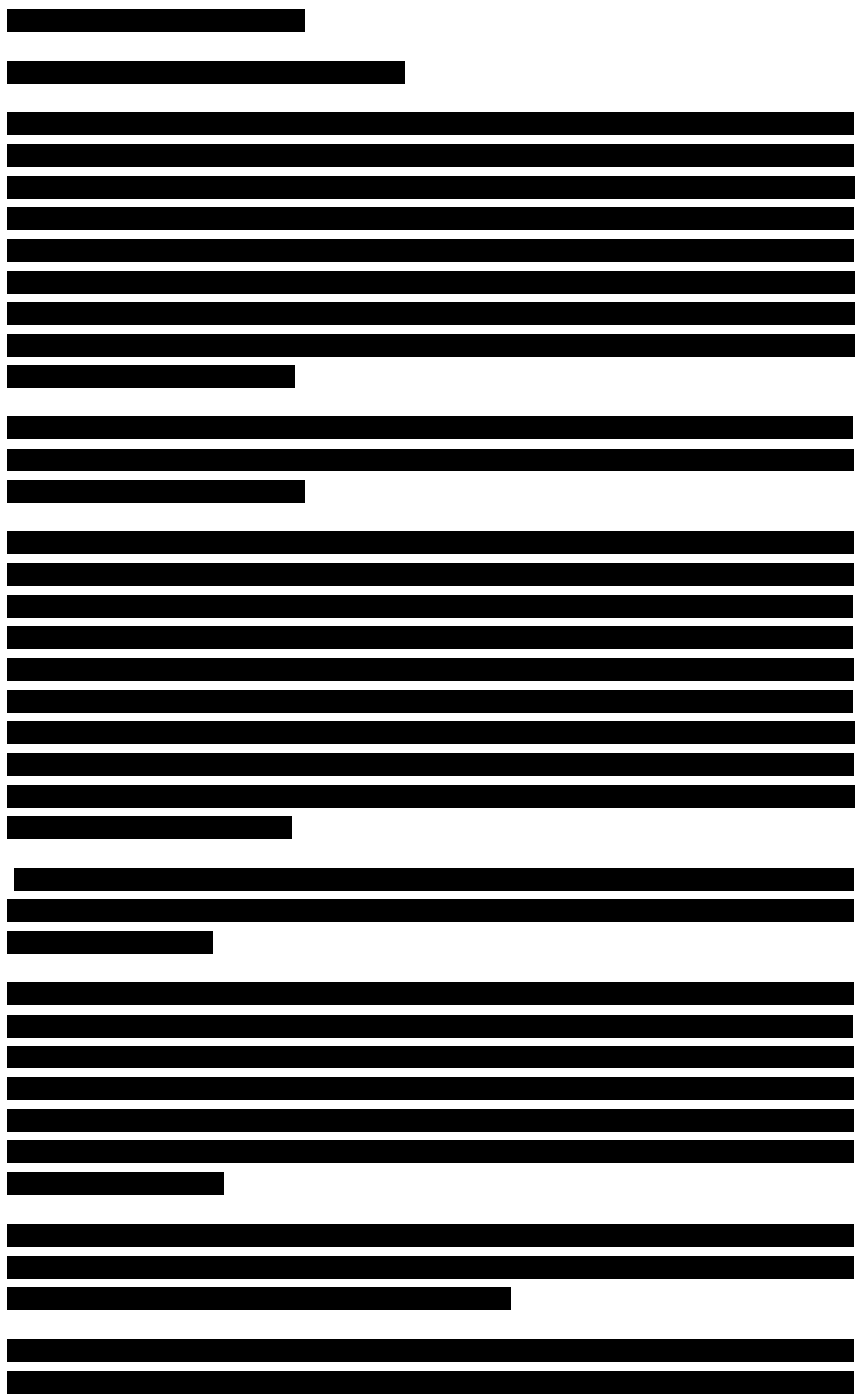



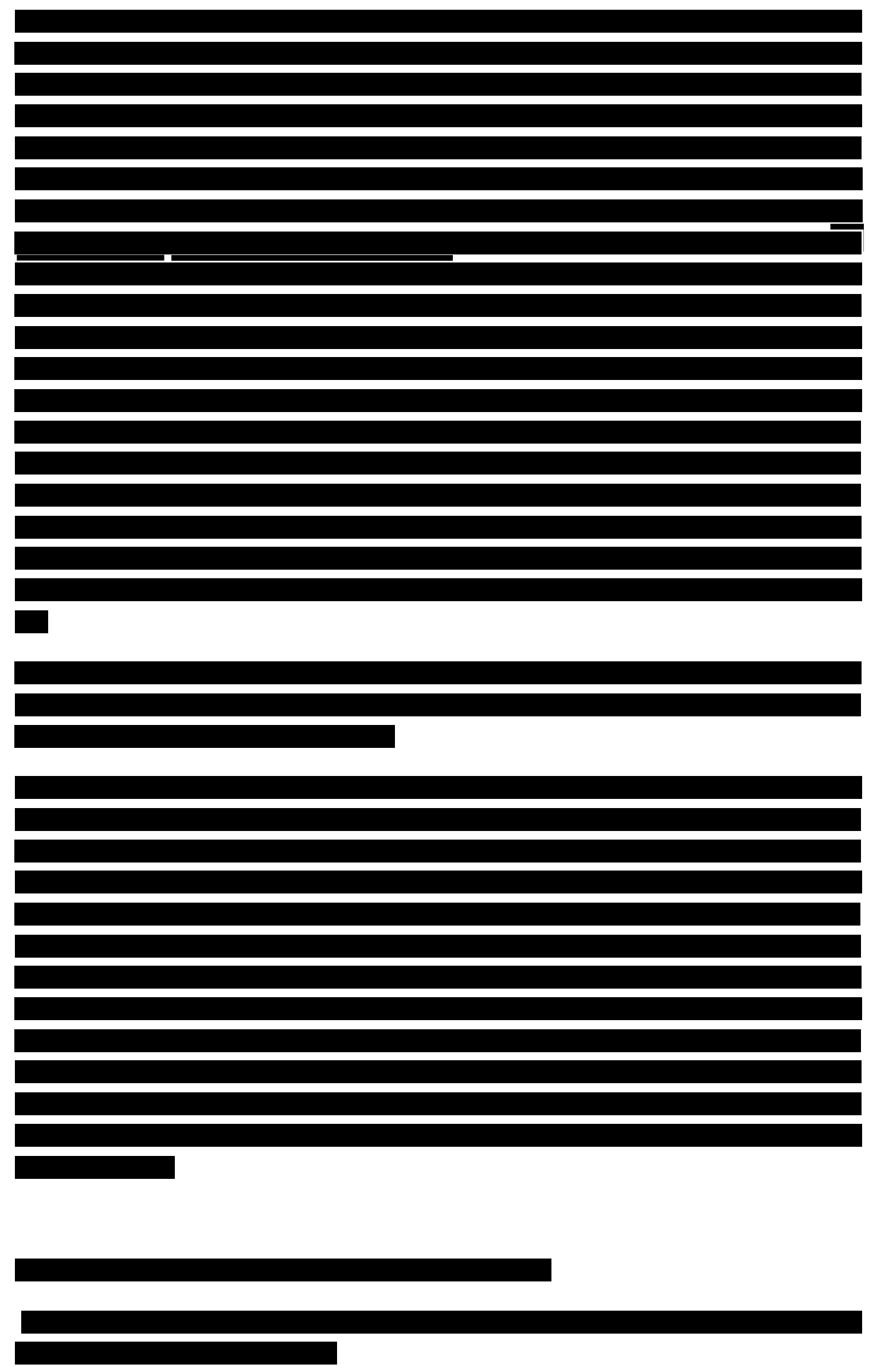


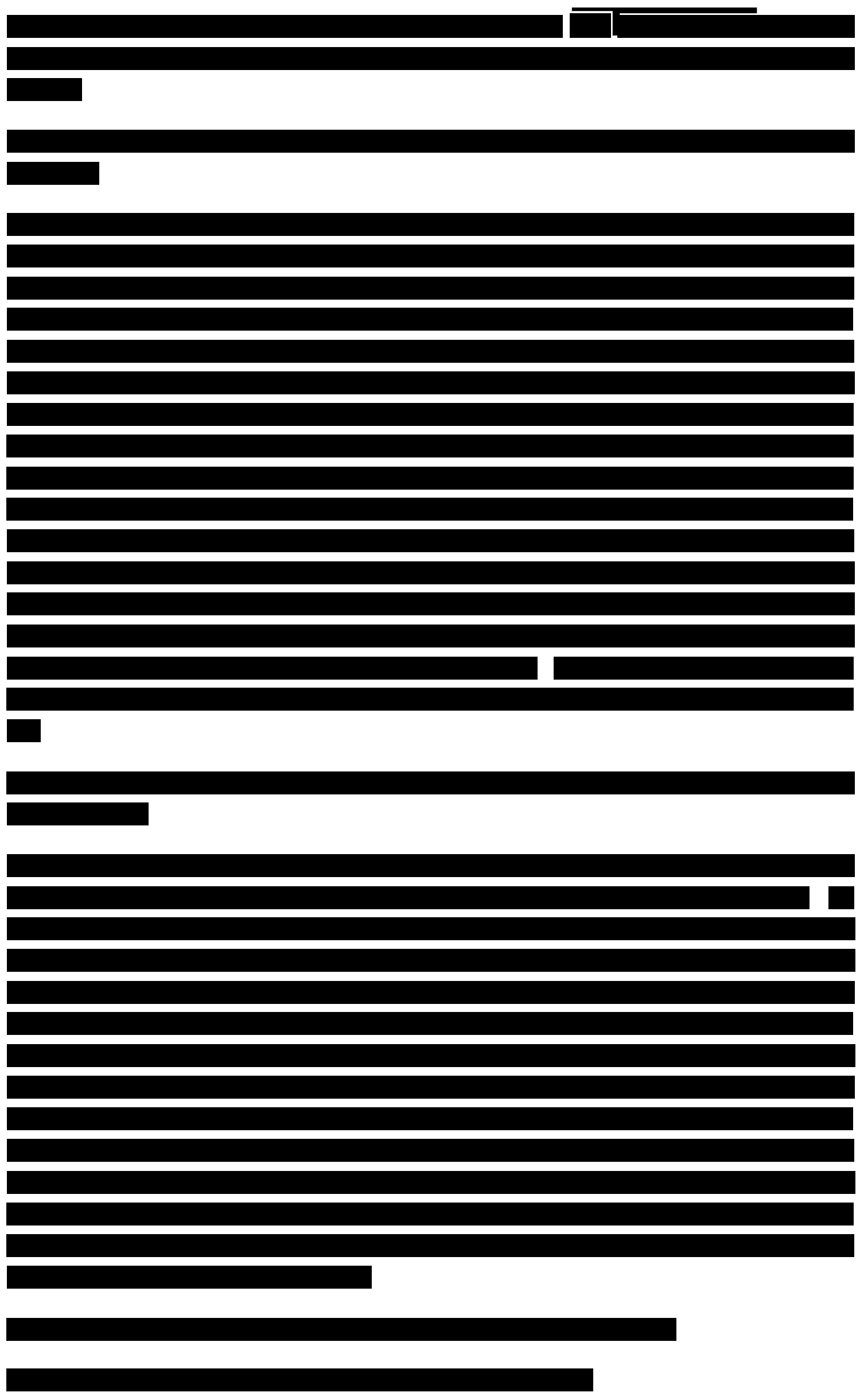




\subsection{Participant demographics}

\begin{tabular}{|c|c|c|c|c|}
\hline Interviewee & $\begin{array}{c}\text { Age at } \\
\text { time of } \\
\text { interview }\end{array}$ & M/F & Connection to SDSA & $\begin{array}{l}\text { Interview } \\
\text { location }\end{array}$ \\
\hline Molly B. & 81 & $\mathrm{~F}$ & $\begin{array}{c}\text { Parent and Ladies Guild } \\
\text { member }\end{array}$ & Home \\
\hline Roggan B. & 84 & $\mathrm{~F}$ & Ladies Guild member & Home \\
\hline Peter Be. & 84 & $\mathrm{M}$ & Trustee & Home \\
\hline Peter Ba. & unknown & $\mathrm{M}$ & Sibling of service user & Coffee shop \\
\hline Joyce C. & 84 & $\mathrm{~F}$ & Staff member & Home \\
\hline Kelly C. & unknown & $\mathrm{F}$ & Service user & Day Centre \\
\hline Ron D. & unknown & $\mathrm{M}$ & Parent and trustee of charity & Home \\
\hline Pat F. & 69 & $\mathrm{~F}$ & Parent and trustee of charity & Home \\
\hline Margaret G. & unknown & $F$ & $\begin{array}{l}\text { Aunt of service user and } \\
\text { Ladies Guild member }\end{array}$ & Home \\
\hline Helen $\mathrm{H}$. & unknown & $F$ & $\begin{array}{c}\text { Granddaughter of first Work } \\
\text { Centre supervisor }\end{array}$ & Home \\
\hline Jean $\mathrm{H}$. & 69 & $\mathrm{~F}$ & Sibling of service user & Home \\
\hline Sharon $\mathrm{H}$. & unknown & $\mathrm{F}$ & Sibling of service user & Museum \\
\hline Sheila M. & 59 & $\mathrm{~F}$ & Service user & Home \\
\hline Joan O. & 89 & $\mathrm{~F}$ & Parent and trustee of charity & Home \\
\hline $\begin{array}{l}\text { Christopher } \\
\text { P. }\end{array}$ & 48 & M & Service user & Day Centre \\
\hline Pat P. & 68 & $\mathrm{~F}$ & Staff member & Home \\
\hline Elsie R. & $80+$ & $\mathrm{F}$ & Parent & Home \\
\hline Peter R. & unknown & $\mathrm{M}$ & Staff member (music) & Home \\
\hline Andrew S. & unknown & $\mathrm{M}$ & Service user & Home \\
\hline Melanie T & 55 & $\mathrm{~F}$ & Staff member (student) & Hotel \\
\hline Sarah T. & unknown & $F$ & $\begin{array}{c}\text { Granddaughter of first Work } \\
\text { Centre supervisor }\end{array}$ & Home \\
\hline Gillian Y. & unknown & $\mathrm{F}$ & $\begin{array}{c}\text { Daughter of first Work Centre } \\
\text { supervisor }\end{array}$ & Home \\
\hline Sylvia L. & unknown & $\mathrm{F}$ & Respite nurse & Public House \\
\hline Mary & unknown & $\mathrm{F}$ & Respite nurse & Public House \\
\hline
\end{tabular}




\subsection{Renovation of Carlson House school (1940s)}

Images courtesy of Cerebral Palsy Midlands.
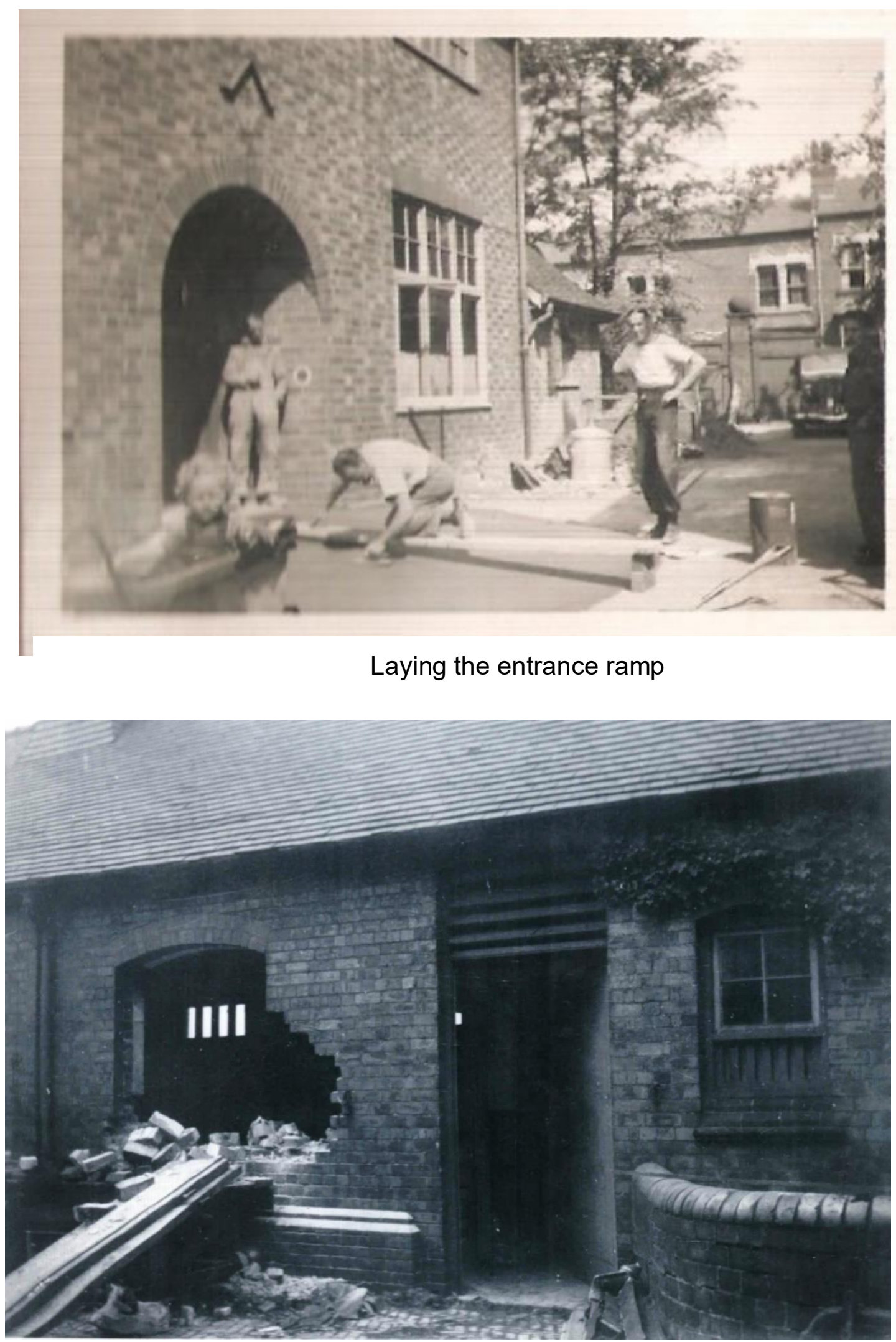

Adapting the stables to a treatment centre 
Images courtesy of Cerebral Palsy Midlands.

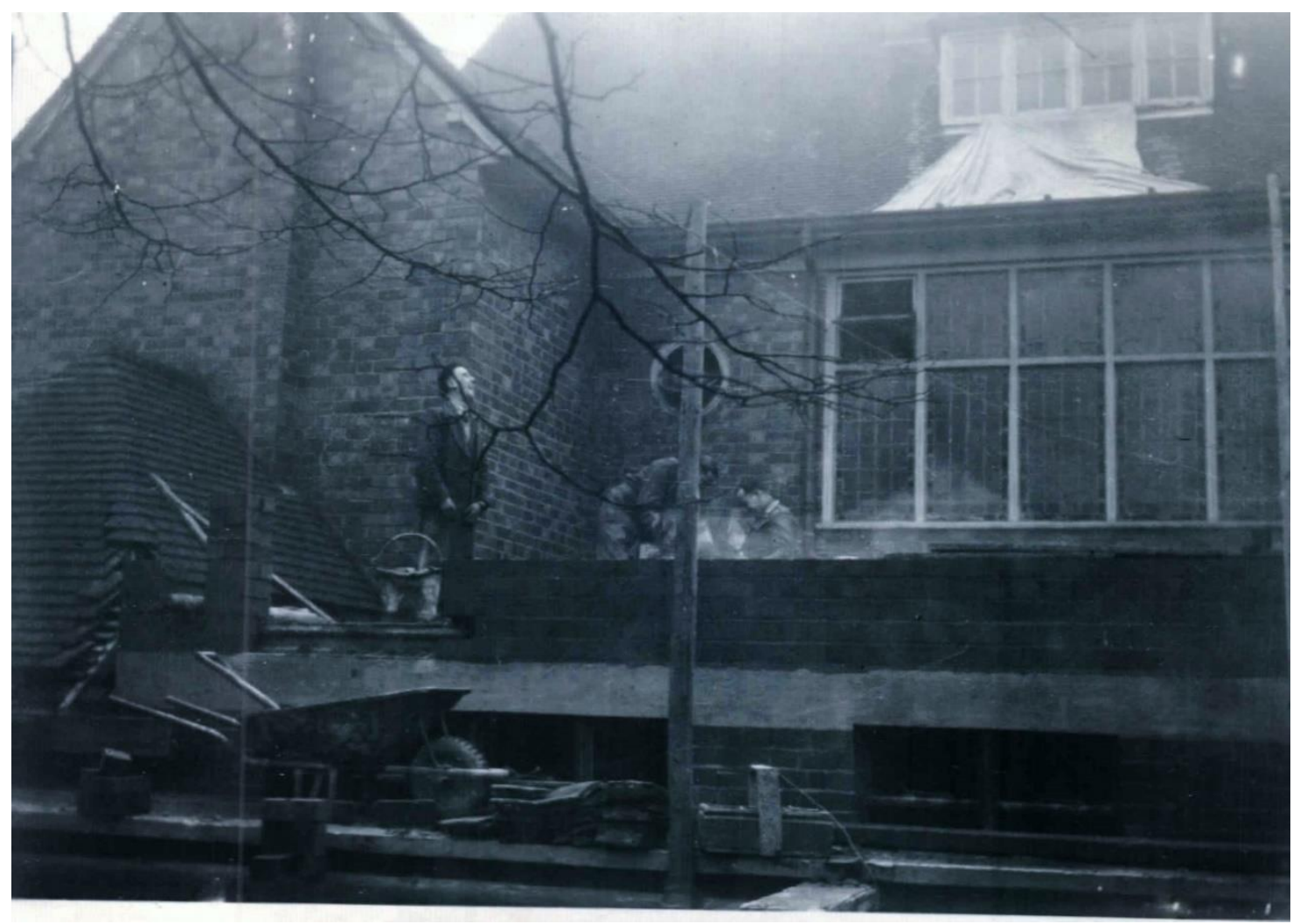

Roofing the cloakrooms

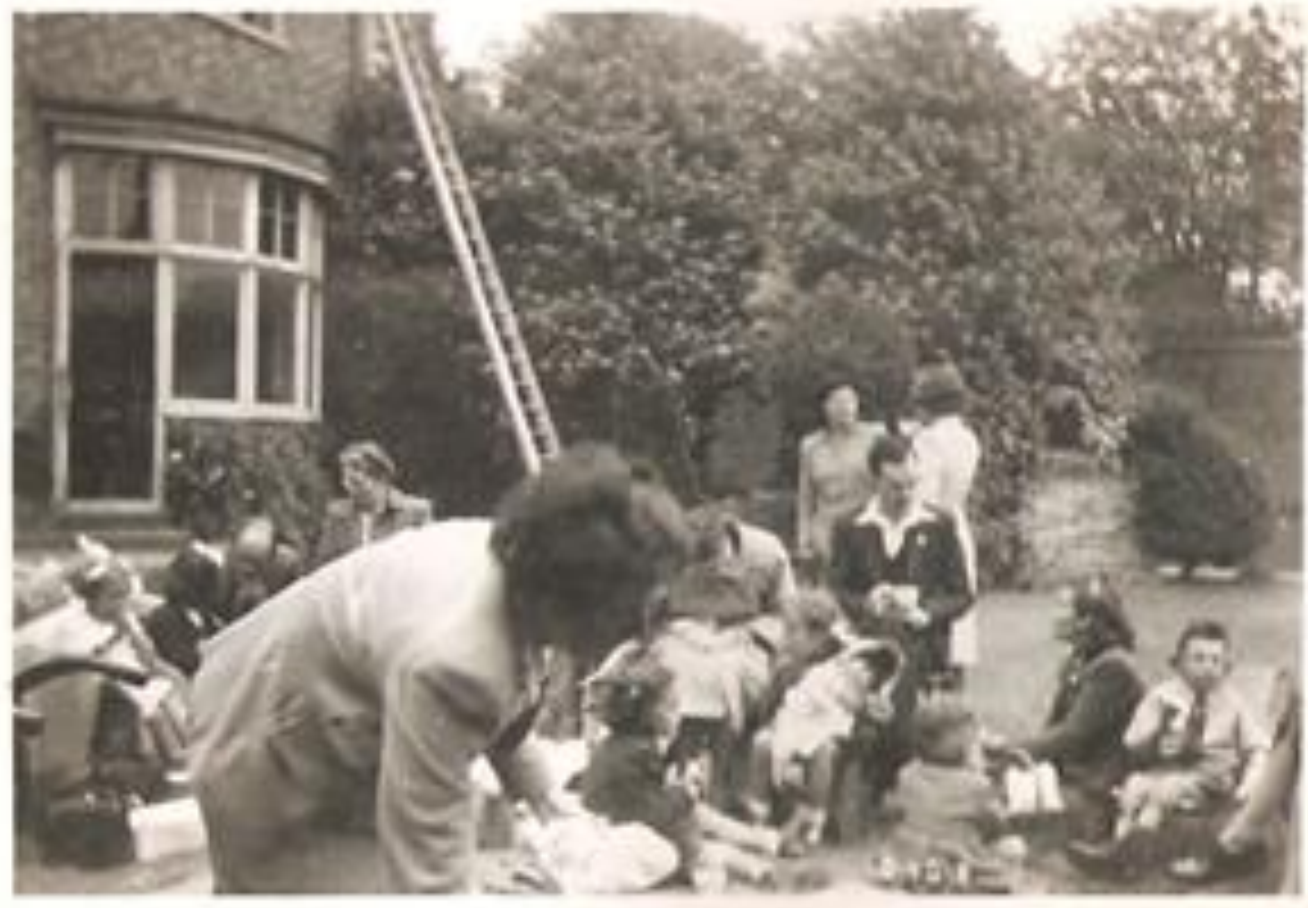

Saturday working parties picnicking 


\subsection{Innovative equipment at Carlson House school (early 1950s)}

Images courtesy of Cerebral Palsy Midlands.

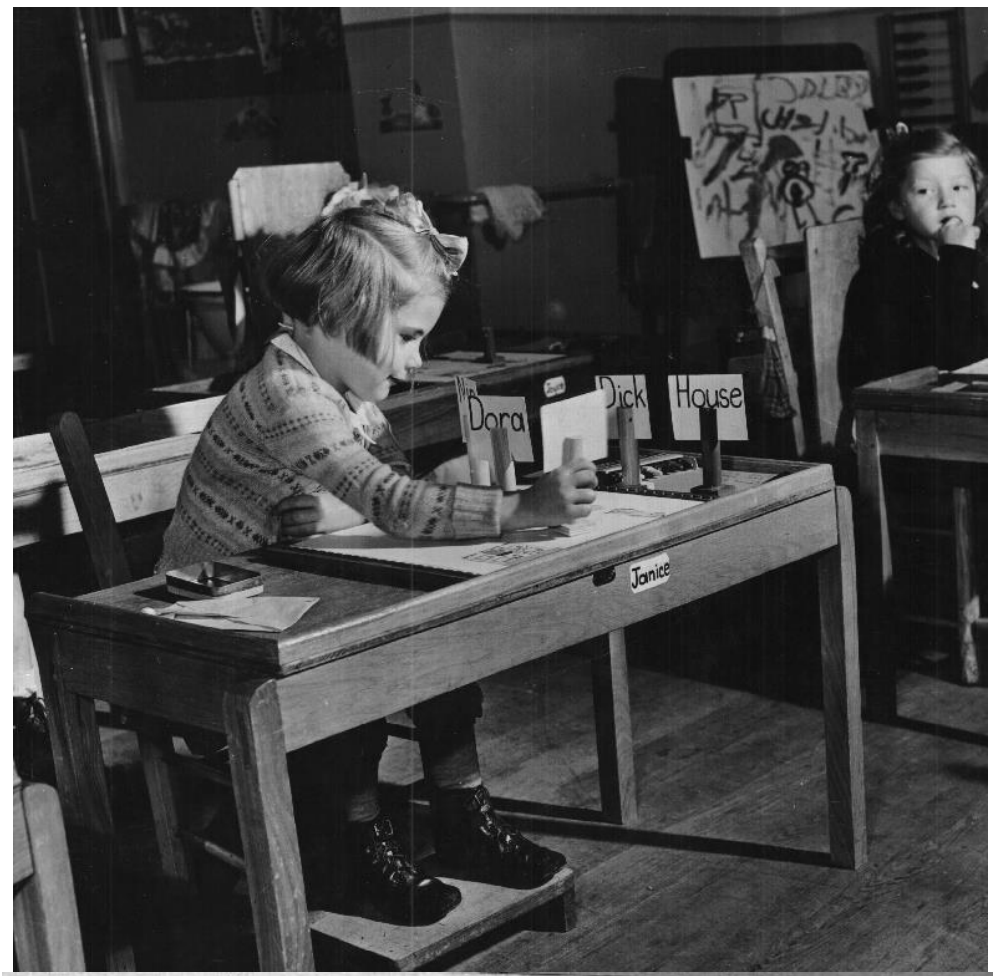

These two images show how the use of pegs make learning achievable.

Janice, one of the pupils in the Junior Class of the school is seen using pegs marked with names to identify the subjects on her school is specially adapted to meet the junior class and throughout the suffering from various disabilities.

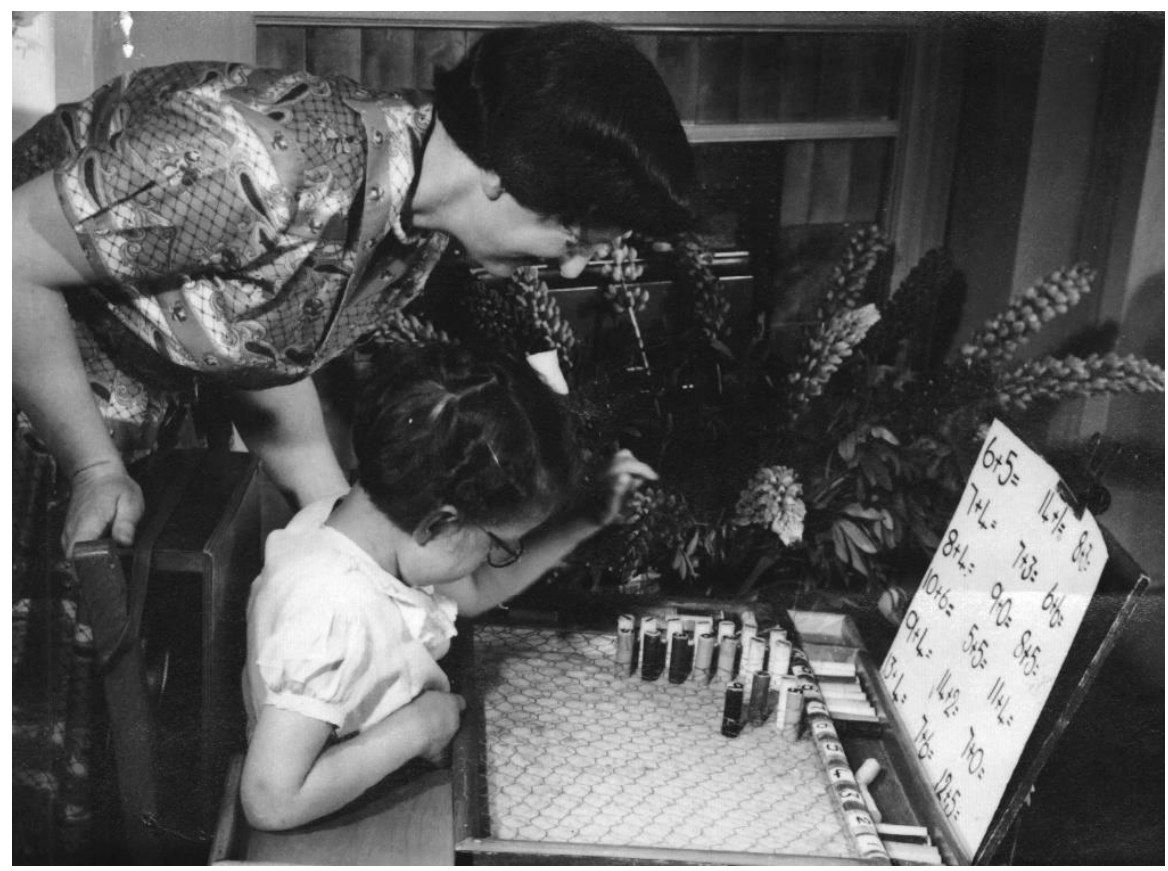


Images courtesy of Cerebral Palsy Midlands.

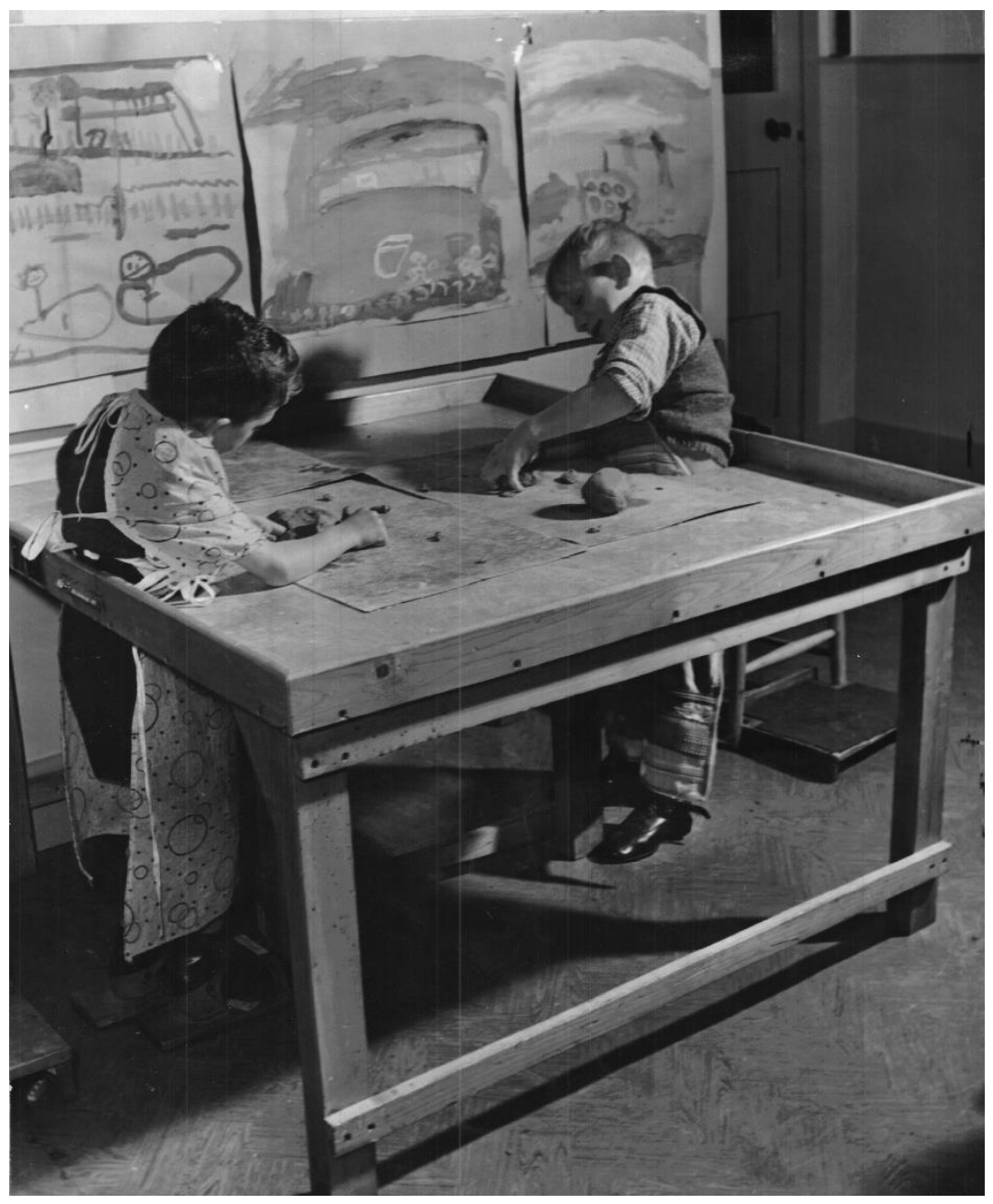

These two images show how equipment was modified for use.

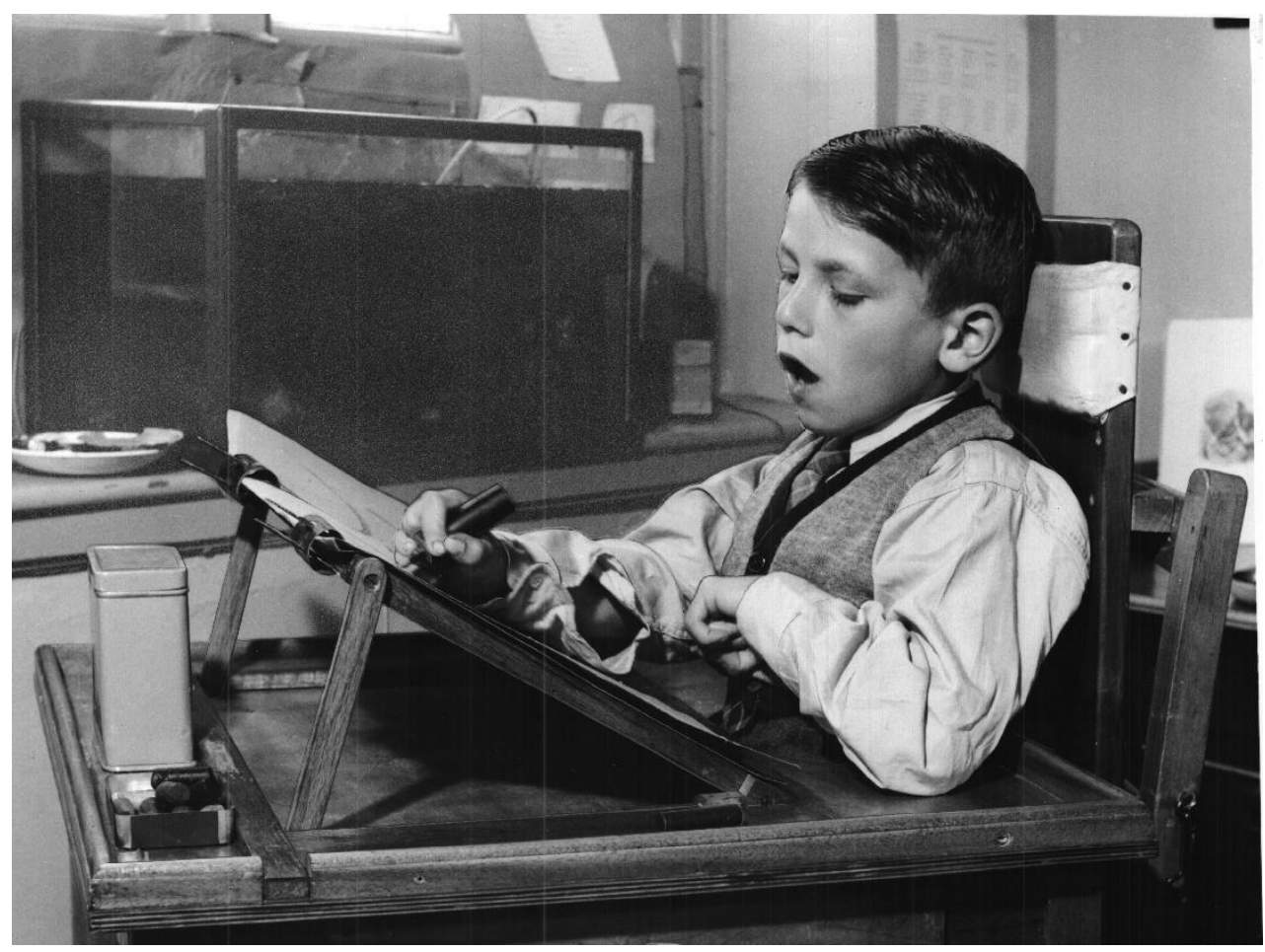


9.6 Extract from the National Spastics Society Annual report (1954)

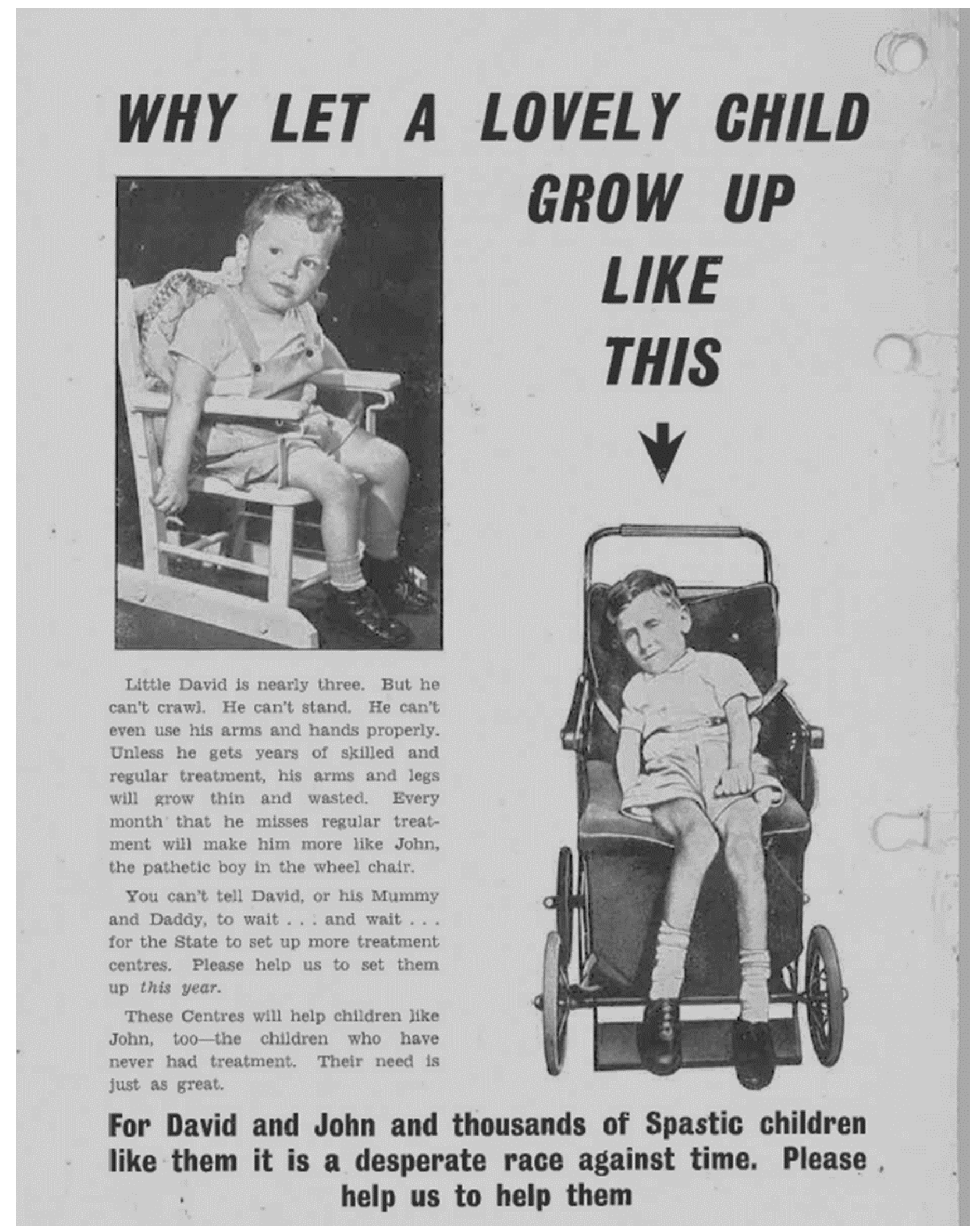

Image courtesy of Scope. 
9.7 Cover of the National Spastics Society Annual report (1964)

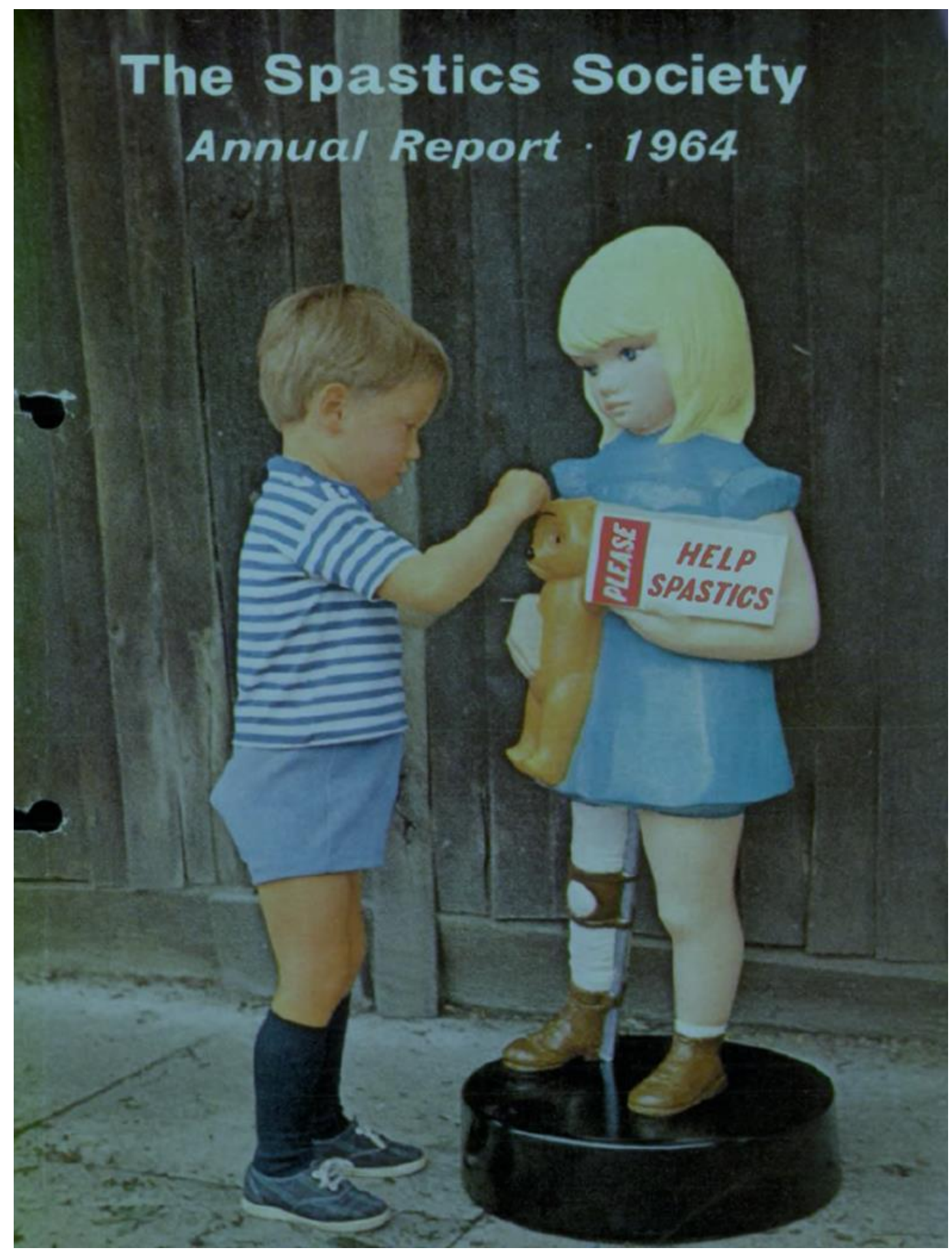

Image courtesy of Scope. 


\title{
Bibliography
}

\author{
Primary sources
}

\section{ARCHIVE SOURCES}

\section{CEREBRAL PALSY MIDLANDS ARCHIVE, Harborne, Birmingham}

\section{British Council for the Welfare of Spastics Publications}

Minutes of inaugural meeting held 12 December, 1946

The Medical, Educational \& Social Aspects of The Cerebral Palsy Problem, first Annual Report, April 1948

Incidence of Cerebral Palsy, Report, 1948

Report for the period 1948-1952

Addresses given at a one-day conference on The Cerebral Palsy Problem Today, November 1953

Annual Reports 1948 to 1958

\section{Carlson House school}

School Inspection March 1952

Carlson House records 1948 - 1975

A pupil's school report, July 1959

Details of Birmingham school leavers, 1961

A survey of Carlson House school leavers 1960-1975

Notice of a parent's meeting to be held on 20 October 1975

A series of photographs of the early days of the school

\section{Correspondence}

Letter to Stephen Quayle from Paul Cadbury dated 11 July 1946

\section{Midland Spastic Association Reports}

Annual Report 1949

Minutes of Annual General Meeting 17 January 1955

Minutes of Annual General Meeting 25 October 1957 
Record of a discussion over lunch on Tuesday, 18 December 1957 Minutes of Annual General Meeting 1982

\section{Midland Spastic District Association Yearbook Articles}

A Flatlet Comes To life', Midland Spastic Association Year Book 1984

Abel, Edgar, 'Thirty Years Development in the Day Centre,' in Midland District Spastic Association Year Book 1978

Barrett, Mavis, 'From a room in a School to an organised department', in Midland Spastic Association Year Book 1978

Cadbury, Paul S., 'The President looks back - and forward!' in Midland Spastic Association Year Book 1977/78

Cocksedge Kent, Harry, 'Sir No. 1 looks back' in Midland Spastic Association Year Book 1972

Further Education', in Midland Spastic Association Year Book 1972

Hull, Roy, 'A Parent's Experiences in the Early Days', in Midland Spastic Association Year Book 1972

Jackson, Annette, 'A younger Spastic - then and now' in Midland Spastic Association Year Book 1972

Jackson, Annette, 'Three Spastics remember the excitement of progress' in Midland Spastic Association Year Book 1978

Jeramiah, Marjorie, 'Three Parents Look Back to the Early Days' in Midland Spastic Association Year Book 1978

Jottings from the Welfare Office' in Midland Spastic Association Year Book 1974

Pritchard, Maureen, 'The Excitement of Progress,' in Midland District Spastic Association Year Book 1978

The Whitbread Family, 'Three Parents Look Back to the Early Days' in Midland Spastic Association Year Book 1978

Quayle, Stephen K., 'Paul Strangman Cadbury 1895-86', in Midland Spastic Association Year Book 1986

Woodall Christine, 'The Headmistress of Carlson House School talks of the Pattern of Progress since 1947' in Midland Spastic Association Year Book 1978 Woodall, Christine, in Midland Spastic Association Year Book 1978 
Other printed primary sources held at Cerebral Palsy Midlands archive

A report of Birmingham school leavers 1961

Carlson, Dr Earl, Report to the New Zealand Government and New Zealand Crippled Children Society on the Problem of Cerebral Palsy, March 1948

Dunsdon, Marjorie I., B.A., M.A., (Lond.), An account of a three months visit paid to the United States of America for the purpose of observing the work being done there for children suffering from cerebral palsy, June 1946

Evans, E. Stanley, F.R.C.S., 'Cerebral Palsy', [Reprinted from Proceedings of the Royal Society of Medicine, April 1946, Vol. XXXIX, No.6, pp.317-320 (Section of Orthopaedics, pp. 15-18)]

Griffiths, M. I., 'The Increasing Problem of Employment for the Cerebral Palsied - a Prospective Survey from Birmingham', in Industrial Society and Rehabilitation - Problems and Solutions ed.by Werner Dicke, Marlis Muller, Kurt A. Jochheim \& Harald Thorn (ISRD-Proceedings of the Tenth World Congress, 1966)

Marlow, Enid, Thomas, Mary and Innes, Alexander, 'Spastics in Ordinary Schools', a report (1967)

Phelps, Dr. Winthrop, M.D. Baltimore, Maryland, 'The Rehabilitation of Cerebral Palsy', in Journal of the Southern Medical Association, 1941

Photographs - a series of images held at Cerebral Palsy Midlands

Schonell, F. Eleanor, M.A. (Lond.), Report of a visit to the spastic centres of Australia. September 1948

Schonell, F. Eleanor, Suggested forms of educational provision for cerebral palsied children with varying degrees of mental and/or physical disability, 31 October 1949

The Farthest Corner - An outline of the cerebral palsy problem, prepared under the direction of Winthrop M. Phelps, M.D. for The National Society for Crippled Children and Adults, Inc., 11 South La Salle St., Chicago 3, Illinois

Williams, Mr and Mrs J.L., St Margaret's School, Croydon, Treatment of cerebral palsy in Australia, May 1947

\section{WELLCOME LIBRARY, London}

\section{Spastic Society magazine}

Booth, Betty, 'Why Help Parents'? Spastics News Magazine of the Spastic Society, September 1965 
Brett, Bernard, '(II) The Opening Door', Spastics News Magazine of the Spastic Society, February 1965

Course on Cerebral Palsy for Wales and the West', Spastics News Magazine of the Spastic Society, September 1961

Cruel to send all handicapped children to comprehensive schools, says new Report', Spastics News Magazine of the Spastic Society, January 1974

Clifton, C A, 'The Changing Emphasis of the NSS Schools Programme', Spastics News Magazine of the Spastic Society, February 1963

Davies, H. B., 'Preparation for School Leaving', Spastics News Magazine of the Spastics Society, July 1961

Dawson-Shepherd, Rosemary, '(I) Plans for a spastics' conference', Spastics News Magazine of the Spastic Society, February 1965

Howlett, R., 'The most ambitious course that has ever been run in this country', Spastics News Magazine of the Spastic Society, September 1960

Loring, J. A., 'The Spastics Society and the World', Spastics News Magazine of the Spastic Society, September 1965

Loring, J. A., 'The Role of Charity in the 1960s', Spastics News Magazine of the Spastic Society, September 1963

'N.S.S. New Venture, Parents' Training Course' Spastics News Magazine of the Spastic Society, May 1960

'Prejudice at first - but now school integration is a success', Spastics News Magazine of the Spastic Society, April 1970

\section{WEST GLAMORGAN ARCHIVE SERVICE, Swansea}

\section{Longfields collection}

D/D LA 3/1 Management and AGM Minutes 1952-1954

D/D LA 5/1 Morgan M. R., 'After School - What'? in Swansea \& District Spastic Association Year Book 1959/60

'Organised Events in 1959-60' in Swansea \& District Spastic Association Year Book 1959/60

Paton, Bill, 'Through Indomitable Faith was Born a Resolve' in Swansea \& District Spastic Association Year Book 1959/60

Rowley, Gordon, M.Ch. Orth., 'Parent remains the most important link', in Swansea \& District Spastic Association Year Book 1959/60 
D/D LA 5/2 Hargreaves, William, 'Over 300 Placed in Employment', in Swansea \& District Spastic Association Year Book 1960/61

Morris, Percy, 'Their happiness depends entirely upon you' in Swansea \& District Spastic Association Year Book 1960/61

Rasbridge, Ethney, 'Trainees Organise Social Club' in Swansea \& District Spastic Association Year Book 1960/61

D/D LA 5/3 'Courageous' in Swansea \& District Spastic Association Year Book 1961/62

Paton, Bill, 'Tremendous Boon To Young People', in Swansea \& District Spastics Association Year Book 1961/62

Rumbelow, Laura, 'New Venture which Proved a Success,' in Swansea \& District Spastic Association Year Book 1961/62

D/D LA 5/5 Watts, Gloria M., 'A friendly and happy environment', in Swansea \& District Spastic Association Year Book 1964

D/D LA 5/6 Kingsley-Davies, B. 'A look at the South Wales Region' in Swansea \& District Spastic Association Year Book 1966/67 McKelvie, H., 'A pointer to the rapid growth of our centre', in Swansea \& District Spastic Association Year Book 1966/67

D/D LA 5/7 Davies, Owen, 'Scholarship for Living', in Swansea \& District Spastics Association Year Book 1981/82

D/D LA 5/9 Davies, Owen, 'What's in a name ....' in Swansea \& District Spastics Association Year Book 1984/85

D/D LA 11/1-4 Newspaper Cuttings relating to Longfields Association 1954-2007

\section{WOLFSON CENTRE FOR ARCHIVAL RESEARCH, Birmingham}

\section{Records of the Cadbury Trusts}

MS 1579/1/4/6/3 A report to the trustees of the Paul S. Cadbury Charitable Trust 


\section{FILM}

Children at Carlson House, dir.by Staff of Carlson House (Morland Braithwaite Ltd., 1950), online film recording, You Tube, $<$ https://www.youtube.com/watch?v=VBUOw99rivE $>$ [accessed 14 August 2017]

Door to Freedom, dir. by lan Sinclair, (A Sovereign Production for the National Spastics Society, 1956), online film recording, Wellcome Library $<$ http://catalogue. wellcomelibrary.org/record=b1679258> [accessed 9 March 2018]

Special Equipment, dir.by Staff of Carlson House (Morland Braithwaite Ltd., 1956), online film recording, YouTube, $<$ https://www.youtube.com/watch?v=Xv9jV0JDVs0 $>$ [accessed 14 August 2017]

Stand up the real Glynn Vernon, dir. by Yvette Vanson (Vanson Wardle Productions, 1996), online film recording, VANSON < http://www.yvettevanson.com/file/57> [accessed, 27 June 2018]

Steps to Independence, dir. by Staff of Carlson House (Morland Braithwaite Ltd., (date unknown)) [DVD]

The Chance of Their Lives, dir. By I. Sinclair (Sovereign Productions, National Spastics Society, 1952) online film recording, You Tube $<$ https://www.youtube.com/watch?v= IhMkm9-X9A $>$ [accessed 18 October 2017]

The Management of Work Centres, dir. by Michael Holmes (Heron Film Productions for The Spastics Society, 1973), online film recording, Wellcome Library < https://wellcomelibrary.org/item/b16743453\#?c=0\&m=0\&s=0\&cv=0> [accessed 9 March 2018]

The Right to Work, dir. by Nigel Evans (A Randel Evans Production for The Spastics Society, 1974), online film recording, Wellcome Library $<$ https://wellcomelibrary.org/item/b16744421\#?c=0\&m=0\&s=0\&cv=0> [accessed 9 March 2018]

\section{NEWSPAPERS AND MAGAZINES}

'Aid For Handicapped Children', The Times, 15 April 1948. Gale Cengage The Times Digital Archive < http://tinyurl.galegroup.com/tinyurl/BYbHP1>

Bosworth-Smith N.D., 'Education of Spastics', The Times, 3 June 1952. Gale Cengage The Times Digital Archive <http://tinyurl.gale.com/tinyurl/BbJus1>

Bosworth-Smith, N.D. 'Mr. Henry P. Weston', The Times, 31 December 1953. Gale Cengage The Times Digital Archive $<$ http://tinyurl.galegroup.com/tinyurl/BYGFF1> 
Brice H. M., 'Handicapped children', The Times, 3 June 1978. Gale Cengage The Times Digital Archive <http://tinyurl.galegroup.com/tinyurl/BZSDm1>

Buller, Georgiana, 'Education of Spastics, The Times, 13 June 1952. Gale Cengage The Times Digital Archive <http://tinyurl.gale.com/tinyurl/BbK8R7>

Educational Reform The New ACT', The Times, 2 January 1945. Gale Cengage The Times Digital Archive < http://tinyurl.galegroup.com/tinyurl/BYFbE5 $>$

Handicapped Children at School', Times, 25 May 1978. Gale Cengage The Times Digital Archive <http://tinyurl.galegroup.com/tinyur//BZRY67>

Hevey, David, 'Fear for sale', New Internationalist, 5 July 1992.

$<$ https://newint.org/features/1992/07/05/fear> [accessed 20 May 2019]

'Live Letters' The Daily Mirror, 22 January 1952. NexisUK $<$ https://www.nexis.com/>

Miles, Tony, 'The Penny Crusade has boomed into a £1,000,000 charity!' The Daily Mirror, 12 March 1957. NexisUK < https://www.nexis.com/>

Mittler Peter, 'Obituary: Stanley Segal', Independent, 9 July 1994. $<$ https://www.independent.co.uk/news/people/obituary-stanley-segal1412745.html> [accessed 26 March, 2016]

'News in Brief', The Times, 2 August 1947. Gale Cengage The Times Digital Archive <http://tinyurl.galegroup.com/tinyurl/BYH231>

'Heads seek schools for handicapped', The Times, 28 August 1975. Gale Cengage The Times Digital Archive $<$ http://tinyurl.galegroup.com/tinyurl/BZSAD4>

Philpot, Terry, 'Maureen Oswin: Singlehandedly, she exposed the scandal of children's hospitals', Guardian, 1 August, 2001.

<https://www.theguardian.com/news/2001/aug/01/guardianobituaries1> [accessed 1 May 2019]

Prasad, Raekha, 'Looking Different', Guardian, 20 November, 2002. $<$ https://www.theguardian.com/society/2002/nov/20/disability> [accessed 2 September 2018]

'Spastic Children In Mental Homes', The Times, 27 October 1954. Gale Cengage The Times Digital Archive <http://tinyurl.gale.com/tinyurl/BbKEV5>

'Speaking out in Support of Sheltered Workshops', EP Magazine, May 2017,<https://reader.mediawiremobile.com/epmagazine/issues/200979/viewer? page $=59>$ [accessed 27 January 2019] (pp.58-60) 
ORAL HISTORY

British Library Sounds, London, Speaking for Ourselves: An Oral History of People with Cerebral Palsy

$\begin{array}{ll}\text { Berwick, Lin } & \text { C1134/04/01-07 } \\ \text { Counsell, Alan } & \text { C1134/08/01-08 } \\ \text { Cox, Desmond } & \text { C1134/12/01-03 } \\ \text { Edwards, David } & \text { C1134/18/01-13 } \\ \text { Entwistle, Pat } & \text { C1134/24/01-04 } \\ \text { Hall, Bill } & \text { C1134/11/01-05 } \\ \text { Hawkridge, John } & \text { C1134/20/01-15 } \\ \text { Johnson, Pauline } & \text { C1134/30/01-05 } \\ \text { Lang, Valerie } & \text { C1134/10/01-25 } \\ \text { Morgan, Barry } & \text { C1134/07/01-08 } \\ \text { Mills, David } & \text { C1134/29/01-02 } \\ \text { Munday, Dorcas } & \text { C1134/23/01-13 } \\ \text { Ross, Joan } & \text { C1134/21/01-03 } \\ \text { Smart, Judy } & \text { C1134/05/01-12 } \\ \text { Williams-Findlay, Bob } & \text { C1134/15/01-08 }\end{array}$

Cerebral Palsy Midlands, Harborne, Birmingham, Oral History Heritage Fund Project, Fulfilment through Achievement

B., David, Interview, 22 January, 2014

B., Christine, Interview, 14 October 2013

H., Angela, Interview, 7 May, 2014

Q., Cedric, Interview, 21 May, 2014

Oral history interviews conducted by Teresa Hillier about the history of Longfields Association (formerly known as Swansea and District Spastic Association)

Ba., Peter, 29 March 2018

B., Molly, 3 February 2017

Be., Peter, 6 June 2017

B., Roggan, 21st June 2017

D., Ron, 11 August 2017

H. Jean, 11 April 2017

M., Sheila 16 August 2017

O., Joan, 2 June, 2016

P. Christopher, 17 February 2017

P., Pat, 14 August 2018

R., Elsie, 22 April, 2017 
S., Andrew, 12 February, 2018

T., Jackie, 17 November, 2017

Y., Gillian, H., Helen and T., Sarah, 15 March, 2018

\section{Parliamentary Debates}

House of Commons, Hansard's Parliamentary Debates: Education [Online] $<$ https://hansard.parliament.uk $>$ [accessed 24 October 2016]

House of Commons, Hansard's Parliamentary Debates: Spastic Children (Education) [Online] < https://hansard.parliament.uk > [accessed 24 October 2016]

House of Commons, Hansard's Parliamentary Debates: Spastic Children [Online] <https://hansard.parliament.uk> [accessed 24 October 2016]

House of Commons, Hansard's Parliamentary Debates: Spastic Children, Wales [Online] <https://hansard.parliament.uk> [accessed 24 October 2016]

\section{Printed Primary Sources}

'Advertisement' in Swansea \& District Spastic Association Year Book 1985/86

Asher, Patria and Schonell, F. Eleanor, 'A Survey of 400 Cases of Cerebral Palsy in Childhood', Archives of Disease in Childhood, 25 (1950) 360-379 $<$ http://dx.doi.org/10.1136/adc.25.124.360>

Birch, C. Allan, 'Spastics Society', in The BMJ, 1:377 (1965)

$<$ https://www.bmj.com/content/1/5431/377.3>

Collis, Eirene, A Way of Life for the Handicapped Child, (London: Faber \& Faber, 1947)

Counsell, Alan, So Clear in My Mind (London: Hutchinson \& Co. (Publishers) Ltd., 2007)

Davies, Chris, Changing Society A personal history of Scope 1952-2002 (Chippenham: Scope Creative Services, 2002)

Davies, Owen, 'A shift of emphasis' in Swansea \& District Spastic Association Year Book 1979/80

Davies, Owen, 'Owen Davies' in Swansea \& District Spastic Association Year Book 1979/80

Davidson, Margaret B., You Tell Me, (Edinburgh: William Blackwood \& Sons Ltd., 1977)

Dimbleby, Richard, Every Eight Hours (London: Hodder \& Stoughton, 1964) 
Dunsdon, M.I., The Educability of Cerebral Palsied Children (London: Newnes

Educational Publishing Co., Ltd., 1952)

Hewett, Sheila, Newson John and Newson Elizabeth, The Family and the Handicapped Child (London: George Allen \& Unwin Ltd., 1970)

Lang, Valerie, 'The Use of the Word "Spastic" or, What's in a Name?' in Swansea \& District Spastic Association Year Book 1980

Miller, Derek, 'To Sara - and Others - The Computer Brings Hope', in Swansea \& District Spastic Association Year Book 1980/81

Ministry of Education, The Health of the School Child: Report of the Chief Medical Officer of the Ministry of Education for the Years 1946 and 1947, (London: His Majesty's Stationery Office, 1949)

Ministry of Education, The Health of the School Child: Report of the Chief Medical Officer of the Ministry of Education for the Years 1950 and 1951 (London: His Majesty's Stationery Office, 1952)

Ministry of Education, Pamphlet No. 5: Special Educational Treatment, (London: His Majesty's Stationery Office, 1946)

National Spastics Society Annual report (1953) National Spastics Society Annual report (1954) National Spastics Society Annual report (1961) National Spastics Society Annual report (1970) National Spastics Society Annual report (1971) National Spastics Society Annual report (1973) National Spastics Society Annual report (1979) National Spastics Society Annual report (1981)

Peacey, M. S., 'Unrealistic Aspirations' in The Spastic School Child and the Outside World, (Oxford: William Heinemann Ltd., 1966), pp.106-112

Pridmore, C. and Rumbelow, L., 'Our social clubs round of activities' in Swansea \& District Spastic Association Year Book 1964/65

Saunders, Joan and Napier, Marjorie, eds., Spastics in Cheyne Walk, An Account of the Centre for Spastic Children, Cheyne Walk, Chelsea, London: Pitman Medical Publishing Company, Ltd., 1957)

Schonell, F. Eleanor, 'What is a spastic?', Educational Review, 1:3, (1949) 158160

Segal, Stanley S., No Child is Ineducable (Oxford: Pergamon Press Ltd., 1974)

Segal, Stanley S., Society and Mental Handicap: Are we Ineducable?', (Tunbridge Wells: Costello Educational, 1984) 
Schlesinger, Hilary and Whelan, Edward, Industry and Effort, A study of Work Centres in England. Wales and Northern Ireland for severely disabled adults, (London: The Spastics Society in conjunction with William Heinemann Medical Books Ltd., 1979)

Warnock, Mary, Special Educational Needs: Report of the Committee of Enquiry into the Education of Handicapped Children and Young People (London: H.M.S.O., 1978)

Wedell, K., 'Intelligence and Educability: The Communication of Prognostic and Diagnostic Information to Parents' in The Spastic School Child and the Outside World (Oxford: William Heinemann Ltd., 1966), pp.67-73

Wigglesworth, Robert, 'The Value of Early Part-Time Developmental Training' in The Spastic School Child and the Outside World (Oxford: William Heinemann Ltd., 1966), pp.1-12

Woodall, Christine, 'Carlson House, Harborne An experimental school and treatment centre for spastic children', Educational Review, 1:3, (1949) 161-163

\section{Websites}

Ansell, Kate, Viewpoint: Does this Spastics Society statue start the right conversations? (2015), <https://www.bbc.co.uk/news/blogs-ouch-33440475> [accessed 2 September, 2018]

BECTU History Project, Transcript of Yvette Vanson, Interview 569, 22 June 2007

$<$ https://historyproject.org.uk/sites/default/files/HP0569\%20Yvette\%20Vanson\% 20-\%20Transcript.pdf> [accessed 25 June 2018]

Clark, Laurence, Spastic fantastic (2008), $<$ http://www.bbc.co.uk/ouch/opinion/spastic-fantastic.shtml> [accessed 2 September, 2018]

Hunt, Paul, Hidden now Heard - unearthing stories (2017), $<$ https://www.ldw.org.uk/hidden-now-heard-unearthing-stories/ > [accessed 26 August 2019]

Lang, Valerie, Twenty years on: Why I campaigned for The Spastics Society to change its name (2014), <https://blog.scope.org.uk/2014/03/31/why-icampaigned-for-the-spastics-society-to-change-its-name/> [accessed 25 June 2018]

Millington, Peter, An interview with David Barnsley (2014), <http://www.disability.co.uk/blog/2014/01/28/interview-david-barnsley > [accessed 2 November, 2016]

Pybus, Julie, NEWSMAKER: A question of priorities - Richard Brewster, Chief executive, Scope (2002), <https://www.thirdsector.co.uk/newsmaker-question- 
priorities-richard-brewster-chief-executive-scope/article/611685> [accessed 18 September 2019]

Rose, Damon, Formerly known as the Spastics Society: The importance of charity names (2014), <https://www.bbc.co.uk/news/blogs-ouch-26788607> [accessed 2 September, 2018]

White, Alex, More than words: The changing language of disability, (November 2016), <https://community.scope.org.uk/discussion/30680/more-than-wordsthe-changing-language-of-disability $>$ [accessed 15 August 2018]

\section{Secondary sources}

\section{Books and articles}

Abrams, Lynn, Oral History Theory (Abingdon: Routledge, 2010)

Adams, Joan, 'Provision: Who needs special needs'? in Controversial Issues in a Disabling Society, ed. by John Swain, Sally French \& Colin Cameron (Maidenhead: Open University Press, 2005), pp.122-130

Anderson, Julie, War, disability and rehabilitation in Britain (Manchester: Manchester University Press, 2011)

Armstrong, Felicity, 'Disability, Education and Social Change in England since 1960', History of Education, 36:4-5 (2007) 551-568

$<$ https://doi.org/10.1080/00467600701496849>

Atkinson, Dorothy, Jackson, Mark and Walmsley, Jan, 'Introduction: Methods and Themes', in Forgotten Lives: Exploring the History of Learning Disability, ed. by Dorothy Atkinson, Mark Jackson and Jan Walmsley (Kidderminster: British Institute of Learning Disabilities, 2003)

Barnes, Colin, Disabling Imagery And The Media: An Exploration of the Principles for Media Representations of Disabled People (Halifax: The British Council of Organisations of Disabled People and Ryburn Publishing Limited, 1992), <https://disability-studies.leeds.ac.uk/wp-

content/uploads/sites/40/library/Barnes-disabling-imagery.pdf> [accessed 8 May 2019]

Barnes, Colin, Disabled People in Britain and Discrimination (London: C. Hurst \& Co. Publishers Ltd., 2000)

Barnes, Colin and Mercer, Geof, Disability (Cambridge: Polity Press, 2003) Barnes, Colin and Mercer, Geof, Exploring Disability (Cambridge: Polity Press, 2010) 
Barnes, Colin and Mercer, Geoffrey, Independent Futures: Creating user-led disability services in a disabling society, (Bristol: Policy Press, 2006). ProQuest Ebook Central <https://ebookcentral.proquest.com/lib/swanseaebooks/detail.action?doclD $=419302>$ [accessed 27 May 2019]

Blakemore, Ken and Drake, Robert, Understanding Equal Opportunity Policies, (Hemel Hempstead: Prentice Hall Europe, 1996)

Blakemore, Ken and Warwick-Booth, Louise, Social Policy an introduction, $4^{\text {th }}$ edn (Maidenhead: Open University Press, 2013)

Borsay, Anne, Disability and Social Policy in Britain since 1750 (Basingstoke: Palgrave Macmillan, 2005)

Borsay, Anne, 'History, Power and Identity', in Disability Studies Today, ed. by Colin Barnes, Mike Oliver and Len Barton (Cambridge. Polity Press, 2002), pp.98-119

Borsay, Anne, 'From Representation to Experience: Disability in the British Advice Literature for Parents, 1890-1980', in Disabled Children: Contested Caring, (1850-1979), ed. by Anne Borsay and Pamela Dale (London: Pickering \& Chatto Ltd., 2012), pp.87-101

Borsay, Anne and Dale, Pamela, 'Introduction: Disabled Children - Contested Caring', in Disabled Children (1850-1979), ed. by Anne Borsay and Pamela Dale (London: Pickering \& Chatto Ltd., 2012), pp.1-13

Boyd, Victoria A., Ng, Stella L. and Schryer, Catherine F., 'Deconstructing language practices: discursive constructions of children in Individual Education Plan resource documents', Disability \& Society, 30.10 (2015), 1537-1553 $<$ https://doi.org/10.1080/09687599.2015.1113161>

Calderón-Almendros, Ignacio and Calderón-Almendros, Rafael, 'I open the coffin and here I am: disability as oppression and education as liberation in the construction of personal identity', Disability \& Society, 31.1 (2016) 100-115 $<$ https://doi.org/10.1080/09687599.2015.1133400>

Campbell, Jane, 'Developing our Image - Who's in control?', 1990 $<$ https://disability-studies.leeds.ac.uk/wpcontent/uploads/sites/40/library/Campbell-DEVELOPING-OUR-IMAGE.pdf> [accessed 20 August 2018]

Carey, Allison C., Block, Pamela and Scotch, Richard K., 'Sometimes Allies: Parent-Led Disability Organisations and Social Movements', Disability Studies Quarterly, 39.1 (2019), <http://dx.doi.org/10.18061/dsq.v39i1.6281>

Chappell, Anne Louise, 'From normalisation to Where?' in Disability Studies: Past Present and Future, ed. by Len Barton and Mike Oliver, (Leeds: The Disability Press, 1997), pp. 45-62 
Chazan, Maurice and Laing, Alice, The Early Years (Milton Keynes, The Open University Press, 1982)

Conner, Laura, 'Reflections on inclusion: how far have we come since Warnock and Salamanca?', Research in Teacher Education, 6.1 (2016) 18-23

<http://dx.doi:10.15123/PUB.5096>

Cooter, Roger, 'The Disabled Body', in Companion to Medicine in the Twentieth Century, ed. by Roger Cooter and John Pickstone (London: Routledge, 2003), pp.367-383

Corbett, Jenny, Jones, Elaine \& Ralph, Sue, 'A Shared Presentation: Two Disabled Women on Video', Disability, Handicap \& Society, 8:2 (1993) 173-186 $<$ https://doi.org/10.1080/02674649366780141>

Davis, Lennard J. Enforcing Normalcy: Disability, Deafness, and the Body (London: Verso, 1995), pp.23-49. ACLS Humanities E-Book < https://hdl.handle.net/2027/heb.02823> [accessed 18 September 2019]

Davidson, Margaret B., You Tell Me, (Edinburgh: William Blackwood \& Sons Ltd., 1977)

Drake, Robert F., Understanding Disability Policies (Basingstoke: Macmillan Press Ltd., 1999)

Elks Martin, 'Clinical Photographs: "Feeblemindedness" in Eugenic Texts', in Picturing Disability, (New York: Syracuse University Press, 2012), pp.75-98

Finkelstein, Vic, 'Disability and the Helper/Helped Relationship. An Historical View,' in Handicap in a Social World. ed. by Ann Brechin, Penny Liddiard and John Swain (Sevenoaks: Hodder and Stoughton Educational, 1983), pp.58-63

Finkelstein, Vic, 'Rehabilitation Services' in Reclaiming the People's Health, ed. by T. Lobstein and Namibia Support Committee Health Collective (Namibia: AON Publications, 1984) < https://disability-studies.leeds.ac.uk/wpcontent/uploads/sites/40/library/finkelstein-Rehabilitation.pdf> [accessed 19 August 2019]

Foreman, Phil, 'Language and Disability', Journal of Intellectual \& Development Disability, 30.1 (2005) 57-59

$<$ http://web.a.ebscohost.com/ehost/pdfviewer/pdfviewer?vid=1\&sid=7be487c45a69-4324-9aa6-5265fefbfce4\%40sessionmgr4008> [accessed 15 May 2019]

Garland Thomson, Rosemarie 'Seeing the Disabled: Visual Rhetorics of Disability in Popular Photography', in The New Disability History: American Perspectives, ed. by Paul K. Longmore and Lauri Umansky (New York: New York University Press, 2001) pp.335-374 
Gillman, Maureen, Swain, John \& Heyman, Bob, 'Life History or "Case" History: The objectification of people with learning difficulties through the tyranny of professional discourses', Disability \& Society, $12: 5$ (2010) 675-694 $<$ https://doi.org/10.1080/09687599726985>

Gleeson, Brendan, Geographies of Disability (London: Routledge, 1999). ProQuest Ebook Central < https://ebookcentral.proquest.com/lib/swanseaebooks/detail.action?doclD=165264> [accessed 23 July 2019]

Goble, Colin, 'Dependence, Independence and Normality', in Disabling Barriers - Enabling Environments, ed. by John Swain, Sally French, Colin Barnes and Carol Thomas (London: SAGE Publications Ltd., 2014), pp.31-36

Goodley, Dan, 'Disability rights and wrongs revisited' in Disability and Society, 29:4, (2014), 659-661 < https://doi.org/10.1080/09687599.2013.864874>

Goodley, Dan, Disability Studies An Interdisciplinary introduction (London: SAGE Publications Ltd., 2017)

Groce, Nora 'Disability and the League of Nations: the Crippled Child's Bill of Rights and a call for an International Bureau of Information, 1931', Disability \& Society, 29.4 (2014), 503-515

<http://dx.doi.org/10.1080/09687599.2013.831752>

Hampton, Jameel, Disability and the welfare state in Britain (Bristol: Policy Press, 2016)

Harris, Jennifer and Roulstone, Alan, Disability, Policy and Professional Practice (London: SAGE Publications Ltd., 2011)

Hevey, David, The Creatures Time Forgot (London: Routledge, 1992)

Hughes, Bill, 'Disability and the Body', in Disability Studies Today, ed. by Colin Barnes, Mike Oliver and Len Barton (Cambridge. Polity Press, 2002), pp.58-76

Jenner, Mark S.R. and Taithe, Bertrand O., 'The Historiographical Body', in Companion to Medicine in the Twentieth Century, ed. by Roger Cooter and John Pickstone (London: Routledge, 2003), pp.187-200

Johnson, Kelley and Walmsley, Jan with Marie Wolfe, People with Intellectual Disabilities - Towards a good life? (Bristol: The Policy Press, 2010). ProQuest Ebook Central <https://ebookcentral.proquest.com/lib/swanseaebooks/detail.action?doclD=619185> [accessed 27 May 2019]

King, Steven and Taylor, Steven J., "'Imperfect Children" in Historical Perspective', Social History of Medicine, 30.4 (2017),718-726 $<$ https://doi.org/10.1093/shm/hkx095> 
Kurtz, Richard A., 'The Sociological Approach to Mental Retardation', in Handicap in a Social World, ed. by Ann Brechin, Penny Liddiard \& John Swain (Sevenoaks. Hodder and Stoughton Educational, 1983), pp.14-23

Longmore, Paul K., Telethons: Spectacle, disability and the business of charity (Oxford: Oxford University Press, 2016)

Middleton, Laura Disabled Children: Challenging Social Exclusion (Oxford: Blackwell Science Ltd., 1999)

Middleton, Laura, 'The Social Exclusion of Disabled Children: The role of the voluntary sector in the Contract Culture', Disability and Society, 14:1 (2010), 129-139 <https://doi.org/10.1080/09687599926424>

Oliver, Michael, The Politics of Disablement, (London: The Macmillan Press, 1990)

Oliver, Michael, 'What's so Wonderful about Walking'?, Inaugural Professorial Lecture, $9^{\text {th }}$ February $1993<$ https://disability-studies.leeds.ac.uk/wpcontent/uploads/sites/40/library/Oliver-PROFLEC.pdf> [accessed 19 August 2019]

Oliver, Michael, 'Disability and Dependency: A Creation of Industrial Societies' in Disability and Dependency, ed. by Len Barton (Lewes: The Falmer Press, 1989)

Oliver, Michael, Understanding Disability (Basingstoke: Palgrave Macmillan, 2009), pp.6-22

Michael Oliver, 'The social model of disability: thirty years on', in Disability and Society, 28:7, (2013), 1024-1026

< http://dx.doi.org/10.1080/09687599.2013.818773>

Oliver, Michael, 'The Social and Political Context of Educational Policy: The Case of Special Needs', in The Politics of Special Educational Needs, ed. by Len Barton, (Lewes: The Falmer Press, 1988) pp.13-31

Oliver, Michael and Barnes, Colin, Disabled People and Social Policy (Harlow: Addison Wesley Longman Limited, 1998)

Osborne, Stephen P. and McLaughlin, Kate, 'Modelling government - voluntary sector relationships: emerging trends and issues', European Business

Organization Law Review, 4:3 (2003), 383-401

< https://doi.org/10.1017/S1566752903003835>

Oswin, Maureen, 'An Historical Perspective', in Growing up with Disability, ed. by Carol Robinson \& Kirsten Stalker (London: Jessica Kingsley Publishers Ltd., 1998) pp.29-41

Panteliadis Christos, Panteliadis Panos and Vassilyadi Frank, 'Hallmarks in the history of cerebral palsy: From antiquity to mid-20 $0^{\text {th }}$ century', Brain and 
Development, 35 (2012), 285-292

$<$ https://doi.org/10.1016/j.braindev.2012.05.003>

Perks, Robert and Thomson, Alistair, 'Introduction to the second edition', in The Oral History Reader, ed.by Robert Perks and Alistair Thomson $2^{\text {nd }}$ edn (Abingdon: Routledge, 2006), pp. ix-xiii

Philips, Gordon, The Blind in British Society: Charity, State and Community c.1780-1930 (Hampshire: Ashgate Publishing Limited, 2004)

Priestley, Mark, 'Generating Debates: Why We Need a Life-Course Approach to Disability Issues', in Disabling Barriers - Enabling Environments, ed. by John Swain, Sally French, Colin Barnes and Carol Thomas (London: SAGE Publications Ltd., 2014), pp.99-106

Pritchard, D.G., Education and the Handicapped 1760 - 1960 (London:

Routledge \& Kegan Paul, 1963)

Rix, Jonathon, 'Does it matter what we call them? Labelling people on the basis of notions of intellect', Ethical Space: The International Journal of Communication Ethics, 3.4 (2006), 22-28.<http://oro.open.ac.uk/id/eprint/6515> [accessed 3 May 2018]

Rolph, Sheena, 'The role and perspectives of families', in Community Care in Perspective, ed. by John Welshman and Jan Walmsley, (Basingstoke: Palgrave Macmillan, 2006), pp.173-186

Richardson, Ann, 'If you love him, let him go', in Making Connections: Reflecting on the Lives and Experiences of People with Learning Difficulties, ed. by Ann Brechin and Jan Walmsley (London: Open University1989), pp.5-12

Roulstone, Alan and Prideaux, Simon, Understanding Disability Policy (Bristol: The Policy Press, 2012). ProQuest Ebook Central $<$ https://ebookcentral.proquest.com/lib/swanseaebooks/detail.action?doclD=3030239> [accessed 27 May 2019]

Runswick-Cole, Katherine and Hodge, Nick, 'Needs or rights? A challenge to the discourse of special education', British Journal Of Special Education, 36.4 (2009), 198-203 <https://doi.org/10.1111/j.1467-8578.2009.00438.x>

Russell, Philippa, 'Warnock and After - A Parent's View', Special Education, Forward Trends, British Journal of Special Education, 5-3 (1978), 29

Rye, James, The Spastics Society to Scope: The story of the name change and relaunch November 1994 (Produced by Scope's Creative Services 3431)

Shakespeare, Tom, Help. (London: Venture Press, 2000)

Shakespeare, Tom, Disability Rights and Wrongs. (Oxon: Routledge, 2006) 
Shakespeare, Tom, Disability Rights and Wrongs Revisited, 2nd edn (Oxon: Routledge, 2014)

Shakespeare, Tom, 'The Social Model of Disability', in The Disability Studies Reader, ed. by Lennard J. Davis (New York: Routledge, 2010), pp. 266-73

Shakespeare, Tom and Watson, Nicholas, 'The social model of disability: an outdated ideology'? Research in Social Science and Disability, 2 (2002) 9-28

Sheldon, Alison, 'Disability Rights and Wrongs'? in Disability and Society, 22:2, (2007), 209-234 < https://doi.org/10.1080/09687590701195274>

Slim, Hugo and Thomson, Paul with Bennett, Olivia and Cross, Nigel, 'Ways of Listening', in The Oral History Reader. ed. by. Robert Perks \& Alistair Thomson (Oxon: Routledge, 2006), pp.143-154

Shopes, Linda, 'Oral History and the study of communities. Problems, paradoxes, and possibilities', in The Oral History Reader. ed. by. Robert Perks and Alistair Thomson (Oxon: Routledge, 2006), pp.261-270

Swain, John, French, Sally and Cameron, Colin, Controversial Issues in a Disabling Society (Maidenhead: Open University Press, 2005)

Symonds, Anthea, 'The social reconstruction of care: from the state to the community', in The Social Construction of Community Care, ed.by Anthea Symonds and Anne Kelly (Basingstoke: Macmillan Press Ltd., 1998), pp.33-50

Taylor, Margaret, 'Disabled in Images and Languages', in Disability on Equal Terms, ed.by John Swain and Sally French (London: SAGE Publications Ltd., 2008), pp.31-41

Thomas, Carol, 'Disability Theory: Key Ideas, Issues and Thinkers', in Disability Studies Today, ed. by Colin Barnes, Mike Oliver \& Len Barton (Cambridge. Polity Press, 2002), pp.38-57

Thomson, Mathew, 'The Psychological Body' in Companion to Medicine in the Twentieth Century, ed. by Roger Cooter and John Pickstone (London:

Routledge, 2003), pp.291-306

Tomlinson, Sally, Education in a Post Welfare Society, $2^{\text {nd }}$ edn (Maidenhead: Open University Press, 2005), pp.13-28. ProQuest Ebook Central $<$ https://ebookcentral.proquest.com/lib/swanseaebooks/detail.action?doclD=295501> [accessed 2 April 2017]

Turner, David M. and Blackie, Daniel, 'Introduction' in Disability in the Industrial Revolution: Physical Impairment and British Coalmining, 1780-1880 (2018), (pp.1-22) <https://doi.org/10.7765/9781526125774.00008> 
Viner, Russell and Golden, Janet, 'Children's Experiences of Illness', in Companion to Medicine in the Twentieth Century, ed. by Roger Cooter and John Pickstone (London: Routledge, 2003), pp.575-587

Wall, Kate, Special Needs and Early Years (London: Paul Chapman Publishing, 2003)

Walmsley, Jan, 'Ideology, Ideas and Care in the Community, 1971-2011', in Community Care in Perspective: Care, Control and Citizenship, ed. by John Welshman and Jan Walmsley (London: Palgrave Macmillan, 2006) pp.38-55

Walmsley, Jan, 'Life history interviews with people with learning disabilities', in The Oral History Reader. ed. by. Robert Perks and Alistair Thomson (Oxon: Routledge, 2008), pp.126-139

Walmsley, Jan and Atkinson, Dorothy, 'Oral history and the history of learning disability', in Oral History, Health and Welfare, ed. by Joanna Bornat, Robert Perks, and Paul Thompson (London: Routledge, 2000), pp.181-204. ProQuest Ebook Central $<$ https://ebookcentral.proquest.com/lib/swanseaebooks/detail.action?doclD=240373> [accessed 26 February 2017]

Walmsley, Jan, Tilley, Liz, Dumbleton, Sue and Bardsley, Janet, 'The changing face of parent advocacy: a long view', Disability \& Society, 32.9 (2017) 1366$1386<$ http://dx.doi.org/10.1080/09687599.2017.1322496>

Walmsley, Jan and Welshman, John, eds. Community Care in Perspective: Care, Control and Citizenship, (London: Palgrave Macmillan, 2006)

Welshman, John, 'Ideology, Ideas and Care in the Community, 1948-71', in Community Care in Perspective: Care, Control and Citizenship, ed. by John Welshman and Jan Walmsley (London: Palgrave Macmillan, 2006), pp.17-37

Wheatcroft, Sue, Worth Saving, Disabled children during the Second World War (Manchester: Manchester University Press, 2013)

White, Alex, ed. Can You manage stares? The life of Bill Hargreaves, (Cambridge: Black Bear Press, 2002)

Yakas, Laura, 'Work is Love Made Visible": Purpose and Community in Clubhouses', Disability Studies Quarterly, 37.4 (2017) <http://dsqsds.org/article/view/6096/4826 > [accessed 22 May 2019] 